Portland State University

PDXScholar

$10-25-2021$

\title{
God-Talk in Catholic High Schools: Theology \\ Teachers Doing Theological Education for and with Religiously Diverse Student Populations
}

David Michael Avram Gregory

Portland State University

Follow this and additional works at: https://pdxscholar.library.pdx.edu/open_access_etds

Part of the Curriculum and Instruction Commons, and the Educational Leadership Commons Let us know how access to this document benefits you.

\section{Recommended Citation}

Gregory, David Michael Avram, "God-Talk in Catholic High Schools: Theology Teachers Doing Theological Education for and with Religiously Diverse Student Populations" (2021). Dissertations and Theses. Paper 5857.

https://doi.org/10.15760/etd. 7728

This Dissertation is brought to you for free and open access. It has been accepted for inclusion in Dissertations and Theses by an authorized administrator of PDXScholar. Please contact us if we can make this document more accessible: pdxscholar@pdx.edu. 
God-Talk in Catholic High Schools:

Theology Teachers Doing Theological Education for and with Religiously Diverse Student Populations

by

David Michael Avram Gregory

A dissertation submitted in partial fulfillment of the requirements for the degree of

\author{
Doctor of Education \\ in \\ Educational Leadership: Curriculum and Instruction
}

Dissertation Committee:

Dot McElhone, Chair

Anita Bright

Karen Eifler

Elisabeth Ceppi

Portland State University

2021 
(C) 2021 David Michael Avram Gregory 


\begin{abstract}
High school students deserve educations that honor and respect their cultural positionalities, of which religious beliefs are frequently an integral part. Almost $25 \%$ of students in Catholic high schools identify as non-Catholic, but the U.S. Catholic bishops have mandated that Catholic secondary theological education (through their 2008 Doctrinal Elements of a Curriculum Framework for the Development of Catechetical Materials for Young People of High School Age) be catechetical. In writing and promulgating this document, the bishops presupposed that Catholic schools' students are Catholic, or (should) desire to become Catholic. For decades, scholars have critiqued catechesis as an inappropriate mode of theological education for non-Catholic students. In Catholic schools, non-Catholic students are subject to systemic oppression on academic, religious, and cultural levels. The Framework fails religiously diverse students in its lack of relevance for and sensitivity to their beliefs.

In this qualitative interview study, I interviewed five theology teachers in Pacific Northwest Catholic high schools. I investigated their goals for theological education of religiously diverse students, how they meet the needs of such students, and how they diverge from the bishops' Framework in their teaching. I discovered that: my participants' experiences and educational backgrounds influence their approaches to theological education; my participants oppose catechesis as a mode of theological education in secondary education and instead strive to make theology relevant, responsive, and sustaining of their students' diverse beliefs; and that my participants
\end{abstract}


follow the Framework's general structure, but diverge from and/or adapt its content in critical ways. 


\section{Dedication}

"Education is an act of love, and thus of courage." - Paulo Freire

I dedicate this work to all the students I have taught, and to all the students I will ever teach. I pray that my life has been a liberating presence of the crucified and risen Christ for you, as your lives have been for mine. 


\section{Acknowledgements}

Writing these acknowledgements is bound to be a futile act, as words cannot possibly convey the gratitude I need to express for the generosity that many have bestowed on me.

For my teachers (especially George Watson, Jill Johanson, Christian Talbot, William Carew, and Pedro Acosta) from Regis High School, who loved me into my humanity, and embodied joy, humor, and love: your lives instilled within me the desire to teach, and I owe much of who I am to you all. For my Georgetown professors (especially Alan Mitchell, Frank Ambrosio, and the late Alfonso Gomez-Lobo, Fathers Tom King, S.J., and James V. Schall, S.J.), you showed me that the truest vocation of a teacher is not only to move hearts and minds, but to make it so that, in the words of Fr. Schall, "your students don't need you anymore.” This is, in part, nonsense, because I continue to recall your love of Christ and how that manifested in intellectual pursuits. I am particularly thankful for Fr. King, at whose daily 11:15pm Mass I fell in love with the Nazarene, because that relationship has animated all that I do, all these years later. For my graduate and post-graduate school professors (especially Marvin Sweeney and Grace Kao of the Claremont School of Theology and Daniel Smith-Christopher of Loyola Marymount University), you taught me that the Bible is indeed a universe unto itself, and all my teaching flows from what you taught me: I combat its weaponization so that it can be a force for liberation, rather than oppression.

For my colleagues at Xavier College Prep (especially Jimmy Tricco, Steph DePrez, Dan Masterton, Matt Emerson, Erin Conway, Jesus Palomino, Greg Thielen, and 
Mark Hunter), thank you for revealing to me my vocation as an educator. For my colleagues at De La Salle North Catholic High School (who would be unwieldy to name) you continue to inspire me with your generosity and brilliance, and your kindness over the years has buoyed me through all the academic turmoil.

For my cohort members, especially those in my writing group (Brad Parker, Josie Emmrich, Lina Goma, and Sarah Dutton-Breen) who helped me to get past the finish line, I hope that my presence in your academic journey has been as impactful as yours has been in mine. Truly, there is no such thing as learning without community, and in retrospect, I more fully realize how impossible all this work would have been without walking (trudging, sweating) in solidarity together.

For my professors at Portland State, especially my seminar leaders Dot McElhone and Anita Bright, who have graciously read and critiqued my writing over and over and over again: you exposed the many injustices within educational theory and praxis for our cohort. I am forever transformed because of the texts you selected, the relationships you forged, and the conversations you generated. I hope that you never cease to feed your pupils beet hummus, and in turn, foment revolution.

For my anonymous participants, without whose kindness and interest I could never have completed this project: you voluntarily shared your passions and praxes with me over many hours, and I will continue to learn from your insights in the years to come. If the only people who read this are my committee, I will be satisfied, because your lives as educators have transformed me into a better educator, simply through the power of our 
conversations. It has been an honor and a privilege, and I am humbled to be witness to your lives.

For my committee members Dot McElhone, Anita Bright, Karen Eifler, and Liz Ceppi: your support and kindness have been unwavering, and writing this monster simply would not have been possible without your keen eyes, critical thoughts, and unfathomable generosity. None of you had to do this (especially Karen Eifler of the University of Portland, and Liz Ceppi, whose role as Graduate School Rep was deemed unnecessary following the proposal defense), and I am grateful for the sacrifices you made to be a part of my life. Dot, you have been the best advisor that I could have asked for: not only is your intellect awe-inspiring, but your humor has been a life-giving force.

And finally, for my family. To the family I married into (yay Allens and Burchs!), our relationships mean the world to me, and our mutual fondness for cocktails, wine, and food has provided the nourishment I needed to get through this. Dad, I wish you were around to see this come to fruition, but I believe that the Resurrection has restored you to fullness of life. I feel your presence daily. Thank you for inspiring an absurdist and selfdeprecating love of Catholicism within me, and for dragging me to Mass when I had no desire to go. Mom, thank you for your infinite support and generosity over these many years. You are the utmost model of love and care, and through all our recent loss, your light has not wavered, and I stand in admiration of your tenacity.

Last, but certainly not least, GingerFace (a.k.a Sarah). There are not many partners who bear their lesser half starting doctoral work three months after getting married. I am sorry for all the Friday nights I had to be in class, not to mention the 
countless hours I spent reading and highlighting and writing. From here on in, I promise our marriage will be free from coursework (unless I do something absurdly silly, like become a deacon or a sommelier) and dissertations. You and Jack (and Genevieve) have carried me through all this. I hope that the rest of our lives together are free from stress and anxiety induced by academic pursuits. I love you three.

Ad majorem Dei gloriam inque hominum salutem. 


\section{Table of Contents}

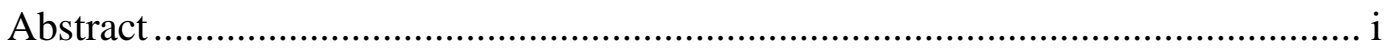

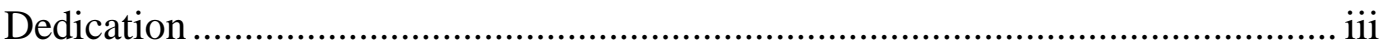

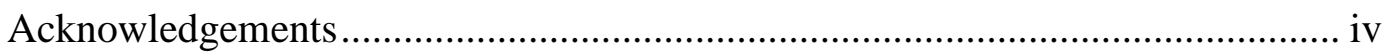

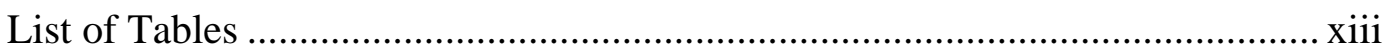

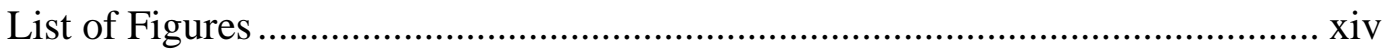

Chapter 1: Statement of the Problem ........................................................................

Some Contexts to Be Addressed ..............................................................

Context: Catholic Schools and Catholic Education .................................3

Context: Evangelization and the Question of Catechesis .......................6

The Purposes and Natures of Evangelization ..............................

The History and Purpose of Catechesis .......................................8

Context: Organizational Culture in the Catholic Church......................12

Context: Religious Diversity of Catholic High Schools .......................22

Context: A Critique of the USCCB Framework ..................................23

Interlude: Statement of Positionality .................................................30

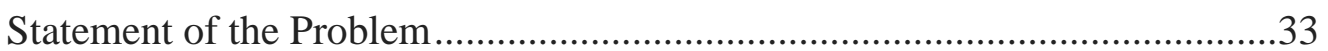

Articulation of the Problem ....................................................................33

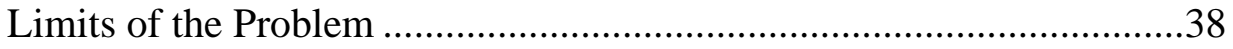

Validation of the Problem....................................................................39

Significance of the Research Problem ....................................................44

Catholic Education and Emancipatory Pedagogies ..............................44

Catholic Theological Education for Religiously Diverse Populations ...47

Research Purpose and Rationale for the Purpose .......................................49

Presentation of Research Question and Methods..........................................50

Research Questions ...................................................................50

Data Collection Procedures..............................................................51

Data Analysis Procedures ...........................................................52

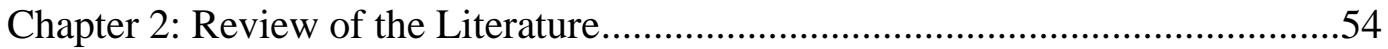


Theoretical and Conceptual Frameworks .....................................................55

Theoretical Frameworks ..................................................................56

Freire's Emancipatory Pedagogy ............................................57

Culturally Relevant Pedagogy ..................................................61

Culturally Responsive Teaching. ............................................62

Culturally Sustaining Pedagogy ...............................................64

Critical Religious Education ..................................................65

The Conceptual Framework: CRSP ...............................................67

Critique of the Theoretical Frameworks and Conceptual Framework....73

Catholic and Religious Education...................................................... 75

Documents from the Magisterium of the Catholic Church....................76

Documents from the CCE ....................................................78

Documents from the USCCB.....................................................84

Historical Overview of the Models of Religious Education ..................91

Concluding Thoughts on Theoretical Literature .........................................93

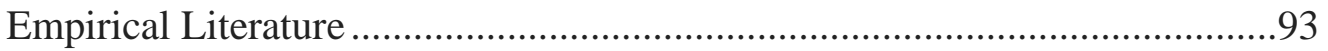

Catholic Schools and Religious Education in Catholic Schools.............94

Catholic Schools and Their Students ........................................95

Religious Education in Catholic Schools...................................99

Emancipatory and Critical Pedagogies ..............................................106

Critical Pedagogies and Religious Education ............................106

Critical Pedagogies in Catholic Schools ..................................109

Critical Pedagogies: CRP, CRT, CSP, and CRE ........................118

Religious Education in Non-Catholic International Contexts .............125

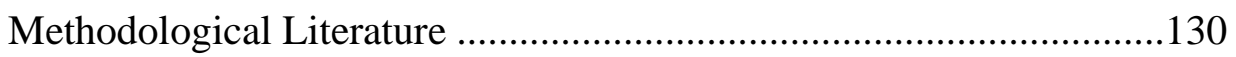

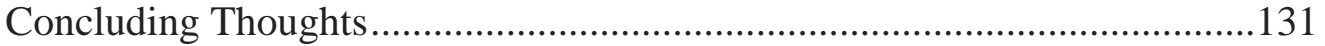

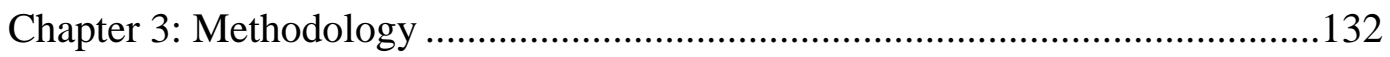

Statement of Philosophical and Paradigmatic Positionality ........................135

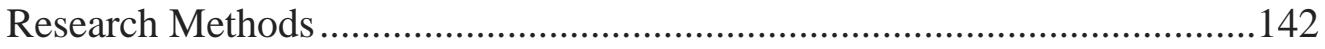

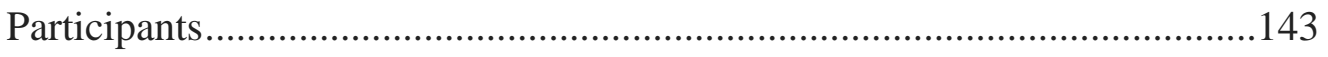




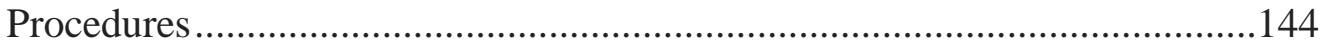

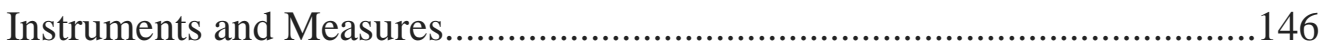

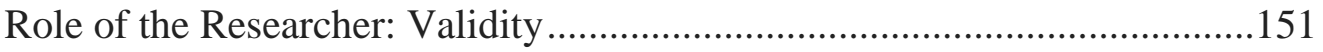

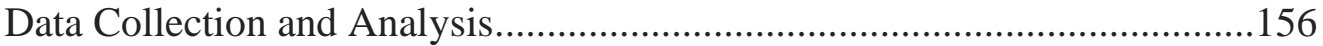

Chapter 4: Findings and Discussion ................................................................167

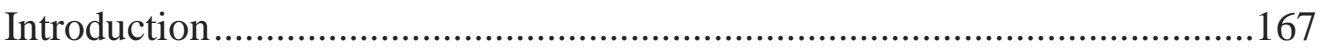

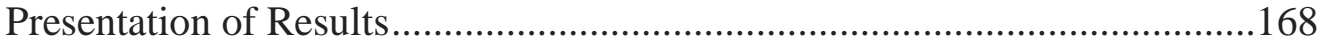

Concept Maps for Participants ..............................................................169

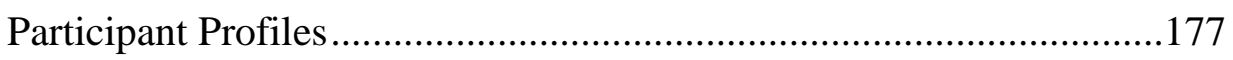

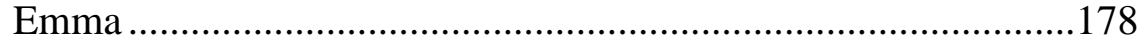

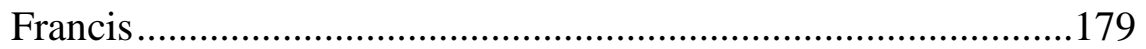

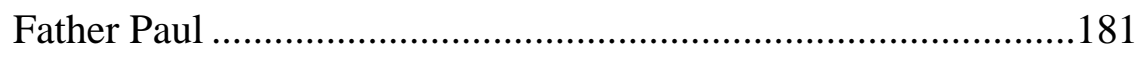

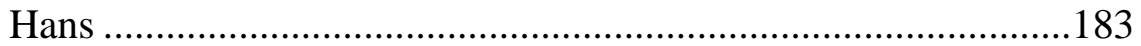

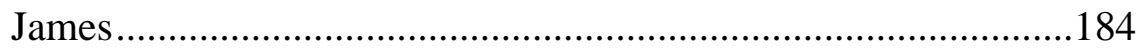

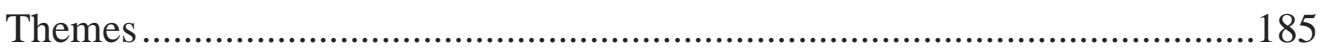

Research Question 1: Beliefs About Theological Education..................187

Opposition to Catechesis and the Framework …………..............187

Existential Meaning and Relevance ............................................202

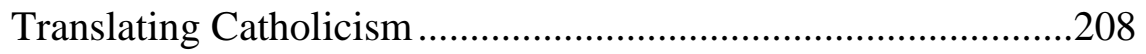

Personal Well-Being and Spirituality ………………………......211

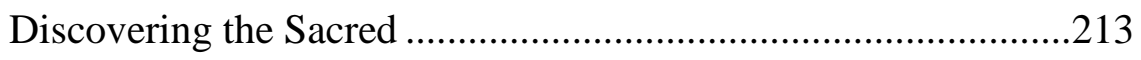

Freedom for Authentic Self-Expression and Exploration............215

Exploration of Content...................................................... 215

Assessments .................................................................. 216

Research Question 2: Curricular and Pedagogical Decisions ................218

Relationship-Building ...............................................................218

Classroom Culture and Environment................................. 220

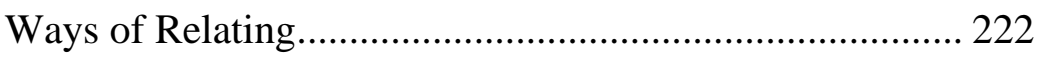

Critical Exploration....................................................................224

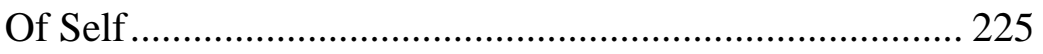


Of Content.................................................................... 226

Instructional Delivery ......................................................228

Centering Student Voice ................................................ 229

Responding to Student Need.......................................... 230

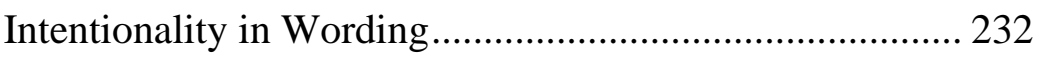

Essential Questions .................................................... 233

Research Question 3: Use of the Framework ..................................234

Structural Adherence ........................................................238

Benefits of the Framework .................................................241

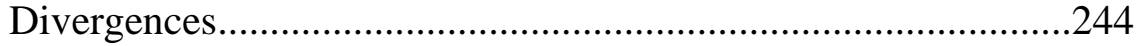

Omissions..................................................................... 246

Additions .............................................................. 248

Emphasis and De-Emphasis.......................................... 249

Limitations of the Study................................................................251

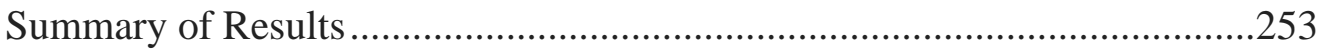

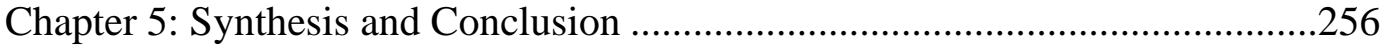

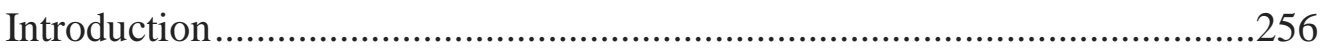

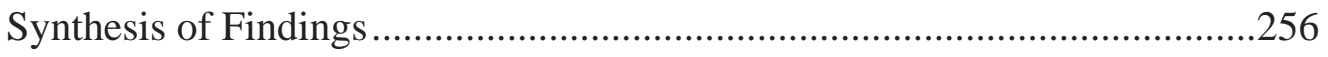

Overarching Goals of Evangelization and Emancipation....................257

The Tenets of Critical Religiously Sustaining Pedagogy ....................259

Nurturing and Loving Relationships....................................259

Existentially Meaningful Content .........................................261

Religiously Sustaining Instruction .........................................264

Use of the USCCB Framework ...................................................270

Situated in the Larger Context of Scholarship ..........................................2271

Research Question 1: Beliefs About Goals and Catechesis ..................272

Research Question 2: Pedagogy for Non-Catholics...........................276

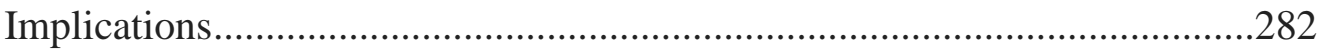

Reconsidering the Framework and Catechesis ..................................282

Considering a Different Scope and Sequence...................................284 
Leaning into Critical Theories of Pedagogy .......................................285

Future Considerations and Recommendations for Research .......................2286

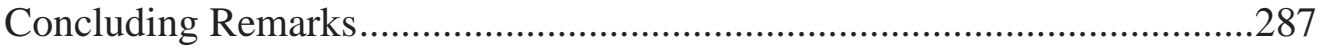

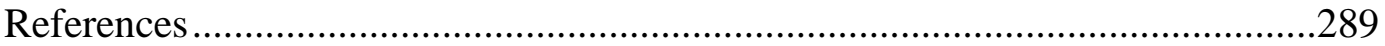

Appendix A: Invitation Letter to Principals and Department Chairs ..................326

Appendix B: Invitation Letter to Theology Teachers .........................................327

Appendix C: Consent Form for Participants...................................................329

Appendix D: Interview Protocol for First Interview........................................333

Appendix E: Interview Protocol for Second Interview....................................335

Appendix F: Interview Protocol for Third Interview........................................337

Appendix G: Interview Protocol for Focus Group Interview .............................339 


\section{List of Tables}

Table 1 Research Questions, Data Collection and Analysis, and Validity Threats .. 164

Table 2 Themes Generated from Analysis....................................................... 186

Table 3 Participants' Perceptions of Their Students' Religious Demographics....... 196 


\section{List of Figures}

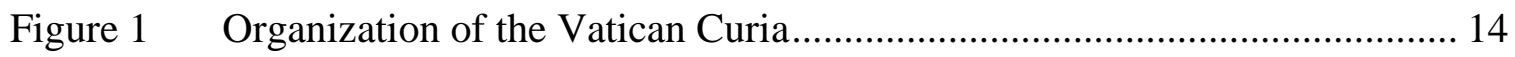

Figure 2 Organization of the United States Conference of Catholic Bishops ............ 16

Figure 3 The Conceptual Framework: Critical Religiously Sustaining Pedagogy ..... 68

Figure 4 Snapshot of a Section from the USCCB Framework ............................... 88

Figure 5 General Concept Map: Participant Positionality Influencing Attitude, Goals, and Practice. 170

Figure 6 Detailed Concept Map: Participant Positionality Informing Attitude Toward Theological Education. 172

Figure 7 Detailed Concept Map: Participant Attitude Influencing Goals and Teaching Practice 175

Figure 8 Hierarchy Chart of Child Codes within "Evaluation of Catechesis" 189

Figure 9 Hierarchy Chart of Child Codes within "Evaluations of USCCB

Framework" 190

Figure 10 Bar Graph Depicting Matrix Coding Query of Participants’ References to "Evaluations of Catechesis Codes" 192

Figure 11 Bar Graph Depicting Matrix Coding Query of Participants’ References to "Evaluations of Institutional Catholicism Codes"..... 193

Figure 12 Bar Graph Depicting Matrix Coding Query of Participants’ References to "Evaluations of USCCB Framework" Codes..... 193

Figure 13 Hierarchy Chart of Child Codes within Parent Code "Purpose of Theology Teaching". 204

Figure 14 Hierarchy Chart of Child Codes "Goals for Relevance" within "Purpose of Theology" Codes ..... 205

Figure 15 Bar Graph Depicting Matrix Coding Query of Participants' Purposes of Theology. 206

Figure 16 Bar Graph Depicting Matrix Coding Query of Participants’ Reference "Building Relationships" Codes.... 220 
Figure 17 Hierarchy Chart of Child Codes within Parent Code "Use of the

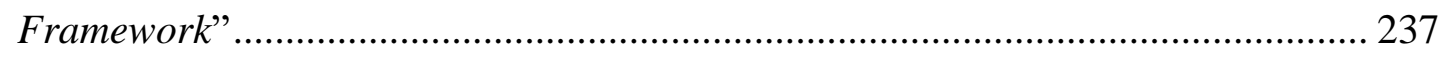

Figure 18 Bar Graph Depicting Matrix Coding Query of Participants' References to "Uses of the Framework" Codes ....................................................................... 238

Figure 19 Hierarchy Chart of Child Codes within "Use of the Framework:

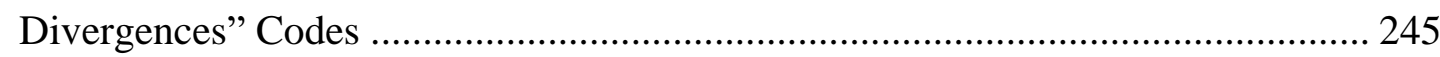




\section{Chapter 1: Statement of the Problem}

From its very inception, education in the United States has been heavily

influenced by Christianity. Students in one-room schoolhouses became literate through reading the Bible, and the nation's first colleges educated its earliest clergy. Although Catholicism is a Christian denomination, Catholics in the United States developed their own schools to provide a counter-narrative of sorts to Protestant-dominated educational institutions, whose adherents ostracized and excluded Catholics from schools in the early colonies and states. And while the first Catholic schools in the 1800s served largely impoverished immigrant communities, and aimed to preserve the cultural and Catholic religious heritage of immigrant students, Catholic high schools in the 21 st century now serve students of greater demographic diversity across socioeconomic, racial, cultural, and religious backgrounds. The religious diversity of contemporary Catholic school students, however, raises a question with regard to religious education: should religious educators within Catholic schools prioritize the aim of perpetuating Catholicism when not all students are Catholic?

Over the course of this problem statement, I aim to achieve several goals. First, I hope to provide a concise yet informative overview of Catholic secondary education in the United States, specifically foregrounding the nature of theological/religious ${ }^{1}$

\footnotetext{
1 The terms "religious education" and "theological education" carry different connotations, depending on the context within which they are used, or from whose mouth they emerge. For example, in Protestant churches, religious education generally entails the study of Christianity for the purposes of its propagation, while in universities, it entails the study of religion from a strictly academic perspective. Catholic high schools, on the other hand, share highly similar curricula among them, although their departments go by different names: Religion, Religious Studies, or Theology. The three high schools I have taught in, and the one I attended, have all used this latter term, which literally means - in the words of Roland Faber, my systematic theology professor at the Claremont School of Theology_ “God-talk." Thus, I will be using the
} 
education within Catholic high schools. Second, I aim to introduce divergent ideas surrounding the purposes and roles of studying theology, ideas which primarily center around problematized and varied understandings of the role of evangelization (broadly, living out Christian faith) and catechesis (the particular mode of religious education used for educating would-be converts to the faith, or those who are already Catholic) in Catholic schools. I will also analyze the clash of cultural beliefs and assumptions among and between organizations in the hierarchy of the Catholic Church, which clarifies how the problem of practice at the heart of this dissertation came to be. I hope to accomplish all this in such a manner that the non-Catholic reader, or the reader who is entirely unversed in any of this background, will be able to understand the crux of my problem of practice: religious education in United States Catholic high schools, which the United States Catholic bishops (USCCB, 2008) have mandated to be catechetical through their Doctrinal Elements of a Curriculum Framework for the Development of Catechetical Materials for Young People of High School Age (henceforward "the Framework"), fails religiously diverse ${ }^{2}$ student populations in its lack of relevance for and sensitivity to the beliefs of U.S. teenagers.

\footnotetext{
terms "religious education" and "theological education" interchangeably, though they may not be interchangeable in some contexts, and my personal preference is for the latter.

2 Throughout these chapters, I refer to "religiously diverse" student populations, and I would like to clarify that the students within Catholic schools represent a wide variety of religious traditions. While I am particularly interested in the inclusive theological education for non-Catholic students, I also recognize that theology classrooms in U.S. Catholic schools often have Catholic students and significant numbers of nonCatholic (that is, non-Catholic Christian, non-Christian, and non-religious) students. Thus, for the most part I tend to use the term "religiously diverse" rather than "non-Catholic" to describe the student populations I am concerned with. However, there are some instances wherein I use the more narrow term "non-Catholic" to describe certain student populations with greater specificity.
} 


\section{Some Contexts to Be Addressed}

In order to understand the factors surrounding this problem, several contexts need to be addressed and explicated. I will first provide a brief overview of the history of Catholic schools and Catholic education before discussing the questions of evangelization and catechesis in schools, which concern how Catholic school staffs and faculties live out their missions to spread the Gospel message and perpetuate the religious tradition of Catholicism from one generation to the next. I will then turn my attention to the organizational culture of the Catholic Church to highlight the differences between the perspectives of the global Church and the Church in the United States, particularly with regard to the relationship between their hierarchical structures. I believe that a largely unacknowledged clash of cultures exists between these two spheres of hierarchical culture, which in turn influences how Catholic schools approach religious education around the world. Finally, before moving on to my articulation of the problem, I will discuss the religious diversification of Catholic school students in the United States and provide a critique of the Framework, which the U.S. bishops have mandated to guide theological education in Catholic secondary schools.

\section{Context: Catholic Schools and Catholic Education}

Catholic schools in the United States originally served newly arrived immigrant communities in the 19th century, springing up in those urban centers where Catholic immigrants suffered discrimination and bias (Louie \& Holdaway, 2009). Men and women of various religious orders ${ }^{3}$ staffed these schools, frequently taught students in the

${ }^{3}$ In the Catholic Church, there exist various "orders" of men and women who profess perpetual vows of poverty, chastity, and obedience in the pursuit of common mission. Some of these orders, such as the De La 
students' native tongues, and offered religious education in order to help students sustain their own religious beliefs in the midst of a largely Protestant culture that was wary of "papish" (to use a colloquial, derogatory term that described Catholic intruders) influence in the early American colonies. For example, John Carroll, whose cousin was the sole Catholic signatory of the Declaration of Independence, founded Georgetown College in 1789 as a refuge for Catholics and other Christian minorities who faced overt discrimination. Prior to his ordination to the priesthood, Carroll attended Catholic school in Europe because in the years leading up to the American Revolution, early American colleges, which originally trained Protestant clergy, did not welcome Catholics.

In offering this, I do not aim to paint a rosy portrait of Georgetown (or other early Catholic schools, for that matter) as an institution that came to exist as gloriously righteous rebellion against systematic religious discrimination. The college's Jesuit priests, after all, enslaved Africans, and sold them in order to keep the college afloat during an economic crisis of the early 19 th century. I offer this simply because I am a former Jesuit novice of the Maryland Province, and Georgetown is my alma mater. I have only come to grapple with this evil history in recent years, having met a theology teacher from New Orleans who is one of the many descendants of the slaves that Georgetown's Jesuits sold. I must acknowledge that my own education and formation in Catholic institutions were (in no small part) made possible by the exploitation and spilled blood of enslaved peoples.

Salle Christian Brothers, the Sisters of Saint Mary of Oregon, and the Society of Jesus (the Jesuits) have focused their missions on education. 
In the early decades of Catholic education following Georgetown's origins through the mid-1800s, the priests and sisters and brothers responsible for founding schools, and administrating and teaching in them, understood their work as divine calling. Their vows of poverty meant that Catholic schools could operate with minimal expenses. The financial support of Catholic parish communities enabled immigrant families of little socioeconomic means to send their children to school. Catholic schools existed to help immigrant Catholic children maintain connections to their home cultures, and frequently educated students in their own native languages, thus modeling some of the tenets of Culturally Responsive, Relevant, and Sustaining Pedagogies (Gay, 2018; LadsonBillings, 1995a; Ladson-Billings, 1995b; Ladson-Billings, 2014; Paris, 2012; Paris \& Alim, 2014; Paris \& Alim, 2017) long before such models were formally articulated in the scholarly literature surrounding education.

In the past half century, the tone and timbre of Catholic education have shifted tremendously. The majority of Catholic high schools charge exclusionary tuition rates, and families who seek matriculation into them perceive that Catholics schools offer a combination of rigorous discipline, loving community, and thorough academic preparation. Because of this constellation of perceived (and hopefully actual) qualities that many families believe distinguish Catholic schools over and above their public counterparts, in recent decades Catholic schools have diversified in many respects. In the 1970s, Catholic educational institutions "transformed themselves from closed institutions focused on maintaining the status quo to pluralistic institutions that mirrored the religious plurality of society in general" (Gleeson, O'Gorman, Goldburg, \& O'Neill, 2018, p. 84). 
Racially, socioeconomically, and religiously diverse families send their children into the world of Catholic education for a variety of reasons (Eide, Goldhaber, \& Showalter, 2004; Fleming, Lavertu, \& Crawford, 2018; Hallinan \& Kubitschek, 2010). Some evidence (Maney, King, \& Kiely, 2017) has even demonstrated that some non-Catholic parents specifically choose Catholic schools primarily because Catholic school educators foster conversations and experiences that aim at the realms of the spiritual and religious.

In short, Catholic schools no longer primarily serve ghettoized immigrant Catholic populations, but rather open their doors to any and all who can afford to attend, be it through their own financial resources or through the help of scholarship opportunities. Catholic schools' revenues remain largely tuition-driven, causing many of them to become elitist, and causing urban Catholic schools to frequently participate in segregationist practices. Burke and Gilbert (2016) indicated that for those areas that are

home to multiple Catholic schools, while one or two might serve "low-income" (read: of Color) students, others almost exclusively educate affluent, white students while maintaining some scholarships for tokenized students of Color. Catholic schools are thus by no means immune to the insidious nature of white supremacist ideology.

\section{Context: Evangelization and the Question of Catechesis}

In order to help the reader understand what makes the USCCB Framework so lacking, I must first flesh out the theological purposes that undergird its existence. In the following sections, I will explicate the difference between evangelization and catechesis, and the potential ways in which these two concepts overlap. 
The Purposes and Natures of Evangelization. Like those working in any ministry of the Catholic Church, educators operating Catholic schools seek to live out the mission of evangelization, a term which possesses a wide variety of connotations, both positive and negative. In its most literal sense, the term "evangelization" comes from the Greek noun euangelion, or the "good news" of the incarnation, life, death, and resurrection of Jesus of Nazareth. In their belief, Christians of any denomination are called by the Gospel (from the Old English "God spell," or "God's word") to spread and live out their conviction that Jesus was God incarnate, that he preached a loving message of repentance for the forgiveness of sins and the immanent approach of the Kin-dom ${ }^{4}$ of God, and was crucified and resurrected from the dead for the salvation of humanity.

Evangelization has two sides: on one, Christians have been instructed by Jesus to convert non-Christians to follow him, and on the other, Christians are called to live out their faith in myriad ways, without the intent of converting others. Catholic Social Teaching (hereafter "CST"), or the body of ethical tenets espoused by the Catholic Church, is, for example, a means of achieving this latter sense of evangelization. While CST's tenets regarding marriage and abortion are the most well-known of its corpus (because they are the most hotly contested in public discourse), CST encompasses many more areas of human existence, such as labor rights, immigration, and just war and pacifism. Christians "evangelize" when they undertake acts of care through the so-called

\footnotetext{
${ }^{4}$ Various theologians in recent years have removed the "g" from "Kingdom" in their writing, in order to get at what they believe the heart of Jesus's mission was: a radical re-envisioning and re-creation of the systematic evils of this world into a world where all know loving solidarity with one another and with their Creator. I tend to prefer "Kin-dom" over "Kingdom" as well, because it foregrounds the concept of kinship and removes the masculine framing that patriarchal theologians have constructed around the Divine.
} 
"corporal (bodily) works of mercy": burying the dead, offering asylum to the immigrant, feeding the hungry, clothing the naked, caring for the sick and infirm, and visiting the imprisoned, for example. Thus, when those working in Catholic soup kitchens offer hot meals to those experiencing food instability, they evangelize, even though soup kitchen staff do not seek to convert the famished. One can evangelize without converting others. On the other hand, a Catholic parish community that prepares children to receive their First Communion evangelizes as well, though in a totally different manner, precisely because the community aims to perpetuate Catholicism in its youth. Catholics do not always distinguish between these types of evangelization, but these modes do all exist under the large umbrella of living the Gospel message.

The History and Purpose of Catechesis. In the years surrounding the 16thcentury Protestant Reformation, various bishops and theologians (who as a general principle received their local bishop's approval) penned catecheses ${ }^{5}$ in various languages, in order to help Catholics understand and defend their religious beliefs against the rise of Protestantism. The invention of the printing press, which coincided with the Reformation, enabled European literacy to explode, and catecheses became popular educational materials for schools, parishes, and homes across Europe. Given these historical roots surrounding the Reformation, catechetical instruction tends to be "apologetic" in nature

\footnotetext{
5 "Catechesis" can function as either a verb or a noun. In the former sense of the word, a teacher can catechize others, or teach students doctrinal points of belief. In the latter sense, a catechesis is a textual artifact, a document that systematically lays out the theological beliefs of the Catholic Church. In the United States, the Baltimore catechism was in wide use until the Catechism of the Catholic Church, the most complete catechesis ever written, was published by the Vatican in 1992, under the leadership of Saint Pope John Paul II. Catecheses have been around for almost as long as Christianity. When the religion as an institution exploded in the first centuries of the first millennium, catecheses were used as instructional aides for the education of new converts.
} 
(from the Greek apologia, or "defense"), preparing Catholics to "defend" their religious beliefs. Religious education in early American Catholic schools was thus geared toward catechesis, that is, the mode of religious education through which children memorized theological doctrines and dogmas from catechetical texts. This said, the tone and timbre of contemporary catechesis has shifted away from this defensive posturing, given that the Protestant Reformation is not quite viewed as a looming threat any longer. Because Christianity tends to focus on orthodoxy (that is, "right belief") over orthopraxy ("right action," as in Judaism or Hinduism, for example), catechesis has always incorporated the transmission of doctrine and dogma in order to foster "correct" belief. A vital thing to note is that catechesis, unlike other methods of religious education, presupposes an existing Catholic faith within the student, or a student's desire to convert to the Catholic faith.

Nowadays, catechetical educators aim to help Catholics, adults and children alike, understand their faith on a deeper level. Papal writings, especially Evangelii nuntiandi, "Evangelization in the Modern World” by Pope Paul VI (1975) and Catechesi tradendae, "Evangelization in Our Time” by Pope John Paul II (1979), have specifically focused on catechesis as a means of engaging, interacting with, and even converting (potentially secularized) cultures outside of Catholicism. Pope John Paul II's (1970) notion of the "New Evangelization” from his Encyclical letter Redemptoris missio, “The Mission of the Redeemer," was about re-engaging secularized European persons that were once Catholic, in the hopes of reinvigorating lapsed Catholics, and even aiming to reChristianize those national cultures that had strayed toward secularism. This renewed 
papal emphasis on catechesis in the second half of the twentieth century has influenced parish- and school-based programs that prepare children for receiving the Sacraments of First Communion or Confirmation. In the Catholic Church, Communion and Confirmation are the formal rites through which a person is received into the Church and commits to the faith, and programs for adults (such as the Rite of Christian Initiation for Adults) invariably include catechetical preparation as well.

A central question at the heart of the chapters to follow is whether religious education in Catholic high schools needs to catechize (and convert) students as part of the evangelizing mission: can Catholic high school educators "evangelize" by providing quality education, or do they need to also foster experiences of religious conversion? And relating to issues of power dynamics, who gets to dictate the necessity of catechesis? Or determine if another mode of religious education is more appropriate? Which voice, among many competing ones (of families, students, teachers, and bishops, for example), should take precedence, and does the victor in these debates depend on context? I will explore these questions in my review of the literature in the second chapter, but for now I simply want to drive across the point that catechesis is but one aspect of the evangelizing mission of the Catholic Church: catechesis fosters Catholic faith formation through intellectual engagement, which in turn leads to affective belief of the heart. If a new Catholic is to commit wholeheartedly to the faith, or commit even without believing the entirety of Catholic doctrine and dogma, they must first understand what it is that they agree or disagree with, and why they agree or disagree. Catechesis is of great help in this process. In sum, beyond being a physical document explaining the content of Christian 
doctrine and dogma (which is a catechesis), catechesis (more broadly) is also a pedagogical approach used by Catholic institutions to proselytize (i.e. attempt the conversion of) others.

The mission to evangelize, or live out Christian belief, however, encompasses far more than memorizing catechetical content. Since the Second Vatican Council of the mid-1960s - a major council of bishops and theologians that caused a paradigm shift for Catholicism, which will be discussed in my review of the literature-Catholic religious education has actively moved through various waves and trends, highlighting and emphasizing different aspects of engagement with religious tradition, from the psychological to the philosophical to the experiential to the interreligious. These waves and trends, more often than not, have had other raisons d'être apart from (and/or in addition to, depending on context) catechesis. I will expand on these trends in the second chapter, but for now I hope to convey that catechesis is by no means the only mode of religious education that has occurred within Catholic schools. However, the problem of practice at hand - that is, the oppressive and inadequate theological education of nonCatholics within Catholic high schools - has been most greatly influenced since 2008 by a certain document produced by the United States Conference of Catholic Bishops (henceforward, the "USCCB") that is entirely catechetical in its intent: Doctrinal Elements of a Curriculum Framework for the Development of Catechetical Materials for Young People of High School Age. 


\section{Context: Organizational Culture in the Catholic Church}

In order to provide some broader context of the various stakeholders within this problem, I use Schein's (2017) theories of organizational culture to explain the organizational dynamics therein. Several organizational cultures are at play, two of which directly involve the institutional structure of the Catholic Church. As a hierarchical institution, the Church possesses many organizational layers, each with its own role and degree of authority. And those agents within organizational layers, I will argue here, frequently maintain varying, and even opposing, perspectives. Institutionally centralized in Rome, the Catholic Church is certainly a macro organization possessing a macro culture. Schein (2017) defined macro culture as belonging to "nations, ethnic groups, and occupations that have been around for a long time and have, therefore, acquired some very stable elements, or 'skeletons,' in the form of basic languages, concepts, and values" (p. 77). In this context, I am not concerned with articulating the various stable elements of Catholicism's macro culture (such as rituals, traditions, and sacred texts), but it is nonetheless valuable to note that the cultures and micro organizations I am about to identify belong to a broader macro organization and macro culture.

The Vatican Curia, or the headquarters of the Catholic Church, possesses various constitutive branches that form the Church's metaphorical central nervous system in Rome. The Congregation for Catholic Education (hereafter the "CCE"), the first micro organization involved with my problem of practice, is one of nine "Congregations" that are comprised of cardinals and bishops; each Congregation focuses on a particular area, analyzing and engaging various aspects of the Church's existence and activities. While 
the term "congregation" more frequently connotes a group of people attending a given church, I want to clarify that a Vatican Congregation is a different sort of organization. As Cardinal Grocholewski, the head of the CCE, pointed out (2015), the CCE is divided into three jurisdictions pertaining to seminaries, universities, and primary and secondary Catholic schools. Regarding that final jurisdiction, primary and secondary Catholic schools, Grocholewski stated that the "primary purpose of the Schools Office is to apply general principles of the Universal Church to the field of Catholic Education and to communicate these ideas through meetings, briefings, conferences and documents" (p. 140). Thus, the CCE is responsible for coordinating with and helping bishops of dioceses ${ }^{6}$ around the world administer the schools within their dioceses through a spectrum of activities and aids. As depicted in Figure 1, the Vatican Curia is divided between different organizational entities that serve different purposes, ranging from internal courts to judge on matters of Church law to an office that oversees the protection of minors. Some of these offices and councils have been created by Pope Francis since he was voted into the papacy in 2013, others have origins in the first centuries of the first millennium, while others were the product of the Second Vatican Council.

\footnotetext{
${ }^{6}$ In the Catholic Church, a "diocese" is a geographic region over which a bishop has authority. Some dioceses are smaller than others, given that they might have a more highly concentrated population, or have been founded at an earlier point in time; for example, New York State has eight dioceses, and Oregon has two. Every geographic region in the world belongs to a Catholic diocese.
} 
Figure 1

Organization of the Vatican Curia

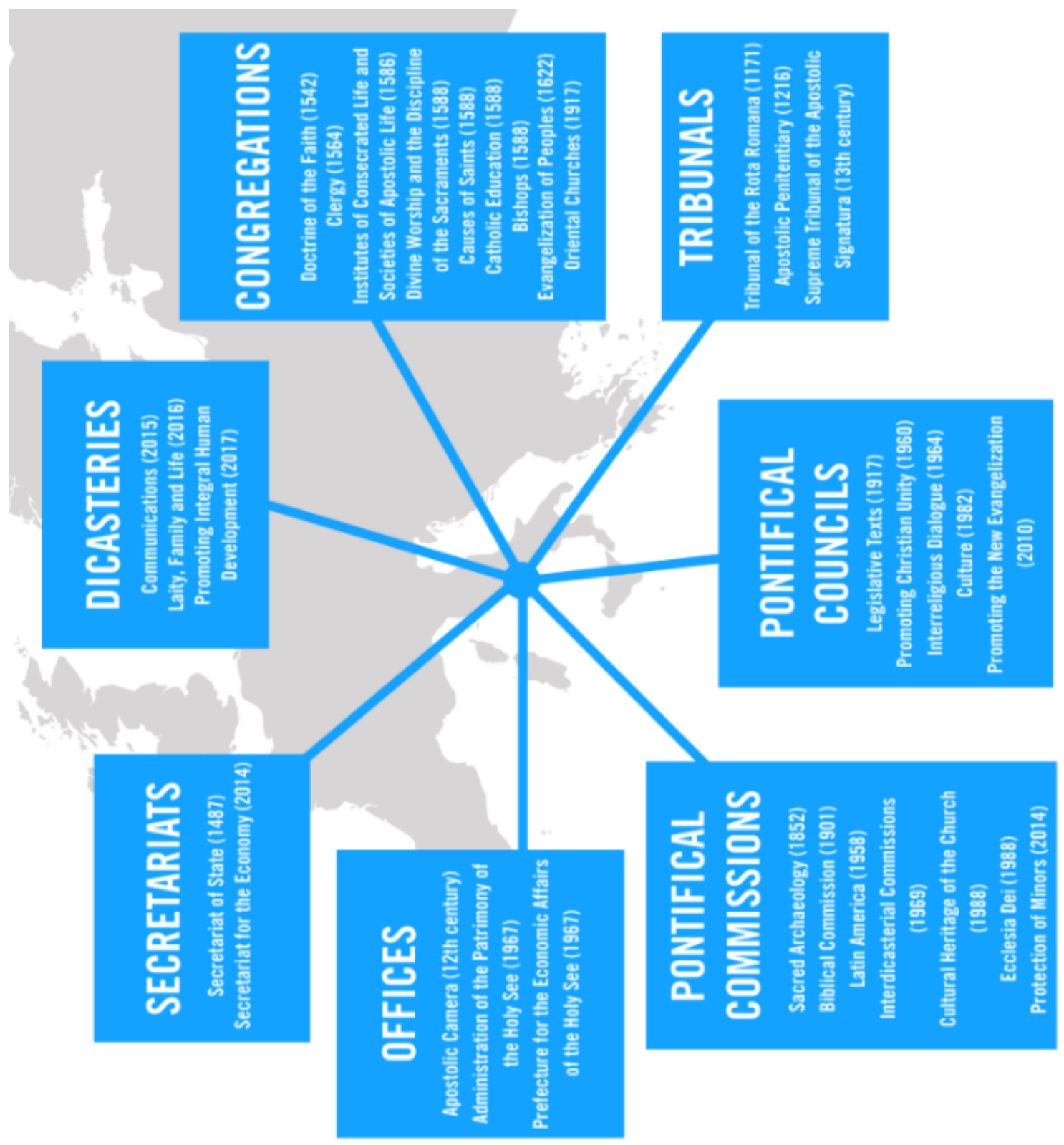


The second micro organization (micro, in Schein's conceptualization, does not refer to size but rather to subordinate positioning), the USCCB, is the governing ecclesiastical body of the Catholic Church in the United States; it forms the metaphorical nervous system of the Catholic Church in the United States, and has distinct, though not unrelated authority, from the Curia's congregations. The Conference is divided into many offices and committees (depicted in Figure 2) that operate in a similar fashion to the branches of the Vatican Curia. The USCCB is responsible for collaborating on vital issues concerning the Catholic Church and broader society, coordinating with the Church on a global scale, and offering assistance to bishops within the United States. The aforementioned USCCB Framework, jointly produced by the USCCB's Committee for Catholic Education and the Committee for Evangelization and Catechesis, is of primary interest to my problem. In their Framework, which was a product of the bishops' own ecclesiastical (that is, pertaining to church structure) and hierarchical cultures, the bishops attempted to determine how students in Catholic high schools would experience theological education by providing a list of standards for them to learn. I would like to note that even though the bishops cooperate with one another within the larger structure of the Conference, no two Catholic bishops are entirely alike. Each approaches his work with his own beliefs, experiences, and assumptions, and bishops have been known to dialogue and debate over more controversial topics. When the USCCB does publish a document such as the Framework on behalf of the entire Conference, the implication is that as a collective whole, the bishops have approved of its publication through a drafting and voting process. 
Figure 2

Organization of the United States Conference of Catholic Bishops

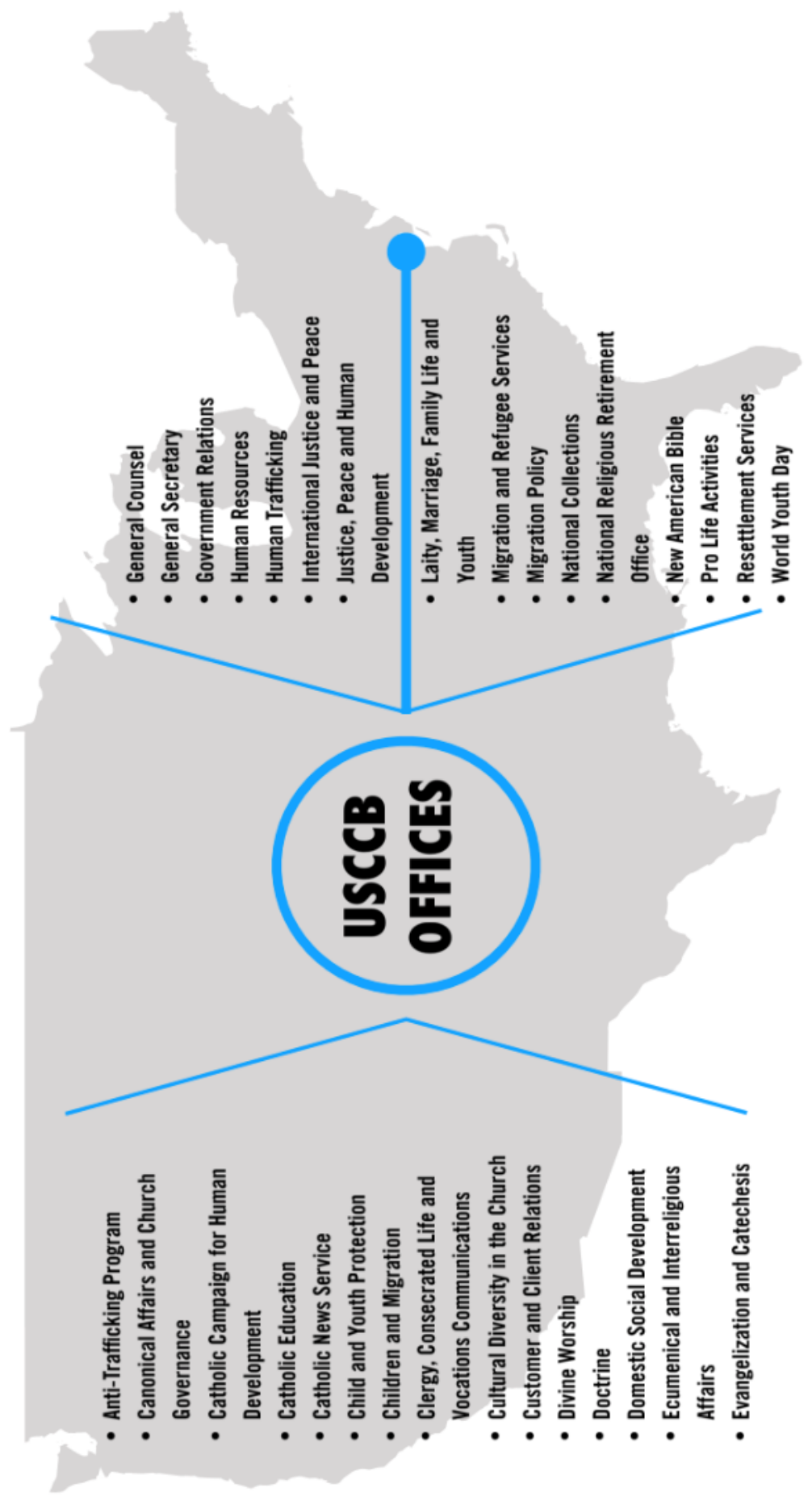


The third micro organization at hand is the Catholic high school. These institutions are themselves quite diverse in terms of geographic location, student population, mission, and affiliation with particular religious orders (such as the $\mathrm{De} \mathrm{La}$ Salle Christian Brothers, the Sisters of Saint Mary of Oregon, and the Jesuits). In short, little can be assumed about the subculture that defines any given Catholic high school. While diocesan Catholic high schools fall under the direct purview of their local diocesan bishop, many other high schools operate under the sponsorship of the aforementioned religious orders, even though they belong to a particular diocese and fall under a particular bishop's jurisdiction. If a high school was founded by a particular religious order, the local bishop gave his approval to the order. These high schools sponsored by religious orders, while still under the authority of their local bishops (who fall under the authority of the Pope), often operate with a bit more institutional freedom than their diocesan counterparts can and do. For example, while a diocesan high school falls under the direct authority and influence of the local diocesan bishop, a high school affiliated with a religious order (like the De La Salle Christian Brothers) has a bit more autonomy apart from the bishop's influence. This said, bishops still maintain authority over the operations of Catholic high schools run by religious orders; there have been several examples, for example, in which bishops have challenged the Catholic affiliation of high schools because they refused to terminate the employment of LGBT faculty and staff. I apply Schein's (2017) theory of organizational culture, which consists of three layers (artifacts, or the "visible and feelable structures and processes" within a group's culture that are "difficult to decipher"; espoused beliefs and values, or the explicitly 
stated "ideals, goals, values, and aspirations," and "ideologies" of a group's culture; and underlying basic assumptions, or the "unconscious, taken-for-granted beliefs and values" that a group holds [Schein, 2017, p. 18]), to better understand these micro organizations. Engaging the problem of practice through Schein's theory draws out a clash of cultural beliefs and assumptions between the CCE and the USCCB. Documentary artifacts published by the bishops of these two micro organizations reveal the bishops' differing assumptions about the populations of students that Catholic schools serve, which in turn illuminates the primary conflicts underlying the problem of practice: these micro organizations, according to their respective subcultures, articulate contradicting espoused beliefs according to their differing assumptions. As compared to those of the CCE, the USCCB's bishops' assumptions and beliefs have greater influence on theological education within United States Catholic high schools (given their geographic jurisdictions through diocesan structure), even though this influence proves deleterious for nonCatholics in ways that I will explore later.

While the CCE maintains a global perspective on Catholic education, and acknowledges that Catholic schools serve highly diverse student populations around the world, the USCCB remains preoccupied with Catholic education within the context of the United States. While this focus is understandable, given that the USCCB is comprised of bishops who are U.S. citizens, and are responsible for the functioning of the U.S. Catholic Church, it would probably have behooved the USCCB's bishops to have consulted their brother bishops in the CCE before issuing the Framework. And although I cannot say that this definitely did not happen, I suspect that it did not, given the 
catechetical nature of the document and its blatantly derogatory language regarding nonChristian religious traditions. The bishops of the CCE (2014) stated that religious education implemented by Catholic schools can and should adapt to different contexts, instructing that religious education does not need to catechize, but rather the mode of religious education ought to shift depending on the cultural context of any given school.

By contrast, we can infer from the Framework that the USCCB bishops produced, that these bishops assumed that students within Catholic high schools are Catholic, or should desire to become Catholic, and their catechetical impetus for theological education follows accordingly. According to Ostasiewski (2010), the bishops based their Framework (2008) on the Catechism of the Catholic Church (1992/1997), which had been published some years prior; the Catechism was a "genuine, systematic presentation of the faith and of Catholic doctrine" that was meant to aid catechists to "present, with renewed fervor, each and every part of the Christian message to the people of our time" (Catholic Church, p. xv). This is why the term "catechetical” appears in the Framework's full title, because its authors assumed that the only model of religious education appropriate for Catholic high schools was that of catechesis.

Schein (2017) articulated that when it comes to micro organizations, "subgroups will eventually share enough experience to create subcultures based on occupational, national, and uniquely historical experiences" (p. 229). Unsurprisingly, the global experience of the CCE differs profoundly from the U.S. experience of the USCCB, which in turn leads to contrasting concerns and assumptions embedded within these micro organizations' respective subcultures. Because the USCCB's bishops designed the 
Framework around the organizing principle of catechesis, the document did not aim to foster dialogue between students of different faith traditions, or to draw non-Catholics into dialogue with Catholicism. The bishops simply aimed to convert non-Catholics and deepen the faiths of those who are already Catholic. As Schein (2017) noted, the "power of culture comes about through the fact that the assumptions are shared and, therefore, mutually reinforced" (p. 25), and the Framework is the product of mutually reinforced assumptions shared by the USCCB membership, which by definition excludes anyone who is not an ordained Catholic bishop within the United States. According to Schroeder (2015), then-Archbishop of San Francisco William Leveda “expressed profound concern for the lack of religious literacy among contemporary Catholics" (p. 9), a sentiment shared amongst some of his fellow bishops. In reviewing the USCCB's bishops' writings, I see no evidence that the bishops considered modes of religious education apart from catechesis, a distinction which the CCE's global perspective more easily highlights.

This hierarchical clash of cultures influences theological education within United States Catholic high schools, which are not culturally monolithic by any stretch of the imagination. As noted earlier, we must keep in mind that Catholic schools as individual institutions cannot be generalized as serving the exact same sort of student populations: according to McDonald and Schultz's (2021) data, non-Catholic students increasingly enroll in Catholic schools, and it is this religious diversification that causes the problem of practice to exist. Through their Framework, the USCCB bishops mandated that religious education be catechetical, although $23.4 \%$ of students in U.S. Catholic high 
schools are not Catholic (McDonald \& Schultz, 2021); in the Western region of the U.S., this average is as high as $29.4 \%$, and in the Plains region, as low as $11.9 \%$.

In Schein's theory of cultural layers, theology classes are tangible artifacts of culture within schools, and while the bishops' Framework attempted to impose beliefs, values, and underlying assumptions upon how these classes operate, doing so is a profound disservice to non-Catholic students. With its broader, global perspective, the CCE has articulated a different set of assumptions, and therefore conveyed a diverging perspective regarding what religious education should be about. Educators within United States Catholic high schools, therefore, find themselves caught between ecclesiastical cultures at odds with one another.

The bishops of the CCE grounded a Catholic school's identity in the lives of its teachers and staff, who are "called upon to present faith as an attractive option, with a humble and supportive attitude" (CCE, 2014, III.1.a). Catholic educators' religious beliefs feed their vocation to teaching (Cho, 2012), and they approach teaching as an extension of their religious beliefs, in a sort of circularly mutual relationship. Cardinal Baum of the CCE (1988) echoed this sentiment, and thoroughly rejected the prospect of moral violence that religious imposition could propagate in religious education. However, the USCCB's documents and mandates hold greater sway for educators in the United States. Even though educators may disagree with the USCCB's underlying assumptions and espoused beliefs regarding this catechetical intent, they are nonetheless beholden to the Framework, regardless of whether they work in a diocesan school, or in a school affiliated with a religious order. 
Schein's theory of organizational culture proves useful not only for understanding the levels of organization at play within this problem of practice, but for understanding why a clash of cultures between these organizations problematizes theological education within Catholic high schools. Bishops in the United States cannot share the same perspective as bishops in Rome do, simply by nature of their differing backgrounds and contexts. Beyond the United States' bishops' underlying assumptions about students' religious identifications, bishops' espoused beliefs (regarding the supposedly catechetical purpose of theological education) seem to stem from an uninformed-intentional or otherwise - understanding of who attends Catholic schools. Based on available documentary evidence, I suspect that this ignorance grounded the Framework's genesis. In my research, I aimed to investigate how theology teachers navigate this clash (or, truly, these clashes) of cultures in their service of non-Catholic students.

\section{Context: Religious Diversity of Contemporary Catholic High Schools}

According to data from the National Catholic Education Association (McDonald \& Schultz, 2021), Catholic high school student populations have gone through tremendous demographic shifts in recent decades. Not only are schools diversifying with regard to race, ethnicity, and socioeconomic status, but religious identity as well. According to recent NCEA data, almost 25\% of students (McDonald \& Schultz, 2021, p. 22) in all Catholic high schools are not Catholic, a percentage that has skyrocketed from $2 \%$ in the early 1970 s. A wide variety of factors contributed to this religious diversification, but central among them is the fact that Catholic schools are perceived by families to provide disciplined, community-focused, and academically rigorous 
educational environments (Bryk, Lee, \& Holland, 1993; Eide, Goldhaber, \& Showalter, 2004; Fleming, Lavertu, and Crawford, 2018; Hallinan and Kubitschek, 2010). Precise exploration of why non-Catholic families send their children to Catholic schools is outside of my scope of interest for this problem, and is thus unnecessary to dive into, although awareness of these recent trends in students' religious diversity is important. Also worth mentioning is the 2020 Supreme Court ruling of Espinoza et al v. Montana Department of Revenue et al, in which the Court established an important precedent for the siphoning of taxpayer dollars into religious schools, and one can only speculate that this ruling will further contribute to policies that result in the continued religious diversification of Catholic schools (although, more importantly, the tragic siphoning of taxpayer dollars into private education).

\section{Context: A Critique of the USCCB Framework}

In the following pages, I offer a critique of the USCCB's Framework, although I do so in the sense of Eisner's (2000) sense of critique: my critique is not strictly a condemnation of this document, but is rather an attempt to open avenues of dialogue and inquiry into the Framework's role in Catholic high school education. While critique certainly involves a degree of highlighting perceived shortcomings, it also highlights unexplored terrain regarding the Framework's implementation and the broader context within which it is situated. Critique, in Eisner's (2000, pp. 63-66) words, is a matter of connoisseurship rather than fault-finding.

As previously noted, in 2008, the USCCB published Doctrinal Elements of a Curriculum Framework for the Development of Catechetical Materials for Young People 
of High School Age (the "Framework"), which set out a standard theology curriculum for use in all United States Catholic high schools. In theory, the bishops require theology and religious studies departments and Catholic textbooks to abide by the catechetical model that the bishops outlined in their almost sixty-page Framework, although scholars and educators (Groome, 1999; Groome, 2011; Harris \& Moran, 1992; Harris \& Moran, 1998; Moran, 1983; Moran, 1989; Moran, 1997; Moran, 2018; Rossiter, 1982; Rossiter, 2011; Rummery, 1975; Schipani, 1988; Switzer, 2006; Wright, 2007) have questioned—for several decades, long before the Framework came into existence-whether the aforementioned catechetical mode of religious education effectively engages nonCatholics.

The USCCB's bishops intended to address increasing Catholic disaffiliation ${ }^{7}$ through a catechetical conveyance of Catholic doctrine, and crafted their Framework to address this decline. Smith and Denton's (2009) large scale qualitative and quantitative study of the religious and spiritual lives of U.S. teenagers confirmed the bishops' perception: they found that only $29 \%$ of teens reported the belief that only one religion is true, while $60 \%$ reported the belief that many religions may be true, and concluded that "most American teens appear to take a fairly inclusive and pluralistic position about the truth that different religions claim to possess" (p. 74). Open-minded, and highly influenced by U.S. consumerism and individualism, teenagers in the U.S. approach religion through a process of bricolage, as they sift through different religious and spiritual traditions in order to piece together a worldview that they find meaning in

7 One need only look at any number of reports from the Pew Research Center to track the continuing decline of those who identify as Catholic. 
(Freathy, Doney, Freathy, Walshe \& Teece, G. 2017). Smith and Denton (2009) also reported that only $8 \%$ of U.S. teenagers go to church and partake in religious community weekly, while another $27 \%$ participate in religious activities a couple of times per month, $17 \%$ sporadically do so, and $12 \%$ are almost or totally disengaged from religion. I suspect that some bishops would argue that teenagers' open-mindedness with regard to religious and spiritual exploration is a lack that could be corrected through catechesis.

My problem of practice is not about the coercive use of religious education as a means of reversing the trend of declining numbers in the United States Catholic Church, although it is necessary to note that the bishops' intent behind the Framework certainly was set on remedying this decline (Schroeder, 2015). The bishops stated that the "Christological [understanding of Christ] centrality of this framework is designed [...] to be a vehicle for growth in one's relationship with the Lord so that each may come to know him and live according to the truth he has given to us" (USCCB, 2008). The bishops believed that a student is not simply to learn about Jesus, but to learn to become a loving and faithful follower of Jesus. The bishops therefore approached religious education as catechetical, although as Rymarz (2011) articulated, equating religious education with catechesis fails "to recognize the diversity of commitment [that is, religious affiliation] in classrooms and the background of many parents and students in Catholic school communities" (p. 544), and the Framework errs deeply in this regard.

In 2009, soon after the Framework's publication, America Magazine — one of the most circulated Catholic periodicals - printed an exchange between two priest-educators with opposing views on the Framework. Father Bill O’Malley, S.J., a Jesuit priest and 
theology teacher ${ }^{8}$ of over 40 years at Fordham Preparatory in the Bronx, penned a stinging critique of the Framework in America Magazine. According to O'Malley (2009), the USCCB Framework failed on a number of fronts, and completely misunderstood (due to the fact that it did not incorporate guidance from experienced theology teachers) the spiritual and experiential context of the U.S. teenager. He opined (correctly, in my judgment) that the Framework "presumes too much of what our audience [high school students] does not have: faith, awareness of the transcendent, appreciation of altruistic values, among much else" (O’Malley, 2009). Father Alfred McBride, O.Praem., a Norbertine priest and consultant to the Framework's authors, delivered a rebuttal to O'Malley in America several weeks later. McBride (2009) argued that the Framework gave structure to the love story of salvation history recounted in the Jewish and Christian Scriptures, and confirmed that "the catechist calls students to conversion to Christ and a lifetime commitment to him and his body, the church.” Oddly enough, McBride's response failed to address O'Malley's primary critique, that the Framework showed no evidence of considering the lived experience or beliefs of teenagers.

Apart from the Framework's inadequacy of even accomplishing its stated goals of developing followers of Jesus, as noted in the above priestly dialogue, catechetical religious education potentially has more sinister consequences. Exclusive emphasis on catechesis through the transmission of doctrine, as the bishops advocated, potentially implements theology as a coercive academic discipline, whose narrative goes something like this: "I (the teacher) believe, and you (the student) do not, and therefore I must

\footnotetext{
${ }^{8}$ Interestingly, Father O'Malley also had a minor role as the fun-loving, piano-playing priest in the 1976
} film The Exorcist. 
convert you." I believe that encouraging conversion for unwilling Catholic students is nothing less than an imposition of Catholic beliefs and identity upon the non-Catholic, which is in turn an act of epistemological and spiritual violence. As Foucault (1975/1995) wrote, "all the authorities exercising individual control function according to a double mode; that of binary division and branding [...] and that of coercive assignment," and all "the mechanisms of power $[\ldots]$ are composed of those two forms from which they distantly derive" (pp. 199-200). The bishops in power branded, and continue to brand, non-Catholic students as undesirable Others, thereby embracing deficit thinking and approaching non-Catholics as in need of catechesis. Thus, in mandating that theology teachers use their Framework in their work, the bishops coercively assigned the role of catechist upon teachers. More so, they coercively labeled non-Catholic students as catechumens, that is, people who are to be catechized because they need religious conversion to Catholicism. The bishops weaponized theological education for coercive violence upon non-Catholic religious imaginations, thereby catalyzing the silencing of non-Catholic students' identities and deeply held systems of belief. Although the bishops promoted inclusive language for non-Catholic students in other publications (USCCB, 1997; USCCB, 1998; USCCB, 2005), the fact that the Framework is catechetical revealed the bishops' unspoken assumptions that non-Catholics do not belong in the theology classroom, and therefore must be converted.

Approaching the bishops' intentions through a more sympathetic lens, I must acknowledge that as ordained leaders, they are the shepherds of Catholics within their dioceses, and are responsible for safeguarding and perpetuating a sacred religious 
tradition. The final lines of Matthew's Gospel (New Revised Standard Version, 2010, Matthew 28:18-20) end with Jesus's command to his disciples:

All authority in heaven and on earth has been given to me. Go therefore and make disciples of all nations, baptizing them in the name of the Father and of the Son and of the Holy Spirit, and teaching them to obey everything that I have commanded you. And remember, I am with you always, to the end of the age.

Without a doubt, the impetus to evangelize stemmed from Jesus's injunction, and of course I support the bishops in their deeply held convictions to carry this evangelizing mission forward. However, I argue that the high school theology classroom is not the venue for catechetical evangelization.

Through a critical, theoretical lens, I believe that the "social position" of nonCatholic students in relation to the bishops develops into a "positional identity-into dispositions to voice opinions or to silence oneself, to enter into activities or to refrain and self-censor, depending on the social situation" (Holland, Lachicotte, Skinner, \& Cain, 1998, pp. 137-138). By means of their Framework, the bishops attempt to strip students of their voices and identities, discarding whatever religious beliefs these students hold as erasable. Catechesis, therefore, proves nothing less than an invisibilization of nonCatholic religious imaginations, treating non-Catholic students, and containing them, as members of a subaltern class — to borrow from Gramsci's theories (Simon, 2015)— wherein they can be controlled all the more. In light of Foucault, Burke (2015) discussed the power dynamics of Catholic educational systems and the power that certain agents (presumptively, bishops, administrators, and teachers) exert over students, and forcefully articulated: 
This imposition of influence over the student body, presumably into the realm of the soul, is a part of religious instruction, but also extends the power and control of the educator, the educational system. It, to borrow ... from Foucault, moves from the [bishops', administrators', and teachers'] care for the student to [the bishops', administrators', and teachers'] control of the self and soul whereby each comes to "contaminate the others." (p. 335)

In drafting their Framework, the bishops failed (either intentionally or unintentionally) to incorporate the outside perspectives of educators and students and families into their work (Schroeder, 2015) because, I believe, they feared a contamination of Catholicism. As I will discuss in my review of the literature, the USCCB has published a number of pieces that made clear their intention to preserve and perpetuate the faith in the midst of ongoing secularization.

In silencing of these stakeholders' voices, the bishops prevented anyone who did not belong to the Magisterium - that is, the teaching authority of the Catholic Church embodied by the pope and bishops - from contributing meaningfully to the Framework, and since 2008 the bishops have not endorsed any non-catechetical form of religious education for use in Catholic high schools. In dictating a doctrinal system that religiously diverse student populations ought to learn and believe in, these magisterial authorities exerted power and control over the non-Catholic Other. And in mandating exclusive use of their Framework for high school classrooms, the bishops attempted to subsume theological educators into their Framework's catechetical mindset and heartset. Teachers who educate non-Catholic students are thus confronted with a choice: either they adhere to the Framework, accept the bishops' branding of them as catechists, brand non-Catholic students as those in need of conversion, and thereby violate principles regarding students' religious freedom, or they engage modes of religious education apart from catechesis. 
In sum, when bishops, administrators, and teachers implement catechetical religious education for non-Catholics, they promote a form of education that silences, invisibilizes, and oppresses non-Catholic students.

\section{Interlude: Statement of Positionality}

When I began teaching nine years ago at Xavier College Preparatory High School in California, my principal, Chris Alling, asked that I develop a theology curriculum for freshmen, approximately one-third of whom were not Catholic. He suggested (with the permission of the Most Reverend Gerald Barnes of the Diocese of San Bernardino, California) that I depart from the standard USCCB Framework, as the then-extant firstyear curriculum (which adhered to the Framework's outline) failed to resonate with our sizable non-Catholic student population. Crafting such a theology class from scratch began my interest in theological education for non-Catholics within Catholic high schools.

I now teach at De La Salle North Catholic High School in North Portland, where roughly two-thirds of our students are not Catholic, or whose families do not practice religion with any regularity. Just over $90 \%$ of De La Salle's students are of Color; many come from evangelical (that is, non-denominational and/or fundamentalist) or pentecostal traditions, and many come from non-religious families. De La Salle North's religious demographics pose no surprise, given that recent Gallup findings (Norman, 2018) describe Oregon's population as being among the least religious in the country. I do not view my role as a theology teacher to promote conversion to Catholicism, and so I still do not abide by the standard USCCB Framework. Rather, I hope to help my students 
understand and critically engage religion through epistemological, philosophical, historical, and social lenses. I have no qualms in rebelling against the Framework's strictures, for the primary reason that I do not understand myself to be a catechist. After all, I prioritize serving my students rather than my bishop.

I undertook my graduate education in biblical studies from a progressive Methodist seminary that prepared ministers and academics from a wide spectrum of religious traditions and positionalities. My master's degree focused on the Hebrew scriptures, and I encountered theologians from global and non-Catholic contexts, and in the process discovered a deep appreciation for Latin American and African American liberation theology. In short, my master's studies helped me to appreciate the world of theology outside of Catholicism, all of which has heavily influenced my own pedagogical practice. Given this background, I have developed my teaching around several primary principles. When I teach the Bible, I do so through the hermeneutical lens of historicalcritical methodology, which means exploring the historical, cultural, political, and religious contexts in which its books were written. I invite and encourage dialogue and debate, and ask students to write reflection papers discussing their lives, experiences, and beliefs. I make it clear to students and their families that I am not there to convert them, but to help them explore the big, existentially meaningful questions that pervade human existence. Hammering fifty-something pages of doctrinal and dogmatic bullet points into the minds of teenagers is simply not my idea of a good, relevant, or productive time.

Through anecdotal evidence and personal conversation, I have come to realize that I am not the only theology teacher who struggles with the USCCB Framework. Over 
the course of my relatively brief teaching career, I have met several dozen religion and theology teachers who are equally, if not more, dissatisfied. Prior to the Framework, theology teachers had greater freedom to base their teaching upon other sources and models of religious education, which I will explicate in the second chapter's literature review. Many veteran teachers had to completely upend their curricula when the Framework was published in 2008 (Schroeder, 2013), having been asked by the bishops to guarantee that their students knew and understood the many pages of doctrinal points embedded within the Framework. Other scholars and educators view the document as failing to accomplish anything beyond intellectual comprehension of Catholic doctrine (Martin, 2016), which does not help students to critically engage their beliefs or the world around them with those beliefs. Still other teachers, such as Father O’Malley (2009), maintain that theology teachers basing their curriculum on the Framework fail to reach the hearts of students, offering little that helps young adults make sense of their lives or engage the world around them.

I began my doctoral work in the hopes of understanding how broader pedagogical theories might inform the contemporary state of theological education within United States Catholic high schools. Much of my problem of practice is rooted in a theoretical and empirical critique of the assumptions, underlying philosophy, and catechetical intent of the USCCB Framework. In the pages that follow, I will attempt to engage my critique through the lenses of Freirean emancipatory education and several critical pedagogies, all the while remaining grounded in the rich tradition of Catholicism. For the non-Catholic reader, or for the reader who is unfamiliar with faith-based and/or religious education, I 
hope that the above context has drawn out the problematics that rigid catechesis fosters in religiously diverse Catholic high schools. And for my fellow Catholic educators, I hope that the above context has clarified that catechetical religious education's appropriateness entirely depends on the religious identities of students. For theology teachers working in schools whose students are entirely Catholic, catechesis poses fewer problems, apart from its depending on the banking model of education (Freire, 1970/2018) and lacking relevance for the spiritual lives of teenagers. On the other hand, I hope that the above context has made it clear that the catechetical Framework is entirely inappropriate for religiously pluralistic students.

\section{Statement of the Problem}

Now that I have addressed the theoretical, historical, and organizational contexts that have influenced the theological education of religiously diverse student populations in U.S. Catholic high schools, I can define the problem that I studied. Once I have articulated the problem itself, I will delineate the problem's boundaries and provide evidence for the gravity and seriousness of the problem.

\section{Articulation of the Problem}

I believe that the USCCB Framework is not only ineffective at converting nonCatholics to Catholicism (because religious conversion entails far more than the learning of doctrine), but that it also systematically oppresses non-Catholic learners, both on religious and cultural levels. Ultimately, the U.S. bishops, in attempting to catechize and deepen students' Catholicity through their Framework, fail to educate non-Catholics 
appropriately or respectfully, and do symbolic violence upon them through theological coercion.

In their Framework, the bishops provided little more than a list of doctrinal and dogmatic items that they expect high school students to learn through theology coursework. Furthermore, the Framework's catechetical formation demonstrated the bishops' espousal of the "banking model" of education, which Freire had so vigorously critiqued in Pedagogy of the Oppressed (1970/2018). According to Freire, depositing knowledge is nothing less than "projecting an absolute ignorance onto others," which is "a characteristic of the ideology of oppression" because it "negates education and knowledge as process of inquiry" (p. 72). While part of the bishops' role is to provide authoritative guidance in line with their Magisterial authority (that is, their authority as ordained teachers of the faith), much of their understanding of a "correct" education has most likely been influenced by their own experiences of education. And given that bishops in general tend to be over the age of 60 , catechetical religious education shaped their collective experience. As I will explain in the review of the literature, noncatechetical models of religious education only became popular in the years following the Second Vatican Council. Thus, it is logical to infer that the bishops intended for their Framework to enforce catechesis because that is what they knew and understood in their own educational experiences. The Framework's catechetical intent is, after all, stated outright in its full title, and it mirrors the structure of the Catechism of the Catholic Church (1992/1997). In reviewing the literature, I will explicate the Framework's content, and the implications thereof, in greater depth, but for now it suffices to say that 
the bishops' creating and mandating the Framework was apparently an attempt to resurrect a particular culture of religious education which they found appropriate, rewarding, and (in their minds) ideal. Such a culture of religious education would rectify a church culture that, since the Second Vatican Council, has drifted away from doctrinal emphases.

In crafting the Framework, the bishops did little to engage stakeholders, such as the hundreds of theology teachers, or the many thousands of students taking theology classes in Catholic schools around the United States (O’Malley, 2009; Schroeder, 2015). The meetings leading up to the Framework's publication were closed-doors, and there is scant evidence of the bishops taking students' and/or teachers' voices into account. This approach is unsurprising, and results from the Catholic Church being a systematically hierarchical institution.

While the bishops are perfectly within their rights (given their roles of authority) to exercise control over how religious education is undertaken in Catholic high schools, I critique whether they have exercised those rights pastorally (that is, as empathetic and sympathetic pastors of those faithful entrusted to their care), or even in accord with teachings published by the Vatican. After all, Dignitatis humanae, the "Declaration on Religious Freedom" produced by the Second Vatican Council in 1965 (Pope Paul VI, 1965a) articulated the immense value of a person's well-formed religious conscience, and condemned any government intrusion into that particular freedom. And given that catechizing those who do not seek catechesis is nothing less than a violation of religious freedom, the bishops of the USCCB directly contradicted a core value of Catholic Social 
Teaching. I will explore this theme further when I review literature published by the CCE, but the only context in which catechesis does not violate religious freedom would be one in which non-Catholics freely accept catechesis in full knowledge of its content and purposes. I suspect that sustaining the religious freedom of non-Catholic students was simply a negligible goal for the bishops, because they were primarily concerned with sustaining Catholic students' doctrinal literacy.

There are certainly theology teachers who agree with the bishops, and would maintain that catechesis is the preferred mode of religious education for Catholic high schools. However, based on Vatican documents and select empirical evidence from extant scholarship, I argue that catechesis can only appropriately be applied to homogeneous Catholic student populations. In the words of Crawford and Rossiter (2006), "No amount of religious education can generate faith or bring about committed participation in a parish" (p. 397). In short, helping students become faithful Catholics requires more than catechetics. It requires parental involvement and regular participation in religious community; if these two things (that are beyond a school's control) are missing from a teenager's life, catechesis will do nothing whatsoever towards achieving the goal of prompting conversion to or deepening of the faith.

Thus, when the bishops of the United States mandated that their Framework guide not only theological textbook publication, but also the coursework and education offered by high schools (including those sponsored by religious orders) and parishes, they failed to abide by the ideals set forth by the Vatican's CCE; even more so, the bishops failed to pay attention to the contexts within which their Framework would be implemented. I am 
unable to discern precisely why the United States bishops ignored the CCE's ideals and the contexts of U.S. high schools, although I suspect it has to do with the fact that the CCE comprises bishops from around the world, and that U.S. bishops spend little time in Catholic high schools. In order to provide a theoretical critique of the Framework and the repercussions of its use in Catholic high schools, I will employ several key strands of thought: Freire $(1970 / 2018 ; 1984 ; 1998 ; 2014)$ helps us to see that catechesis embodies the banking model of education; Foucault (1978/1995) helps to focus the Freirean critique along the lines of power, coercion, and victimization; and creators of the more recent theoretical movements of Culturally Responsive, Relevant, and Sustaining Pedagogies (Gay, 2018; Ladson-Billings, 1995a; Ladson-Billings, 1995b; LadsonBillings, 2009; Ladson-Billings, 2014; Paris, 2012; Paris \& Alim, 2014; Paris \& Alim, 2017) highlight the importance of drawing student culture into educational practice.

Ultimately, the bishops of the USCCB interpreted theological education as catechetical, and in so doing, employed the banking model of education in their crafting and mandating of the Framework. To apply Freire's thought (1970/2018), the bishops undertook "[c]ultural invasion, which serves the ends of conquest and the preservation of oppression," and "always involves a parochial view of reality, a static perception of the world, and the imposition of one world view upon another" (p. 160). Moreover, the very nature of catechetical religious education, which potentially forces Catholic doctrine upon those who are not Catholic, or might not want it, "implies the 'superiority' of the invader and the 'inferiority' of those who are invaded, as well as the imposition of values by the former, who possess the latter and are afraid of losing them" (Freire, 1970/2018, p. 
160). The USCCB's bishops approached theological education as something done upon students, rather than as a critical process of dialogue concerning the spiritual and religious dimensions of human existence.

In the words of the De La Salle Christian Brother Rummery (1975), who was among the first to dive into the prospect of catechesis for religiously diverse student populations, "this kind of authoritative approach has little chance of leading towards personal faith as distinct from the social experience of faith" because the "very presumption of faith with many adolescent pupils in these circumstances, seems sufficient to alienate them" (p. 168). Not only does catechesis alienate non-Catholic students, however, but it others, silences, negates, degrades, oppresses, and invisibilizes their religious and spiritual cultures and beliefs.

\section{Limits of the Problem}

The problem of practice has a couple of major bounds. First of all, not all Catholic high schools are religiously heterogeneous in their student composition. On the whole, while many of these institutions have been marked by increasing religious diversity in recent decades, there are schools that still serve predominantly Catholic students. In such educational contexts, catechetical religious instruction embodied by the USCCB Framework makes sense, as Catholic students who seek a deepened understanding of their tradition's systematic beliefs are well-served by doctrinal catechesis. Therefore, my research agenda does not pertain to those schools or teachers who serve predominantly Catholic student populations. 
Second, the great diversity of Catholic theology and religion teachers' academic and personal backgrounds, coupled with a complete and total lack of uniform credentialing and preparation for their profession (Cook \& Hudson, 2003), means that not all teachers are aware of (or, potentially, even care about) the complexities and nuances that follow. I, for one, who double-majored in philosophy and theology at a Catholic university, spent time in formation to become a Jesuit priest, and studied the Bible in graduate school, never received an ounce of formal preparation in education before becoming a teacher. I do not fault my brother and sister theology teachers for a similar ill-preparedness, but I do need to acknowledge the current state of affairs. Unlike teachers in other academic disciplines, theology teachers often do not require credentials or teaching certification (simply because they cannot receive credentials in religious education, except in Nebraska), and it is left up to the discretion of individual schools to hire according to their own expectations. Many high schools require theology teachers to possess at least one degree in theology and/or religious studies, often from a Catholic institution of higher education, though older theology teachers began teaching simply because they were practicing Catholics who demonstrated a thorough passion for their faith. Consequently, I cannot predict with any surety the degree to which other theology teachers are familiar with these contexts surrounding the problem of practice.

\section{Validation of the Problem}

Available research demonstrates that catechesis geared toward religious conversion encourages apathy and disinterest toward religious tradition among students who are not already devout Catholics (Aldana, 2015). If a student enters Catholic school 
without any degree of familiarity with or interest in Catholicism — which largely depends on their family's religiosity — catechetical education will prove meaningless at best and harmfully coercive at worst. Dilworth (1996), Ellis (1996), and Irvine (1996) have all written autoethnographic accounts of being African American and non-Catholic cultural outsiders in the book Growing Up African American in Catholic Schools, and no doubt some of their critiques of Catholic school culture would continue to be relevant in certain institutional contexts. In Irvine's (1996) words, the stories of African American students in Catholic schools contain "examples of cultural incongruity, denial of cultural heritage, silenced voices, marginalization of racial identity, strict and often unreasonable discipline, and religious proselytization" (p. 171).

Donlevy's dissertation (2003) and subsequent research (2007a; 2007b; 2009a; 2009b) have specifically focused on the challenges surrounding the inclusion of nonCatholics in Canadian Catholic schools, and Donlevy (2009a) posited ten dimensions of inclusion for non-Catholic students: social/cultural, political, financial, legal, racial, administrative, pedagogical, psychological, spiritual, and philosophical. Donlevy’s findings highlighted exclusionary attitudes of Canadian Catholic high school administrators toward the presence of non-Catholic students in their schools, and also noted the tensions experienced by, and validated the efforts of, theology teachers who worked to include non-Catholic students in their classrooms.

Catholic education predicates itself upon inclusive relationships (Maney, King, \& Kiely, 2017), and the presence of non-Catholic students presents a variety of challenges to teachers and administrators. Religious Muslims, for example, can be either victimized 
or understood and accommodated by their teachers in classroom settings, and the ways in which a teacher approaches Muslim students often results from that teacher's education, beliefs, and experiences (Niyozov \& Pluim, 2009). Although Canadian schools are not influenced by the USCCB Framework as United States schools and publishers are, the same tensions arose in Donlevy's studies. Catechetical education does not foster teachers' appreciation for non-Catholic religions, nor does it inherently foster empathy for and engagement with non-Catholics. Donlevy's (2007) teacher participants desired to respect the religious consciences of non-Catholics, while administrators expressed less concern for their inclusion. Nowhere did the USCCB's bishops address the fundamental right of students to religious freedom in their Framework.

Most specifically, Martin’s (2016), Hortsch’s (2021), Schroeder's (2013), and McGah's (2013) dissertations have homed in on the question of religious education in Catholic schools in the years since the Framework's publishing. Martin (2016) found that high school seniors in one particular Catholic school regarded their theology classes as having little impact on their self-understanding, and failed to be relevant for their lives. Hortsch (2021) conducted a survey and focus groups amongst 106 graduates of a Catholic high school in order to assess the impact of religion classes on cognitive, affective, and behavioral realms. He found that there were four desirable educational outcomes, as reported by students: "foster student questions," "tailor instruction to meet diverse needs," "invite students to 'see themselves' in the story of Christianity," and "maintain and expand experiential learning" (Hortsch, 2021, p. 172). In sum, Hortsch’s study highlighted the need to provide theological instruction that is relevant and 
sustaining for students by focusing on their desires and needs. Schroeder (2013), on the other hand, studied how theology teachers grappled with the Framework's goals; her study, in particular, uncovered teachers' general dislike of the Framework because they felt overburdened by hundreds of doctrinal points, and identified it as largely inappropriate for high school students. Schroeder did not indicate that these educators' struggles with the Framework originated in their lack of skill or experience, but rather in the stark and sudden shift in mindset and pedagogical practice that it required of them. Imparting dozens of pages of doctrine into teenagers' minds is a task particularly wellsuited for transmission via Freire's banking model, a task with which most of Schroeder's participants disagreed. McGah (2013) studied the best instructional practices reported by Catholic high school theology and religion teachers in Washington state through a survey, and her participants reported "discussion," "application to real-world situations," “application to student's own life," "questioning by teacher," "cooperative or collaborative learning," and "identifying similarities and differences" to be their best practices (p. 85), along with using a variety of materials (such as textbooks, the Bible, and the Catechism) and technologies (primarily, computers, the internet, and a Smart Board); McGah's findings highlighted the efforts of her participants to engage students through discussion and questioning, and personal relevance.

Researchers of other religious schools echoed the dangers of indoctrination as well, and while my review of the literature will delve into international and non-Catholic religious education in greater detail, certain elements of these studies are worth mentioning here. Merry (2018) posited the potential harm done by indoctrination in 
Islamic schools as consisting of "lowered self-respect, lowered opportunities to be challenged and learn, educational failure, and the additional harm of lifelong failure that may ensue" (p. 166). Theological assertions are impossible to epistemically validate, and because catechesis posits Catholic doctrine as indisputable truth, it prohibits nonbelieving students from contesting or debating. Given that these claims are not open for debate, on a psychological level, indoctrinatory catechesis might damage a nonCatholic's sense of self.

Scholarship from international contexts (Everington, ter Avest, Bakker, \& van der Want, 2011; Everington et al, 2016; Franken \& Vermeer, 2017; Mitchell, 2016; Zilliacus, 2013) has focused on the opportunities that religious educators take when helping students to learn about religion for the purposes of religious tolerance in society, as opposed to learning from religion, which is geared toward indoctrination. More specifically, other scholarship (Aronson, Amatullah, \& Laughter, 2016; Franck, 2015; Hand, 2004; Hill, Harris, \& Martinez-Vasquez, 2009; Wright, 2008) has outlined the harm that is done by indoctrinatory religious education, which includes, but is not limited to, the silencing of religiously diverse voices, the invisibilization of non-dominant religious identities, the degradation of students' beliefs, and academic struggles. Even more specifically, other scholars have demonstrated the difficulties that non-Catholic students face when attending Catholic schools, either culturally (Donlevy, 2007a; Donlevy, 2007b; Donlevy, 2009a; Donlevy, 2009b; Francis, 1986; Village \& Francis, 2016) or academically in theology classrooms (Aldana, 2015; Martin, 2016; Schroeder, 2013). Ostasiewski (2010) and Schroeder (2013) specifically levied critiques of the 
USCCB Framework on theoretical and empirical grounds (to which the USCCB has not publicly responded), respectively. Those educators implementing strictly catechetical models of religious education, which are intended for the religious conversion of students, cannot actively acknowledge or sustain alternative religious perspectives.

\section{Significance of the Research Problem}

The crux of the research problem is this: now that the USCCB Framework has been in use for over a decade, little is understood about how theology teachers are diverging from and/or adapting it for the education of non-Catholic students. Theology textbooks used by Catholic high schools in religion classes go through a formal vetting and approval process with the USCCB, and so directly reflect the Framework's content and intentions, all of which embody a banking model of education. In turn, non-Catholic students are potentially invisibilized, silenced, and coercively indoctrinated if their teachers wholeheartedly embrace the Framework and the catechetical mode of religious education. Learning about the pedagogical decisions theology teachers make in light of the Framework's presence will hopefully advance the tools and knowledge that other theology teachers have at their disposal, which will in turn help to give voice to, and better serve, religiously diverse student populations in Catholic high schools.

\section{Catholic Education and Emancipatory Pedagogies}

At the heart of this problem are the non-Catholic students who find themselves in Catholic education, be it by their own choice or their parents' prerogatives. I have spent my teaching career thus far in Catholic high schools whose students' religious identities are far from homogeneous, and I have been tasked with creating curricula from scratch in 
each of the two schools that I have served. My principals and department chairs, who recognized the general irrelevance of the USCCB Framework, prompted this work, and they either had the permission of the local bishop, or were confident in their ability to defend this decision. Beyond this, and beyond the aforementioned anecdotal evidence from personal relationships and conversations, the select research available demonstrated that my inclinations and curiosities surrounding this problem are well-founded.

The sum of this evidence leads me to posit that because catechesis is grounded in the banking model of educational practice, the Framework pays no regard to the relevance of theological doctrine for helping the catechized to understand the world around them, or to engage praxis for the betterment of the world, namely the liberation of those who are oppressed or their oppressors. In Freire's (1970/2018) own words, in "banking concept of education, knowledge is a gift bestowed by those who consider themselves knowledgeable upon those whom they consider to know nothing" (p. 72), and in those educational systems that oppress individuals, the "oppressed are regarded as the pathology of the healthy society" (p. 74). Freire's stinging words directly rebuke the attitude with which the bishops introduced their Framework, which they posited as an offering of "catechetical" (USCCB, 2008, p. 1) guidance for textbook publishers, educational institutions, and teachers.

The discipline of theology, however, especially when grounded in the liberation theology that arose in the 1970s in Latin America (Gutiérrez, 1973; Sobrino, 1988; Sobrino, 1993), and in African American (Cone, 1970/2010; Cone, 2013; Thurman, 1949/1996; Williams, 1993/2013) and Asian (Pieris, 1988) communities in subsequent 
decades, possesses an immense potential for praxis, which is the interdisciplinary process of reflecting upon and acting toward the transformation of unjust systems (Freire, 1970/2018). Schipani (1988), for example, has taken Freirean themes such as conscientization and hope and praxis - that is, developing a critical awareness of the world, instilling a desire for a transformation of the status quo, and acting upon this consciousness and desire - and applied their practice to religious education through the lens of liberation theology. These examples make clear the potential for theology to be an emancipatory discipline.

Ultimately, I hope that my critique of the USCCB Framework, alongside my subsequent interview research and analysis, serve to illuminate the path toward and of emancipatory theological education for religiously diverse classrooms in Catholic high schools. As it stands, catechetical theological coursework based on the Framework does little more than provide students with a comprehensive overview of Catholic doctrine, without helping them to make sense of their lives, their communities, and their world in the service of these various spheres. And while advocates of the Framework might argue that praxis is the purview of other academic disciplines, as a critical educator influenced by Freire, I would argue that any learning that does not involve an awakening of consciousness toward the betterment of the world is inadequate. More so, doctrine alone does nothing to foster the pursuit of and engagement with emancipatory praxis to alleviate suffering. I am confident that many theology teachers within Catholic high schools are subversively refusing to abide by the Framework's strictures precisely because they care for and love their students, and I have attempted to discover and share 
how they go about doing so. My research unveils the concrete practices, positionalities, and attitudes of theology teachers who approach their teaching with the intent to aid in the emancipation of their students, and I provide a firmer ground upon which we theology teachers might collectively draw from others' wisdom and experience.

\section{Catholic Theological Education for Religiously Diverse Populations}

With the emancipatory potential of liberationist theological education in mind, alongside the central dynamics of Culturally Relevant, Responsive, and Sustaining Pedagogies (which will be explored in the subsequent review of the literature), the research problem revolves around how theological educators are diverging from and/or adapting the USCCB Framework in their service of non-Catholic and religiously diverse student populations. Little research explicitly addresses this particular failure of the U.S. bishops, although the empirical evidence that does exist points to it. Now that the Framework has been in place for over a decade, and given that administrations and teachers have had a not insignificant number of years to grapple with its implementation, the time is indeed ripe for investigating how theological educators are engaging with (or refusing to engage with!) the Framework's catechetical impetus. While investigating student experience of theological education within U.S. Catholic high schools would certainly provide fruit for the consideration of scholars and practitioners, I believe that foregrounding the voices and perspectives of educators in this study provides more immediate impetus and reason for effecting change. The extant literature already reveals student dissatisfaction with theology classes but does not explore what theology teachers are doing about that dissatisfaction. 
In researching and reporting how teachers go about contextualizing the Framework in service of their uniquely particular student populations, I aim to provide a theoretical and empirical groundwork for other educators whose classrooms consist of non-Catholic and Catholic students. Educators in the European landscape of religious education, as I will discuss in my second chapter, have been grappling with the question of religious education for religiously diverse student populations for decades. I believe that the work of European religious educators, who promote understanding of religious traditions through interreligious dialogue, has much to teach those of us who work in the U.S. And while this international scholarship covers a broad range of state-sponsored and faith-based schools, relatively little of it addresses religious education within Catholic schools, much less on religious education so narrowly defined by documents such as the USCCB Framework.

Given my own educational background of studying the Hebrew scriptures from Jewish professors in a Methodist seminary, I am firmly convinced that religious education can most definitely sustain a student's religious identity through interreligious dialogue. In a very tangible way, we can learn what we believe and why we believe what we believe through dialoguing with those whose religious imaginations and beliefs differ from our own. Catholic universities generally require theology and philosophy classes, but these classes are by no means catechetical, and treat these academic disciplines as means to explore a fundamental facet of human existence (Carey \& Muller, 1997; Sigelman, 2014). And so, while Catholic theology teachers in high schools can certainly undertake the immensely important work of religious education by drawing from the 
depth of the Catholic theological tradition, they can do so while being attuned to the needs and desires of non-Catholic students, which in part depends on a teacher's experiences and educational background. Indeed, a Catholic school's religious identity can even promote culturally responsive and inclusive practices with regard to religious culture. For example, the particular mode of French secularism (known as "laïcité") and related Islamophobia have prompted French Catholic schools to provide a sort of refuge for Muslim students whose religious practices are not necessarily tolerated in the French public school system (Bennhold, 2008). I suspect that the resources offered by the theoretical frameworks of CRP, CRT, and CSP have much to provide in this regard. The catechetical Framework, in stark and unyielding contrast, does not.

\section{Research Purpose and Rationale for the Purpose}

In conducting a qualitative interview study, I sought to understand how theology teachers in Pacific Northwest-area Catholic high schools either diverge from or adapt the USCCB Framework in their service of religiously diverse classrooms, and assumed that there are educators who were doing so. Based on conversations with other theology teachers and anecdotal evidence from my ten years of teaching (five of which have been in Portland, Oregon), and empirical literature, I believe that educators in U.S. Catholic high schools are keenly aware of and sensitive to the needs of their non-Catholic students. In what ways do they diverge from the Framework, and in what ways do they attempt to incorporate elements of the Framework, and to what degree, and for what reasons? On the one hand, this dissertation is for theology teachers in the United States, but on the other hand, I hope this research — in serving teachers - ultimately serves 
religiously diverse students. I view learning from other theology teachers to be an act of solidarity and collaboration.

Ultimately, I discovered valuable insights from this study regarding theology teachers' experience and perception of the phenomenon of teaching non-Catholic students.

\section{Presentation of Research Question and Methods}

In this qualitative interview study, I relied upon interview data, documentary artifact data, analytic memos, and subsequent analysis in order to draw conclusions regarding my research questions, which are as follows.

\section{Research Questions}

The key research questions of this qualitative interview study are:

1. What do Catholic theology teachers in Pacific Northwest Catholic high schools believe about the purposes and goals of religious education for religiously diverse student populations, especially with regard to the role of catechesis therein?

2. What particular curricular and pedagogical decisions do Catholic theology teachers in Pacific Northwest Catholic high schools make in order to meet the needs, interests, and positionalities of their nonCatholic students?

3. How do theology teachers in Pacific Northwest Catholic high schools consciously diverge from/and or adapt the USCCB Framework (if at all) in their service of religiously diverse student populations who 
represent Catholic, non-Catholic Christian, non-Christian, and nonreligious traditions and contexts?

\section{Data Collection Procedures}

I recruited five participants who teach theology in Pacific Northwest Catholic high schools, conducted a series of semi-structured interviews with them, and recorded interviews through Zoom (https://www.zoom.us). Beyond semi-structured interviews, I attempted to implement methodological triangulation by collecting and analyzing pertinent documentary data (such as scope-and-sequence documents and assessments) and writing and analyzing analytic memos. This triangulation searched "for convergence of, or consistence among, evidence" (Brantlinger et al, 2005, p. 201) from multiple methods; I was ultimately not able to collect as many documentary artifacts as I initially hoped for, and therefore chose not to code artifacts for fear of skewing the data by injecting my biases into it.

In each of the three interviews, open-ended questions with teachers addressed their understandings of the role of evangelization in the Catholic school, their opinions on catechetical religious education, and what decisions they make in educating religiously diverse student populations. I aimed to make this process as collaborative as possible, and made it clear that as theology teachers, we are working toward the betterment of our teaching, and I sensed that my peers were at least somewhat excited to contribute their thoughts.

My conceptual framework, "Critical Religiously Sustaining Pedagogy,” adapts and synthesizes central tenets of critical pedagogies (such as Culturally Responsive 
Pedagogy, Culturally Relevant Teaching, Culturally Sustaining Pedagogy, and Critical Religious Education). I used this framework as a lens that informed my literature review, research design, analyses, interpretations, and discussion, although I did not use it to judge whether a given participant was more or less in line with the framework than other participants were. CRSP was immensely valuable throughout the process of designing my research and collecting and analyzing data; I believe that if we focus the lenses of the aforementioned critical pedagogies on theological education, they do become capable of illuminating previously unexplored territory by means of approaching it through a unitary conceptual framework. I will explicate the specifics of this framework in the following chapter's literature review.

\section{Data Analysis Procedures}

Digital transcriptions of interviews provided the basis of data analysis through qualitative computer software, and I supplemented interview data with evidence from documentary artifacts, all the while writing analytic memos as I collected and began to analyze the data. With the help of the CAQDAS software NVivo 12 for Windows (https://www.qsrinternational.com/nvivo-qualitative-data-analysis-software/about/nvivo), I coded the data in a two-stage process (Saldaña, 2016) using a variety of coding methods (such as structure coding, sentiment coding, values coding, evaluation coding, and holistic coding), analyzed the codes, and generated a description of the most relevant thematic findings. In the fourth chapter, I present the findings of themes through detailed narrative in order to discuss the interconnecting themes. Upon the completion of the first three rounds of interviews, I conducted a focus group interview with four of the five 
participants, and once I wrote a draft of my findings, analysis, and discussion, I offered participants the opportunity to member check a solid draft of my interpretations. I offer this preliminary overview of my methodology with the hopes that the reader will keep it in the back of their mind as they move into the subsequent chapter. 


\section{Chapter 2: Review of the Literature}

My review of the extant scholarship that follows is divided into two broad sections. First, I begin with theoretical literature, which consists of my conceptual framework and documents produced by the United States Conference of Catholic Bishops (hereafter the "USCCB”) in Washington, D.C. and the Vatican's Congregation for Catholic Education (hereafter the "CCE") in Rome. The conceptual framework is comprised of strands from various theoretical frameworks: emancipatory pedagogy, as pioneered by Freire; Culturally Relevant Pedagogy (hereafter “CRP”); Culturally Responsive Teaching (hereafter "CRT”); Culturally Sustaining Pedagogy (hereafter “CSP”); and Critical Religious Education (hereafter "CRE”). With this conceptual framework, which I am terming “Critical Religiously Sustaining Pedagogy,” or “CRSP”) at hand, I will examine, synthesize, and critique the texts and documents produced by the magisterial organizations within the Catholic Church, namely the CCE and the USCCB. In light of this exploration, I will delve into the literature concerning religious education from bishops and theologians of the Catholic Church before providing a brief overview of religious education over the past half-century; this will, I hope, better situate the problem of practice and research problem at hand.

In the second part of the review of the literature, which focuses on empirical literature, I attempt to lay out the following topography surrounding the problem of practice. First, Catholic bishops within the U.S. and the Vatican disagree with one another on the purposes of religious education in Catholic schools; the former group has overturned many years of progressive theological education in favor of mandating a 
catechetical approach through their 2008 Framework. Second, Catholic school teachers, administrators, and cultures have harmed, malserved, or underserved non-Catholic students in some contexts, while other Catholic school educators have greatly benefitted non-Catholic students and historically underserved students. Third, values embedded within specific critical pedagogies (CRP, CRT, and CSP) help educators provide culturally responsive, relevant, and sustaining learning experiences for culturally diverse students; religious education in international contexts frequently holds these same aims, but specifically for religiously diverse classrooms. Given all this, I argue that the 2008 USCCB Framework is harmful for non-Catholic students, but no scholarship exists that examines how theology teachers in the U.S. are adapting or diverging from the Framework in their service of religiously diverse (that is, both Catholic and nonCatholic) students.

\section{Theoretical and Conceptual Frameworks}

Catalyzed by interest in multicultural education in the 1970s, scholar-practitioners developed several philosophical outlooks and theoretical orientations of educational practice over the past few decades. While the pioneers of these approaches did not characterize them as "theoretical frameworks" in a technical sense, I approach them as such (for the purposes of writing a dissertation, that is), and in so doing, I hope to preserve their meaning and integrity as educational theories. These selected frameworks of Culturally Relevant Pedagogy (CRP), Culturally Responsive Teaching (CRT), and Culturally Sustaining Pedagogy (CSP) were created by U.S. educators, specifically with regard to the need for teachers to better understand and educate culturally diverse 
students, but largely do not discuss the notion of religion as being part of culture. However, if one considers religion to be part and parcel of a student's cultural context (Cohen, 2011), it soon becomes clear that the lenses of CRP, CST, and CSP can be refocused, as it were, on religious beliefs, which are so integral to many people's ways of moving and being in our world. In addition to these, I borrow from Critical Religious Education (CRE), which emerged from the European context of multi- and interreligious education sponsored by governmental educational institutions. By synthesizing all of these theoretical frameworks, I have created my conceptual framework of Critical Religiously Sustaining Pedagogy (CRSP) ${ }^{9}$, which I will elaborate below. This conceptual framework is of great help, I believe, in focusing some of the central tenets of the above theoretical frameworks on the theological education of religiously diverse student populations in U.S. Catholic high schools.

\section{Theoretical Frameworks}

In order to provide a coherent lens to approach the problem of practice, I borrow elements from various strands of critical pedagogical models and theories. Most broadly, Freire's ideas and labors around emancipatory pedagogy provided a foundation upon which subsequent thinkers built other theories of critical pedagogy. Of these theories, I have selected CRP, CRT, CSP, and CRE. These critical pedagogies all draw from and expand upon Freirean themes and theories, on the whole emphasizing the need to approach students' cultures as assets rather than deficits. In particular, the creators and proponents of CRP, CRT, and CSP aimed to draw students' cultures into their

\footnotetext{
9 I considered also naming it "Critical Religiously Applicable Pedagogy," but refrained from doing so
} when I more fully considered the academic appropriateness of the acronym. 
educational experiences, in order to ensure that teachers are providing delivery of content and assessments that reflect and engage students' diversity of cultures.

Freire's Emancipatory Pedagogy. Lauded as one of the most influential educational theorists and practitioners of the past century, Paulo Freire has deeply inspired my own vocation in education, and his theories concerning emancipatory pedagogy form the foundation upon which my conceptual framework rests. As a theological educator, I find it especially intriguing that Freire's work surrounding emancipatory pedagogy influenced the movements of Latin and North American liberation theologies (as discussed in Chapter 1), to such an extent that he can properly be called a founder of liberation theology (Kirylo \& Boyd, 2017). Indeed, in his educational theorizing and work, Freire drew upon certain concepts and vocabularies from his Christian spirituality and religious imagination. In Freire's mind, the potential of education to be a liberating and emancipatory act lies in the recognition and uplifting of students' dignity, or "life-affirming humanization" (Freire 1970/2018, p. 68). This goal of humanizing students resonates with the Abrahamic religious traditions, wherein the dignity of the person rests in the reality that he or she is created in the imago Dei, the image and likeness of the divine, and that God unceasingly interrupts history on behalf of the socially, religiously, and politically oppressed. This, at least, is the central thesis of liberation theology.

I believe that Freire's notion of emancipatory, problem-posing education, which is "prophetic (and, as such, hopeful)" and "affirms women and men as beings who transcend themselves" (Freire, 1970/2018, p. 84), emanates from the rich prophetic 
tradition of the Bible, wherein prophets condemned unjust religio-political structures that exploited the anawim (the "weak," in Hebrew) of society. After all, even though Freire was a Catholic who believed in Jesus, "he was not one who was caught up in religiosity or the institutional church, as it were; he was, however, a man who richly contributed to the thinking of liberation theology" through his personal friendships with Latin American bishops and theologians (Kirylo \& Boyd, 2017, p. 88). Freire (1992/2014) wrote a small treatise about the relationship between hope and education, and reflected upon the role of hope throughout his exile and career. In Pedagogy of Hope (1992/2014), Freire proclaimed that "I do not understand human existence, and the struggle needed to improve it, apart from hope and dream" (p. 2). Hope is one of the three "theological virtues" within the Christian tradition (the other two being faith and love), which has long asserted that in times of suffering or oppression, a faithful person perseveres and acts because they maintain hope for the re-creation of earth, and for the union of heaven and earth. Freire's central concept of conscientização, or the awakening and raising of consciousness, is geared toward praxis, or "critical intervention in reality" (Freire, 1970/2018, p. 81, italics in the original). Emancipatory education invites students to critically interrogate their lives, and the world in which they live, in order to catalyze action in the battle against the death-dealing forces that ripple throughout and undergird systemic injustice. Freire (1970/2018) went so far as to describe problem-posing, emancipatory education as "biophilic" (life-loving) and the banking model of education as "necrophilic" (death-loving) when he contrasted the two models. 
Jesus's parables likewise prompted his listeners to re-imagine their understandings of God and God's relationship with creation. These imagined thought experiments were, in my mind, Jesus's first-century Roman-occupied Judean version of drawing forth his listeners' conscientização. For example, through his parables concerning Heaven and the Kingdom of God, Jesus invited his listeners to reconsider who put themselves at risk of damnation and who could receive salvation: God's heart beats for the prodigal son, the lost sheep, the beggar Lazarus, and the repentant sinner. In short, the parables told by Jesus catalyzed paradigm shifts in the religious imaginations of his followers so as to prompt them to re-evaluate their relationships with those oppressed peoples on the margins of first century, occupied Judean society, and to question their preconceived theological notions. The model of catechesis explicitly predicates itself upon the banking model of education (the catechist offers "answers" to questions posed by students, which "fix" misconceptions), a means of education which Freire so vigorously sought to overturn. Emancipatory education is a dialogic process, and Freire (1970/2018) asserted that through "dialogue, the teacher-of-the-students and the studentsof-the-teacher cease to exist and a new term emerges: teacher-student with studentsteachers" (p. 80).

Indeed, these themes continue to resonate in a variety of critical pedagogies, and have been advanced by other scholars. Darder (2017), who was a student of Freire, built upon her mentor's envisioning of emancipatory education as an act of love, because it "was through such love, he surmised, that teachers could find the strength, faith, and humility to establish solidarity and struggle together" (p. 80) with their students. Thus, 
emancipatory educators embrace and uplift the dignities of their students, and educate with and alongside them, rather than upon them, as the banking model would have it. Moreover, the act of raising consciousness "calls upon educators to assume pedagogical responsibility for employing culturally appropriate and creative ways to engage students with respect to "mandatory knowledge"” (Darder, 2015, p. 93). In turning her attention toward the classroom and pedagogical practices of teachers who sought to engage culturally diverse learners, Darder thus recast Freirean insight in the mold of the already extant CRP, a move that made much sense.

Turning toward the democratizing and political implications of critical, emancipatory pedagogy, Duncan-Andrade and Morrell (2008) picked up on Freire’s (1985) thoughts on the politics of education. In his text The Politics of Education (1985), which is about the potential of education to upend unjust political systems, Freire wrote two chapters on liberation theology and African American liberation theologian James Cone. In one particularly incisive rebuke of a church that refused to involve itself in political history on behalf of the oppressed, Freire wrote that the church "takes a road of formalism in bureaucratic rites where hope, detached from the future, becomes only an alienated and alienating abstraction" because it "forbids itself the Easter it preaches" and is consequently "freezing to death, unable to respond to the aspirations of a troubled, utopian and biophile youth" (1985, p. 127). In consciously or unconsciously ignoring the oppressive forces that threaten the well-being of people, the church negates one of its central theological claims concerning Easter resurrection. Christian belief in the eventual re-creation of the world, and belief that God's love overcomes human sin and death, 
invites Christians to live and move in the world grounded in hope. Propelled by belief in the Easter resurrection and Jesus's victory over death brought on by public, statesanctioned lynching, Christians are called to act for a more just world. Without an emphasis on this sort of justice-oriented praxis, catechists promoting the rote memorization of doctrine and dogma posit theology as an irrelevant thing to the lives and meaning-making of young people.

Culturally Relevant Pedagogy. In 1995, Ladson-Billings based her model of Culturally Relevant Pedagogy on her studies of educators working with African American students, and conceived CRP as "specifically committed to collective, not merely individual, empowerment" (1995a, p. 160). In her pursuit of working for collective student empowerment, Ladson-Billings argued that CRP helps every student experience academic success, engage culturally competent practices, and develop a critical consciousness through which they can challenge hegemonic, systemic forces in culture and society. Given her accentuation of critical consciousness, I view LadsonBillings as building upon Freire's conceptualization of conscientização, and even more essentially (and relevantly, for the purposes of education in the United States), expanding Freire's ideals of emancipatory pedagogy toward the horizon of engagement with culturally oppressed and marginalized student populations, specifically African American and Latinx children in the U.S. (Ladson-Billings, 2009). In Ladson-Billings' (2009) own words, "dreamkeepers" are those teachers who "focus on student learning, cultural competence, and sociopolitical consciousness in their work with African American and 
Latino students" (p. 157). This value of raising of students' socio-political consciousness built directly upon Freire's thought.

In sum, Ladson-Billings's development of CRP and subsequent iterations of its central tenets (Irvine, 2010; Milner, 2010b) reject deficit models of education, which view non-White and/or non-Eurocentric cultures as lacking. One can thus draw an analogy between CRP and religious education: catechesis approaches non-Catholic religious traditions through a deficit lens. While I consider Freire to be nothing short of foundational, Ladson-Billings's work with CRP pushes my thought further, focusing my attention on the particular students whose cultures have been maltreated and disserviced in educational settings. And with regard to religious education, the emphasis of CRP on approaching students' qualities as strengths, rather than deficits, prompts me to consider non-Catholic beliefs as enriching rather than detrimental. Related to CRP, Gambrell (2017) created the concept of "spiritually relevant pedagogy," which acknowledges that students' spiritualities are frequently embedded within their cultural worldviews, although Gambrell's valuable theorizing remains undeveloped otherwise. This said, when applied to the purposes of theological education in Catholic high schools, CRP provides an effective ground for critiquing the Framework's catechetical impetus.

Culturally Responsive Teaching. Geneva Gay had been working on multicultural education for many years before the advent of CRP and highlighted various features in her own framework of Culturally Responsive Teaching (CRT) that she believed to be "validating and affirming" (Gay, 2000/2018, p. 37) of students. CRT remains rooted in the lived experience and practices of educators, and Gay (2000/2018) 
delineated central features of CRT, which: "acknowledges the legitimacy of cultural heritages," and influences how a student learns and what content they might want to learn; "builds bridges of meaningfulness between home and school experiences" and "between academic abstractions and lived sociocultural realities"; "uses a wide variety of instructional strategies" so as to accommodate each and every learner; "teaches students to know and praise their own and one another's cultural heritages," which characterizes asset-based pedagogies; and "incorporates multicultural information, resources and materials in all the subjects and skills" (Gay, 2000/2018, p. 37). This list of qualities is not so much a list of best practices, but a series of focal elements upon which culturally responsive educators can base their teaching. Gay's thinking gave further weight to the inadequacies of, and potential harm caused by, those models of education that perpetuate hegemony.

Even though Gay and Ladson-Billings did not address religious education, I reiterate that catechetical religious education is an example of the hegemonically-oriented pedagogy that Gay and Ladson-Billings critiqued. Catechesis acknowledges the legitimacy of only one religious tradition, fails to develop bridges of meaning between students' learning and life worlds, and approaches non-Catholic religious traditions through a deficit lens. I must acknowledge the challenges of discussing religion and culture as being intertwined, because while the two do not always and everywhere overlap, there is certainly confluence between these two spheres of human existence. I can, for example, think of members of both the Jewish and Catholic sides of my family who would identify as culturally Jewish or Catholic, but not religiously so. Likewise, I 
have friends who view their religious beliefs as part and parcel of their ethnic, racial, and cultural identities. In applying CRP and CRT to religious education, I am working under the assumption that a student's religious (or non-religious) beliefs form an aspect (more or less central, depending on the student) of their identity, and that their religious beliefs may or may not be influenced by their cultural heritage.

Culturally Sustaining Pedagogy. Culturally Sustaining Pedagogy, as pioneered by Django Paris and H. Samy Alim (Paris, 2012; Paris \& Alim, 2014; Paris \& Alim, 2017; Paris \& Winn, 2014), pushed the extant bounds of CRP and CRT. "Instead of being oppressive, homogenizing forces, CSP asks us to reimagine schools as sites where diverse, heterogeneous practices are not only valued but sustained," and therefore "demands a critical, emancipatory vision of schooling that reframes the object of critique from our children to oppressive systems" (Paris \& Alim, 2017, p.3). From a starting point of asset-based (rather than deficit-based) pedagogy, advocates of CSP leverage students' skills alongside their cultural and linguistic funds of knowledge, while recognizing that these resources are fluid, dynamically coexisting, and moving between cultural worlds.

Paris and Alim (2014, 2017) offered three loving critiques of Ladson-Billings's CRP, arguing that: pedagogy can be relevant without being culturally, ethnically, or linguistically sustaining; previous asset-based pedagogies approached the cultural worlds that students inhabit as being statically fixed, even though culture is, in reality, fluid and dynamic; and finally, greater critical reflexivity is necessary so as to avoid the further reification of "existing hegemonic discourses about, as examples, gender, race, sexuality, and citizenship" (Paris \& Alim, 2017, p. 10). Ladson-Billings (2014) agreed with this re- 
mixed, 2.0 version of her original model, and supported this movement forward. Thus, working through the lens of CSP, I posit that catechetical educators, when they reify one particular belief system over any others, inherently refuse to sustain diverse belief systems. Catechesis reifies hegemonic religious discourse, which directly contradicts the tendencies of U.S. teenagers, who form their beliefs through a process of bricolage, selecting and choosing elements from various traditions to ground their spiritualities (Freathy, Doney, Freathy, Walshe \& Teece, G. 2017; Smith \& Denton, 2009). Simply put, U.S. teenagers express their openness to spirituality and spiritualities, while at the same time expressing wariness of belonging to any one particular tradition. Therefore, CSP's tenet of cultural hybridity can also be applied to the religious hybridity of many U.S. high school students. Irizarry (2007), although not commenting on CSP in particular, did present a "bilingual aesthetic" for religious education (p. 125), and argued that cultivating such an approach can aid in "sustaining the value of diversity in matters of doctrines, theological approaches, worship expressions, and traditions" (p. 126). Irizarry's writing approached religious education through a culturally sustaining lens, although the theoretical connections between the two remain empirically unexplored.

Critical Religious Education. For the past fifteen or so years, Andrew Wright in the U.K. has been the pioneering advocate for the still-developing theoretical and pedagogical model of religious education he entitled "Critical Religious Education" (henceforward "CRE"). While CRE has been discussed and critiqued in a number of articles since 2004 (Barnes \& Wright, 2006; Franck, 2015; Teece, 2005; Teece, 2010; Wright, 2004a; Wright, 2004b; Wright, 2007; Wright, 2008), Wright and his colleagues 
published a handbook for religious educators in 2019 (Easton, Goodman, Wright, \& Wright, 2019) as a detailed resource for critical religious educators, containing curriculum maps and lesson plans. In 2007, Wright detailed the progression of classical religious education (to which catechesis belongs) into what he called "liberal religious education" (p. 79) in the 1970s, which aimed to engage with the disparate religious worldviews in many U.K. classrooms. In his 2007 book, Wright argued that CRE could accomplish the goals of liberal religious education, but could additionally "rehabilitate the pursuit of ultimate truth and reunite it with the cultivation of truthful living" (p. 104). Interested in philosophical framing, Wright believed that religious education should encourage students to explore questions of religion through the lenses of various religious traditions, and in so doing, encourage students to consider the ways in which they want to live in accordance with their beliefs. Wright (2007) based CRE on the theoretical grounds that we "have a moral obligation to seek to hold true beliefs" and the assumption that society will flourish if citizens can "respond intelligently to questions about the ultimate meaning and purpose of life" (p. 104). Wright viewed this pursuit of true beliefs as being worthwhile for the spiritual development of students.

As the authors of the 2019 handbook of CRE stated, it is "the only approach to RE which has explicitly forwarded a non-confessional realist approach over the last two decades" (Easton, Goodman, Wright, \& Wright, 2019, p. vii) because it is explicitly grounded in critical realism as its philosophical framework. By conceptualizing CRE as "non-confessional," these authors expressed their axiological foundation as not being rooted in a particular religious, or "confessional" tradition. Meanwhile, three principles 
undergird critical realism: ontological realism acknowledges the veracity of reality as uninfluenced by human perception; epistemic relativity acknowledges the limitations of human perception, which constantly shifts, both within an individual's own perception, and between people; and judgmental rationality holds that human beings can critically construct their perceptions of and interactions with reality.

I believe that the philosophical grounding of CRE provides a valuable resource for the conceptual framework of my study, and coupling it with the aforementioned critical pedagogies offers further definition. Educators working under the tenets of CRE aim to foster students' critical consciousness concerning the plethora of religious worldviews and perspectives, which entails not only reflecting upon and analyzing the belief systems that the self holds, but upon the beliefs of others as well. If fostering of critical consciousness with regard to belief systems can be accomplished in such a manner that respects and sustains the beliefs that students may hold, in addition to demonstrating why religious education of a critical bent is imminently relevant to understanding and engaging the broader world, then I argue that culturally relevant, responsive, and sustaining pedagogies have much to offer. Taken together, these theoretical frameworks can help us explore the largely unstudied dynamics of Catholic theological education in the service of religiously diverse classrooms.

\section{The Conceptual Framework: CRSP}

Combining elements from each of these critical pedagogies, with evangelization and Freirean emancipation providing an underlying foundation, I have created the conceptual framework of "Critical Religiously Sustaining Pedagogy" (henceforward 
“CRSP”). LoFaro (2019) had created a similar framework for the purposes of science education, and her dissertation was my inspiration for my own conceptual framework, the latter of which is depicted in Figure 3. CRSP is predicated upon the overarching goals of emancipatory education and the Catholic educational mission of evangelization, which surround CRSP's three fundamental tenets: religiously sustaining instruction; nurturing and loving relationships; and existentially meaningful (that is, meaningful to students' lived experiences) content. Neither the overarching goals nor the fundamental tenets exist in isolation. Rather, they feed into one another, remaining in constant contact and interdependency. Moreover, I must note that just as the creators of CRP, CRT, and CSP did not posit their theories as evaluative, I do not view CRSP as such either.

\section{Figure 3}

The Conceptual Framework: Critical Religiously Sustaining Pedagogy

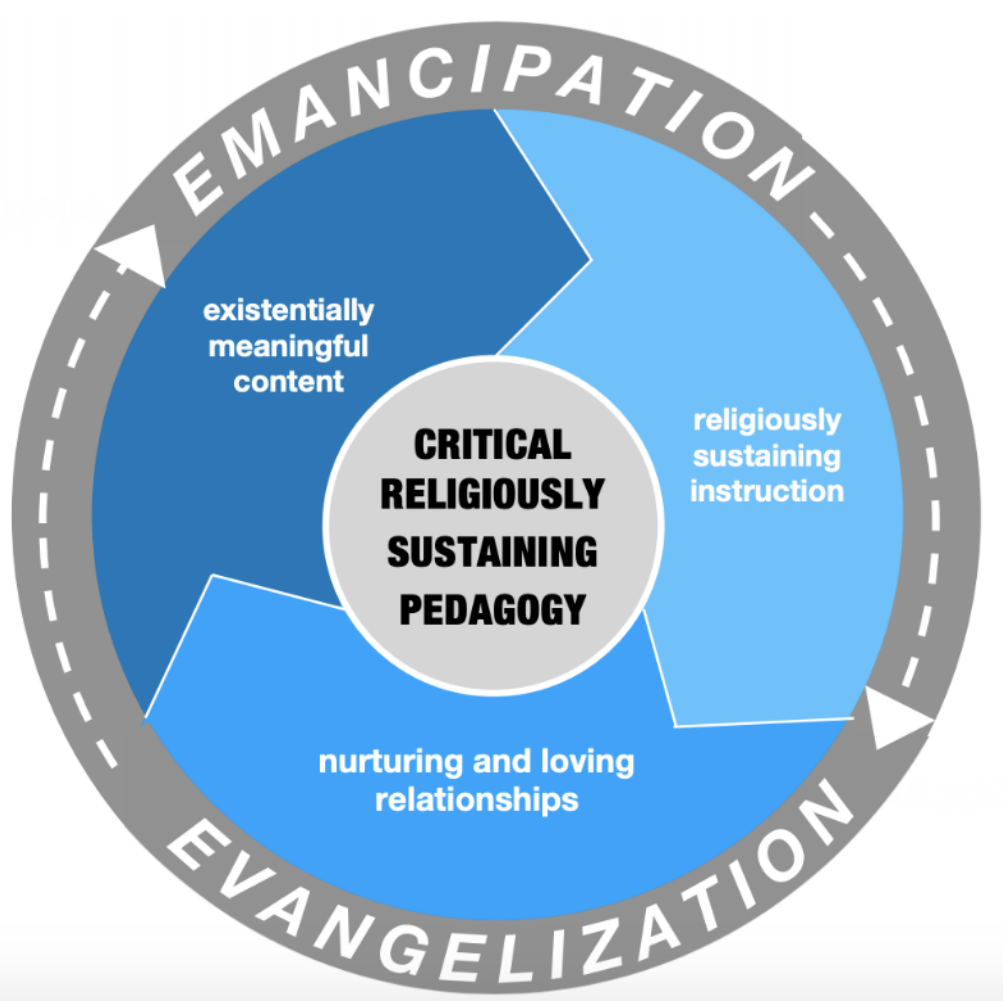


The universal mission of Catholic education centralizes evangelization, as articulated by the Congregation for Catholic Education (the CCE). To revisit a theme from the problem statement, I presently employ "evangelization" not in the sense of attempting the conversion of non-Catholics to Catholicism, but rather in terms of theology teachers living out their faiths, and teaching their students while grounded in faith-filled love of Jesus, thereby fulfilling the mission of Catholic schools to live out the Gospel message. In this, I sympathize with Pope Francis (2013), who in his apostolic exhortation Evangelii gaudium ("The Joy of the Gospel”) wrote that:

Instead of seeming to impose new obligations, they should appear as people who wish to share their joy, who point to a horizon of beauty and who invite others to a delicious banquet. It is not by proselytizing that the Church grows, but "by attraction." (III.14)

Throughout his exhortation, Francis called for Catholics to consider new and creative means of evangelization apart from the transmission of doctrine, so as to combat wicked forces such as the idolatry of money, the disposability of the human person, and injustices that spawn violence. For Francis, evangelization involves far more than simply passing down the faith to successive generations. Given that all theology teachers in Catholic high schools are Catholic, I consider such a consideration of evangelization to be a perfectly healthy and reasonable goal of Catholic secondary education. Second, Freirean emancipatory education provides a more focused foundation for CRSP to rest on. Freire's tenets of praxis-oriented conscientization, problem-posing and constructive dialogue, and humanizing relationships echo throughout CRSP's central elements.

CRSP's three tenets are based upon elements from the theories of CRP, CRT, CSP, and CRE. By existentially meaningful content, I refer to the curricular content in 
theology classes, particularly with regard whether or not it helps students to understand their beliefs, the beliefs of those in their immediate communities, and the ways in which religious dynamics influence culture and society. Hence, even if a student does not possess or seek to possess any form of religious belief, the study of theology can still possess immense relevance in pursuit of reading the world around them, to cast this notion in Freirean language. The goal of pursuing existentially meaningful content is starkly opposed to the goals of catechetical religious education, which is not necessarily relevant for the lived experience of teenagers. Given this tenet, I aimed to illuminate the ways in and through which certain theology teachers attempt to help students understand their immediate worlds and communities through the discipline. Just as CRP and CRT approached students as being in need of culturally responsive and relevant engagement, and CSP approached student cultures as fluid, theological education that is sensitive to students' religious diversity can approach their religious and non-religious beliefs in a similar manner.

Religiously sustaining instruction refers to the means in and through which theology teachers engage students with the content of a given theology class, and how they invite students to express and interrogate their religious beliefs through this instruction. Regardless of what religious tradition or atheistic or agnostic beliefs a student ascribes to, religiously sustaining theological education can help students understand why they believe what they believe. I view this humanizing work as parallel to what Paris and Alim prioritized in CSP, because religiously sustaining theological education would not negate, silence, or oppress non-Catholic beliefs, but rather help a non-Catholic student to 
define those beliefs, which can be accomplished either through dialogue or reflective elements within a curriculum. By "religious," I do not necessarily mean that which belongs to organized religion, but rather that which belongs to questions of religious and spiritual significance more broadly: the existence of God, the immortality of the soul, the meaning of human existence, the exploration of good and evil, so on and so forth. While this is by no means an exhaustive list of themes that occur in all religious traditions, I paint with broad brushstrokes to articulate that which undergirds theological education in the Catholic tradition. Certainly, an authentically sustaining theological education would consider the questions that students themselves raise. Encouraging students' voices can enable them to understand their beliefs, and learn to communicate them in a democratic and religiously diverse society, as well as engage the beliefs of others with understanding and compassion; studies pertaining to international religious education, which I will describe later, highlight such potential.

Finally, the tenet of nurturing and loving relationships refers to the learning relationships that teachers foster, and how teachers learn about and engage students regardless of what beliefs students hold. Any high quality educator understands that their students learn best in the context of authentic relationships (Valenzuela, 1999): many first-year teachers are exposed to the pithy maxim “they don't care about what you know until they know that you care," which does indeed contain an immense amount of truth. In my own experience of working with students, especially those who have suffered ambient or direct trauma, I find this dictum to be pointedly accurate. In my own experience, I perceive that some non-Catholic students enter Catholic high schools 
nervous that they will be converted, and certain teenagers are understandably hostile or hesitant to theology class at first, especially if they are resolutely religious (or nonreligious) themselves and do not want their beliefs interfered with. Such nervousness, and even negative tension, can be overcome if caring relationships are cultivated. Just as the potential barriers erected by racial, ethnic, and cultural tensions can be dissolved through authentic love (precisely because that love challenges systematic injustice), so too can relationships overcome potential educational challenges caused by religious difference. I do not posit the import of authentic love in a romanticized or an idealized way: informed by Freire's emphasis on the presence of hope in emancipatory education (Freire, 2014), I recognize that authentic love confronts injustice and interrupts and battles to overcome systematic oppression, even in the face of futility. The centrality of relationships between educators and students resonates throughout the theoretical frameworks of CRP, CRT, and CSP, and so I take up this mantra in CRSP. Consequently, I worked to discover how theology teachers go about cultivating nurturing and loving relationships with nonCatholic students.

I deem it important to assert that none of these three elements exists in isolation from the other two. They feed into one another, support one another, draw from one another, and depend on one another. For example, a critical religiously sustaining pedagogy fosters nurturing and loving relationships between teacher and student through mutual self-revelation, which is to say the sharing of personal beliefs and the ensuing dialogue about them. The teacher demonstrates their care for the student by respecting their beliefs, perhaps even amplifying those beliefs, and thereby uplifting the student's 
dignity and reverencing the student's positionality. This, in turn, motivates the teacher to pursue existentially meaningful instruction that generates constant connections between the student's lived experience and the theological content of study.

\section{Critique of the Theoretical Frameworks and Conceptual Framework}

The difficulty of applying these theoretical frameworks lies in doing so within the specific context of religiously diverse high school classrooms in U.S. Catholic high schools. None of the above pedagogies were created with this niche context in mind, and the creators of CRP, CRT, and CSP developed their ideas through the several decades of theory and practice grounded in multicultural education since the 1970s. Although CRE does center around religious education, it does so from a European perspective, where religious education is widespread across many types of educational institutions. Wright and other advocates of CRE apply it for use in non-confessional contexts (as well as for use in U.K.-sponsored Anglican schools), while my problem of practice is very much embedded within schools of a given religious tradition. Given the mismatch between these frameworks and my particular problem, there is a dearth of literature concerning the application of these pedagogies to understanding the specific context of religious education. This said, I maintain that because religion is potentially a central aspect of students' cultures, the main ideas of these pedagogies can be applied to a theology classroom in particular ways.

Moreover, not every element of these theoretical frameworks helps to illuminate and engage the problem of practice at hand. For example, linguistic dynamism, fluidity, and hybridity are more pertinent for CSP's approach to literacy studies than they are for 
religious education. Although religious fluidity and hybridity are documented phenomena (though not in the literature surrounding CSP), in this study I was not concerned with the ways in which theology teachers are attempting to address the maltreatment of culturally fluid or hybrid students under hegemonic, monocultural, and monolingual pedagogies. I am, however, interested in the maltreatment of multireligious, nonreligious, antireligious and non-Catholic students in Catholic high schools. And to investigate how theology teachers engage such students through an asset-based (as opposed to a deficit-based) lens, I have created the conceptual framework of Critical Religiously Sustaining Pedagogy. Given that none of these theoretical frameworks is directly applicable to the particular context of theological education in U.S. Catholic high schools, I have engaged in a process of bricolage (Maxwell, 2013) in order to draw out their most suitable elements.

The conceptual framework of CRSP is limited in its usefulness to understand how theology teachers approach their work, particularly given the absence of uniformity in preparation and training that theology and religion teachers undergo (Cook \& Hudson, 2003). Theology is an uncredentialable subject in the U.S., and theology teachers complete undergraduate and graduate coursework not in education, but in theology and religious studies; consequently, unless they have sought out or received professional development in critical theories, theology teachers are not necessarily familiar with them. However, given the increasing popularity of these critical pedagogies, I suspect that many have at least some basic familiarity. Moreover, I believe that many theology teachers are already seeking to foster relationships with non-Catholic students, helping to sustain their beliefs, and providing existentially meaningful instruction. Certain tenets of these 
pedagogies run through the lifeblood of Catholic education, particularly their focus on caring relationships and humanizing education. This said, not all theology teachers would agree with Freirean thought (perhaps because it originates in Marxism, an ideological tradition that Popes John Paul II and Benedict XVI have repeatedly expressed hostility toward) or with the theories at hand.

Because not all teachers ascribe to the critical pedagogies within the theoretical framework due to an unfamiliarity for which they are not culpable, CRSP cannot entirely explain the phenomenon of theology teachers' experience of educating religiously diverse student populations. I believe that CRSP can offer certain signposts to watch out for, or certain interpretive lenses to peer through. If a theology teacher is dedicated to a critical examination of theological areas, and cares about developing relationships with students, and wants to invite student perspectives and beliefs into the classroom, I tend to think that CRSP is already being enacted by theology teachers. Implementing CRSP in this study enabled me to ask questions that probed and explored how certain teachers are willingly doing so, rather than evaluate their practice. This study investigated how and why that is happening within teachers' experiences and pedagogical decisions.

\section{Catholic and Religious Education}

Now that I have laid out my conceptual framework, I will review literature that pertains to Catholic education and religious education in particular. In order to better understand the clash of cultures between the CCE and the USCCB, I will examine documents that have been produced by these two organizations over the past five decades, which must, in turn, be understood in light of the theological conclusions and 
emphases from the Second Vatican Council of the 1960s, as I will explain below. With this literature in mind, I will look at scholarship pertaining to different models of religious education, catechesis, and religious education in Catholic schools.

\section{Documents from the Magisterium of the Catholic Church}

Any discussion of contemporary Catholic education must begin with a brief discussion and overview of the theology that arose from the Second Vatican Council, which took place between 1962 and 1965. At this ecumenical council, bishops, theologians, and members of Protestant and Orthodox churches (between 2,100 and 2,300 at any given point) from around the world gathered in Rome to address the needs, activities, and work of the Catholic Church over the course of these three years. In light of globalization and secularization, the Council's members acknowledged the need to reassess and rearticulate how Catholicism would engage these modern complexities in the second half of the 20th century. Members of various "commissions" (comprising Catholic bishops and theologians) met on and off throughout the course of the Council, in order to draft, critique, and revise documents that would be promulgated at the Council's conclusion. One of the Council's texts, Nostra aetate ("In our age"), or the Declaration on the Relation of the Church to Non-Christian Religions (Pope Paul VI, 1965a), discussed the presence of truth in non-Catholic and non-Christian religions, and asserted that non-Catholics could go to Heaven. From a 21 st century perspective, this theological assertion might seem flippant, but it revolutionized the tone and timbre with which Catholicism would engage non-Catholics. This newly articulated willingness to pursue dialogue with other religious traditions, not for the sake of converting the religious other, 
but for the sake of enhanced understanding and harmony, would catalyze a paradigm shift for many spheres within Catholicism.

We can consider Gravissimum educationis, the Declaration on Christian Education, in light of the paradigm shift toward cultural dialogue catalyzed by the Council. In a sweeping stroke, the council's theologians and bishops articulated that, over and above other secular educative goals, a Christian education forms followers of Jesus in prayer, worship, practice, and participation in society (Cattaro \& Russo, 2015). While the council recognized the broader values of educational institutions, its published documents articulated that the salvation of students' souls is the primary purpose of Catholic education. According to Gravissimum's authors, part and parcel of forming students' Christian faith identities is catechetical instruction, "which enlightens and strengthens the faith, nourishes life according to the spirit of Christ, leads to intelligent and active participation in the liturgical mystery and gives motivation for apostolic activity" (Pope Paul VI, 1965b, II 4).

Religious and secular goals do not mutually exclude one another; for example, while catechesis's religious dimension is certainly about the passing on of traditional beliefs, its moral dimension forms students' values so that they might act thoughtfully and in accord with a well-formed conscience. Having taken up the Council's ecumenical and inter-religious inclinations, Gravissimum's authors acknowledged the education of non-Catholic students, which "is possible by the witness of the lives of those who teach and direct them," and especially those "who give them the doctrine of salvation in a way suited to their age and circumstances and provide spiritual aid in every way the times and 
conditions allow" (Pope Paul VI, 1965b, ๆ7). In this statement, Gravissimum struck a chord that echoed throughout subsequent ecclesial documents: teaching on salvation is to be offered to non-Catholic students, but the means of doing so remain contingent upon student age and broader educational context. And as demographic data of students attending Catholic schools shows (McDonald \& Schultz, 2021), Gravissimum's authors forecasted the increasing religious diversity of Catholic schools' students.

Documents from the CCE. Although the Congregation for Catholic Education (CCE) has existed for centuries, following the Second Vatican Council, its internationally-minded bishops began to more explicitly address the roles, goals, and purposes of Catholic education in the 21st century, especially in light of the Council. In accord with Gravissiumum educationis, the authors ${ }^{10}$ of The Catholic School (CCE, 1977) posited that Catholic education cannot merely be about the simplistic transmission of doctrinal knowledge, but is rather concerned with the formation of the whole person, of which religious education is an integral part. Garrone (CCE, 1977) insisted that "the danger of a so-called proselytism, of imparting a one-sided outlook" (II.19) potentially arises from an inappropriate implementation of Christian education. Thus, the Catholic school evangelizes, but does not need to proselytize.

Toward the latter paragraphs of The Catholic School, Garrone provided nuance regarding the Catholic education of non-Catholics. Regarding students of disparate

\footnotetext{
${ }^{10}$ I would like to offer a note on the citation of these documents: although the CCE comprises several bishops and cardinals, the documents are signed by the Congregation's "prefect," and sometimes secretary. Presumably, the Cardinal Prefect is the primary signatory, and writes on behalf of the entire Congregation, although there may be unsigned co-authors. Throughout this review, I reference these prefects (such as Baum, Garrone, and Grocholewski) as the main authors.
} 
cultures within the same school, Garrone articulated that the Catholic school "does not exacerbate differences, but rather aids cooperation and contact with others" because it "opens itself to others and respects their way of thinking and of living" (CCE, 1977, IV.57). Encounter and dialogue with the other, in Garrone's mind, result in empathy, understanding, and harmony in the midst of cultural diversity. Therefore, should nonChristian families entrust their children's education to a Catholic school, they should expect that their children's consciences will be fully respected. Garrone (CCE, 1977) concluded The Catholic School with an expression of his care for those students whose families do not ascribe to Catholicism:

In the certainty that the Spirit is at work in every person, the Catholic school offers itself to all, non-Christians included, with all its distinctive aims and means, acknowledging, preserving and promoting the spiritual and moral qualities, the social and cultural values, which characterise different civilisations. (VI.85)

In this statement, Garrone echoed the Second Vatican Council's assertion that the divine is present in non-Christian religious traditions, spelling out the implications thereof for Catholic education globally. And in so doing, I would argue that he foreshadowed some of the fundamental tenets of CRP, CRT, and CSP.

In 1988, Cardinal William Baum of the CCE elaborated upon these pre-existing themes of welcoming non-Catholic students into Catholic schools. In the introduction to The Religious Dimension of Education in the Catholic School (CCE, 1988), Baum wrote:

Not all students in Catholic schools are members of the Catholic Church; not all are Christians. There are, in fact, countries in which the vast majority of the students [in Catholic schools] are not Catholics - a reality which the Council called attention to. The religious freedom and the personal conscience of individual students and their families must be respected, and this freedom is explicitly recognized by the Church. On the other hand, a Catholic school cannot relinquish its own freedom to proclaim the Gospel and to offer a formation based 
on the values to be found in a Christian education; this is its right and its duty. To proclaim or to offer is not to impose, however; the latter suggests a moral violence which is strictly forbidden, both by the Gospel and by Church law. (Introduction.6)

Baum believed that the consciences of non-Catholic and non-Christian students cannot be infringed upon, because so doing would be an act of symbolic moral violence; we can contrast this stance easily with earlier Catholics' attitudes, as many Catholics had no qualms about acting with physical violence upon the non-Catholic Other, be it in forced conversion, war, or participation in the slave trade. The bishops of the USCCB failed to echo the safeguarding of personal conscience and religious freedom in any of their documents pertaining to education.

Baum's 1988 document highlighted the tensions between catechesis and more general religious education: "unlike religious instruction, catechesis presupposes that the hearer is receiving the Christian message as a salvific reality" and "takes place within a community living out its faith at a level of space and time not available to a school: a whole lifetime" (CCE, 1988, IV.1.68). The onus to provide sufficient catechetical formation, in Baum's mind, was therefore on the Catholic parish and family, because the aims of a school are more appropriately centered around ends other than faith formation. In Baum's own words, religious education can be a means through which students "learn the virtues of self-respect and self-love, and of love for others-a love that is universal" (CCE, 1988, IV.3.76). Thus, while a student's religious beliefs might be explored and deepened in school, the civic virtues of tolerance, acceptance, empathy, and solidarity are to be pursued as well. Freire (1985) also highlighted such educational goals, which are desirable for people in a democratic society. 
I believe Baum's (CCE, 1988) most striking statement continues to carry vital implications for the theological education of non-Catholic students. In religiously diverse Catholic schools,

evangelization is not easy-it may not even be possible. We should look to preevangelization: to the development of a religious sense of life. In order to do this, the process of formation must constantly raise questions about the "how" and the "why" and the "what" and then point out and deepen the positive results of this investigation. (V.2.108)

In this stunning articulation, Baum revealed his deep sensitivity to the needs of schools, families, and students. Not all students seek evangelization of a catechetical nature, and religious education for these students ought to cultivate an openness to the value and importance of humanity's religious experiences. Simply, students deserve more than catechesis can provide when it comes to existentially meaningful learning: CRSP focuses on content and instruction that is existentially relevant for non-Catholic and Catholic students alike.

Laghi (CCE, 1997) broadened the evangelizing mission of Catholic schools to address the physical and spiritual poverties that exist in human society, and stated that Catholic schools contribute to the common, public good. The authors of more contemporary CCE documents, namely Educating to Intercultural Dialogue in Catholic Schools: Living in Harmony for a Civilization of Love from 2013 and Educating Today and Tomorrow: A Renewing Passion from 2014, directly addressed religious diversity. Cardinal Grocholewski (CCE, 2013) wrote about the value of interreligious and intercultural dialogue within Catholic schools, and stated that such dialogue provides "a framework for reciprocal witnessing among believers who belong to different religions. 
In this way, one gets to know the other's religion more deeply and better, as well as the ethical behaviours that derive from it" (I.15). Grocholewski thus implied that a nonCatholic student can (and even ought to) deepen his or her faith identity through dialogue with Catholicism: non-Catholic students witness (that is, articulate, and live out) their respective belief systems in one another's immediate presence, while reciprocally bearing witness to the belief systems of others. Similarly, in harmony with Grocholweski's (CCE, 2013) comments, a critically-minded theological educator promotes encounter and dialogue in order to sustain students' diverse beliefs.

Characteristic of interreligious education, this dialogue necessitates bringing nonCatholic traditions into the theology classroom. As Grocholewski (CCE, 2013) explained, religious education can help students to overcome the ignorances and fears that spur hateful intolerance, consequently arriving at a positive valuation of diverse beliefs. Even more forcefully, Grocholewski (CCE, 2013) asserted that Catholic schools "must become places of pluralism, where one learns to dialogue about the meanings that people of different religions attribute to their respective" traditions because this allows the sharing and discovery of values "such as solidarity, tolerance and freedom" (V.63), all of which are held by the Catholic Church to be individually attainable virtues that collectively contribute to the common good.

The 2014 CCE document Educating Today and Tomorrow: A Renewing Passion echoed Grocholewski’s perspective from 2013, and he wrote that non-Catholic students' beliefs "should not be seen as a barrier, but as a condition for intercultural dialogue, helping each pupil grow in their humanness, civic responsibility and learning" (CCE, 
2014, II.6). Therefore, the reality of religious diversity should not be perceived as an obstacle to a school's Catholic identity (or even evangelizing mission!), but rather as fruitful soil that invites cultivation of Catholic identity and mission. At the same time, however, this appreciation of and respect for religious diversity does entail a tension with the impetus to evangelize. In Educating Today and Tomorrow, Grocholewski articulated that at "the heart of Catholic education there is always Jesus Christ: everything that happens in Catholic schools and universities should lead to an encounter with the living Christ" (CCE, 2014, III). This statement, boldly intent on introducing students to relationship with Jesus, poses a paradox.

How can a Catholic school introduce students to such a relationship with Jesus of Nazareth while upholding freedom of religious conscience, so as to avoid the moral violence condemned by Cardinal Baum (CCE, 1988)? Indeed, Grocholewski (CCE, 2014) brought this tension to light: the "answer" to this challenge of multiculturalism and multireligiosity "cannot be to seek shelter in indifference, nor to adopt a kind of Christian fundamentalism, nor-lastly_ - to define Catholic schools as schools that support 'generic' values" (III.1.i). Thus, if theology teachers are not sensitive to and willing to engage with religious pluralism, they might very well inappropriately attempt to catechize through a fundamentalist approach.

It is difficult to determine to what degree teachers across the United States are even familiar with the above guidelines, attitude, and documents of the CCE. As with any system of belief, there are (to paint with inadequate broad brush strokes) "conservatives" and "progressives" who teach theology, and there are certainly theology teachers who 
espouse catechesis to be perfectly appropriate because they understand the purpose of evangelization to be the conversion of others by means of catechesis.

Documents from the USCCB. In 1997, the USCCB produced Renewing the Vision: A Framework for Catholic Youth Ministry, which outlined the bishops' intentions for parish- and school-based ministry programs in the United States, and was driven by episcopal concern about consumerism, the dehumanizing effects of media consumption, and the decline of familial relationships. A fear of secularization's effects lurked under the bishops' words. According to the bishops, as U.S. families fell under the influence of values perpetuated by consumerist culture, they have consequently lost the religious impulses that once drove family life. In order to combat these isolationist and areligious tendencies, the bishops proposed that "catechesis is an essential component of youth ministry and one that needs renewed emphasis. If we are to succeed, we must offer young people a spiritually challenging and world-shaping vision that meets their hunger for the chance to participate in a worthy adventure" (USCCB, 1997). Catechesis, the bishops believed, through the impartment of sound theological doctrine, could provide a needed antidote to the aforementioned isolationist and areligious tendencies, as a religious worldview can reinvigorate a teenager's entire attitude toward their surrounding world with meaning-driven purpose. Other USCCB documents are a bit more broadly focused, although they do contain hints of the bishops' concerns regarding religious illiteracy. Sharing Catholic Social Teaching: Challenges and Directions (USCCB, 1998), for example, conveyed the bishops' concern over the lack of uniformity and comprehensive 
understanding of Catholic Social Teaching within educational institutions serving children and adult learners alike.

On another note, the bishops have addressed ethnic and cultural diversity, calling for youth ministries to maintain sensitivity and inclusiveness in their work through "affirming and utilizing the values and traditions of their ethnic cultures" (USCCB, 1997). Consequently, I think it important to dwell on the notion of erasing prejudice and bias in the effort to foster hospitable communities marked by different forms of diversity. Sensitive to increasing racial and cultural diversity within Catholic schools, in Renewing Our Commitment to Catholic Elementary and Secondary Schools in the Third Millennium (USCCB, 2005b) the bishops advocated for the elimination of any boundaries (such as policies that explicitly or implicitly discriminate) within educational institutions that might engender hostilities toward immigrant students and families. This position implied, therefore, an awareness on the bishops' part that divisive boundaries did in fact exist. While the USCCB's 1997 Renewing the Vision emphasized culturally sensitive and inclusive practice in adolescent ministry, this 2005 document failed to offer further words on how non-Catholic students are to be welcomed into Catholic schools. The bishops' omission, intentional or otherwise, cognizant of religious diversification or ignorant of it, left room for the Framework to make a similar omission as well.

The General Directory for Catechesis (USCCB, 2005a) was published by the U.S. bishops just a few years before the Framework, the latter of which was almost certainly written with the former in mind. This 302-page text laid out the U.S. bishops' thoughts and attitudes toward the role of catechesis as a mode of theological education 
within parishes, schools, seminaries, and a variety of Catholic educational ministries. The Directory described six overarching "fundamental tasks" of catechesis. According to the bishops, catechesis: "promotes knowledge of the faith"; "promotes a knowledge of the meaning of the Liturgy and the sacraments"; "promotes moral formation in Jesus Christ"; "teaches the Christian how to pray with Christ"; "prepares the Christian to live in community and to participate actively in the life and mission of the Church"; and "promotes a missionary spirit that prepares the faithful to be present as Christians in society" (USCCB. 2005a, pp. 60-62). Two of these six goals/tasks directly concern the transmission and acquisition of doctrine and dogma (in Freirean speak, representing the "banking" model of education). And so, while catechesis encompasses a somewhat broader spectrum of goals for catechists to pursue (other than depositing knowledge into the heads of catechumens), all of them assume that those being catechized are Catholic, or desire to become Catholic. Given that the Framework comprises almost sixty pages of doctrinal and dogmatic theological points, I suspect that that 2008 text is centered around the first and second tasks pertaining to the promotion of knowledge (of the faith and the meaning of Liturgy and sacraments).

Interestingly, in the National Directory, the bishops articulated a few "challenges to catechesis" that they perceived, among which were "pervasive secularism of our culture," "religious indifference, religious ambiguity, and the growth of sects, cults, and New Age spirituality," and the "significant number of Catholic children and young people who are not enrolled in any systematic catechetical program" (USCCB, 2005a, p. 13). In light of this statement, and the last challenge in particular, I believe that the 
Framework was an attempt made by the U.S. bishops' to mandate catechesis in a place (the U.S. Catholic high school) where catechesis was not the presumed universal mode of theological education. One of the oddest passages in the Directory (USCCB, 2005a, p. 15) states that:

catechesis must incorporate the fact that parents are likely to cultivate independent thinking and problem-solving skills in the children, so that their children are more likely to succeed economically. Consequently, young people today are also-more critically-minded in their learning styles than ever before, and they develop those skills at earlier stages.

It is almost as if the bishops are assuming that catechesis of prior years was directed toward students who were gullible, devoid of critical thinking skills, and more willing to accept whatever teaching had been dictated to them. And so, the U.S. bishops acknowledged that catechesis in the $21^{\text {st }}$ century must meet the needs of those who have been taught the art and skill of critical thought (which is [according to the bishops?] apparently a means toward financial privilege, rather than part and parcel of liberatory praxis!). I could spend many more pages reflecting upon the Directory's contents, but I will refrain from doing so, at the risk of misdirecting focus away from the text that is really at the heart of my problem of practice: the USCCB Framework.

Finally, the USCCB Framework (2008) is itself just under 60 pages. As a point of reference, please see Figure 4, which is a screenshot of a section from one page of the Framework (USCCB, 2008, p. 22); the vast majority of the Framework consists of pages divided into two columns, enumerating a list of hundreds of theological doctrines, dogmas, and points for learning. 
Figure 4

Snapshot of a Section from the USCCB Framework

C. Holy Eucharist: the sacrament which re-presents in the Mass the sacrificial Death of Christ and his Resurrection-making it possible for us to eat his Body and drink his Blood (CCC, no. 1323).

1. Understanding the sacrament.

a. Scriptural basis: Ex 12; Mt 14:13-21; Mt 26:

26-29; Mk 6:30-33; Mk 14:22-25; Lk 9:10-17;

Lk 22:14-20; Jn 2:1-12; Jn 6:22-59; Jn 13-17;

1 Cor 11:23ff. (CCC, nos. 1337-1344).

1) The Eucharist is pre-figured in the Old Testament, beginning with the priest-king Melchizedek (Gn 14:18-20), Israel eating unleavened bread every year at Passover, and Yahweh providing manna from heaven (CCC, nos. 1333, 1544).

b. Historical development (CCC, nos. 13241332, 1345).

c. Theology.

1) Signs (CCC, nos. 1333-1336).

2) Institution (CCC, nos. 1337-1340).

3) "In memory" (CCC, nos. 1341-1343).

4) Thanksgiving and praise (CCC, nos. 1359-1361).

5) Sacrificial memorial (CCC, nos. 1362-1372).

6) Ecclesia de Eucharistia.

The text has a one-page introduction, followed by two major sections: the "Core Curriculum" consists of six courses ("The Revelation of Jesus Christ in Scripture"; "Who Is Jesus Christ?”; “The Mission of Jesus Christ (The Paschal Mystery)”; “Jesus Christ’s Mission Continues in the Church"; "Sacraments as Privileged Encounters with Jesus Christ"; "Life in Jesus Christ") and the second section of elective coursework outlines 
five optional courses ("Sacred Scripture"; "History of the Catholic Church"; "Living as a Disciple of Jesus Christ in History"; "Responding to the Call of Jesus Christ"; and "Ecumenical and Interreligious Issues"). In order to understand the purpose of this document, it is beneficial to cite some of the introduction's statements in full:

First, the bishops designed the Framework in order to guide catechetical instruction for young people of high-school age wherever and however it takes place: in Catholic high schools, in parish religious education programs, with young people schooled at home, or within the context of the catechetical instruction which should be part of every youth ministry program. (USCCB, 2008, p. 1)

It is a bit hard to imagine how ministries apart from high school curricula might implement this Framework, given that it is divided into (what are essentially) eight semester-long courses. These introductory sentences immediately acknowledged the catechetical nature of the following framework.

While CCE texts quite explicitly discussed issues of religious freedom and conscience, the USCCB bishops remarked that

The Christological [centered on Jesus Christ] centrality of this framework is designed to form the content of instruction as well as to be a vehicle for growth in one's relationship with the Lord so that each may come to know him and live according to the truth he has given to us. In this way, disciples not only participate more deeply in the life of the Church but are also better able to reach eternal life with God in Heaven. (USCCB, 2008, p. 1)

The bishops designed their Framework to place students in relationship with Jesus, to form them into disciples, or those who participate in the life of the Church in order to attain salvation. Apart from the question of how well this Framework can accomplish those stated goals, given that it is a fifty-something page outlined list of doctrinal and theological points to be learned, I am concerned with the question of how those goals are 
intended to be presented to non-Catholics. Accounting for the CCE's warning against using theology as a coercive discipline amongst non-believers, and considering its encouragement to undertake "preevangelization" (Baum, 1998, V.2.108) in those contexts where outright evangelization would be inappropriate, I interrogate and critique the bishops' assumptions regarding whom the Framework serves.

In addition to describing the content of catechetical instruction, the Framework took an apologetic stance to defend Catholic theology against so-called "challenges" (USCCB, 2008, p. 1). Each section of the Framework, after presenting a series of doctrines and topics (which are cross-referenced against the Catechism of the Catholic Church, the encyclopedic compendium of Catholic doctrine and teaching), included a number of questions and challenges to those doctrines and topics, as well as formulated responses. For example, in the Framework's final section on ecumenical and interreligious issues, the "challenge" question "Isn't one faith or religion just as good as any other?" is posed, to which the bishops responded with: "No, that statement is not true. The fullness of Revelation and truth subsists in the Catholic Church" and "If one has been given the gift of faith and chooses to reject or neglect that gift, that person acts in a way that is gravely wrong" (USCCB, 2008, p. 53). According to this language, which contradicts the promise and essence of the Second Vatican Council's Nostra Aetate, nonCatholic students who have received catechetical education and choose to maintain their religious identity are choosing wrongly, grievously so. In Catholic theological speak, such students sin. The bishops condemned their religious identities, and although their Framework spoke of dialogue "characterized by respect" and "a refusal to treat one as 
less worthy because of differences," it also stated that "Catholics are to be respectful of people in their intrinsic dignity but not tolerant of falsehood" (USCCB, 2008, p. 53). Previously referenced CCE documents promoted tolerance, inclusivity, and the wholehearted, loving acceptance of non-Catholic students. The Framework's language in this section on interreligious issues, however, directly contradicts that spirit, which is widely accepted by the Catholic community, from theological scholars to faithful laity.

\section{Historical Overview of the Models of Religious Education}

Prior to the 1950s, religious education in Catholic schools emphasized learning the "absolute truths" contained within Catholic doctrine, which in turn supposedly led to the salvation of one's soul. In the late 1960s and throughout the 1970s - the years following the Second Vatican Council—religious educators' (Lee, 1971; Westerhoff, 1976/2012) attention turned toward existential meaning-making, social justice, and human relationships. In the 1960s, the "kerygmatic" (from the Greek kerygma, "to proclaim" or "to teach") movement in religious education was short-lived, and attempted to "proclaim" the life, death, and resurrection of Jesus through stories, activities, theater, and music, and elicit a positive response from students to that proclamation. Following the kerygmatic movement, "life-centered" and "situational" religious education moved away from catechesis, and relied instead upon reflection upon and discussion about real life situations from student experience (Rummery, 1975). In the 1970s, "group-centered" religious education emphasized teaching and learning about how and why religion operates in human society, culture, and experience (Rummery, 1975). From the 1980s through the 2000s, the forces of neoliberal consumerism and individualism increasingly 
rendered religious truth to be an obsolete notion in Western culture, centering the value of a human person on how much money they can make, and the material goods they could buy. Crawford and Rossiter (2006) noted a movement toward interpreting traditional religious meanings in light of students' lived experiences (Groome, 1999). Thus, analytical, psychological, hermeneutical, interreligious, story-making, and phenomenological approaches to religious education have arisen, which respectively approach religion from an objective, sociological perspective and from the perspective of lived human experience (Dillen, 2015; Fowler, 1981; Heft, Groome, Taymans, \& Lund, 1997; Hill, 2009; Lee, 1971; Rothrock, 2014; Samuel, 2013); these approaches are potentially non-confessional, or not taught from a distinctly Christian perspective. Attempts at multicultural religious education, on the other hand, have largely been from a Christian perspective, and attempted to make religious education possible for nonWestern, non-White, and non-hegemonic cultural contexts (Wilkerson, 1997) for the purposes of proselytization.

In 1982, one of the Catholic Church's eminent lay scholars on religious education, Graham Rossiter, called into question the catechetical imperative of Catholic religious education, and argued that the increasing diversification of Catholic school students required a "creative divorce" between catechesis and other modes of religious education. He wrote that "Catholic school-based religious education should be reconceptualized more along educational than catechetical lines" (Rossiter, 1982, p. 22) because the imperative to evangelize "will always have to be balanced against the overriding importance of the personal liberty of all those concerned-pupils certainly, but teachers 
as well" (p. 27). Rossiter stressed that religious education in Catholic schools ought to complement catechesis that takes place at homes and in churches, rather than aim toward catechesis itself; Harris (1987), Moran (1983; 1989; 1997), Harris and Moran (1992; 1998), and Scott (2015) have echoed and developed Rossiter's notion of the creative divorce. Much of the scholarly conversation surrounding the appropriateness of catechesis in Catholic religious education references Rossiter's thesis, and I approach it as a foundation of my own perception regarding the problem of practice at hand.

\section{Concluding Thoughts on Theoretical Literature}

Ultimately, I believe that the USCCB overlooked (intentionally, or otherwise) the literature published by the Vatican's CCE due to a combination of factors: lack of awareness regarding students' religious demographics in Catholic high schools; ecclesiastical culture, which is hierarchical and authoritarian by nature; and fear of increasing religious illiteracy among Catholics and declining numbers in the U.S. Catholic church. The U.S. bishops and the bishops of the CCE are clearly at odds with one another in their approach to religious education. While the bishops based in Rome have kept in mind the global contexts of Catholic schools, U.S. bishops remained committed to catechetical religious education, and their Framework overrode decades of progress made by advocates of various other models of religious education.

\section{Empirical Literature}

This section of the literature review, which covers empirical scholarship, is divided into four main sections: Catholic schools and religious education within them; emancipatory and critical pedagogies; religious education in international contexts; and 
methodological literature. First, I turn my attention to Catholic schools and their microcultures, specifically to explore the ways in which teachers, administrators, and staff potentially and actively promote culturally inclusive and sustaining communities, and the role of religious education within Catholic schools. In the second section, I explore the literature surrounding the critical pedagogies that form the base of my conceptual framework; while the vast majority of these pedagogies understandably have nothing to do with theological education, these empirical studies do offer insight into how critical pedagogical frameworks can be enacted by educators in their lived experience. In the third section on international religious education, I examine studies that shed light on religious education for religiously diverse student populations. European schools frequently require or offer religious education at the secondary level, often from nonindoctrinatory and non-confessional stances. Such instances of religious education are geared toward the common good, which is certainly a distinct goal from the perpetuation of a single faith tradition. In the fourth and final section, I explore studies that have influenced my research design.

\section{Catholic Schools and Religious Education in Catholic Schools}

The first of the two subsections that fall in this portion of the literature review explores the ways in and through which the staff of Catholic schools engage students' cultures and beliefs. The second subsection examines the empirical literature pertaining to religious education in Catholic schools. Of particular import are those studies that deal with diversity in Catholic schools, be it cultural or religious. 
Catholic Schools and Their Students. Regarding Catholic education on a global scale, Paletta and Fiorin (2017) analyzed 142 survey responses from bishops, school heads, teachers, families, students, and alumni from Catholic schools around the world about the CCE document "Educating Today and Tomorrow" (2014), which discussed contemporary challenges facing Catholic schools. The study's findings indicated that Catholic schools on a global scale encounter the same tensions and opportunities faced by United States schools: respondents understood the Catholic educational mission to be that of evangelization, but also questioned how to undertake this mission in light of relationships, economic diversification, and cultural secularization. Hall, Sultmann, and Townend (2019) conducted a Leximancer analysis (quantitative analysis of vocabulary and themes from data) and an inter-rater authenticity process for eight of the most important documents from the Second Vatican Council and the Congregation for Catholic Education, in order to generate the most common themes, sub-themes, and narratives between these texts spanning the past 50 years. What inclusion looks like for Catholic school curricula was not specified, although most interestingly, Hall, Sultmann, and Townend identified five emerging models of Catholic school culture, which vary in their approaches to placing Catholic culture in conversation with pluralism and secularization. This study confirms the dissonance I have noted between the USCCB Framework and these CCE texts: some Catholic schools' students are almost entirely Catholic, while for others the reverse is true, and given this reality, to impose a standard model of education upon this wide diversity of contexts seems erroneous. On a similar note, Garcia-Huidobro (2017) examined literature about Catholic school curricula 
published in the U.S. and the U.K. since 1993, and outlined four models that Catholic schools use to approach curriculum (pp. 69-70). With regard to my problem of practice, schools employing Garcia-Huidobro's identity-focused model would be most accepting of catechetical education, whereas the dialogical, open, and secular models would, I suspect, exemplify an openness to other modes of theological education. While GarciaHuidobro posited pure forms of these four identities, a certain hybridity is to be expected given the varying epistemological positionalities of teachers and administrators.

In a study that examined the motivations of Catholic school educators, Cho (2012) concluded that "religious reasons as a whole were continually more influential than professional, environmental, or economic reasons" for 751 Catholic teachers who choose continued employment in Catholic schools (p. 132). Cho's findings demonstrated the importance of religious belief in teachers' motivations, although these beliefs might impact Catholic school communities negatively, as evidenced by Evangelinou-Yiannakis' (2016) small qualitative study of a new and relatively conservative Catholic school in rural Australia. Based on ethnographic field research, this study (Evangelinou-Yiannakis, 2016) found that various non-Catholic families and community stakeholders did not always react favorably toward the school's rigidity of doctrine and liturgical practices. On a similar note, McDonough (2016) took a more explicitly theological approach toward studying how teachers' expressions of Catholic identity affected the spiritual formation of students by interviewing 16 students at a Canadian Catholic high school. McDonough discovered that a rigid and doctrinaire understanding of Catholicism often clashed with students' spiritualities. 
A few studies directly homed in on the presence of non-Catholic students in Catholic schools. In one of the earliest such studies, Francis (1986) studied the responses of 2,895 students in British Catholic secondary schools, and analyzed their attitudes toward Christianity. Francis discovered that non-Catholic students within British Catholic schools expressed disfavor toward their schools' Catholic ethos and identity, which "might well have been a function of the incompatibility between their own religious background and the doctrinal, liturgical and catechetical assumptions of the schools" (Francis, 1986, p. 125). Francis concluded that Catholic church attendance was the single most influential predictor of students' favor (or disfavor) toward Catholicism (p. 124). Thirty years later, Village and Francis (2016) examined data from the Teenage Religion and Values Study, which investigated 33,982 9th and 10th grade students' responses in British and Welsh schools in the 1990s, and concluded that "being non-religious in a Catholic school seems to be associated with lower self-esteem, greater endorsing of agerelated illegal behaviors and a more negative attitude toward school than among nonreligious students in schools without a religious foundation," which meant that "Catholic schools may need to work particularly hard with this group of students to avoid possible detrimental effects on their socialization within the school community and beyond" (Village \& Francis, 2016, p. 107). Compared to their Catholic peers, non-Catholic students attending Catholic schools often rebel against the behavioral, disciplinary, and religious strictures imposed upon them. I find the discovery of lower self-esteem and negative attitudes toward school among non-Catholic students to be of particular note given that I studied how theology teachers in Catholic schools engage non-Catholic 
students, although Village and Francis did not indicate to what degree religious education contributed to their perceptions. After all, other causal relationships might be at play in the dynamics that Village and Francis researched: perhaps students who have been subjected to potentially unjust disciplinary mechanisms are sent to Catholic schools by parents in restless search of disciplinary solutions.

In one particularly fascinating study, Gleeson, O'Gorman, Goldburg, and O'Neill (2018) compared 3,389 survey responses from educators in U.S. Catholic schools with 2,278 responses from Australian Catholic school educators in Queensland. Australian Catholic schools receive state funding, and non-Catholic, middle-class families are increasingly choosing Catholic schools for their families, though Australian survey responses were far more favorable than were their U.S. counterparts toward the presence of non-Catholic students in their schools. Moreover, while $90 \%$ of U.S. administrators and $92 \%$ of U.S. religion teachers believed that religious education ought to present Catholic teachings to be "essential," only $45 \%$ of Queensland administrators and $48 \%$ of Queensland religion teachers responded similarly (Gleeson et al, 2018, pp. 91-92). I wonder what "essential" meant to these educators: was the "essential" nature of religious education predicated upon a sense of it being catechetical? It is clear that U.S. Catholic educators approach religious education quite differently than do their Australian counterparts, who may very well possess a greater sensitivity to the religious diversity of their students, but we do not know anything about these differences impacting students in the two countries. 
These studies demonstrated that Catholic school administrators and teachers approach non-Catholic students with varying levels of acceptance and inclusivity. Individuals determine how a Catholic school's mission to evangelize is lived out, which has repercussions that reverberate through academic and hidden curricula, or the norms and values into which students are socialized outside of formal classes (Giroux \& Penna, 1979). These manifestations of Catholic identity can either positively or negatively impact a student's experience.

Religious Education in Catholic Schools. In 2003, Cook and Hudson examined the results of The Next Generation: A Study of Catholic High School Religion Teachers from 2000-2001, in which these researchers collected survey data from 959 U.S. Catholic high school religion teachers. Although this study is approaching 20 years old, U.S. Catholic schools had reached significant religious diversification in their student populations at the time, and it seems that the opinions of religious educators across the nation were acknowledging this demographic shift. In responses to a binary choice question, Cook and Hudson (2003) found that " $45 \%$ [of teachers] selected religious instruction as their primary role and 55\% chose catechesis" (p. 9). This finding implies, I believe, that just a few years before the Framework's publication, many theology and religion teachers understood their roles as involving more than catechesis, although it is unknown how teachers would respond now.

Looking to English and Welsh Catholic and Anglican schools, Francis and Robbins (2011) analyzed 149 survey responses from religious educators, which solicited their opinions on the purposes of religious education. Their study found that religious 
educators in these schools were "not concerned, through RE, with promoting religious and spiritual nurture," but with "enabling pupils to reflect on ultimate questions, to think critically about religion, and to understand the influence of religion in society, rather than shaping the religious and spiritual commitment of their pupils" (Francis \& Robbins, 2011, p. 231). In other words, religious educators of faith-based schools belonging to the two main Christian denominations of the United Kingdom were not concerned with catechesis, or even faith formation, and were primarily focused on helping students to critically engage religion and theology. In contrast, Go (2018) analyzed 1068 survey responses from teachers in 14 Catholic primary and secondary schools in the Philippines, and examined the lack of critical pedagogy in those institutions. Those educators in the study who held an absolutist epistemology—which is "the prevailing religious epistemology among Catholic religious educators"(p. 196) in the Philippines-were unwilling to dialogue with the worldviews and perspectives of other faith traditions. Such educators were inclined to support a religion curriculum that is, much like the USCCB Framework, catechetical in its intent. These studies definitively spoke of the diverging ways that Catholicism is understood, lived out, and taught by teachers of various positionalities and epistemological stances, which is partially what I investigated in my own research. My study explored the beliefs and practices of teachers, specifically with regard to religiously diverse student populations, which has largely been ignored by extant literature.

Buchanan's 2009 study of religious educators in Australia examined participants' attitudes and beliefs concerning a change in religious education curriculum addressing 
content similar to that of the USCCB Framework. In 2001, George Cardinal Pell implemented a top-down curriculum change for Catholic schools in the Archdiocese of Melbourne. According to Buchanan (2009), some religious education coordinators found that the new textbooks "over-emphasised religious doctrine," and were consequently worried that teachers "would be required to teach only Church doctrine" (p. 148). This sentiment resonates with my own perception that many U.S. theology and religion teachers in those schools with substantial non-Catholic student populations, a decade into the Framework's implementation, are attempting to merge (or even eschew) its doctrinal and catechetical emphases with other modes of religious education that anteceded the Framework. McDonough (2009) conducted interviews with religion teachers from publicly-funded Canadian Catholic high schools, to explore how they navigated tensions over controversial issues, and how they articulated pedagogical shortcomings in approaching these controversial topics. In aiming to implement student-centered pedagogy, the fourteen religion teachers felt compelled to incorporate student voices of dissent toward Catholic doctrinal teachings, though they could not escape the imposed "doctrinal similarity" of magisterial authority, which opposed the "pluralistic confederation of diverse points of view" that the teachers identified as "the primary aim in these schools" (McDonough, 2009, p. 198). In other words, McDonough's research spoke to the strain that religion teachers felt between doctrinal authority and student voice, which I think accords with the contrast between Freire's conceptions of banking education and emancipatory education. The active involvement of student voice and belief, moreover, is a fundamental aspect of CRSP. 
In a large study, Rymarz and Cleary (2018) explored the emerging worldviews of over 13,000 Catholic school students in Australia via a 47 question survey with Likerttype scale questions. The survey respondents found themselves confused by many different competing religious and secular worldviews, and identified their interest in dialoguing about positions and insights other than their own. Smith and Denton's (2009) and Freathy, Doney, Freathy, Walshe, and Teece's (2017) studies had confirmed the willingness of contemporary teenagers to engage in conversation and dialogue about various religious traditions for the purposes of constructing their own religious imaginations. Rymarz and Cleary's (2018) study implied that religious education needs to be relevant and approachable if students, regardless of their religious or cultural background, will be interested in engaging it, just I posit through CRSP.

In her eminently relevant dissertation, Schroeder (2013) conducted a qualitative study of six high school theology and religion teachers in order to examine how they taught in light of the USCCB Framework. Prompted by the fact that only a single dissertation existed (Ostasiewski, 2010) at the time, which had levied a theoretical critique of the Framework (in Ostasiewski's words, the bishops "are not inviting, serving, or engaging the students. They are telling them so that their joy may be deposited in the students" [p. 150]), and that no empirical studies existed about the Framework, Schroeder investigated the struggles and challenges of teachers working with the Framework. Although Schroeder did not focus on the education of non-Catholic students, this topic arose several times throughout her research, especially with regard to the Framework's 
relevance for those students. The participants' expression of their pedagogical challenges is worth citing in full, and involved:

managing the Framework's repetitive material, engaging students both cognitively and affectively, creating time for personal sharing and in-depth discussions, relating the Framework's content to students' everyday lives, cultivating students' intellectual curiosity despite the Framework's cut-and-dried style, nuancing the confrontational language of the Framework and of Framework -based textbooks, allocating time to pursue tangential topics that students find to be important or meaningful, and utilizing student-centered rather than teachercentered methodologies. (p. 318)

Overwhelmed by the sheer quantity of doctrinal points to be taught, many of which were relatively advanced theological concepts, Schroeder's participants were already beginning to diverge from the Framework's strictures, even four or five years after its publication. Although the study's participants often taught substantially non-Catholic populations, Schroeder did not discuss exactly how the teachers adjusted instruction to serve the needs of non-Catholic students. In another dissertation study that foregrounded the views and practices of teachers, McGah (2013) studied teachers' self-reported best practices in Washington state Catholic high schools, and her participants reported (through a survey that included open-ended questions) that they emphasized "discussion," "application to real-world situations," "application to student's own life," "questioning by teacher," "cooperative or collaborative learning," and "identifying similarities and differences" in their practice (p. 85). Although McGah briefly referenced the USCCB Framework as being "new," and stated that "research on the best lessons and instruction for high school religion can now be aligned to the framework" (p. 112), she did not examine teachers' practices in light of the Framework. 
In his 2016 dissertation, Martin undertook a case study in order to understand how religious education and faith formation programs influenced students' "cognitive, affective, and behavioral dimensions of a lived Christian faith" (p. 3) at a particular U.S. Catholic high school. In his study, only 37\% of Martin's participants identified as Catholic, while the rest were nonreligious (20\%), non-Christian (5\%) and non-Catholic Christian (38\%) (p. 108). Even though all of Martin's 118 participants (especially the non-religious and atheist students) reported the influence of theology classes on their cognitive knowledge of Christianity, they all reported that theology classes had weak influence upon the affective and behavioral dimensions of a "lived Christian faith" (p. 187); even for a majority Christian audience of students who supposedly sought deeper faith, theological coursework did not accomplish a deepening of faith. Other aspects of school, such as service work and retreats, had far greater effect on students' religious beliefs and identities in the affective and behavioral realms, per students' self-reports. Given that these students' courses followed the USCCB Framework, these findings effectively demonstrated the USCCB bishops' misunderstanding that a Christocentric and apologetic curriculum could effectively bring students into relationship with Jesus. In a similar study, Stockdale's (2019) dissertation examined the faith formation of students at an all-boys Jesuit high school in the Northeast, and $29.48 \%$ and $34.7 \%$ of his participants reported that theology class was "very important" and "important" to their spiritual and religious growth (p. 131). Stockdale, in contrast to Martin, was not quite so specific in his survey data collection, and did not define what religious and spiritual growth meant, 
whereas Martin was more meticulous in his partitioning of this growth into cognitive, behavioral, and affective realms.

In a final empirical dissertation, Radice (2016) was much more sympathetic to the USCCB Framework than either Ostasiewski (2010) or Schroeder (2013) were, and did a multiple case study in order to understand the instructional methods that religion teachers used to implement the Framework. Radice concluded that her seven participants "were steadfast in their Christocentric emphasis of the Framework" because many "seemed to rely solely on their textbooks to deliver the doctrinal elements identified in the Framework" (pp. 248-249). All this said, Radice only tangentially mentioned the presence of non-Catholic students in one of her participants' classrooms, and that particular teacher expressed general concern about the growing presence of non-Catholic students. While Radice's case study demonstrated that the USCCB Framework is not so much a hard-and-fast curriculum as it is a framework that can be taught in a variety of ways, absent from her conclusions was a critique of the Framework's applicability to a diversity of Catholic high schools. My own interest is not in those Catholic schools wherein a catechetical and apologetic model of religious education would be arguably appropriate, but in those schools where such a model is patently inappropriate, and even potentially harmful for non-Catholic students.

Given the Framework's newness, little extant scholarship has empirically explored how teachers have approached and taught it, nor has research addressed students' perceptions and experiences of the Framework. Truth be told, theologianeducators and theologian-scholars tend toward the theoretical, and shy away from the 
empirical; hence, while much literature explores the theory of Catholic religious education, little scholarship takes an empirical approach. The dissertations discussed above have especially piqued my attention, although Schroeder, McGah, Martin, and Hortsch stopped short of the territory I ventured into. I believe that my research concerning the theological education of non-Catholic students in light of the USCCB Framework pushes the edges of their research forward into currently uncharted territory by exploring specifically the pedagogical decisions of theology teachers who simultaneously educate non-Catholic and Catholic students.

\section{Emancipatory and Critical Pedagogies}

This section of the literature review covers the breadth of emancipatory and critical pedagogies, both within and without the contexts of Catholic schools and religious education. I will focus on empirical research grounded in CRP, CRT, CSP, and CRE as these pedagogical frames have contributed to my conceptual framework of CRSP. Qualitative studies, of the ethnographic and case study varieties, unsurprisingly dominate the literature. In my discussion of this scholarship, I hope to accentuate the ways in which these studies' themes and conclusions bear on my own research in the theological and religious education that occurs in religiously diverse Catholic schools.

Critical Pedagogies and Religious Education. Jeynes (1999; 2002a; 2002b; 2003a; 2003b; 2003c; 2004; 2005; 2009; 2010a; 2010b) has conducted large-scale metaanalyses and studies examining the so-called "achievement gap" and how faith-based schools and student religiosity affect low-income students and students of Color. His studies demonstrated that not only did religious schools help to reduce the achievement 
gap, but that more than any other factor, religiosity among students of Color is positively correlated to their academic achievement, and Jeynes postulated that this is perhaps because belief in God provides a certain moral imperative to strive for academic success. This finding held true even for those students who did not ascribe to the particular religious tradition of their schools. Jeynes (2010a) concluded that to "overlook faith as a potential vehicle to reduce the achievement gap might be imprudent” (p. 264), which raises possible implications for my own research interests. While correlation between religiosity and academic achievement does not necessarily imply a causative relationship, it might very well be that when students' religious beliefs are sustained and nurtured (rather than overridden and/or negated), along the lines of CRSP, they perform better in school. Jeynes' meta-analyses focused on students of Color rather than on all nonreligious students, but the implications thereof are nonetheless intriguing for my inquiry, especially given that many students of Color in Catholic schools are not Catholic. A study from Frabutt, Holter, and Nuzzi (2013) echoed Jeynes' findings; through examination of articles and documents about PK-12 Catholic education from 2005-2010, the most "intriguing" (in the authors' perspective) research highlighted that "Catholic schools have tended to have disproportionate [academic, and causal, supported by the research designs] effects on students with multiple disadvantages who live and attend school in what might be called the urban core" (p. 89). This analysis of extant scholarship did not mention the presence of non-Catholics, though given demographic shifts of Catholic schools in certain areas of the United States, the "Catholic school advantage" (that is, the positive benefits of Catholic schools for students typically associated with the 
so-called "achievement gap") frequently pertains to students from non-Catholic backgrounds. Unfortunately, certain scholars frame particular student demographics within deficit terminology (e.g. "multiple disadvantages" in the prior citation).

In his ethnographic and interview research, Rackley (2016) found that religiously devout Methodist and Latter-Day Saint students were motivated to engage their religious texts for several key reasons: first, students' engagement with the texts deepened their understanding and knowledge of their beliefs; second, they learned how to apply this religious knowledge to their lives; and third, these texts gave them strength and comfort, and enabled them to develop a connection to God. By highlighting the potential of religious texts to motivate religious youth, these insights resonate with Jeynes's (1999; 2002a; 2002b; 2003a; 2003b; 2003c; 2004; 2005; 2009; 2010a; 2010b) research, providing a possible means of understanding how students' religiocultural capital might be used to leverage their academic success. Reddie (2010) conducted a qualitative study of a model of religious education for Black Christian students in Britain, and the model is a particular example of CRP in religious education. Reddie developed a curriculum based on Freire and liberation theology specifically for Black, African Caribbean children, in order to "promote increased levels of self-esteem and self-identity, in order to dispel the ravages of self-negation" (Reddie, 2010, p. 225). This study demonstrated the potential to draw from students' funds of knowledge on cultural and religious levels. All of this research synchronizes with the tenets of my conceptual framework as well, given that CRSP foregrounds students' beliefs. 
While there are few empirical studies of Critical Religious Education, given its newness, Ucan and Wright (2019) examined Islamic religious education (IRE) in two British seventh grade IRE classrooms through a CRE lens, and articulated the need for teachers and designers of RE to actively incorporate the religiocultural capital of religious students. Apparently, the standardized textbooks and curricula for IRE included in this research neither accurately reflected the diversity of Islamic traditions, nor fostered interreligious understanding. Most recently, Kimanen (2019) conducted field research in Finnish Lutheran and Islamic RE classrooms, where he learned that teachers attempted to foster classroom environments that were open to critical and reflective dialogue. Teachers were sensitive to avoid imposing their own beliefs on students, as they did not discuss their own religious commitments, and "did not force anybody to reveal theirs, although some assignments seemed to assume some degree of commitment" (Kimanen, 2019, p. 154). CRE thus enabled teachers to approach religious education through means that expressly avoid indoctrination, and the potential harms that it entails.

Critical Pedagogies in Catholic Schools. A number of studies over the course of the past decade have examined Catholic school culture and Catholic religious education through a critical lens; some of these studies pertained more toward multicultural education and its various strands, while others (though few in number) have discussed the presence and education of non-Catholic students. In this section, I will explore scholarship that pertains to emancipatory and critical pedagogies, specifically in the realms of Catholic school culture and religious education within Catholic schools. 
In one of the very first empirical studies about "minority" students in Catholic schools, originally published in 1982, Greeley's (1982/2002) work is often cited as foundational by those scholars studying multicultural Catholic education. Greeley's language is certainly dated, especially surrounding his reliance upon deficit terminology, but he employed a multilayered model that analyzed family characteristics, student characteristics, and school characteristics. Greeley’s sample consisted of 7,000 Catholic school students, 2,000 of whom belonged to "minority" ethnic and racial groups, and his comprehensive data analysis, based on data collected by the National Opinion Research Center, found statistical significance in the positive impact on academic achievement that Catholic schools have. Greeley's scholarship has been among the strongest in asserting that there is a distinct and so-called "Catholic school advantage," that is, the positive effects that Catholic schools have for certain students over and above public educational systems. Greeley specifically argued that this advantage is not due to Catholic schools' families being more affluent or more educated, but rather to the superior discipline and academic rigor offered by Catholic institutions (pp. 53-54). Although Greeley did not focus on the religious beliefs of students, he did mention that half of all African American Catholic school students were not Catholic (p. 50). Bryk, Lee, and Holland (1993) framed their study of the Catholic school advantage in light of Dewey's aims to foster democratic education geared toward the common good. In their text Catholic Schools and the Common Good, Bryk, Lee, and Holland worked with large data sets, and their analyses concluded that Catholic schools do have a positive impact on students, even when controlling for factors such as socioeconomic status; this work has also been a 
primary resource used to posit the benefits of Catholic education over and above public education.

Through mixed methods survey and interview data, Louie and Holdaway (2009) studied the perspectives of contemporary New York City immigrant students and their families toward Catholic schools. The researchers found that although the religious identity of Catholic schools remained important for Latinx and Catholic immigrant students, "the quality of education and the discipline offered by Catholic schools were seen as their main advantage[s]" (p. 794) for more recent immigrants. Non-Catholic immigrants viewed the New York City public school system as broken and deficient, and sent their children to Catholic schools for the sake of high quality education. In their survey of stories about race and schooling in southside Chicago Catholic schools, Burke and Gilbert (2015) examined the discourse surrounding the maintenance of racial boundaries. They found that many schools employ "the inertia of de facto geographical segregation to maintain schools," and are "intent on hiding racial preference behind religious justifications, explicit or implicit" (p. 539); in other words, Catholic schools in urban areas frequently serve either majority White student populations, or students of Color, and rationalize away such segregation through religious discourse. Burke and Gilbert's observations regarding the Catholic schools' shifting demographics resonated with the findings of Louie and Holdaway (2009), though they took a more critical approach to the racializing of Catholic schools in geographic areas with large immigrant populations and families of Color. 
Some studies have homed in on Catholic education's promotion of interreligious dialogue for the service of the public good in international contexts. Breen's (2009) ethnographic case study concerned Our Savior's, a British Catholic school, which was surrounded by a South Asian community representing people of Muslim, Hindu, and Sikh beliefs. $70 \%$ of this primary school's students were Catholic, and religious education encouraged students to understand members of their immediate community (p. 108), and students engaged in various curricular and extracurricular activities with surrounding schools as a means of "responsive" education (p. 111) and as a means of living out its Catholic identity. Having conducted ethnographic research in one Islamic and two Catholic schools, Parker (2014) studied the role of religious education for peaceful coexistence between religious adherents in Indonesia, which successfully combated religious intolerance, religious fundamentalism, and social conservatism. Parker (2014) observed the danger of the marginalization of religious minorities within a school: "students feel 'different' and they can be marginalized and neglected" (p. 495). In his ethnographic study, Parker learned that one Catholic school did not teach Christianity, but rather interreligious dialogue, and the other has never, over the course of decades, had a Muslim student become Christian or a Christian student become Muslim (Parker, 2014, p. 495). It is therefore clear that in certain religiously diverse societies, the religious identity of a school need not result in religious proselytization to and conversion of students.

One of few studies about multicultural religious education in U.S. Catholic schools was conducted by Kremer (2003), who studied how three religion/theology 
teachers approached multicultural education in their classrooms through liberation theology. She found one religious sister who aimed to center student voice and questioning within her classroom, and another teacher who took an especially Freirean approach to religious education that incorporated students' cultural identities and critiques of systematic injustices. Kremer's participants were thereby embodying aspects of my conceptual framework. In a second study that examined the role of religious education for low-income non-Catholic students and students of Color in Cristo Rey Network schools (that serve low-income students who are predominantly of Color), Aldana (2015) discovered in her interviews that students "generally did not see the value in their religion class," and those students who identified as nonreligious, "particularly the African American students who identified as Non-Catholic, suggested that religion classes be replaced by other courses" (p. 212). A theology teacher solely concerned with catechetical education cannot posit theology as valuable for non-Catholics. Because these teachers failed to draw from these resources, their students reported that religion classes were irrelevant to their lives and experiences. Approached through the lens of the CRSP conceptual framework, Aldana's research in Cristo Rey Network schools sheds light on the failures of some teachers to employ critical pedagogy in their work.

Stenberg (2006), a college English professor, examined her own practices of incorporating liberation theology and Freire's theories in her teaching. Stenberg reflected, "the student whose faith-based knowledge is critiqued or dismissed may experience this as a personal affront - or, as Stephen Barrett puts it, as a "trauma"' and noted that "students whose values and knowledge are dismissed by critical approaches may do one 
of two things: reject them entirely and resist the pedagogy or, if they want to be accepted within a new discourse community, keep that identity closeted" (Stenberg, 2006, p. 279). Educators would therefore do well not to reject the knowledges and values that students hold. Given her experience, Stenberg opined that in order to enrich the student-teacher relationship, amplify critical thought through "both compassion and action," and participate in "ongoing reflection and revision," (Stenberg, 2006, pp. 288-289) the espousal of liberation theology's core principles could be of great benefit. Given that liberation theology is rooted in the political, economic, and spiritual liberation of oppressed peoples, the values of liberation theology and Freirean pedagogy thus overlap, providing theoretical resources for the enactment of CRSP intent upon reflective praxis.

Dallavis $(2013,2014)$ has done studies of Catholic schools through the lenses of critical theories of education. His 2013 study, which entailed 50 interviews and 300 hours of ethnographic observations, explored faith-based schools and their ability to educate toward the raising of sociopolitical consciousness along the lines of CRP; he concluded that Catholic Social Teaching's (CST) stance on controversial topics such as abortion prevented teachers from promoting unrestricted sociopolitical consciousness proposed by CRP. Dallavis's 2014 study on culturally responsive caring in an urban Chicago Catholic school found that teachers' religious beliefs drove their engagement with CRP, and that the school's religious mission provided teachers with a value-laden lens through which they could approach caring relationships.

Bradley-Levine and Carr (2015) used the framework of Catholic Social Teaching ("CST") to guide their ethnographic study of an after-school program in a Catholic 
school, and found that the ethical and moral motivations provided by CST resulted in a dynamic emphasis on caring relationships and nurturing connections. CST, in short, with its emphases on loving relationships and the preferential option for the poor, provided Catholic schools with a firm foundation upon which they could base their efforts. In a study with similar themes, Buck (2016) examined a peace studies program in an urban Latinx Catholic school, and interviewed and observed instructors who came from the same communities as the students and worked for an outside organization. These peace education teachers leveraged their cultural competence, drew from students' funds of knowledge, and "aimed to engender a sense of agency in students in order to promote activism," inviting students "to think of themselves as change agents in the world" (p. 48). Buck's study thus highlighted the potential that educators have to leverage students' funds of knowledge and cultural competencies, and thus, I believe, echo CRSP to promote the Freirean emancipatory goals of conscientization and praxis.

In a final, and particularly fascinating study of critical pedagogy in Catholic schools, Maney, King, and Kiely (2018) surveyed instructional staff, parents, and students in seven Midwestern Catholic schools; most students in three of these schools were African American and non-Catholic. The research centered around the question of why white teachers were failing socioeconomically, racially, and religiously diverse student populations (with regard to fostering relationships and maintaining high academic expectations), and the authors discovered that academic excellence and faith formation were the primary motivators for African American and Latinx families who sent their children to Catholic schools. Even though Catholic schools pride themselves on the 
quality of community, and the role of fostering caring relationships between teachers and students, this study revealed a large disconnect between white teachers and students of Color. Maney, King, and Kiely noted that some teachers reported not knowing their students' religious affiliations, while others perceived a complete disconnect between students' behaviors and "gospel" values (p. 55). If educators in these schools were unaware or uninformed of students' cultures, and intertwined funds of knowledge, how could they possibly serve them effectively and appropriately? More so, the evident cultural clashes between educators and students highlight the pressing need for critical pedagogies in Catholic education. I believe that CRSP could very well help to remedy these problematic and harmful realities as a framework for theological education.

Scholarship surrounding the presence of non-Catholics in Catholic schools is truly rare, and only Donlevy's (2003; 2007a; 2007b; 2009a; 2009b) research has specifically focused on this issue. In his interviews with administrators, Donlevy found the unanimous "expectation $[\ldots]$ that non-Catholic students would overtly display respect for the schools' religious traditions, religious curriculum, and liturgies" (2009b, p. 591). Some administrators "did not see the need for any special programs within their schools for non-Catholic students," and one administrator went so far as to declare: "I don't see changing my school or my programs to meet the needs of other religions [ . . ] This is a Catholic school and we service the needs of Catholic students" (2009b, p. 597). This finding accords with Garcia-Huidobro's (2017) research, which posited various models of Catholic schools, some of which did not open themselves to dialogue with nonCatholic religions and cultures. 
In his 2007 study, Donlevy interviewed 22 high school religion teachers, and learned that teachers in the study were not entirely sure of their role in welcoming nonCatholic students. Overall, teachers "welcomed, appreciated, empathized [with], and sought to protect non-Catholic students and held inclusion as an exemplar to the wider society" (2007a, p. 22), a finding that paints a different picture than that of his study involving administrators. While he did not get into the specifics of these teachers' classroom instruction, Donlevy found that religion teachers in these Canadian Catholic high schools all sought to welcome non-Catholic students, because their questions and worldviews prompted the teachers to reflect on their own teaching and how they fostered a spirit of inclusivity in their contexts. Donlevy did not offer his full methodology or interview protocols, so it is difficult for me to ascertain to what degree participant responses could have been biased. And with regard to the impact of theology teachers on non-Catholic students, Donlevy discovered that even those students who resented Catholic education appreciated and admired some of their theology teachers, which indicated that "orthopraxis rather than orthodoxy may be the key to the spiritual nature of the pedagogical relationship" (Donlevy, 2009a, p. 64). In other words, the degree to which a non-Catholic student feels welcomed and included in the high school classroom depends on the degree to which a teacher actively attempts to welcome them, rather than on the degree to which the teacher conveys orthodox doctrine. Donlevy's research demonstrated that even though the administrative hierarchy might not be particularly interested in serving non-Catholic students with regard to their cultures and beliefs, teachers in the field approach the matter quite differently, though ambiguities and gray 
areas arise. CRSP could certainly be of service to such teachers, who are already attempting to proactively include non-Catholic students, and might illuminate their pedagogical decisions.

In large part, Catholic schools emerged in U.S. culture as a response to an educational system dominated by Protestantism, and sought to sustain and preserve the culture of Catholic immigrants, even providing instruction in students' native tongues. In light of this history, I find it rather curious, although not terribly surprising, to consider the early history of U.S. Catholic education as being more or less in line with the major tenets of CRP, CRT, and CSP. The above literature highlights the strengths of those Catholic schools as providing fertile ground for those tenets to continue to flourish: in centering evangelization at the heart of their mission, Catholic schools attempt to foster loving and caring relationships for all those present within their walls. Moreover, scholarship has also indicated the failures of certain Catholic schools to provide culturally sustaining, welcoming, and inclusive environments for all students. This said, shifting demographics of students within their walls present challenges, and Catholic education's pursuit of loving inclusivity, I believe, has not yet extended to the realms of religious and theological education. Given that the USCCB Framework is only a decade old, little research exists on its implementation.

Critical Pedagogies: CRP, CRT, CSP, and CRE. In this section of the literature review, I will examine empirical studies concerning the practice of the critical pedagogies that have informed my theoretical framework. I have selected to review studies that bear some sort of relevance to my problem of practice and intended research. 
Regarding the problematic disconnect between students' and teachers' cultures, Villegas, Strom, and Lucas (2012) found that although 31 states had implemented policy initiatives to promote ethnic and cultural diversity among teachers, minority teachers were still "even more underrepresented in 2007 than they had been two decades earlier" (p. 296). As will be discussed, many European countries often employ religious educators to teach students of their own religious tradition, although U.S. Catholic high schools exclusively employ Catholics to teach theology and religion. Given that students benefit from sharing a classroom with teachers who represent their own cultural and/or racial backgrounds, non-Catholic students attending Catholic high schools cannot partake of this benefit in their theology classes; there is a consequent need for Catholic theology teachers to be religiously relevant and responsive in their work.

Several studies have examined the relationship between CRP, CRT, and CSP and professional development. Griner and Stewart (2012) created a checklist of best practices in CRP (though creating checklists is a tenuous approach in and of itself). Based on interview data with an urban youth center's students, families, and teachers, Griner and Stewart found that participants indicated their desire for "outreach from the school to students' parents and communities" (p. 596), representation of culture in curriculum, and improved classroom management. Colbert (2010) also studied the process of developing a culturally responsive culture amongst university faculty, and outlined various culturally responsive strategies that colleagues could use for internationally diverse students. Maasum, Maarof, and Ali (2013) studied a training workshop in Malaysia, which addressed self-awareness, awareness of Asian cultures represented in Malaysia, and 
instructional strategies and resources. Regarding professional development about best practices in multicultural education, the 128 teacher participants reported that the workshop on multicultural competence was successful on several fronts, which demonstrated the potential of professional development to enhance the practices of CRT in culturally diverse classrooms. Young (2010) found that newer teachers felt overwhelmed by the potentially contrary needs of covering material and practicing CRP. Given that CRP is a constructivist pedagogy, it stands in opposition to standardized curriculum. Although the bishops identified their Framework as just a framework, it does very much resemble a standardized curriculum (such as the Common Core Standards) with its dozens of doctrinal points that students in Catholic schools are to learn by graduation.

In a study directly pertinent to my problem of practice, Marks, Binkley, and Daly (2014) studied the degree to which elementary and secondary social studies teachers in preservice programs applied religious literacy and knowledge about the First Amendment to culturally responsive practices. Marks, Binkley, and Daly concluded that failure to educate preservice teachers about religion, the First Amendment, and the application of such knowledge to their future classrooms would compromise their ability to promote democratic living because such failure "makes space for ignorance, encourages and reifies stereotypes, and may lead to problematic responses and behaviors based on misunderstanding" (2014, p. 254). This conclusion concurs with the goals of mandated religious education in certain European countries, which approach religious education as means of educating students for the purposes of functional democracy. 
Further studies have explored particular classrooms and particular contexts in which critical pedagogies are practiced. Milner's (2010a) case study of a white science teacher in a racially and culturally diverse urban classroom sought to understand how this instructor built cultural congruence, and discovered that much of this teacher's success predicated itself upon building relationships as he continued to deepen his selfunderstanding and knowledge of his students. In light of this study's conclusions, I question to what degree the USCCB Framework demonstrates curricular and cultural congruence, especially given that it so explicitly (and implicitly) dismissed and demeaned non-Catholic religious traditions. Based upon their examination of an altercation between a Latinx and a Muslim student, Hansen-Thomas and Chennapragada (2018) concluded that culturally responsive educators need to foster socialization between culturally diverse students, in order to generate harmonious environments in superdiverse contexts, given that they remain especially prone to cultural misunderstandings. Such socialization could also be promoted in a religiously diverse theology classroom.

Other researchers have examined specific pedagogical tools and strategies for the purposes of culturally relevant, responsive, and sustaining education, such as cultural asset mapping (Borrero \& Sanchez, 2017), writing and sharing autoethnographies (Camangian, 2010), and employment of ideological literacy (Camangian, 2010). These strategies could very well be adopted for the purposes of theological education, because they promote students as agents of their own learning, invite students' worldviews into the classroom, and foreground students' interactions with and beliefs about the worlds they inhabit. Shahjahan (2005) and Shahjahan, Wagner, and Wane (2009) have 
researched the presence of dominant discourses surrounding non-Western and nonCanadian spiritualities within the academy of higher education, arguing for greater inclusion of dialogue surrounding indigenous spirituality. This Western hegemonic control of discourses surrounding spirituality, in turn, speaks to the need for hegemonic religious and spiritual forces to terminate their collective silencing of non-Christian and/or non-Western religious imaginations.

In a study that is more pertinent to my problem of practice, Lewthwaite et al. (2015) studied the education of Aboriginal students in Catholic schools within the diocese of Townsville in Queensland, Australia. The research team noted a complete lack of empirical literature about best practices in Indigenous education, and informed their project through a CRP framework and Participatory Action Research, conducting individual and group interviews with Aboriginal students and their caregivers. Lewthwaite et al. concluded that students and families perceived deficit views and pathologizing of Aboriginal culture, and possessed "astute awareness" (p. 153) of how teachers maintain control over abling or disabling learning. Although this study did not mention non-Catholics, nor did it discuss the religious beliefs of these families, a discussion of best practices that the researchers developed could certainly provide fruit regarding the areas of religious culture and student belief.

Empirical research in Culturally Sustaining Pedagogy is far more recent given the framework's relative newness, and several studies have pushed the boundaries of CRP forward in light of Paris and Alim's (2017) loving critique of the prior framework. Puzio et al. (2017) analyzed narratives of five teachers of various experience who reported 
failures in practicing CSP, and concluded that because teaching is "institutional and hierarchical $[\ldots]$ educators may find themselves teaching against their personal beliefs in conformity with local policies and authority figures" (p. 230). This conclusion certainly accords with Schroeder's (2013) and Buchanan's (2006) research in Catholic education, which spoke similarly to teachers' confusion surrounding the reform of theological curricula. Jaffe-Walter and Lee (2018) directed their research toward recent immigrants in New York City schools in order to investigate how CSP is leveraged for students new to the United States. Teachers in two high schools that served low-income, newly arrived immigrant students often invited students to study issues in their homelands, and to write and speak about them in a variety of subjects; this dependence on students' funds of knowledge sustained students' cultures and identities, while helping them to feel a sense of belonging in their new homes. In a study with similar themes, Kidwell and Herrera (2019) drew on educational vignettes about an Ixil Guatemalan student in the United States and about an English teacher in a predominantly Indonesian school, and highlighted three best practices for teachers enacting CSP: learn about students, integrate students' cultures into their school experience, and undertake self-examination. Scanlan et al. (2016) studied CSP at a national network of Catholic schools that served culturally and linguistically diverse (CLD) students and employed Communities of Practice. Their findings suggested that intentional collaboration between scholars, educators, and families can help respond to the needs of CLD students.

Regarding the potential of CSP to better serve religious minorities, Machado Vaughan, Coppola, and Woodard (2017) did a case study of a high school English 
teacher who employed CSP as he taught a poetry unit. In this research, a Jewish student who was "keenly aware of his status as a religious minority," (p. 371) used poetry in order to explore his ethnic and religious identity, and developed his talent for using Hebrew and Yiddish alongside English in his poetry:

\section{Every week I practice \\ Practice Torah \\ Haftarah \\ Davening \\ It's a lot of work. \\ But}

This is important to me

Just as much as getting good grades.

Although this study had nothing to do with religion or theology as academic disciplines, Machado, Vaughan, Coppola, and Woodard's research brings to the fore the potential for a member of a religious minority to position themself as a cultural insider, developing expertise in identity through articulating their funds of knowledge in unexpected ways. Other students also expressed cultural hybridity and fluidity through their poetic writing, and appreciation of such cultural fluidity and hybridity is a particular feature of CSP's theory.

Esteban-Guitart et al. (2019) explored the implementation of CSP in two Catalonian classrooms through Participatory Action Research, specifically focusing on the concept of funds of identity, which emphasized "students' lived experiences, identities and meaningful activities" (p. 3) and artifacts of those identities. The researchers concluded that "inclusive educational practice must be aligned with pedagogies of cultural sustainability, legitimizing in the school the sources of meaning and diverse cultural expressions, as well as linking them to the curriculum and 
pedagogical objectives" (p. 10), an insight which can be applied to religious diversity in high school theology classrooms. If such spaces are to aim for inclusivity rather than exclusivity, CSP provides a valuable framework through which the USCCB Framework can be interrogated and critiqued.

Although they did not concern theological education, I view the findings of these studies pertaining to various critical pedagogies as being relevant for theological education, either because conclusions focused on certain elements of CRSP or because they dealt with complexities surrounding students' religions. I have attempted to demonstrate how the various conclusions of the above researchers can be applied to theology classrooms in U.S. Catholic high schools through CRSP's unifying lens.

\section{Religious Education in Non-Catholic International Contexts}

Religious education on a global level, particularly in Europe, reflects a different set of assumptions, developments, and purposes than does religious education in the United States. While the separation of church and state has shaped the culture and legal mores of the United States, resulting in a widespread lack of religious education in public education, other nations have embraced religious education as a means for fostering harmony and respect amongst their citizens. Consequently, while religious education in the United States has been primarily constricted to the realm of faith-based schools, European nations frequently require religious education in state-funded, non-faith-based educational institutions. Such examples of government funding of religious education seem to be grounded in the notion that requisite religious education contributes to more harmonious, understanding, and peaceable societies (Seligman, 2014). I wonder if such 
religious education mitigates religiously motivated, hate-based violence, which reoccurs time and time again in the United States. Studies done in a number of nations pertaining to critical religious and interreligious education demonstrate that teachers experience tensions in attempting to parse the difference between learning from religions and learning about religions (Everington, ter Avest, Bakker, \& van der Want, 2011; Mitchell, 2016). This section addresses the challenges, tensions, and opportunities that scholars have identified in the international sphere of non-Catholic religious education.

Two studies (Byrne, 2012; Fineafter-Rosenbluh and Perry-Hazan, 2018) indicated some potential dangers of religious education in certain contexts, though with implications for religious education writ large. Byrne's small qualitative study examined the consequences of religious segregation on ten students' perceptions of and engagements with the religious "other." Although Byrne concluded that her small sample size of early childhood students prohibits generalizability, Byrne's findings suggested that "children may exclude those with perceived religious differences and become more excluding during early school years" (2012, p. 329) if they are subjected to segregated religious instruction. Fineafter-Rosenbluh and Perry-Hazan (2018) studied 102 essays from high school students in a U.S. Jewish high school about the consequences of being taught by non-Jewish faculty. While many students indicated positive benefits of teacher diversity, many also expressed potential negative ramifications, such as uncomfortable feelings or biased grading, and just over half of student participants expressed concern over indoctrination, using terms "such as push, force, pressure, or preach to describe indoctrination" (625). Understandably, Jewish students did not want non-Jewish teachers 
to alter their beliefs, although they recognized the benefits of being taught by teachers of other faith traditions.

Regarding interreligious education, Zilliacus (2013) studied minority religion and secular ethics education in the Helsinki area, and interviewed 31 secondary school religious education teachers of various faith traditions. These educators aimed to foster the rights of their students to define and understand their respective religious traditions, even going so far as to use the term "cultural responsiveness" (p. 517) to explain their role. Similarly, Everington, ter Avest, Bakker, and van der Want (2016) investigated how the personal biographies of religious educators across the European Union impacted their understanding of religious education in pluralistic societies. This study likewise concluded that these religious educators serving religiously diverse classrooms "emphasised the importance of enabling students to express their own beliefs, views and experiences" and that most shared the "common concern that the teacher's beliefs and views should not be an obstacle to this or to enabling students to develop the ability to think for themselves" (Everington, ter Avest, Bakker, \& van der Want, 2016, p. 251). These two studies confirmed the possibility of religious education to sustain students' religious beliefs, in accord with CRSP's conceptual lens.

Another study about interreligious education concluded that heads of Catalonian religious schools "had a much more favourable attitude towards interreligious dialogue, and particularly towards education playing a role in these issues," than did the heads of public state schools, who stressed "that they did not think education should play an active role in religious diversity or in boosting interreligious dialogue" (Baños, Niella, Sánchez- 
Martí \& Rubio Hurtado, 2019, p. 7). In sum, these studies demonstrated that religious education for religiously diverse communities does not need to be indoctrinatory, and that European educational systems have made much progress in protecting students' freedom of conscience in religious education. In a study that compared religious education between Sweden and India, Niemi (2018) identified a profound difference between Western European and Indian Hindu conceptions of the roles of religion in schools. Indian schools, though secular, sought to incorporate the religious perspectives of many religious traditions of students, not shying away from these traditions' cultural artifacts. This also echoes the tenets of CRSP, which aims to foreground students' respective beliefs within curricular goings-on, which in turn sustains their religious beliefs.

Several other studies have focused on religious education in faith-based schools. For example, in Belgium and the Netherlands, between 60 and 70 percent of schools are state-funded, faith-based schools. Franken and Vermeer (2017) concluded that these Belgian and Dutch faith-based schools have embraced "the evolution from confessional [religious education] to a more open, inclusive and dialogical form of 'semi-confessional RE'” (p. 10); given increasing secularization, Franken and Vermeer recommended that Belgian and Dutch governments organize non-confessional religious education for all students in all schools. After studying almost 1,500 students in mostly Catholic and Protestant schools in the Netherlands, van Dijk-Groenboer (2017) advised that religion teachers enter into dialogue with their students, most of whom "say they want to believe but do not know how" (p. 25), a sentiment that substantiated Smith and Denton's (2009) findings regarding the spiritualities of U.S. teenagers. This study provided further insight 
into how religious educators in faith-based schools enacted the tenets of CRSP through engaging and sustaining the beliefs of their students. Similarly, Chidester (2003) highlighted the conflict between progressive and conservative advocates of different models of religious education in South Africa over the past two decades, and drew attention to Christian evangelical and fundamentalist factions, who sought to maintain hegemonic control over religious education. Such control is not dissimilar to the USCCB bishops' attempt to standardize theological education in U.S. Catholic schools through their Framework.

Turning toward religious education in non-Christian contexts, Svensson (2010) studied how Kenyan Muslim and non-Muslim teachers working in Islamic religious education (IRE) navigated the complexities of educating students about Islam and into Islam, the tensions of which are elevated given various strands of the Islamic faith. In this research, Svensson learned that educators did not necessarily teach in a manner that would be considered confessional, and concluded that "the Islam constructed in the classroom is somewhat compartmentalised and hence detached from and of limited relevance to the actual religious life world of the students" (2010, p. 256). When viewed through the lens of CRSP, it becomes clear that such compartmentalization and consequent irrelevance leave much to be desired. Aşlamacı and Kaymakcan's 2017 study of Turkish Imam-Hatip schools, which synthesize modern education with classical Islamic thought and theology, discovered that Islamic religious education could verge on the fundamentalist and extremist, depending on the Islamic tradition sponsoring a given Imam-Hatip school. Such Islamic religious education resembles certain modes of 
Catholic education, as it intends to preserve its religious tradition among students, even though those students might not adhere to that particular faith.

\section{Methodological Literature}

As I have made clear by this point, very little research exists pertaining to the presence of non-Catholic students in U.S. Catholic high schools. While there are a few extant dissertations on the practice of teaching theology (Kremer, 1998; McGah, 2013; Radice, 2016; Schroeder, 2013), the effects of such on the spiritualities and religious beliefs of students (Hortsch, 2021; Martin, 2016), and the inclusion of non-Catholic students in Catholic schools (Donlevy, 2003), they all varied methodologically. Kremer (2003) used Van Manen's hermeneutical phenomenology to explore how four teachers taught theology while grounded in the field of liberation theology; Schroeder (2013) conducted an interview study while grounded in the philosophical tenets of Participatory Action Research; McGah (2013) did a mixed methods study using an online survey sent to religion teachers at Catholic high schools throughout Washington state; Hortsch (2021) did a mixed methods study consisting of a survey and focus group interviews with 106 graduates of a Catholic high school; Martin (2016) did a mixed methods study with senior Catholic high school students from his place of employment; and Donlevy (2003) did an objectivist grounded theory study with focus groups of students and teachers in Canadian Catholic high schools. Donlevy’s other articles (2007a; 2007b; 2009a; 2009b), most of which grew from his dissertation research, primarily drew on data from individual and focus group interviews. Regarding the purposes of my study, I find Schroeder's and Donlevy's work to be the most directly pertinent, given the direct 
overlap between their interests and mine. Were I not a teacher, I would have considered ethnographic research grounded in classroom observations, but alas, I did not have the liberty to pursue such methods given the COVID pandemic.

\section{Concluding Thoughts}

The empirical literature at hand addressed the enactment of critical pedagogies in a breadth of ways, means, and contexts. While some focused on helping educators become culturally responsive and sustaining through mechanisms of professional development, other scholars have entered into classrooms to explore dynamics of learning and relationships. These studies have reinforced the importance of intentional learning and curricular design, alongside the centrality of developing relationships between teachers and their students. With all this having been considered, the select researchers in the areas of Catholic education, theological education, and the inclusion of non-Catholic students have guided my thoughts on the research design I employed. 


\section{Chapter 3: Methodology}

Before diving into the methodology of this study, I would like to reiterate the problem of practice at hand: the USCCB bishops' emphasis on doctrinal catechesis for religious education in their Framework (2008) fails religiously diverse student populations in U.S. Catholic high schools. In light of this reality, I am interested in addressing the following research problem: no extant research exists as to how theology teachers are diverging from and/or adapting this Framework in their service of such student populations. In investigating Catholic high school theology teachers' beliefs about the purposes of theological education for religiously diverse student populations, and how they go about educating these students, I believe that my findings provide fruitful ground for other educators and future researchers. I illuminate the creative, brilliant, and critical ways in which theology teachers are working to best educate their non-Catholic students. From these findings, my hope is that theology teachers who experience the USCCB Framework as problematic will have new resources at their disposal, should their contexts be similar to those of my participants. I conducted a qualitative interview study, focusing on the experiences and pedagogical choices of a panel of experienced theology teachers. The research questions are as follows:

1. What do Catholic theology teachers in Pacific Northwest Catholic high schools believe about the purposes and goals of religious education for religiously diverse student populations, especially with regard to the role of catechesis therein? 
2. What particular curricular and pedagogical decisions do Catholic theology teachers in Pacific Northwest Catholic high schools make in order to meet the needs, interests, and positionalities of their nonCatholic students?

3. How do theology teachers in Pacific Northwest Catholic high schools consciously diverge from/and or adapt the USCCB Framework (if at all) in their service of religiously diverse student populations who represent Catholic, non-Catholic Christian, non-Christian, and nonreligious traditions and contexts?

With regard to the goals of this study, on a personal (and practical) level, I hoped to gain a deeper understanding of how other theology teachers undertake the same work that I do. The professional preparation of theology teachers varies widely, and so the educational experiences and personal beliefs of teachers heavily inform the way that they educate students. Through conducting interviews with a selection of participants, I investigated how and why teachers believe what they believe about religious education, and how these beliefs impact their pedagogical stances and decisions. Prior to conducting the study, based on my review of the literature and personal experience, I strongly suspected that theology teachers were already (either consciously or unconsciously) incorporating various tenets of the critical pedagogies present in my theoretical and conceptual frameworks into their work, and I explored this suspicion through my research. By no means did I use CRSP as an evaluative measure, but rather as a means of focusing my research questions, analysis, and interpretations. Moreover, and most 
importantly, given the profound lack of research about how theological educators are engaging, disengaging, adapting, and/or diverging from the USCCB Framework (2008) over a decade after its publication, I shed light on these various forms of (dis)engagement. In doing so, I believe this research provides grounds for empowering other theology teachers who are interested in the work of educating religiously diverse classrooms.

Based on anecdotal evidence and conversations with friends across the country, I know that theology departments and the educators within them are grappling with the Framework in many different ways. While the findings of this study are not generalizable (given the inherently small sample size, and the nature of an interview study) in the same way that the findings of a quantitative study are, I do believe that my analysis and conclusions might very well resonate with theology teachers across the country. This said, Weiss (1994) stated that there might be some grounds for arguing for the generalizability of qualitative findings, namely the respondents' own assessments of generalizability, the similarity of dynamics and contexts about which respondents are interviewed, and the depth of the findings reported. Therefore, I do believe that the findings of my study might very well be transferable, given that many Catholic high schools educate religiously diverse student populations. Finally, not only does this study provide some foundational research for others to build upon, but I hope it might spark conversations within the world of Catholic secondary education, or contribute to already ongoing conversations. 


\section{Statement of Philosophical and Paradigmatic Positionality}

Before I explicate the particulars of the methodology and methods through which I conducted my study, I feel it is important to address the philosophical paradigms that underlie my epistemological, ontological, and axiological positionality. As a Roman Catholic theologian-educator, I believe certain things about the nature of reality: that it was intentionally created by a trinitarian (three-personed) God who is super-personal (because a God who is mysteriously three persons in one being is, theologically speaking, a superordinate, multi-dimensional being of sorts) and incessantly active (because if God is love, as the Christian tradition posits, then God is more of a verb than a noun and more of an action than a thing); that human persons are reflections of this Creator (with regard to our freedom and capacity for love); and that the entirety of this creation is in the constant process of re-creation through the collaboration of divine grace and human agency. I believe that this Divine Mystery labors on behalf of the oppressed. I also believe that this Mystery became en-fleshed in the body of a first-century, Romanoccupied Judean, who was publicly tortured and executed after several years of preaching radical, counter-cultural messages of love and justice, and rose from the dead. Then again, try as I might, I cannot with any sort of surety comprehend the origin or destination of creation, although I think that each and every person lives according to non-falsifiable beliefs regarding the teloi ("purposes") of creation, or of its eschaton (ultimate destination). Each aspect of the created order is a potential means through which human persons can recognize, name, and celebrate the Divine Presence that engraces each and every iota of existence at each and every moment. 
On a broader level, outside of my own religious inclinations, I believe that every person stakes their life on certain beliefs, even if those beliefs aren't religious, explicit, or involve some sort of deity. Guba and Lincoln's (2005) discussion of axiology's role in research paradigms highlighted the influence of a researcher's personal beliefs on their paradigmatic stance: they wrote that "values, or more correctly, axiology (the branch of philosophy dealing with ethics, aesthetics, and religion)" are "a part of the basic foundational philosophical dimensions of paradigm proposal" because axiology helps "us see the embeddedness of ethics within, not external to, paradigms" (p. 200). Our experiences, memories, and contexts shape our ethics, our worldviews, and how we create and maintain relationships; for each person, this matrix of interactions forms a complex belief system, be it consciously or unconsciously held.

Saint Augustine, the fifth-century African bishop and theologian, opened his Confessions with a breathtaking address to God, one that theistically (that is, grounded in belief in God) captured the unceasing nature of our quest for meaning: "you have made us and drawn us to yourself, and our heart is unquiet until it rests in you" (Augustine, trans. 1998/397-400, p. 3). In other words, on an existential level, human beings cannot ever find complete satisfaction in this yearning for beauty, truth, and goodness, because we cannot ever experience complete union with our divine origin, which (in the Christian tradition's belief system) only occurs after death. Considering this Augustinian restlessness, our endless pursuit of beauty, truth, and goodness—or learning and constructing beliefs about them-defines what we do with our lives. In an infinite myriad 
of ways and means, people search for experiences that move their hearts, aid their understanding of their world, and help them to live their lives well.

While this reflection might make me seem like a total absolutist, I recognize that infinite belief systems contradict my own, and that I ultimately could be very well wrong. It is not so much that I "know" that my beliefs are correct, but that I have been formed by them, find meaning and purpose in them, and choose to stake my life on them, in accordance with Frankl's (1964/2006) notions of freedom and meaning-making. In discussing theological education, I must acknowledge the tension that reverberates throughout my experience of it, because beliefs change and shift. Beliefs can be altered, amplified, dissipated. Beliefs are delicate and intensely personal, flowing from our experiences and decisions, and so, in my mind, theological education requires humility and sensitivity on both the part of the teacher and of the student.

Maxwell's (2013) explication of critical realism helped me to clarify my own philosophical position as being critical realism, which is also shared by proponents of Critical Religious Education (Barnes \& Wright, 2006; Franck, 2015; Teece, 2005; Teece, 2010; Wright, 2004a; Wright, 2004b; Wright, 2007; Wright, 2008). Maxwell (2013) wrote that critical realism "combines two common-sense perspectives that have often been seen as logically incompatible" (p. 43). The first perspective, ontological realism, maintains that "there is a real world that exists independently of our perceptions and theories," and does not "accommodate to our beliefs" and the second perspective, epistemological constructivism, acknowledges that our "understanding of this world is inevitably our construction, rather than a purely objective perception of reality, and no 
such construction can claim absolute truth" (Maxwell, 2013, p. 43). Framing this critical realism in the context of my own personal convictions, while I am a Catholic who believes certain things about reality to be true, I know that my beliefs have been subjectively constructed, and therefore might be objectively false. These beliefs affect how I phenomenologically experience reality, but my beliefs do not alter that reality, except insofar as they might influence how I act within and on reality.

Thus, I think that any good learner, be they layperson or professional academic, maintains a tenuous relationship with their beliefs and knowledge. A humble learner works from their beliefs and knowledge, but also recognizes that their beliefs cannot be absolutely and totally provable, nor can their knowledge be conclusively accurate. I agree with Freire, that the act of learning about the world is an act of hope. In Freire's words (2014), learning ought to engage a creative tension between knowing and unknowing, and the learner benefits from undertaking some metacognition about this tension: "first, the one who knows must know that he or she does not know all things; second, the one who knows not must know that he or she is not ignorant of everything" (p. 176). Although in this context Freire spoke of the teacher (the one who knows) and the learner (the one who knows not), each person assumes the identity of learner or teacher at different points in their life, or even simultaneously. Freire's thoughts, I opine, are especially pertinent for theology teachers, who constantly engage and mediate between conflicting beliefs systems, values, and worldviews. My study tapped into my participants' perspectives in this area. We constantly contribute to our epistemic 
understanding and knowledge, but at the same time remain agents who are capable of dispersing that understanding and knowledge, or acting upon it.

Considering the primacy of positionality, I would like to do some metacognitive reflection on how I regularly see all this in my work as a theology teacher. For the past five years, my students and I have entered Room 208 on North Fenwick Avenue (and Google Meet, during the 2020-2021 COVID pandemic) with our own beliefs, assumptions, experiences, and worldviews. I am aware of my own religious convictions, and am cognizant of my students' convictions as well, be they religious or non-religious. I strive to make my classroom a place of hospitality "that welcomes and embraces the other as one's own in a spirit of kinship" and emphasizes "an acceptance of the other as other in the face of religious differences" (Brockman \& Habito, 2010, p. 10). In short, theological exploration and learning require unity in diversity, and celebrating the differences of others. Fostering a community amongst individuals from various religious, non-religious, and anti-religious backgrounds requires that we actively pursue building relationships. Without laying the groundwork of genuine care for other people within the same classroom, empathy becomes impossible, and respectful dialogue remains unattainable. From my perspective, as an academic discipline, theology concerns one of the most important facets of human existence; for many, beliefs provide the basis for action in the world, and determine the ways in which we live, move, and have our being. Because beliefs are so deeply personal, theology touches a tender aspect of human existence as well, and consequently, relationships of trust and empathy must pre-exist or be formed alongside, theological dialogue. Who we are and what we understand about 
ourselves, our world, and God comes into contact with other understandings, be they sympathetic or unsympathetic to our own.

I teach from within the Catholic tradition, with heavy influence from my Jewish cultural background and passion for liberation theology. I celebrate that dialoguing with non-Catholic people and traditions has formed my beliefs: I have learned what I believe through learning and understanding what I do not believe. Given this experience, I try to the best of my ability to make my classroom a place of self-expression and interreligious experience, all so that my students can understand what they believe with greater authenticity.

Finally, to get a bit more intimate, I also must recognize the extreme privilege of my positionality. I'm an upper-middle-class white male who attended nationally-ranked schools. I was a good student and worked hard, but I never had to suffer for my learning, and was never marginalized for my race or gender. I never had to engage my educational experience in a survivalist mode, and I loved most of my teachers, none of whom ever silenced me, denied me opportunity, or ostracized me. I certainly spent most of my life largely ignorant of my extreme privilege, and even though I always partook in opportunities to do community service work, I now question how much of it even interrupted systematic injustice. Regardless, that service work was undertaken out of leisure, and I was able to major in philosophy and theology because of my parents' financial comfort. I was able to teach theology because I did not need to enter a profession that would pay off exorbitant college debt. I could attend graduate school because a radical Methodist seminary offered me (rather than anyone else who was not a 
cis-gendered white male) a full scholarship, apartment, and monthly stipend. I suppose my classmates in that graduate school did sort of question how much I embodied the patriarchal colonialist tendencies of Catholicism, which was entirely fair, and I am grateful for that challenge from folks who embodied and embraced critical perspectives. And today, I can teach in a school whose teachers are among the lowest paid in the entire city of Portland (even lower than the other Catholic schools, which are on a set diocesan pay scale) because of my accumulated privilege.

The fact that my principals and department chairs have always given me free rein to do what I wanted further speaks to the privilege that comes with being able to teach in such institutions. Over the past number of years, I have become a bit more conscious of how all of these liberties I have received over the course of my life impact the way in which I inhabit the world. I tend to assume a lot of confidence in my thoughts and speech and decisions, and can get defensive when those are called into question. It has been a learning process to confront and interrogate these undesirable aspects of my personality, and I could not have done so without my students, colleagues, and friends holding up a metaphorical mirror before me. Only over the past few years would I say I have found some resolution in this struggle, although there is certainly more struggling to be done; acting against the Framework has certainly helped me to embrace and actively include the positionalities of my students. As I undertook my research, I had to consciously and intentionally seek humility, which enabled genuine inquisition. 


\section{Research Methods}

In this study, I believed that qualitative interviews were best suited to answer my research questions. Other methods, such as phenomenology and narrative inquiry, are focused on the meaning of lived experience (Vagle, 2018; Van Manen, 2016a; Van Manen, 2016b) and personal story-telling through narrative inquiry (Clandinin \& Connelly, 2000). While I am interested in these aspects of theology teachers' work, my research questions are not so much about discovering meaning-making in lived experience or narrative. Consequently, I chose to eschew more specific methodologies in order to leave myself the room to explore the questions I was most interested in. Future studies could certainly approach the same problem through these specialized methodologies. Moreover, as a novice social science researcher, I was not confident in my abilities to dive into these specialized methodologies with great skill. However, I did not shy away from these methodologies out of fear, but out of the realization that they were not the best avenue for exploring the research questions at hand.

A qualitative interview study allowed me both flexibility with my protocol questions, some of which were more phenomenological in nature, others of which were more concerned with the pedagogical decisions that teachers make. Moreover, with a qualitative interview study, I was able to select the most appropriate coding methods from the wide variety that are available, in order to most thoroughly analyze my transcript data and generate the most valuable themes and findings from them. 


\section{Participants}

I recruited five participants from Catholic high schools within the Pacific Northwest. As mentioned in my statement of the problem, different Catholic high schools are sponsored by different dioceses and different religious orders. I aimed to develop a "panel of knowledgeable informants" (Weiss, 1994, p. 17) from a variety of backgrounds and a variety of schools. Teachers who consented to participate expressed interest in the theological education of religiously diverse student populations, and believed they had something to offer the study. My five participants came from a variety of backgrounds, experiences, and positionalities. Through my invitation letters to principals and department chairs, and then the pool of theology teachers, I recruited participants who were explicitly interested in the theological education of religiously diverse student populations, and are intentional in how they educate these students; although I have written extensively about the USCCB Framework, I did not foreground my critique within my invitations. I was, however, explicit about inviting those teachers who actively pursue and embody expertise in educating religiously diverse classrooms. With some luck and a well-crafted invitation, five individuals expressed interest in this study, and formed a small pool of knowledgeable folks who were unintentional exemplars of CRSP's central tenets.

While I do not think that the nature of this study directly endangered the employment or welfare of my participants, I could not assume that all principals, department chairs, or authorities within a Catholic diocese (such as Catholic school superintendents or bishops) would take kindly to the goals of this study. By initially 
securing the permission of principals and department chairs before recruiting participants, I intended to nullify potential professional repercussions to the best of my ability. Moreover, participants generated pseudonyms for themselves and for their schools; I removed any potential identifiers, in order to safeguard participants' anonymity. Additionally, as much as I would have loved to have had non-cisgendered and nonheterosexual participants actively contribute to this study, I refrained from asking for this demographic information; some bishops have forced schools to fire staff and faculty on the basis of their being married to a partner of the same sex, and by no means did I want to endanger, or give the impression of endangering, the livelihoods of my participants. In order to mitigate the potential validity threat of selecting participants who would only serve to confirm my own biases, I selected participants regardless of whether they voiced disagreement with my perspectives. I provide further rationale for this mitigation below, where I discuss my role as researcher.

\section{Procedures}

I contacted principals and department chairs from Catholic high schools in the Pacific Northwest, asked permission to reach out to their theology teachers, and upon receiving permission, contacted approximately thirty individuals. I sent these teachers a one-page overview of the study and its purposes, and explained that if I selected them, they would participate in a series of three, and possibly four, interviews. In this letter, I communicated that I was searching for teachers who consciously and intentionally engage their religiously diverse classrooms that are comprised of both Catholic and non- 
Catholic students. In short, I hoped to cultivate a self-selected group of educators who were capable of meaningfully engaging my research questions.

From those interested in participating, I made selections with the intent to represent a variety of educators' educational backgrounds and years of experience. I recruited two teachers who taught before the USCCB Framework was published, and they were able to offer the most thorough and nuanced analyses of theological education before and after the Framework's publication. This said, folks who have taught entirely since the Framework had distinct, and perhaps less frustrated, contributions to make. I asked the five recruits to sign consent forms.

After collecting consent forms, I proceeded to conduct interviews with each participant. Following the recommendation of Seidman (2019), I held three interviews with each participant, spaced approximately one month apart; this left me time to transcribe interviews through Microsoft Word's dictation function and conduct a first cycle of coding for each transcription. I recorded interviews for the purposes of transcription, and wrote analytic memos immediately following each interview (Glesne, 2016; Merriam \& Tisdell, 2016; Patton, 2015), which provided preliminary grounds for analysis. I used CAQDAS software NVivo 12 for Windows, into which I uploaded transcriptions, analytic memos, and documentary evidence provided by theology departments and teachers (such as scope and sequences, syllabi, teaching statements, and other relevant documents). I conducted line-by-line coding of the transcriptions, which numbered nearly 300 single-spaced pages in Word. 
I conducted a focus group interview with interested participants, and generated questions for this interview in tandem with my advisor, Dot McElhone. I had several aims in conducting this focus group: to have participants share their thoughts about their goals and best practices regarding the theological education of non-Catholics; to highlight the areas of agreement or disagreement in these areas; and to arrive at some sort of consensus as to what a four-year theology curriculum for religiously diverse students would look like. I recorded this focus group interview, and transcribed, coded, and analyzed this final set of data, largely in order to member check and mitigate a potential validity threat. Furthermore, each round of interviews provided room to revisit ideas from prior interviews, to provide further opportunity for member-checking. After I transcribed each interview, I sent the transcript to the participant, so they could correct wording or add content, although participants rarely had revisions to make or additions to submit. Once I analyzed the data, and wrote a solid first draft of my fourth chapter, which contained the analysis and my interpretations and discussion, I sent this to participants for further member-checking. I asked them to read through the profiles I wrote for each of them, and to read through my interpretations, so as to amend any misinterpretations or inaccuracies. A few participants elected to clarify some phrasing and word choice, so as to avoid confusion, but they did not otherwise offer significant revisions.

\section{Instruments and Measures}

In the three rounds of interviews with each participant, I used the interview schedules below to elicit data responding to each of my three research questions. 
In the first interview, I sought to understand how a teacher's educational and experiential background influence their understanding of the purposes of religious education. In particular, I explored their beliefs regarding the role of catechesis in high school theology classes with religiously diverse populations, and subsequently other forms of theological education that they implement in their work. On a more fundamental level, this interview was designed to foster rapport and relationship with my participants, so as to develop a level of trust with them. The semi-structured interview schedule provided a series of concrete questions that I asked each participant, although based on their responses, I invited further responses through probing and spontaneous questions. The first interview schedule was as follows:

1. Tell me about your educational background, both in terms of your experience of Catholic school and your preparation in the academic discipline of theology.

2. What did you most appreciate about, or learn from, your academic preparation?

3. Why did you become a theology teacher? Can you describe any defining moments, relationships, or experiences that contributed to that desire?

4. All that said, what do you think about the role of catechesis in high school religious education?

5. (If the teacher does not view catechesis favorably) What other forms of religious education do you pursue apart from catechesis, and why do you pursue them? 
6. (If the teacher does view catechesis favorably) How do you present catechesis to your non-Catholic students? How do you differentiate between the goals of catechesis for students of different religious or non-religious backgrounds?

7. What do you hope your students learn from their time with you, especially if they are not Catholic or not Christian?

The second interview dove more concretely into a teacher's work and pedagogical choices in the classroom. More specifically, I intended to seek out the ways in which theology teachers incorporate the tenets of critical pedagogies from CRSP. The interview schedule for the second round of interviews was as follows:

1. Based on our last interview, do you have any further thoughts on the goals of theological education, either personally or in Catholic secondary education, more broadly? Is there anything you would care to revisit?

2. How do you seek to nurture students' beliefs, regardless of whether or not they are Catholic? How do you support students' beliefs, especially those who are not Catholic?

3. What are some specific strategies or pedagogical approaches in your support of these students?

4. What are the challenges you encounter in building trust and relationships with non-Catholic and non-religious students?

5. How do you go about fostering nurturing and loving relationships with your students, especially non-Catholic ones? 
6. How do you provide instruction and opportunities for learning that help students to make sense of and explore their own beliefs?

7. How do you provide instruction and opportunities for learning that help students to make sense of and explore others' beliefs, and how religious belief shapes society and culture?

8. How do you invite students to share their beliefs, especially if they are not Catholic, with you and their classmates? In other words, how do you center students' voices in the classroom experience?

With all this in mind, in the final round of interviews I explored the teachers' stances regarding their implementation of, adaptation of, and/or divergence from the USCCB Framework. I was especially interested in how theology teachers choose to engage the Framework when their students represent a variety of religious traditions, or non-religious backgrounds. When teachers brought up the Framework in the first or second interviews, I redirected them, and assured them that the third interview would focus more on that subject.

1. Tell me about how and when you were introduced to the USCCB Framework. What did you notice, and what were your first impressions of it?

2. What are your impressions of the Framework these days? How have your impressions shifted over time, if they have?

3. Tell me about your department's use of the USCCB Framework. To what degree does your department align its curricula with Framework standards and expectations? 
4. What are your feelings about implementing the Framework for non-Catholic students?

5. Why do you think the Framework is (beneficial or detrimental) for students?

6. Do you pay attention to the Framework when crafting your curriculum and assignments? Walk me through your process of planning a lesson or a unit when considering non-Catholic students. What resources do you refer to decide what to teach, and how to teach it?

7. (If applicable) In what ways do you change, or adapt the Framework in your curriculum design and teaching?

8. (If applicable) In what ways do you eschew, or ignore the Framework in your curriculum and teaching?

9. If you do adapt or diverge from the Framework, can you tell me about why you make the choices you make?

10. What have you noticed about how your goals and methods have changed over the course of your career?

The final focus group interview provided participants with the opportunity to provide feedback on the study's findings, and to bring up further insights. I developed the focus group protocol with my advisor, and we designed the questions to have participants share their key insights regarding the theological education of non-Catholic students, and to generate consensus or disagreement about what they believe this education should entail. The central questions I posed to the focus group were as follows: 
1. What do you think a non-Catholic student should know, understand, have practiced, or have learned at the end of their four years of taking theology classes?

2. I'm going to give you some time to write down some thoughts on the following question. If you were to create a scope and sequence of a fouryear theology curriculum that would serve practicing and non-practicing Catholic students, and non-Catholic students, what would it look like?

3. Did you consciously make any inclusions or omissions that depart from the current USCCB Framework? Why did you make these decisions?

4. What were you assuming about students' understandings of religion and/or theology as you were writing?

5. Based on all of our conversations up until this point, do you have any final thoughts you'd care to share with the group about theological education of non-Catholic students?

\section{Role of the Researcher: Validity}

As a theology teacher working in a religiously diverse high school, the questions surrounding theological education for religiously diverse populations drive much of what I do. This is my passion, on both a professional and personal level. I entered into this research and research design with my own professional biases against catechetical religious education, and certainly against the Framework. On the one hand, I do believe that many theological educators in U.S. Catholic high schools share similar values, perspectives, and biases to those that my positionality engenders. Not only has my 
experience as a high school educator informed and molded my positionality, but my theological education in progressive institutions of higher education has certainly shaped the way in which I engage and dialogue with non-Catholics. As much as I appreciate and dial myself into this positionality, and the biases that it entails, I also acknowledge that I have no experience whatsoever teaching in a Catholic high school whose students largely identify as Catholic (and there is of course a spectrum of ways in which students do so, per Smith \& Denton's [2009] sweeping study). And so, I recognize that I must bring my biases into the light, and I attempted to lessen their interference with either data collection or data analysis.

This was not so much an attempt to "eliminate" my biases as it was an attempt to mitigate potential "negative consequences" (Maxwell, 2013, p. 124) of their interference, primarily leading my participants to agree with, or reinforce, my own perceptions and positionality. In a very real sense, in this study I hoped to learn from theology teachers who share my values and beliefs, although by no means did I silence those whose views contradict my own; admittedly, it was rare that I found myself disagreeing with a participant. In my analysis and interpretations of the findings, I demonstrate that my critique of the USCCB Framework does not represent the ravings of an unreasonably disgruntled teacher, but rather stems from legitimate and widespread concern for the religious education of non-Catholic students. Simultaneously, however, I acknowledge that other experienced and knowledgeable teachers in my panel of participant experts sometimes implement strategies and pedagogical choices that I disagreed with, and I was genuinely curious to gather data that surprised me, however uncommon these data were. 
This said, I aimed to mitigate the undesirable ramifications of my biases in several key ways. First, in recruiting participants through invitations to principals and department chairs, and then to teachers, my language was as neutral as possible. While I explained the purpose of this study, I refrained from using language that "tipped my hat," as it were, or revealed my positionality's biases: I simply aimed to communicate that I was searching for individuals who acknowledged the religious diversity of their students, and actively shape their pedagogy around that reality. I wanted to recruit participants who believed that they had something of import to offer in this area, and who possessed expertise in their practice.

A second means of mitigating bias was the triangulation of data, which I undertook to the best of my abilities. Not only did I interview multiple participants, but I conducted a series of three interviews, as recommended by Seidman (2019). I shaped the schedule of questions to be as open-ended as possible, so as to not lead my participants in one direction or another, while still inviting them to honestly articulate their responses. Certain questions were optional, and were offered depending on the direction of conversation. These questions, as I expected, did not influence interviewees to "please" me, or to give answers they think are expected or desired. Conducting multiple interviews not only helped me to check my own biases (by allowing me to enter into these research questions with some depth), but also yielded comprehensive, rich insights for concurrent and subsequent analysis. Following Weiss's (1994) and Maxwell's advice (2013), I recorded and transcribed interviews in order to help make sure that my interview data was complete as possible. In an attempt to further triangulate my data, I asked 
participants to collect documentary artifacts, such as curriculum maps, scope and sequence documents, annual plans, reflective journals, and any other documents that would help me to understand their goals, values, beliefs, and practices. For reasons unknown, I collected a number of documents from certain participants, but not all; most of these were essays they had written, or assessments they used, with a syllabus, and departmental statements of teaching philosophy. I was able to substantiate my analysis of interview responses using content within these documentary artifacts. Analytic memos provided a third source of analysis, which helped to flesh out the contents of interview and documentary data. Given that documentary artifacts were skewed, both by type and by participant submission, I refrained from coding them, so as to not skew coding frequency or type in interview texts. I also did not code my analytic memos, so as to avoid inserting data that would confirm my own biases. Triangulation of data sources helped me to collect and analyze data, to conduct analysis, and generate findings as richly and thickly as possible. Interview data, documentary data, and analytic memo data provided multiple lenses of perspective, and multiple (and progressively deeper) layers for analysis, the collection of which enabled me to thoroughly answer the research questions at hand.

In my collection and analysis of data, I was cognizant that my perspective could have very well resulted in misunderstandings or unintentional omissions, and so upon completion of initial analysis and drafting of findings, I brought my writing to my participants. I asked them to check that I did not omit or misunderstand their words, and correct any errors. A final focus group interview with all participants was another 
valuable means through which I conducted member checking. After positing some initial thoughts on preliminary findings, I asked for participants' feedback on the findings, with particular attention to correcting misinterpretations or inaccuracies; they did not have any revisions or critical feedback to offer, as they perceived the findings and my preliminary interpretations to be consistent with their beliefs and practices. Throughout this process, I emphasized a spirit of collaboration and collegiality, and found that the participants looked forward to dialoguing with one another. Maxwell (2013) posited that this process of member checking is the most important step a researcher can take in guaranteeing that the participants' contributions have been collected and interpreted accurately.

Finally, I searched for and incorporated discrepant evidence that contradicted my initial findings. I did not permit my own biases to prevent me from selecting or interviewing those who might have disagreed with me; indeed, I shielded myself from falling into this temptation by not asking potential participants if they agreed or disagreed with the USCCB Framework prior to selection. Instead, I selected a panel of exemplar participants based on whether or not they believed they had something to contribute to a study of theological education for non-Catholic and religiously diverse student populations. Ultimately, five participants consented to participate, and I did not need to recruit further, nor did I reject anyone from participating. Moreover, I intentionally avoided using CRSP to measure whether a theology teacher was "good" or "bad" at enacting CRSP's tenets. Rather, my conceptual framework helped me to formulate this research design (especially in the realm of interview questions), and helped me to analyze interview and artifact data, in order to uncover the ways in which teachers offer 
existentially meaningful content, prioritize religiously sustaining instruction, and foster nurturing and loving relationships with students. This said, I was aware that because I was not conducting classroom observations (due to the COVID pandemic and social distancing restrictions leading to online learning for most of the academic year), the interview and artifact data might not accurately reflect the actual practice of teachers, which is a notable lack in this study. That said, as some instances of discrepant data arose, I did not hesitate to collect and analyze them (especially with regard to coding instances of beliefs or concepts that seemed to contradict CRSP), but attempted to shed light on what they had to tell me regarding the problem of practice and the experiences of theological educators.

\section{Data Collection and Analysis}

I first sent letters of invitation to principals and department chairs of seven Catholic high schools, asking their permission to invite their theology faculty to participate in the study; from the pool of faculty I contacted, five participants responded affirmatively. I worded invitations so as to invite theology teachers who had expertise in educating non-Catholic students, as my intent was to recruit a panel of experts. Over the course of the 2020-2021 academic year, I held three rounds of one-on-one interviews with each participant (yielding fifteen interviews), which ranged between forty-five and ninety minutes in length. In these semi-structured interviews, I largely relied upon a preestablished interview protocol, and asked probing and clarifying questions as appropriate; this said, as a first-time qualitative researcher, I do not think, in retrospect, that I asked as many questions outside of the protocol as I could have. We completed each round of 
interviews before commencing with the next one, and the first interview of each round was a pilot interview with the same participant (Glesne, 2016; Merriam \& Tisdell, 2016; and Weiss, 1994), whom I asked to give me feedback on questions. Through these pilot interviews, I aimed to "test the language and substance of [my] interview questions" (Glesne, 2016, p. 61), and made revisions as necessary if the resultant data did not successfully answer my research questions; my pilot interviewee did not offer many suggestions, and I did not perceive faults in the protocols' questions, and so few revisions were necessary. This pilot participant is one of the five cases involved in the study. After the conclusion of the interviews with individual teachers, I conducted a focus group interview, which four of the five participants were able to attend.

All interviews were conducted through Zoom (https://www.zoom.us), and transcribed by use of voice dictation software in Microsoft Word as soon as possible after each interview. Following each interview, I wrote an analytic memo to summarize the content of the interview, but more importantly, to reflect on the aspects I considered most relevant to the research questions, especially my thoughts on how their theological and educational beliefs and positionalities influence their teaching practice; I also wrote analytic memos as I conducted rounds of coding, so as to reflect on the sorts of codes I was generating, and to consider the process of categorizing and consolidating them. Once I edited the transcripts (removing small talk, editing for grammatical and syntactical clarity, removing all identifying information, and replacing participants' names and schools with pseudonyms of their own choosing), I sent copies to the participants for the purposes of member-checking, so as to offer them the opportunity to edit or add to the 
interview. I deleted recordings of interviews after the transcription and member-checking process, and stored them on a password-protected personal computer along with the transcripts. Interviews were spaced one to two months apart, so as to allow me time to conduct first rounds (and frequently second rounds) of coding. The birth of my first child in October slowed this process down, but paternity leave also gave me the freedom to transcribe and code with more vigor than I would have otherwise been able to while teaching. In addition to interview data, I also asked participants to send me relevant documents (such as departmental documents, scope and sequences, syllabi, assessments, reflection journals, personal statements of teaching philosophy, and so on) for analysis; I received about fifteen such documents, the majority of which were articles teachers had written or examples of assessments.

I uploaded interview transcripts and documentary artifacts (which had been stripped of identifying information) to NVivo 12 for Windows (https://www.qsrinternational.com/nvivo-qualitative-data-analysis-software/home), where I proceeded to analyze the data. I undertook first cycle, line-by-line coding (Saldaña, 2016), using attribute codes, structural codes, and sentiment codes (very negative, moderately negative, moderately positive, and very positive). I then went through interviews for a second round of focused coding (Saldaña, 2016), where I employed theoretical coding, concept coding, evaluation coding, and in vivo coding to begin to generate themes. Once I had finished coding the second round of interviews, I began to consolidate hundreds of codes into more general parent codes, from which I generated preliminary themes. I wrote definitions of each code in the codebook, and also wrote 
analytic memos following each interview (Glesne, 2016; Saldaña, 2016), although I did not code these memos in order to avoid imposing my own perspectives on the data, or draw premature conclusions by injecting data inappropriately. Ultimately, I chose not to code documentary artifacts, because I did not receive the same number or type of artifacts from participants, and lacked artifacts from one participant; I did not want to skew coding matrix queries in the subsequent stage of analysis. Consequently, I used documentary artifacts in my analysis of themes, drawing examples of the themes from these assessments. Excluding structural codes, which I used to organize text for analysis, I coded 2,663 individual references spread across the categories of "concept" codes, "values" codes, "sentiment" codes, "evaluation" codes, and "descriptive" codes.

Following the conclusion of coding, I began the process of analyzing through matrices in a Google Sheet; within this document, I created four individual spreadsheets of matrices for each of the interviews (so I could identify and visualize what each participant said in response to each question), and five spreadsheets for participants (one for each teacher, so I could identify and visualize how their experiences, educations, beliefs, and goals might have influenced their answers across interviews). Based on this analyzing "across" each participant's responses to all interviews and "down" all participants' responses to a given question, I undertook the iterative process of condensing and organizing my codes even further. In this stage of codeweaving (Saldaña, 2016) between my bodies of codes, I worked between and across preliminary categories of codes in order to generate central themes and more accurate categories from the available data. Throughout my analysis, I aimed to uncover themes that directly 
responded to the research questions at hand. Most specifically, I intended to understand the beliefs that theology teachers hold regarding the goals of theological education for religiously diverse student populations, the ways in which they seek to critically sustain the beliefs of students, and finally the ways in which they diverge from and/or adapt the USCCB Framework in their work as educators.

Once I had finished consolidating and organizing codes, I used NVivo 12 to create word clouds for individual participants and interviews, word trees of the most frequently mentioned words (especially those most relevant to analysis, such as "Framework"), and hierarchy charts of codes (which helped me to continue the process of consolidating and organizing codes). I created coding hierarchy charts iteratively with the themes, circling between thinking through and defining themes as I saw how many codes and coding references there were, and how codes were divided between various categories. In beginning the process of analysis, these coding hierarchies helped me to understand which codes were most populous, and how the codes related to one another, simply in terms of their numerical frequencies. Visualizing the hierarchy charts helped me to consider what analyses I wanted to undertake in matrix coding queries, in order to see how frequently (or infrequently) particular codes came up in the transcripts of particular participants, or in response to particular questions. While I am wary of the detrimental effect that displaying hierarchy charts and bar graphs might have in terms of nullifying the forcefulness that my qualitative analyses posit, I want the reader to understand how I came to generate themes and interpret my participants' statements. I 
would rather err on the side of thoroughness of presenting my methods in data analysis, in order to avoid leaving the reader wondering about my motivations and processes.

Each hierarchy pie chart depicts the overall number of instances that I coded codes and child codes, and each "slice" of the hierarchy charts' pies reflects the percentage of codes within an overall parent code that child codes represent; for example, "positive" and "negative" evaluations of catechesis (the references to which are represented by two separate "slices") comprise all evaluation codes of catechesis. Some of the hierarchy charts have branches that jut out from certain child codes, which indicates that those child codes have child codes of their own. I have heavily cropped the original images for the purposes of readability. While I discuss some of these "grandchild" codes in my analysis, I did not consider all of them to be immediately relevant to discussion. Working with the coding hierarchy charts and the matrix coding queries provided me with the groundwork to generate themes. In my interpretation of the themes within chapter four, I provide visualizations of the hierarchies that were most pertinent in my generating themes, along with explanatory discussion of each hierarchy, to provide a sense of the ways in which the code categories influenced my generation of themes.

Based on the sum of this analysis, I generated themes based on the categories of codes. At this point, I performed matrix coding queries in NVivo 12, comparing cases by the codes from interview transcript data, for which I provide visual displays in my interpretation of the data in the fourth chapter. The matrix coding query "facilitates comparisons of qualitative data for subgroups of the sample" (Jackson \& Bazeley, 2019, 
p. 186); in other words, I was able to explore the coded data in a quantitative manner across cases, so that I could compare how frequently codes appeared for each case. The bar graphs in chapter four display the counts of codes above each bar; these counts refer to the number of references to that particular code, or to the sum of child codes under the parent code represented by the bar. For example, there are different sorts of evaluations, or child codes, that comprise an overall sort of evaluation, or parent code (e.g. "the bishops tried to assert their authority through the Framework," and "the bishops did not consult teachers in drafting the Framework," both of which are different child codes that fall under the parent code of "negative evaluations of the institutional Church").

Once I completed this more quantitative-oriented process of analysis, I created concept maps (Figures 5, 6, and 7) of the ways in which participants' educations, experiences, and beliefs influence their pedagogical goals and praxis, including their use of, adaptation of, or divergence from the USCCB Framework. As I analyzed the data, I tried to remain aware of my inclination to impart my own biases (such as my dislike of the Framework) upon the data, and made sure to implement codes that contradicted my own biases (such as when participants positively evaluated the Framework). I went through each transcript multiple times to code, even after all rounds of coding were completed, and I had begun to generate themes, and it was in this process that I discovered more instances of discrepant data that I had unconsciously failed to code in previous rounds. In the fourth chapter's interpretations, I discuss instances of discrepant data that contradicted what I either expected to find, or that ran against overall trends (such as instances where participants expressed positive attitudes towards the Framework 
or catechesis). In undertaking all this analysis, I hoped to understand the multivalenced ways in which participants' positionalities and beliefs impact their pedagogical praxis, and the reasons why they make the decisions they make with regarding to adhering to, adapting, and/or diverging from the USCCB Framework in their service of religiously diverse student populations.

Creating hierarchies of codes and exploring the data with these matrix coding queries turned out to be an extremely beneficial reason to use CAQDAS software for my analysis, because quantifying participants' codes through matrix coding queries allowed me to identify certain trends in how the codes were divided amongst the participants. In turn, I could see with greater clarity how each participant responded to certain overall themes (such as evaluations of items, or goals for their practice). NVivo produces tables for matrix coding queries, which I copied and pasted into Microsoft Excel so that I could visualize the data with bar graphs, which I provide in chapter four; I found that these bar graphs are a simpler means of understanding matrix coding query results. In tandem with thematic analysis on spreadsheets, I used these data in order to develop concept maps of how participants' educations, beliefs, and interests inform their educational goals and pedagogical practices.

Following Maxwell's (2013) suggestion to visualize the components of a research design, I created the table below to outline the ways in which the three research questions at hand guided the design of this qualitative interview study. 
Table 1

Research Questions, Data Collection and Analysis, and Validity Threats

What do I need to know?

RQ1 What do Catholic theology teachers in Pacific Northwest Catholic high schools believe about the purposes and goals of religious education for religiously diverse student populations, especially with regard to the role of catechesis therein?

RQ2 What particular curricular and pedagogical decisions do Catholic theology teachers in Pacific Northwest Catholic high schools make in order to meet the needs, interests, and positionalities of their non-Catholic students?

RQ3 How do theology teachers in Pacific Northwest Catholic high schools consciously diverge from/and or adapt the USCCB Framework (if at all) in their service of religiously diverse student populations who represent Catholic, non-Catholic Christian, non-Christian, and nonreligious traditions and contexts?

Why do I need to know this?

RQ1 The USCCB bishops published the Framework in 2008, and over ten years later, little is known or understood about how theology teachers' positionalities and beliefs impact their approach toward educating religiously diverse students.

RQ2 Little is known or understood about how theology teachers engage non-Catholic students, and invite the perspectives and voices of religiously diverse students into their classes.

RQ3 Little is known or understood about how theology teachers are diverging from and/or adapting the mandated curricular Framework in their service of religiously diverse students.

What kind of data will answer these questions?

RQ1 Interview data from the first interview (questions 4, 5, 6, and 7, in particular); interview data from the focus group interview (questions 2, 3, and 4) in particular); analytic memos following interviews

RQ2 Interview data from the second interview (questions 2, 3, 4, 5, 6, 7, and 8 in particular); interview data from the focus group interview (questions 2, 3, and 4 in particular); analytic memos following interviews

RQ3 Interview data from the third interview (questions 3, 4, 5, 6, 7, 8, and 9 in particular); interview data from the focus group interview (question 4 in particular); analytic memos following interviews; documentary artifacts offered by the participants, such as curriculum maps, scope and sequence documents, departmental documents, or teachers' reflective journals 


\section{Collection and analysis plans}
RQ1 Recording and transcription of interviews; analytic memos; first and second cycle coding of interview and memo data
RQ2 Recording and transcription of interviews; analytic memos; first and second cycle coding of interview, memo, and documentary artifact data
RQ3 Recording and transcription of interviews; analytic memos; first and second cycle coding of interview, memo, and documentary artifact data

\section{Potential validity threats}
RQ1 Researcher bias (i.e. dislike of USCCB Framework) influencing questions, interviews with participants, leading to only investigate data that confirms my biases and beliefs regarding religious education.

RQ2 Insufficient analysis and interpretation of the data, or ignoring of interview data, due to conscious and unconscious bias of the researcher.

RQ3 Inadequate inclusion of discrepant evidence, due to conscious and unconscious bias of the researcher.

Possible strategies for dealing with validity threats

RQ1 Carefully formulating truly open-ended questions, selecting participants as neutrally as possible so as to not select those who would confirm my beliefs, values, and perceptions. Conducting multiple semi-structured interviews with participants and triangulating data sources to provide rich data and analysis

RQ2 Analytic memos throughout the data collection process, thorough coding and analysis of data, member checking through individual correspondence and focus group interview with all participants; not using conceptual framework of Critical Religiously Sustaining Pedagogy to evaluate teachers' beliefs and practices

RQ3 Member checking through individual correspondence and focus group interview with all participants; thorough and inclusive coding and data analysis

\section{Rationale for strategies}

RQ1 I did not want to select participants who would just confirm my biases.

RQ2 I did not want to lead participants into "proving" the tenets of my conceptual framework, nor do I want to place value judgments on their teaching. 
RQ3 I do not want to prove that teachers are diverging from and/or adapting the USCCB

Framework, but I did want to discover how teachers are doing so if they are.

In this chapter, I explained the rationale behind this study, as well as the various elements of its design, focusing on the research questions, my role as researcher, and the various threats to validity and how I attempted to mitigate negative ramifications of those threats. I concluded this chapter with an overview of my data collection and analysis procedures. This design provided the foundation for how to best go about answering my research questions throughout the interviews, and elevating my participants' voices in data collection, analyses, interpretations, and findings. 


\section{Chapter 4: Findings and Discussion}

\section{Introduction}

Students in Catholic high schools deserve theological education that is sensitive, meaningful, and relevant to their systems of belief (or lack thereof). The general problem is that the USCCB Framework, published in 2008 by the bishops of the United States, is not sensitive, meaningfully relevant, or sustaining for students of diverse religious positionalities and identities. The specific problem is that teachers who employ the catechetical USCCB Framework may harm students who do not share the Catholic faith. Over the course of a decade of teaching theology to religiously diverse student populations, I have come to realize that many teachers, both those I worked alongside and those I have conversed with from other schools, were rebelling against and/or ignoring the Framework in their teaching. In this study, I wanted to understand how teachers' positionalities, informed by their educations, experiences, and personal beliefs about education and Catholicism, inform their approach to teaching theology. In light of teachers' positionalities, I sought to examine teachers' goals in educating religiously diverse student populations, their pedagogical praxis, and the decisions they make in adhering to, adapting, and/or diverging from the USCCB Framework.

I interviewed five teachers with a variety of experiences, who taught at Catholic high schools in the Pacific Northwest, one of which was an archdiocesan school, and four of which were sponsored by particular religious orders. Although this was not a Participatory Action Research study, I did strive to elevate and foreground these teachers' voices through in-depth interviews. 
I explored the following research questions:

1. What do Catholic theology teachers in Pacific Northwest Catholic high schools believe about the purposes and goals of religious education for religiously diverse student populations, especially with regard to the role of catechesis therein?

2. What particular curricular and pedagogical decisions do Catholic theology teachers in Pacific Northwest Catholic high schools make in order to meet the needs, interests, and positionalities of their non-Catholic students?

3. How do theology teachers in Pacific Northwest Catholic high schools consciously diverge from and/or adapt the USCCB Framework (if at all) in their service of religiously diverse student populations who represent Catholic, non-Catholic Christian, non-Christian, and non-religious traditions and contexts?

In this chapter, I will present an analysis of the interview data, the interpretation of the findings, and limitations of the study.

\section{Presentation of Results}

In the following section, I first outline participant profiles for each of the five teachers, based on the concept maps in Figures 5, 6, and 7. I then proceed to interpret the themes that respond to each of the research questions. Throughout my interpretation, I make connections between evangelization and emancipation, which are the overarching goals of Critical Religiously Sustaining Pedagogy (CRSP), and existentially meaningful content, religiously sustaining instruction, and nurturing and loving relationships, which 
are CRSP's three central tenets. Throughout my interpretations, I interweave visual depictions (namely, hierarchy code charts and matrix coding queries) and explanations of these results upon which I base my interpretations.

\section{Concept Maps for Participants}

In order to understand the ways in which teachers' positionalities influence their praxis, I created concept maps with Lucid Chart (https://www.lucidchart.com). I had completed first and second coding cycles of all interviews, and had begun to analyze the data before I created these maps, which helped me to organize my thoughts around each individual, supplemented by the analytic memos I had written. I created three different concept maps: Figure 5 presents the overall concept map (without any detail) of how a participant's positionality informs their attitude, goals, and teaching practice; Figure 6 (essentially a zoomed-in version of the first half of the overall concept map) presents a detailed map of how a participant's education, life experiences, and personal interests inform their attitude toward theological education for religiously diverse students; and Figure 7 (essentially a zoomed-in version of the second half of the overall concept map) presents a detailed map of how a participant's attitude toward theological education for religiously diverse students informs their goals, which in turn informs their teaching practices. 


\section{Figure 5}

General Concept Map: Participant Positionality Influencing Attitude, Goals, and Practice

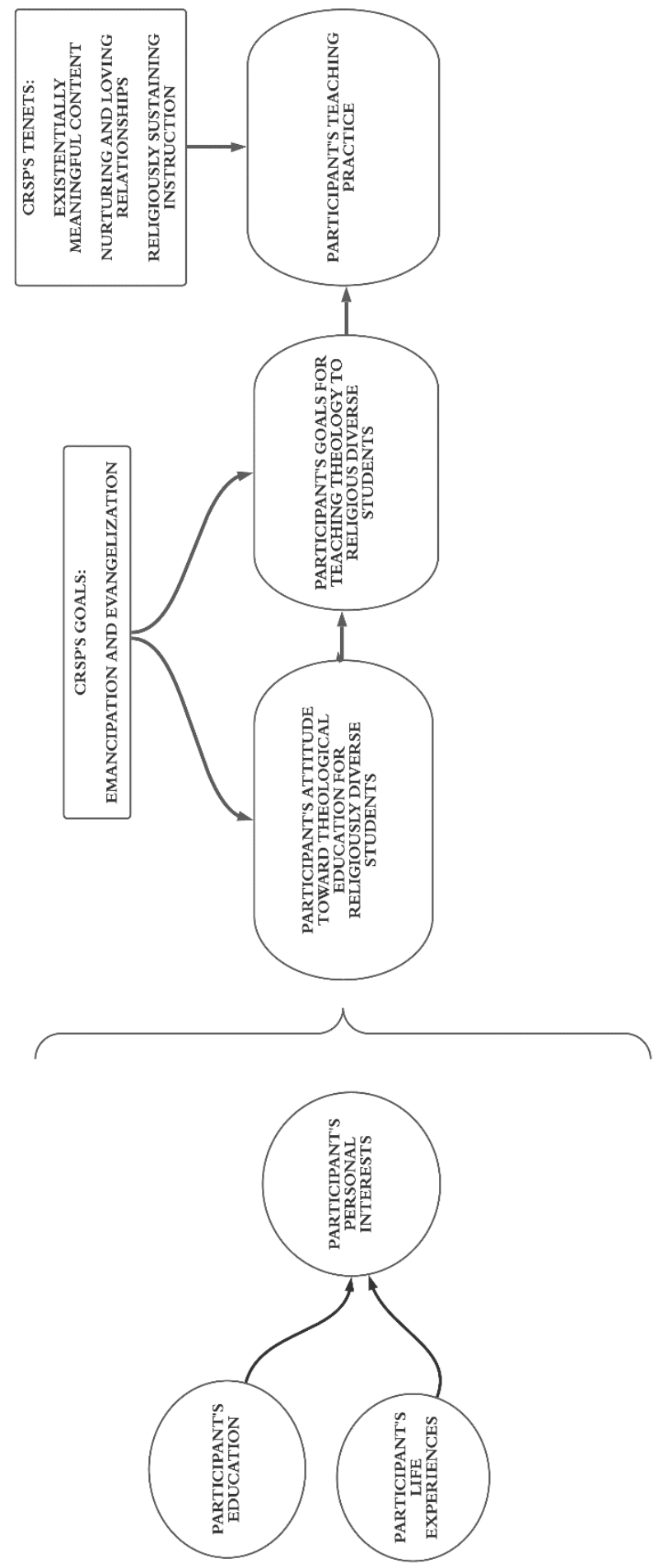


On the left side of the general concept map, the three bubbles constituting education, life experiences, and personal interests comprise a participant's positionality, based on information I learned from the first round of interviews. Teachers did not explicitly address this process, as I did not construct the maps' representations prior to the interviews, but rather inferred the representations following data analysis. A teacher's education and life experiences inform their personal interests. In turn, this overall background shapes a teacher's attitude toward theological education for religiously diverse students, which in turn informs their overall goals for teaching theology, which in turn informs their teaching practice. In thinking through and creating this concept map, it became clear to me that the overarching goals of CRSP, emancipation and evangelization, are embedded within participants' attitudes and goals for teaching theology to religiously diverse students. As for how participants enact these goals in their practice, they do so, in large part, through CRSP's three tenets (existentially meaningful content, nurturing and loving relationships, and religiously sustaining instruction), which I believe are naturally embedded within their practices. To be clear, participants were unaware of the conceptual framework prior to the interviews, and so they could not have consciously explained how the tenets manifest in their teaching; all of the following analysis regarding how CRSP manifests and is embedded within my participants' beliefs, goals, attitudes, and practices, is based on my own inferences. 
Figure 6

Detailed Concept Map: Participant Positionality Informing Attitude toward Theological Education

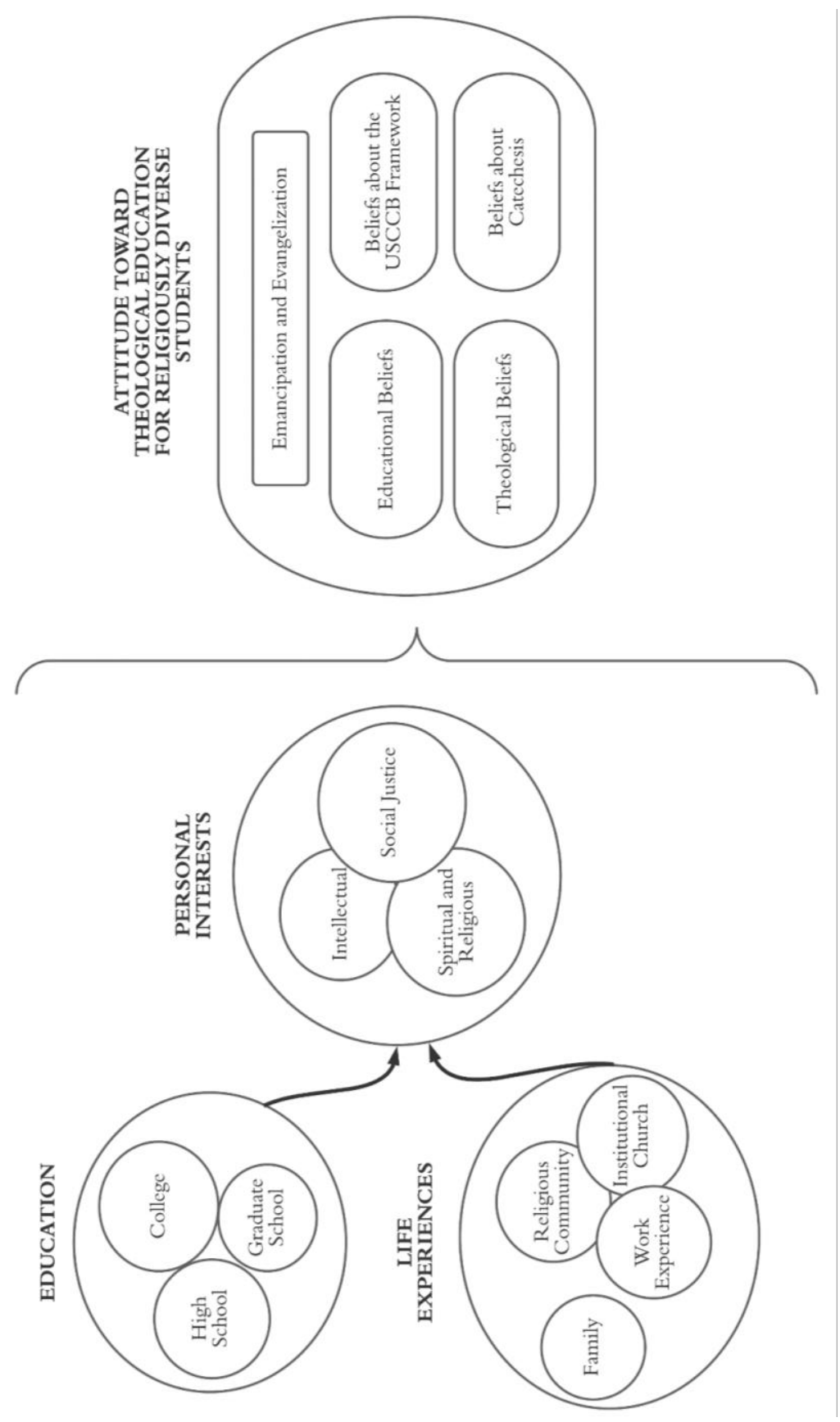


Figure 6 presents the first half of the concept map in greater detail. Teachers spoke about their high school, college, and graduate school educations, as well as their life experiences outside of their educations. While not all participants addressed each aspect of the various dimensions comprising their life experiences (and by no means is this an exhaustive depiction of the infinite aspects that reflect a person's experiences), most participants spoke to most of these dimensions. There is some overlap between a person's religious community (either their belonging to a religious order, or a parish, or a more general community of Catholics), their experience of the institutional Catholic Church (because they belonged to a religious community), and their work experience (because they might have taught, or be teaching as a member of a religious community). In turn, these educational and life experiences inform teachers' current interests, with regard to their intellectual, spiritual/religious, and social justice interests. The sum of these components (once again, a picture is limited, and this is by no means a complete picture, given the infinite mystery and depth that is a human being) constitutes a teacher's positionality, as they made known throughout their interviews. All of these components inform a teacher's attitude toward educating religiously diverse students, in and through which the overarching goals of CRSP, evangelization and emancipation, came to the fore. A participant's attitude is generally formed by four different facets (each of which is colored by a participant's desire to emancipate students and live out the evangelizing mission of Catholic educational institutions). These facets consist of: their educational beliefs regarding educational institutions, theories, and/or practices; their theological beliefs regarding God, Catholicism, interreligious dialogue and activities, personal 
spirituality, and so on; their beliefs about the USCCB Framework, such as their positive and negative evaluations of it; and their beliefs about catechesis as a mode of theological education, such as their positive and negative evaluations of it, and whether or not it is suitable for theological education at the secondary level. At the heart of these teachers' vocations to teach theology is a love for Jesus, a love for Catholic theology, and a desire to teach from these loves. This living out of one's faith, so that it can be a light for others, is a form of evangelization. While I constructed these maps based on inferences based on data analysis, I would posit that the overall processes depicted by the maps are broad and natural enough (in the sense that one's life experiences and educational backgrounds generally inform one's practice) to apply to many theology teachers educating religiously diverse student populations. 
Figure 7

Detailed Concept Map: Participant Attitude Influencing Goals and Teaching Practice

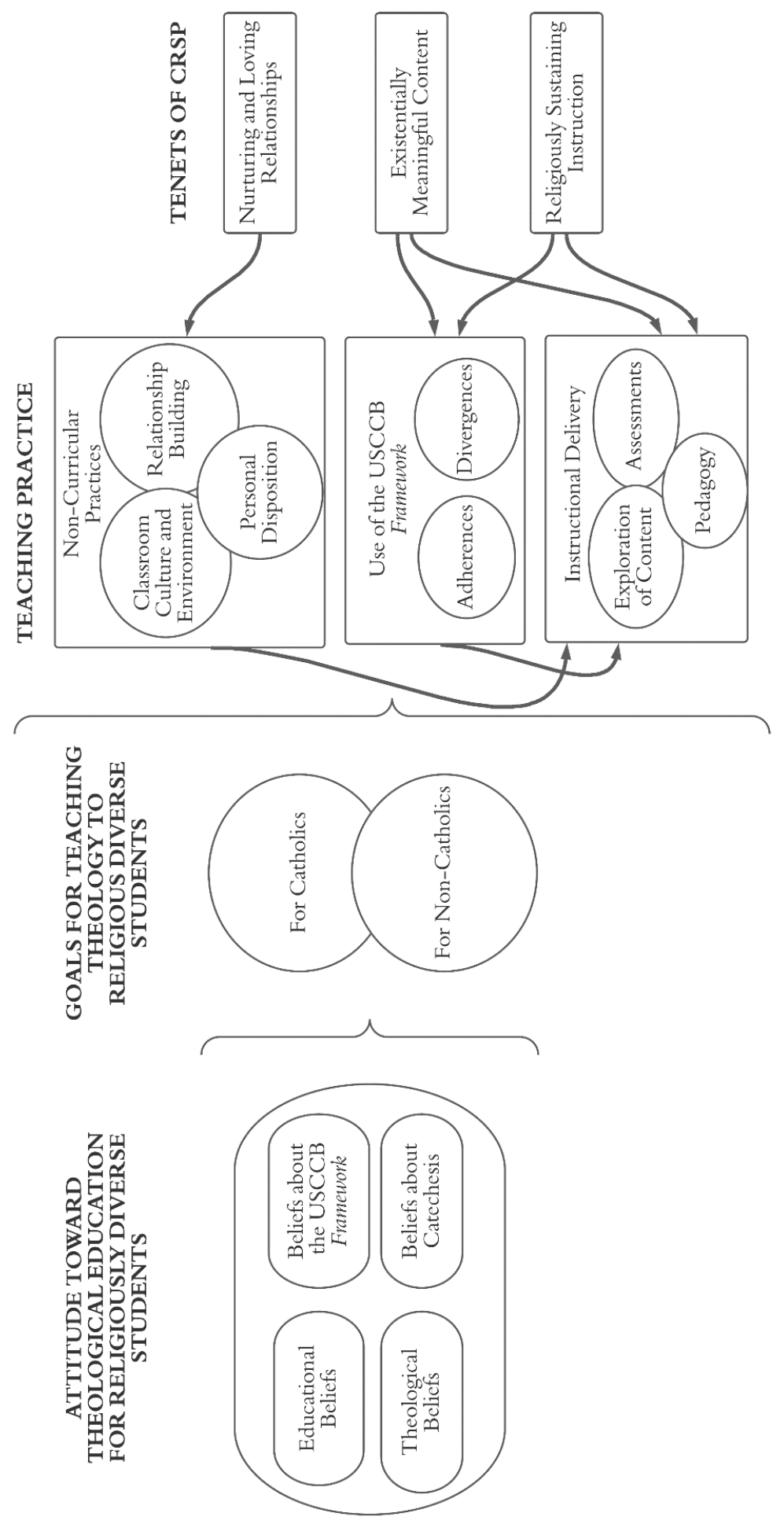


Figure 7 shifts to the right-hand side of the overall concept map, and depicts how a participant's attitude toward theological education for religiously diverse students informs their goals for teaching theology, which in turn informs their teaching practice. A participant's educational and theological beliefs certainly inform their goals for educating religiously diverse students, as do their beliefs about the Framework and catechesis, which I will demonstrate in the individual participant profiles. Participants generally did not differentiate between having different goals for Catholic and non-Catholic students, hence the overlap between these bubbles in the figure (the figure does not accurately represent how much these goals do, in fact, overlap for most participants, given the spacing constraints of creating the graphic).

These goals (such as teaching students Catholic theological ideas, helping them to discover the sacred, and fostering critical exploration of their own lives, or of religion and/or Catholicism) in turn influence how a teacher actually goes about teaching. I discovered three broad areas of teachers' practices, which they addressed in our interviews: non-curricular practices, instructional delivery, and their use of the USCCB Framework. I found non-curricular practices to be difficult to define, as participants discussed a broad spectrum of things they do within and outside of the classroom that are unrelated to teaching content. Some participants spoke about the ways they develop classroom culture and environment (such as co-creating a space that is inclusive, and safe for students to express their opinions and beliefs), some spoke about the general disposition they hold (such as being humorous, friendly, and welcoming), and all spoke to the ways that they build relationships with students, both within the classroom and 
outside of it. As the figure depicts, CRSP's tenet of fostering nurturing and loving relationships manifests in this area of teaching practice. Teachers' approaches to developing relationships influences how they use the Framework, which is the second area of teaching practice, and comprises the ways they adhere to it, and the ways they diverge from it. Teachers' use of the Framework influences the third and final area of their teaching practice, instructional delivery, which involves both how a teacher helps students to explore content (via direct instruction, critical exploration, and/or conversation and dialogue) and how a teacher assesses students (such as through reflection papers, participation, and/or creative assignments). The relationship between content exploration and assessments is interwoven, given that assessments can be projectbased and/or formative rather than summative, and that instruction is frequently guided by formative assessments. I perceived the second and third tenets of CRSP, existentially meaningful content, and religiously sustaining instruction, to emerge from the transcripts in places where participants spoke about their use of the Framework and their instructional delivery. For example, in order to provide existentially meaningful content or to sustain students' religious positionalities, a teacher might adapt or omit content from the Framework, which would consequently affect the content and assessments they deliver.

\section{Participant Profiles}

In the following profiles, I narrate how teachers' educational and life experiences, and theological and educational beliefs influence their praxis, following the concept 
maps' structures. I discuss the participants in alphabetical order of their chosen pseudonyms and maintain this order whenever I list their names concurrently.

Emma. Emma is a white woman who has been teaching for nearly forty years. She holds a bachelor's degree in history from a secular state school, a master's in church history from a Catholic graduate school, and a teaching credential from a secular state school. As a graduate student in church history, Emma encountered professors whom she cited as highly influential, because they were unafraid to challenge episcopal hierarchy, or engage the harm that the Catholic Church has perpetuated throughout history. Emma belonged to a religious order of Catholic sisters, and she began teaching as a sister, but left the congregation in her thirties; in this congregation, Emma worked alongside "wonderful" sisters who served as examples of how to engage and teach theology critically and creatively.

Emma is a department chair at a Catholic high school ("St. John's") that is affiliated with a religious order and primarily educates low-income students, over $90 \%$ of whom identify as people of Color, $32 \%$ of whom are Catholic, and 25\% do not identify with any religious tradition. She currently teaches Morality and Catholic Social Teaching to juniors and Sacraments and World Religions to seniors. Emma has a deep love for Catholicism, but is highly critical of the institutional Church, and much of her perspective has been informed by teaching students whose ancestors have often been oppressed and marginalized by institutional religion. Throughout my interviews with her, Emma emphasized her passion for teaching theology through the lens of human history and narrative experience, which entails doing so with a spirit of honesty and transparency, to 
approach the failures and sinfulness of the Church, "warts and all." Emma does not see herself as a catechist, and loves giving students the freedom to question, doubt, and explore. Above all, she wants to accompany her students as a mentor and companion on the journey of faith, and wants students to be able to discover the sacred in themselves and in the worlds that they inhabit, regardless of whether or not they are Catholic. She very intentionally creates a space for students wherein they are free to question and explore, affirming students' perspectives and expertise, and emphasizing their ability to succeed in theology class. As department chair, Emma uses the Framework to provide an overall structure to the scope and sequence of the four-year theology curriculum, and to make sure that she and her teachers are teaching the entirety of this scope and sequence. Emma describes the Framework as a "skeleton," and the work that she and her colleagues do as giving it a "heart" and "flesh."

Francis. Francis is a white male who has been teaching theology for 30 years, 28 of which have been at his current school (“All Saints"), which is affiliated with a congregation of women religious, and where he is department chair and teaches courses on World Religions and Relationships. Francis approximates that half of his students are Catholic, many are Protestant Christians, and a few are Hindus and Buddhists. He holds a bachelor's in philosophy, and a master's in comparative religions, both of which are from the same secular state school; given his training in philosophy, Francis approaches theology through ontological and hermeneutical lenses (that is, he is interested in the lived experience of faith, and the interpretation of theology for application to lived experience). Growing up in the Midwest, Francis described his experiences of parish life 
as being life-giving in their communal nature, but has been witness and victim to hypocrisy within the institutional Church, having been forced out of his first teaching job after reporting an abusive priest-principal (who called girls "whores" and drank while driving students to athletic competitions) to the archdiocese.

Francis stated that he does not teach theology to "placate bishops," and is not interested in catechesis because "salvation is not information." Throughout and ever since graduate school, Francis's engagement with non-Abrahamic religious traditions, namely Buddhism and Hinduism, has heavily influenced his approach to theology. Francis defines teaching theology as being "ontological," which is to say that he wants his students to engage what is, which includes their lives, their emotional states, and their experiences, in order to open themselves to the transcendent. For Francis, faith is "a way of being," rather than a process of intellectually assenting to doctrine, or a basis of comparing one's own religious beliefs to others' beliefs. Francis emphasizes "translating" Catholic theology in order that students can understand and apply concepts to their lived experiences, and understand the ways in which they experience the transcendent. Francis is very cognizant of toxic influences from culture, and perceives that students live "in the Matrix," where they suffer from inauthenticity, anxiety, stress, and shallowness. His own experiences of seeking therapy for coping with a "narcissistic" mother and an "alcoholic" father have led him to pursue an interest in psychology, which he brings into the classroom by teaching students the psychological benefits of spiritual practices from a variety of religious traditions. In light of these interests and experiences, Francis maintains that theology is a means through which students can grapple with and 
overcome these harmful cultural influences. Exploring the psychological dimension of theology is a means to an end for Francis, and his main goals for teaching theology are to help students "love life" (he interchanges "life" and "God" regularly) and love themselves, and to engage the transcendent dimension of human existence.

Father Paul. Father Paul is a white male who is a priest, and has been teaching theology for eight years at a diocesan high school (St. Joseph's). Father Paul holds a bachelor's degree in theology from a Catholic university, and a master's in divinity from the seminary he trained at to become a priest. Father Paul attended a Christian high school dedicated to "classical" education, which involved exploration of the Western canon and primary sources through Socratic seminars, and he repeatedly cited this education as influencing his love of theology and philosophy (as academic disciplines searching for "beauty, truth, and goodness"). He belongs to an ecumenical community of charismatic ${ }^{11}$ Christians, most of whom identify as Catholic; being a part of this community has made him especially "sensitive" to the needs and beliefs of non-Catholic Christian students. Father Paul primarily teaches freshman and sophomore theology (Revelation and the Bible, and Ecclesiology and Christology, respectively), and taught Morality and Catholic Social Teaching to junior students for the first time in the 2020-21 academic year. He estimates that about $65 \%$ of his students are Catholic, and $35 \%$ are

\footnotetext{
${ }^{11}$ By "charismatic," I refer to the movement within Christianity that dates back to the early twentieth century. Charismatic Christians believe they have been baptized in the Holy Spirit (which is distinctly separate from the Trinitarian baptism that is often given at birth in mainline Christian denominations); this baptism gives them the supernatural gifts of prophecy, speaking in and interpreting tongues, and healing, among others.
} 
non-Catholic Christian, with very few non-Christian students. He thinks that about $20 \%$ of his students attend church regularly.

Father Paul is the most theologically traditional of my participants (he stated in the focus group, for example, that he believes it is inappropriate for teachers to express opinions and beliefs that diverge from Catholic teaching with their students), but I do not want to convey the impression (given much of the rhetoric surrounding the dynamics of U.S.-based Christianity in popular media) that his orthodoxy leads to rigidity and judgmentalism. While he is generally approving of catechesis, which he believes is best undertaken in a parish setting, Father Paul strives to respect the religious consciences of his students and does not try to convert anyone. He does not consider his teaching of theology to be catechetical, because he believes it to be inappropriate for his students, many of whom are not Catholic, and seeks to invite students to question official teaching, thereby giving them freedom of theological exploration. Throughout our interviews, Father Paul emphasized his love for Catholic ideas and teachings, and primarily spoke about engaging students in the sphere of the intellect. His primary goals are to explain the Catholic faith, help students understand Catholicism and the Catholic worldview, and to develop their "first principles" by engaging the Catholic "framework" of "understanding life." I believe that in speaking of these "first principles," Father Paul was referring to the most deeply held beliefs and perspectives that shape one's engagement with oneself, others, and the world; such principles could include, but are not limited to, one's view of God, moral frameworks, beliefs about Jesus, and so on. 
Hans. Hans, a white male who has been teaching theology for seven years, taught English abroad for two years and history in a public school for two years before that. He holds a bachelor's in theology from a Catholic university (where his faith was reinvigorated by a priest-professor of literature and theology, and by his interactions with evangelical Christians), a teaching credential from a secular state school, and a master's in theology from a Catholic graduate school. Hans is a convert to Catholicism, and throughout his young adulthood, he experienced waxing and waning of his faith; he described his heart as "Protestant," and values the role of struggle and doubt in theology. Hans described going through religious education programs that were neither “challenging" nor "meaningful"; and so, he strives to do the opposite for his students, and believes he does a much better job of religious education than what he endured as a teenager. Hans teaches Catholic Morality and Catholic Social Teaching to juniors, a class on Christian Lifestyles to seniors, and a class on Theology and Media to seniors. Hans taught Introduction to Catholicism and Revelation for the first time to freshmen in the 2020-2021 academic year. 60\% of Hans's students identify as Catholic, and he estimates that $20 \%$ are practicing Catholics, $20 \%$ are struggling with their faith, and $20 \%$ are nonpracticing. His remaining students are non-religious or Protestant.

On the theological spectrum, Hans tends toward the orthodox, and has a healthy appreciation for how many evangelical churches approach evangelism, with regard to developing relationships. Consequently, Hans favors an "evangelical" model (in terms of living out the Gospel, and not in terms of Christian denomination affiliation) over a "catechetical" model of religious education in Catholic high schools, which is to say that 
he values witnessing faith to students and offering them opportunities to engage faith, rather than assuming that students are Catholic. He does not believe that catechesis is appropriate in a secondary setting, given that students do not possess familiarity with and knowledge of Catholicism. Hans therefore values the roles of "struggle" and "doubt," and is very intentional with regard to how he goes about providing direct instruction and crafting assignments, so as to include non-Catholic students. This said, Hans is very interested in challenging students with theology, and making it "important" and "real": he aims to give students tools for developing practicable skills (such as various virtues in his Morality class, or discernment tools in his Christian Lifestyles class). His primary goals consist of teaching Catholicism as authentically as possible, so that students understand it and can confront religious hypocrisy or consider its relevance meaningfully, and he wants students to be able to authentically express themselves without having to "pretend" to be Catholic.

James. James is a white male who has been teaching religious education for about 35 years, twelve of which have been in Catholic high schools, including seven at his current employer, "St. Oscar Romero." James taught religious education in parishes for many years, has taught comparative religions in a local community college, and currently teaches a dual-credit World Religions course for seniors, as well as a freshman class on Introduction to Catholic Christianity. James holds a bachelor's degree in English from a Catholic university, where he was in the Air Force ROTC program, and a master's in Comparative Religions from a Catholic university, which he pursued later in life. As a teenager, James survived sexual abuse at the hands of a religious brother who taught him 
in high school. Speaking of this trauma, James stated that it "just so shaped my life, my worldview, the kind of person I am," but it became clear to me that James has forged beauty from evil in his teaching; as a survivor of such profound trauma, he does not buy into the trope that such evil happened to him for a reason. Of the institutional church, James tearfully told me, "I've been so hurt by this institution, I hate it. But there is so much beauty in the Jesus movement, and even in the Catholic expression of the Jesus movement" that drives his teaching.

Several decades ago, James was an officer in the Air Force, but reading the works of Gandhi and the Reverend Dr. Martin Luther King, Jr. catalyzed a religious conversion while working at an Air Force base that possessed and housed nuclear weapons for B-52 bombers, and he consequently left the military as a conscientious objector. This metanoia toward nonviolent resistance initiated a spiritual quest for him, which would last many years and grew out of the tension between James's love for Jesus and James's woundedness. James very much does not care about students memorizing catechetical doctrine, but wants them to develop the self-awareness that they are lovable and good, and to learn how to be in a healthy relationship with themselves, others, creation, and "Spirit" (as James tends to call God). He does not pay attention to the USCCB Framework whatsoever, as he views it as a "heartless" and "bloodless" attempt at indoctrinating students, which he has no interest in partaking in.

\section{Themes}

Table 2 displays the themes that I generated from this study. While each of the three interviews focused on the individual research questions, I created themes across 
interviews, and data pertaining to each research question did not emerge solely from one round of interviews. This said, I divided themes and sub-themes among the three research questions.

Table 2

Themes Generated from Analysis

\begin{tabular}{|c|c|c|}
\hline Research Question & Theme & Sub-Theme \\
\hline \multirow{3}{*}{$\begin{array}{l}\text { RQ1: Beliefs about } \\
\text { purposes and goals } \\
\text { for teaching theology, } \\
\text { and the role of } \\
\text { catechesis }\end{array}$} & $\begin{array}{l}\text { 1. Opposition to } \\
\text { Catechesis and the } \\
\text { Framework }\end{array}$ & \\
\hline & $\begin{array}{l}\text { 2. Existential Meaning } \\
\text { and Relevance }\end{array}$ & $\begin{array}{l}\text { 2a. Translating Catholicism } \\
\text { 2b. Personal Well-Being and Spirituality } \\
\text { 2c. Discovering the Sacred }\end{array}$ \\
\hline & $\begin{array}{l}\text { 3. Freedom for } \\
\text { Exploration and } \\
\text { Authentic Self- } \\
\text { Expression }\end{array}$ & $\begin{array}{l}\text { 3a. Exploration of Content } \\
\text { 3b. Assessments }\end{array}$ \\
\hline \multirow{3}{*}{$\begin{array}{l}\text { RQ2: Curricular and } \\
\text { pedagogical decisions } \\
\text { to meet non-Catholics }\end{array}$} & $\begin{array}{l}\text { 4. Relationship } \\
\text { Building }\end{array}$ & $\begin{array}{l}\text { 4a. Classroom Culture and Environment } \\
\text { 4b. Ways of Relating }\end{array}$ \\
\hline & 5. Critical Exploration & $\begin{array}{l}\text { 5a. Of Self } \\
\text { 5b. Of Content }\end{array}$ \\
\hline & $\begin{array}{l}\text { 6. Instructional } \\
\text { Delivery }\end{array}$ & $\begin{array}{l}\text { 6a. Centering Student Voice in Conversation and } \\
\text { Assessment } \\
\text { 6b. Responding to Student Need } \\
\text { 6c. Intentionality in Wording } \\
\text { 6d. Essential Questions }\end{array}$ \\
\hline \multirow{4}{*}{$\begin{array}{l}\text { RQ3: Use of the } \\
\text { Framework }\end{array}$} & 7. Structural Adherence & \\
\hline & 8. Benefits of the Frame & work \\
\hline & & 9a. Omissions \\
\hline & 9. Divergences & $\begin{array}{l}\text { 9b. Additions } \\
\text { 9c. Emphasis and De-Emphasis }\end{array}$ \\
\hline
\end{tabular}




\section{Research Question 1: Teachers' Beliefs About Theological Education}

I generated three themes in response to the first research question, "What do Catholic theology teachers in Pacific Northwest Catholic high schools believe about the purposes and goals of religious education for religiously diverse student populations, especially with regard to the role of catechesis therein?": (1) opposition to catechesis and the Framework, (2) existential meaning and relevance, and (3) freedom for exploration and authentic ${ }^{12}$ self-expression. These three themes pertain to several key findings in response to this research question. First, I discovered that my participants by and large maintain negative dispositions towards catechesis as a mode of theological education for non-Catholic students (although they did have some positive evaluations of catechesis within a parish setting, or for using it as means of educating curious and sincere Catholic students), and four participants had serious critiques of the Framework because it is catechetical. Second, all of my participants spoke to their desire to provide theological education to students (regardless of their religious beliefs) that is relevant and meaningful for their existences as human beings who breathe and move within this world. Third, each of my participants offers their students the freedom to explore theology as they desire, and to express themselves authentically, both of which are means of honoring and respecting students' identities and positionalities.

Opposition to Catechesis and the Framework. The first theme is opposition to catechesis and the USCCB Framework. Four of the five participants expressed

\footnotetext{
${ }^{12}$ When using the term "authentic" to refer to students' self-expression, I intend to convey the mode of self-expression in and through which a student is unafraid to state and dialogue about their beliefs without pretending to hold beliefs that they do not.
} 
dissatisfaction and disagreement with catechesis on various levels, and all of the participants expressed discontent with the Framework to various degrees. Teachers primarily ground their opposition to catechesis in its focus on memorization, which participants viewed as irrelevant, meaningless, and potentially harmful for students, but participants also raised the Framework's lack of theological depth due to doctrinal narrowness being problematic.

As Figure 8 reveals, participants overwhelmingly spoke of catechesis negatively, both in evaluation (e.g., sub-codes within "negative evaluation of catechesis" included "memorization" and “- irrelevant") and in sentiment. Interestingly, the ratio of negative and positive evaluations of catechesis is quite similar to that of negative and positive evaluations of the USCCB Framework (Figure 9). Visualizing this hierarchy chart, and seeing how strongly participants opposed catechesis, led me to generate theme 1 , "opposition to catechesis and the Framework," in response to the first research question. I believe this is a significant theme in understanding how teachers approach teaching theology, and how and why they diverge from the Framework in their pedagogical practices. These approaches and divergences revolve around their attempts to present existentially meaningful content, and to provide religiously sustaining instruction. I found it revelatory that even when teachers positively evaluated catechesis, it was largely in a conditional way: catechesis is beneficial for committed Catholic students who are interested in learning more about their faith. Thus, such positive evaluations do not give an accurate representation of participants' evaluation of the role of catechesis in high schools with large non-Catholic populations. 


\section{Figure 8}

Hierarchy Chart of Child Codes within "Evaluations of Catechesis"

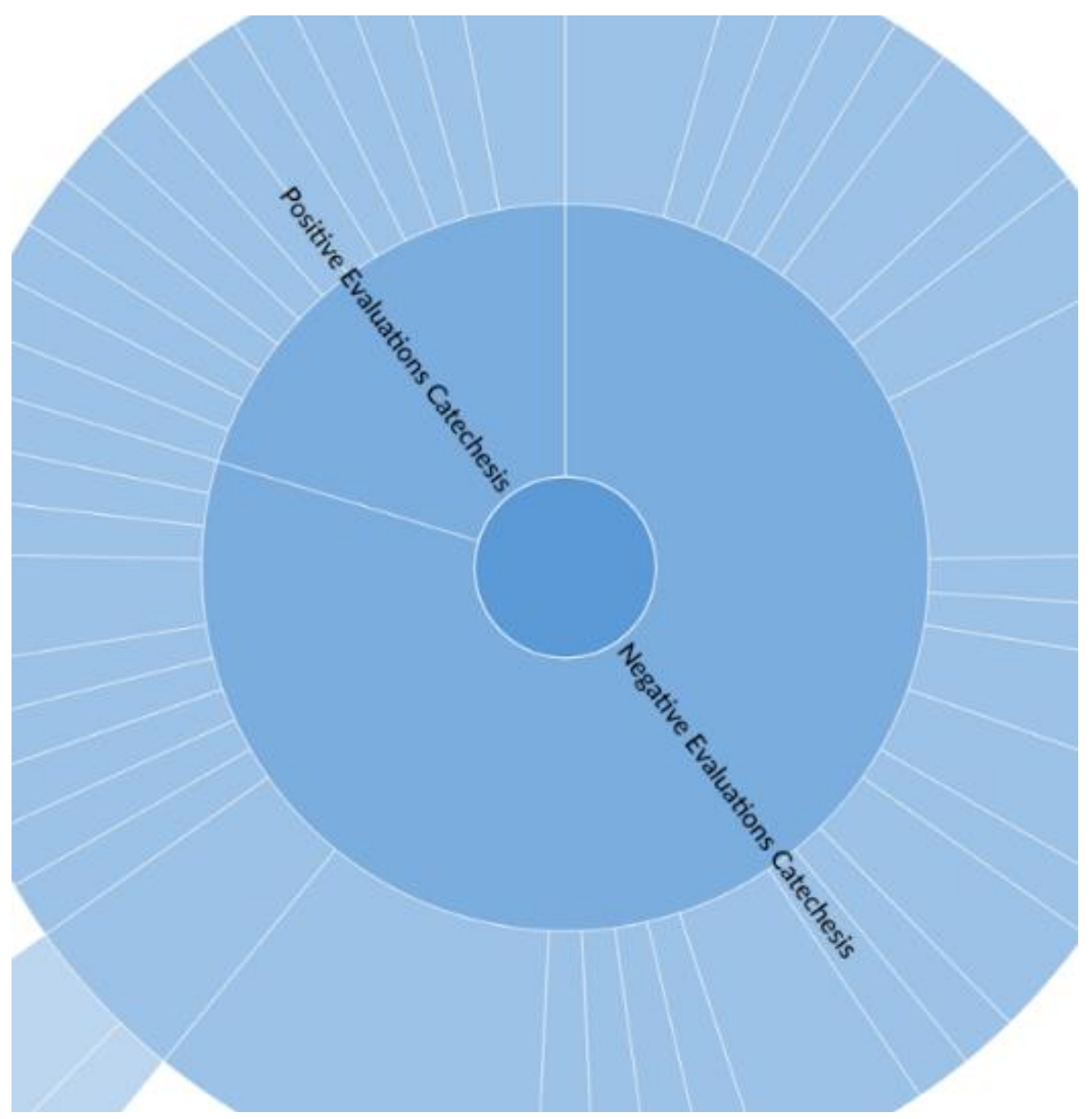

Participants' positive evaluations of the USCCB Framework, depicted in Figure

9, struck a similar dynamic to their positive evaluations of catechesis. Visualizing this hierarchy chart, along with the hierarchy chart of evaluations of catechesis, brought me to generate theme 1. Examining positive evaluations more closely, I discovered that these codes mostly pertained to the role the Framework plays in providing teachers and 
departments with structure for their curricula, and several forms of accountability, such as making sure that teachers are not teaching whatever they want, and are remaining connected to Catholicism outside of their personal interests and biases. As the hierarchy chart displays, there were many reasons (as indicated by child and grandchild codes) why participants disliked the Framework, which gave me ample material to analyze theme 1 and interpret the nuances within it.

Figure 9

Hierarchy Chart of Child Codes within “Evaluations of USCCB Framework”

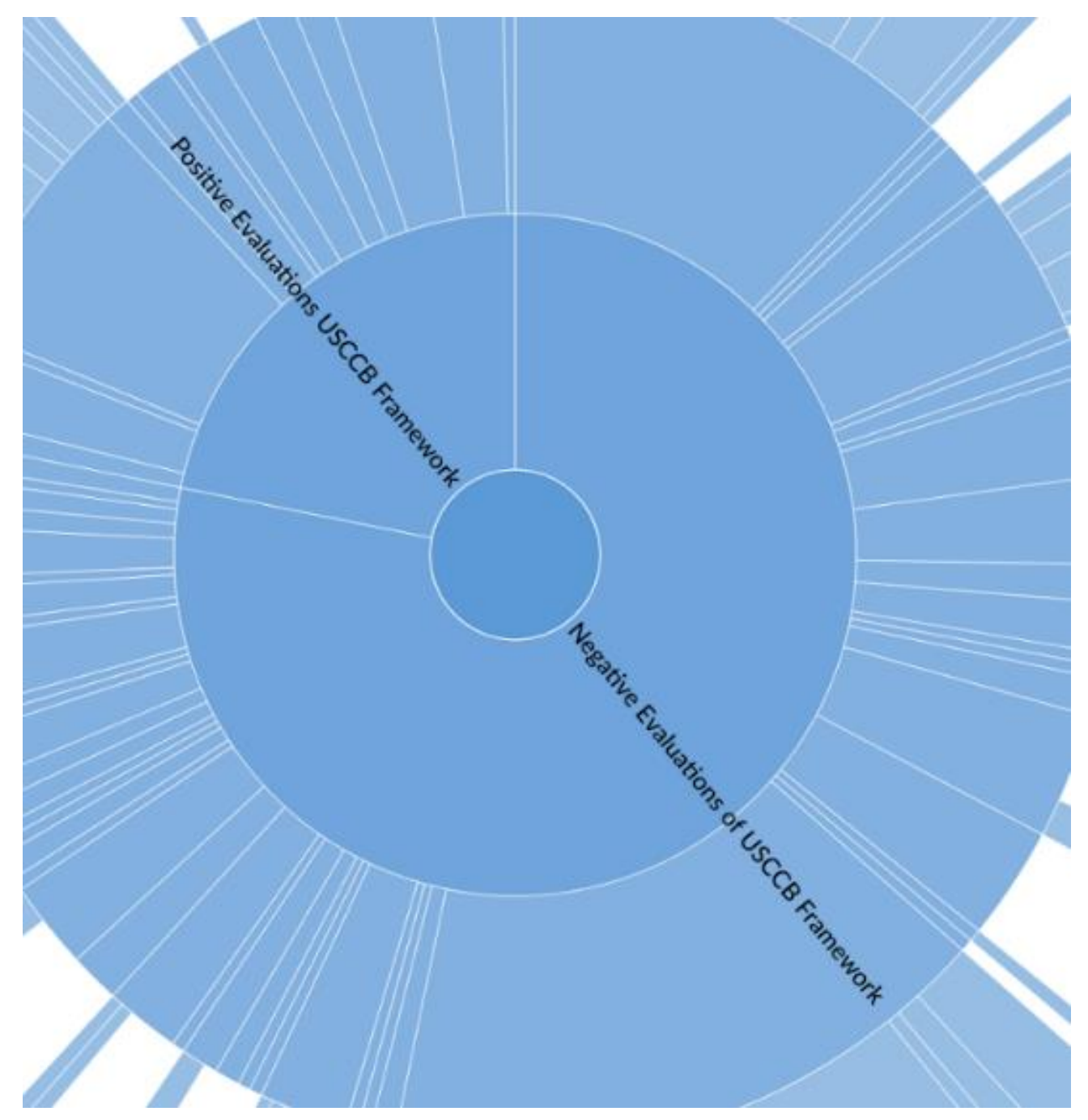


Regarding participants' positive and negative evaluations of catechesis (Figure 10), of institutional Catholicism (Figure 11), and the USCCB Framework (Figure 12), it is rather remarkable how negatively participants spoke about these three topics. I provide these bar graphs in order to help the reader visualize the discrepancies between participants' positive and negative evaluations of these items. I did not ask participants to provide negative or positive evaluations of catechesis as a mode of theological education, or of the institutional Church, which accounts for the relatively low number of references to these particular codes, although I did inquire about their general thoughts on catechesis's role in Catholic high schools, which naturally solicited positive and negative evaluations. With this solicitation in mind, I do think it is notable that despite not having asked participants to evaluate catechesis or the institutional Church, they did nonetheless articulate such evaluations in their responses.

The presence of negative evaluations does not mean that the participants are not Catholic, or do not love Catholicism or Jesus. Rather, their critiques of catechetical theological education, and the institution of the Catholic Church, stem from their deep love of Jesus and Catholic theology. Each of the participants, except for Father Paul, spoke about various wounds they had suffered at the hands of religious authorities and hypocrisies they had witnessed by members of the institutional Church, from being a victim of sexual abuse as a teenager (James) to witnessing inappropriate relationships between priest-professors and students in graduate school (Hans). I found it unsurprising that participants' negative experiences of clergy or Catholicism as an institution might very well inform their negative evaluations of catechesis and the USCCB Framework, 
given that catechesis and the Framework frequently focus on claims to truth flowing from magisterial authority. While these negative experiences might not be the only variable that affected the frequency of participants' negative evaluations (for example, many Catholics have become disillusioned with hierarchical authority in light of the sexual abuse crises since the early 2000s, thereby leading them to generally distrust the bishops), and while I do not believe I can prove a causal connection (given that interview questions did not seek to establish such causal connections), participants did speak to these negative experiences of the institutional church even though I did not ask them to do so. Rather, participants raised these issues when responding to questions about, for example, their general experiences of Catholic education or their introductions to the Framework when it was first published.

\section{Figure 10}

Bar Graph Depicting Matrix Coding Query of Participants' References to "Evaluations of Catechesis" Codes

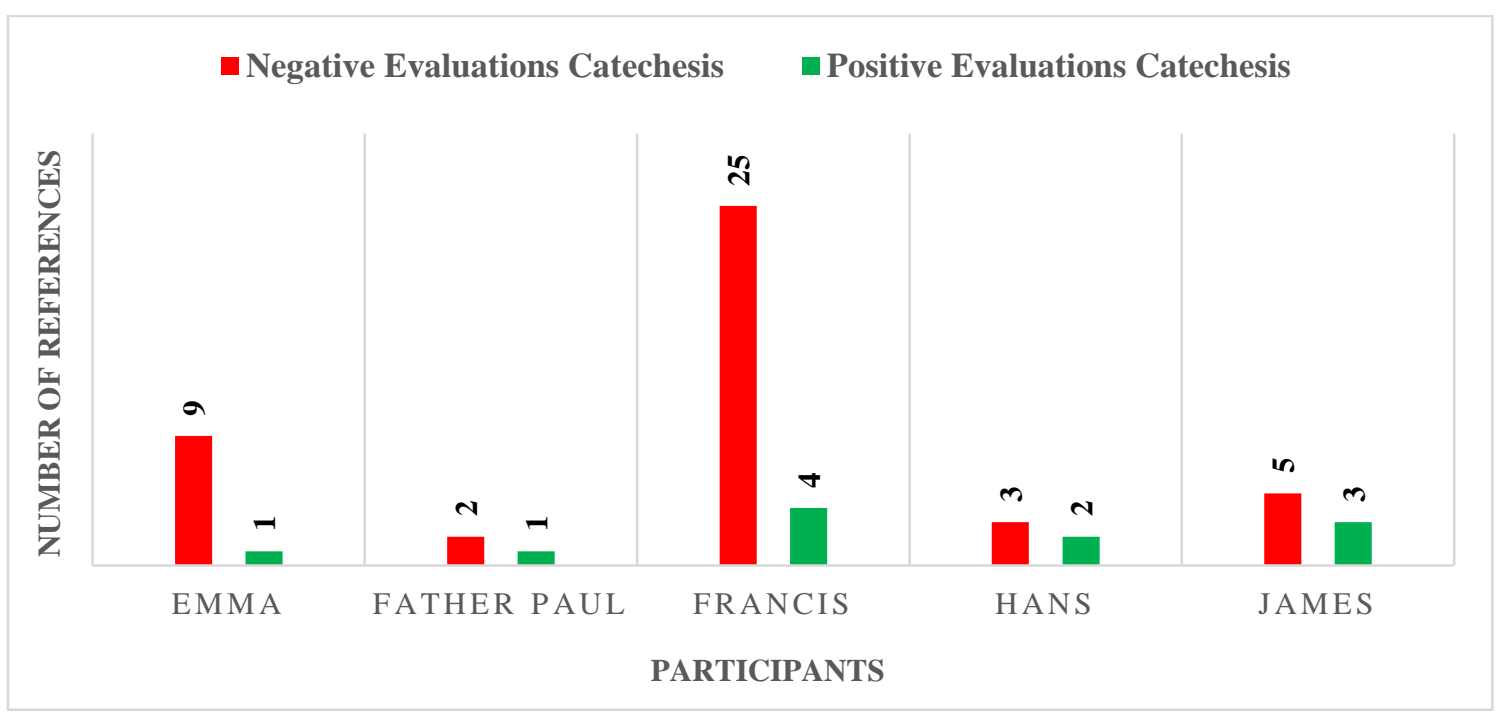


Figure 11

Bar Graph Depicting Matrix Coding Query of Participants' References to "Evaluations of Institutional Catholicism" Codes

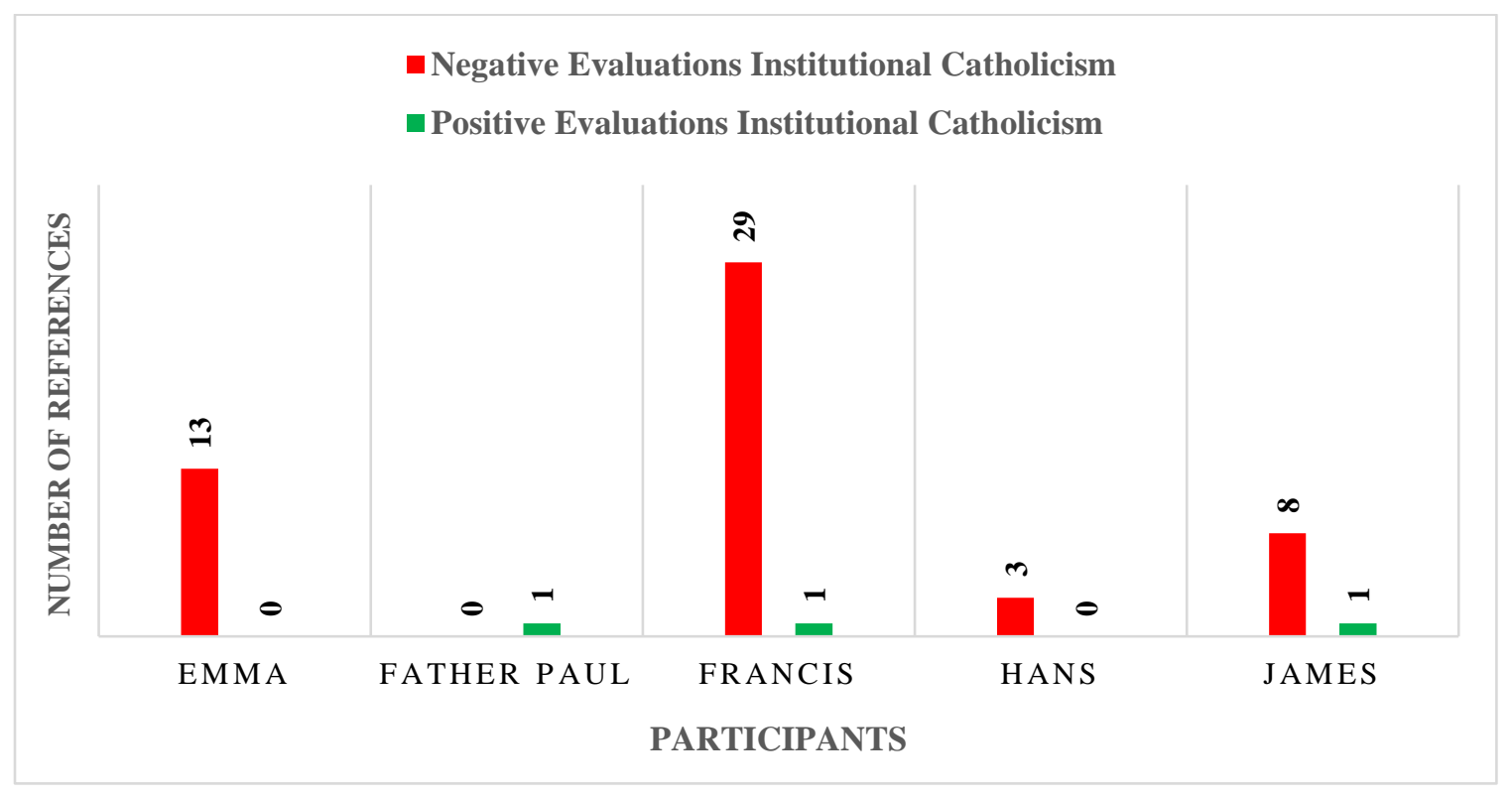

\section{Figure 12}

Bar Graph Depicting Matrix Coding Query of Participants' References to "Evaluations of USCCB Framework" Codes

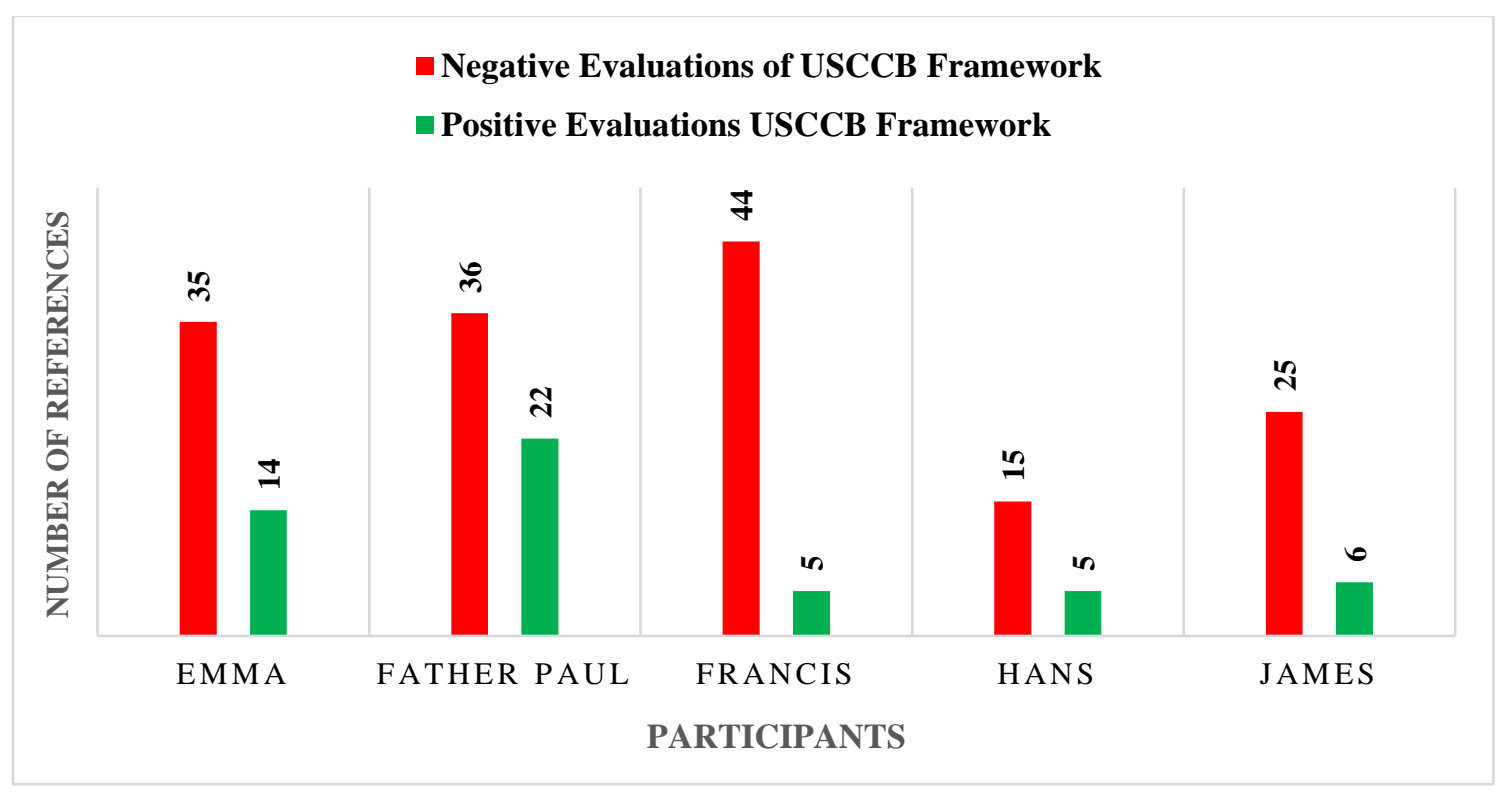


The matrix coding queries of these various evaluations pertaining to catechesis, the USCCB Framework, and institutional Catholicism (the graphs of which are depicted in Figures 10, 11, and 12, respectively) revealed a few interesting insights. First, participants did offer some positive evaluations of the Framework, mostly regarding how it provides structure and consistency for curricula across the nation, and keeps teachers accountable (as I discussed in the coding hierarchy charts). Second, the trends of evaluations across participants maintained very similar ratios. The Framework received the most negative evaluations, followed by institutional Catholicism, followed by catechesis (with Father Paul being the exception, given that he had nothing negative to say about the institutional Church).

Of the five participants, Father Paul is the only person who did not speak negatively about catechesis as a mode of theological education, but he does not view himself as a catechist; Emma, Francis, Hans, and James do not view themselves as catechists either, largely because catechesis focuses on the memorization of doctrine, a goal which none of them share given that they aim to provide content that students will find existentially meaningful, and help to sustain and form students' religious beliefs, even if those beliefs are not Catholic. James went so far as to opine that, "if I had a bishop sitting in on my classroom or Zooming into my classroom, the way I deliver my material would probably be so suspect. I don't know, I don't know. I might be out of a job. And that's my judgment." When James expressed this, it made me all the more aware of the need to safeguard my participants' identities, should this research scandalize a potential reader who could do them professional harm. 
Apart from not identifying as catechists, all of the participants stated that they do not aim to convert students to Catholicism, even to the point of explicitly telling students this in class. Father Paul and Hans did discuss a shared aim of conveying Catholicism authentically to leave students with the opportunity to convert if they so chose. Although Father Paul did not negatively evaluate catechesis as a concept, he did state that it most appropriately belongs in a parish, precisely because its goal is to form disciples of Christ, which he believes is an inappropriate aim for a high school theology class because so many students are not Catholic. Although Father Paul said that he would be "overjoyed" if a student did decide to convert to Catholicism, he does not aim to convert anybody, and is there "to help people with the faith that they do have" through "honest discussion;" I believe this position is indicative of instruction that is religiously sustaining. Each of the participants addressed the reality of the fact that not many students in their classrooms are practicing Catholics, and that many do not practice or identify with any religious tradition whatsoever. With the reality of students' religious diversity in mind, Hans framed his disagreement with a catechetical approach within the broader goal of evangelism:

And I think that's kind of something that I think that schools should wrestle with...is like, are you trying to be evangelical or catechetical, in a sense? And I think we talked about this before.... are you instructing people who are already Catholic and furthering their knowledge base and depth? Or are you talking to people who are not Catholic and kind of giving invitation, challenge, and apologetics [defending one's faith], sort of, as well? Yeah, I see the school where $50 \%$ of the kids aren't Catholic, even nominally, it must be an evangelical model.

Hans thus believes that Catholic school administrators and teachers cannot assume that their students are Catholic, or want to be Catholic, and that Catholic students frequently lack basic religious education that previous generations of Catholics generally received. 
Because such Catholic students lack the "grammar" of Catholic religious education, attempting to catechize with more advanced doctrine simply does not make sense. And so, instead of aiming to catechize, Hans believes that Catholic school teachers must aim to live out their faith, rather than draw students into Catholicism. Hans's statements thereby reflect CRSP's overarching goal of evangelization: he believes that teachers have a greater need to witness and live out their Catholic faith, rather than impart their Catholic faith upon students.

Table 3 displays students' religious identities, according to the participants; each of the participants was confident that a relative minority of students came into their classrooms with significant commitment to their faith tradition, and even those students who identify as Catholic tend not to be churchgoing or practicing.

\section{Table 3}

Participants' Perceptions of Their Students' Religious Demographics

\begin{tabular}{lccccc} 
Participant & $\begin{array}{c}\text { Practicing } \\
\text { Catholics }\end{array}$ & $\begin{array}{c}\text { Non-Practicing } \\
\text { Catholics }\end{array}$ & $\begin{array}{c}\text { Non-Catholic } \\
\text { Christians }\end{array}$ & $\begin{array}{c}\text { Non-Abrahamic } \\
\text { Religious }\end{array}$ & "Nones" \\
\hline Emma & $19 \%$ & $18 \%$ & $27 \%$ & $15 \%$ & $20 \%$ \\
Fr. Paul & $\sim 15-20 \%$ & $\sim 40 \%$ & $\sim 30 \%$ & very few & $\sim 10-15 \%$ \\
Francis & & $\sim 50 \%$ & unknown & unknown & $\sim 30-40 \%$ \\
Hans & $\sim 20 \%$ & $\sim 40 \%$ & very few & very few & few \\
James & & $\sim 66 \%$ & unknown & unknown & unknown
\end{tabular}

As a model for theological education, catechesis aims to have students memorize doctrine and dogma, which Emma, Francis, Hans, and James all viewed as unnecessary and irrelevant. Their statements substantiated my argument that catechesis is unnecessary 
because it lacks existential meaning for the lived experiences of students, and fails to sustain their diversity of religious beliefs. In Francis's words, "salvation is not information," and taking an apologetic stance in theological education that aims to defend Catholicism (either theologically or institutionally) from question and critique is pointless because "nobody ever converted to Catholicism because they lost the argument." Emma pointed to the Framework "not being inspirational," because it "felt much more factdriven," and because of this motivation to memorize doctrine, "looking straight at the document, there wasn't room for a faith journey and it was more of an academic approach to studying things and memorizing essential terms in their minds, but no meaning behind some of it, too." In other words, Emma believes that memorization fails to provide existentially meaningful content and religiously sustaining instruction. Emma and Francis, who were the only two participants who taught high school theology at the time of the Framework's promulgation, and were both department chairs in 2008, said that the bishops failed to consult students, teachers, educational theorists, or adolescent psychologists in its drafting.

As to the bishops' reasons for mandating the Framework's implementation across Catholic schools, Emma, Francis, and James all indicated their belief that the US bishops wrote the Framework as an attempt to preserve and assert their authority in the wake of the sexual abuse scandals that rocked the U.S. Catholic Church several years before its publishing. Catholics in the pews were questioning episcopal authority given the bishops' failings of ethics, honesty, courage and leadership, and so these participants who taught throughout the scandals' unveilings view the Framework in the particular light of 
preserving authority. Francis perceives that the Framework came out of an "inquisition mentality," through which the bishops wanted to answer the questions of: "Are these guys [teachers] really Catholic enough? Or, are these guys, are these religion teachers really teaching the faith?" Likening the U.S. bishops to the widely lampooned and feared Inquisition of the medieval Catholic Church, Francis perceives the bishops as using the Framework as a means to shore up their authority and guarantee doctrinal orthodoxy among high school teachers. In spite of this perceived attempt, Francis acknowledged that the bishops have no "street cred" among students, given the bishops' enabling and hiding of abuse among clergy, and that attempts to exert magisterial authority consequently fall on deaf ears.

Some dioceses and schools within the U.S. require students to take the ACRE (Assessment of Children/Youth Religious Education) test administered by the National Catholic Education Association, which aims to "assist in the evaluation of catechetical/religious education programs in Catholic schools and parishes" and "is based on the Catholic Church's expectations for an organic, systematic, and comprehensive education in Christian discipleship" (National Catholic Education Association, n.d.). Regarding this test, Francis said, "I think the ACRE test is a trivialization of the tradition, at best. It's not a measurement of faith, it's a measurement of religious ideology." In her separate interview, Emma expressed a similar attitude toward the ACRE test: "And that other test, the ACRE test, that's not my favorite thing ever, in terms of trying to reduce the mystery and beauty of faith down to one objective test is not my calling." Emma and Francis were the only two participants to bring up the ACRE test in their interviews, but 
Father Paul, Hans, and James also critiqued the Framework as being too narrow in its doctrinal focus, and therefore lacking theological depth. Assessing and numerically quantifying students' knowledge of Catholic doctrine and dogma does not mean that those students even believe in that doctrine and dogma, after all.

Hans brought up the fact that there are a lot of materials for Catholic religious education for students of elementary school age, and that theological education at the level of higher education is very rich, but there is a dearth of material for students in between those extremes. He critiqued the Framework for abstracting elementary theology in a manner that fails high school students:

And I think this is a problem in Catholic academia in general, that we have very good materials for elementary school students, and we have very good materials for college students and above, we have almost nothing that's good in between. [Laughter] And so, I think that the Framework is kind of a mix of those two extremes. And so, it's kind of looking at the college-level intellectual side, and it's very heady. And at the same time, it asks so little depth and it's just on the surface that it seems to be kind of, like, an upper abstract version of what you would teach to elementary school students too. So it's kind of that odd mix that tends to miss both. That if I'm at a college level, and I'm just learning this, I'll add a lot more depth. And if I'm learning this at a high school level, which is what it's designed for, I'll kind of feel that it's just rote, and kind of a similar, but different mix there.

When I asked Hans whom the Framework benefits, he had trouble coming up with an answer:

And so, I don't know that... any particular group of students that it helps. I suppose, like, I think it could do so for a sincere Catholic student who hasn't thought very deeply about their faith. I think that might be the student who could gain the most from it.

This was consistent with other participants' responses, who also noted that it primarily benefits Catholic students who enter high school with foundational theological knowledge from their families or parish experience, and are curious. In other words, 
participants believe that the Framework benefits the typical audience of catechesis: committed Catholics, or those who desire conversion to Catholicism.

Francis noted a similar lack of depth, or interesting material, within the Framework, and stated that, "The bottom line is just, there's not that much in it. You can teach the whole thing in two weeks. If you just literally wanted to teach the catechism, or teach the Framework, there's really not a lot in there." Even though the Framework is almost sixty pages long, I think Francis might have been hyperbolizing a bit in order to drive across the shallowness of memorizing doctrine. In other words, Francis felt that if the goal of a theology teacher is simply to have students memorize doctrine and dogma, they could accomplish that goal in a relatively short period of time, even though it might not be existentially meaningful or religiously sustaining. When I asked Francis about which students the Framework is detrimental for, Francis told me that students weren't aware of it, because the courses taught at All Saints involve so much more than teaching the Framework's content. Emma, on the other hand, felt that the Framework suffers from an overwhelming amount of "information" that "was impossible to teach." It is important to note that these teachers perceive that the overarching goal of the Framework is the conveyance of knowledge that students are to memorize.

Father Paul feels that he and his colleagues follow the Framework fairly closely, perhaps because they work in a diocesan high school that is more closely tied to its bishop's oversight, and he accurately views the Framework as a guide, rather than a set of lesson plans. Father Paul articulated his perception that the Framework didn't seem to have a lot of direct lesson plans for the students, or anything like that. Of course, not lesson plans, but maybe the language of it, and just the 
presentation of it, didn't seem to be necessarily teacher-lesson-plan friendly, if I'm able to make up a term. That there was going to have to be some fair amount of little steps, you know, mediating the Framework to actual lesson plans in the classroom.

When he spoke about textbooks based on the Framework and sanctioned by the bishops, Father Paul indicated that the books were "too much in lockstep with the Framework and not taking it more like a guide, but taking it more like a lesson plan itself," and consequently "found that there wasn't as much narrative that was flowing well [...] as there should have been." Of the five participants, Father Paul is the only teacher who uses textbooks based on the Framework, which I discuss in themes 7, 8, and 9, on uses of the Framework.

Apart from the Framework's emphasis on memorization of doctrine, several participants described the Framework's catechetical impetus as being harmful to students, in part due to its failure to maintain relevance for students' diverse religious beliefs. James described the Framework as not only irrelevant for non-Catholics, but discouraging and harmful as well:

I find it all uninspiring. It seems, not just like the Framework itself, but then the delivery of the Framework, it's this...it's a download of information. It seems that this is what they want, it's a download of information. I don't see much heart in it. It feels as though it's trying to convince people that Catholics are right. And that the Catholic Church is right. I think the detriment is for those students who aren't Catholic, it's offensive sometimes. And for a lot of people, it's kind of like well whatever, [yawn]. I don't really care, of course [the bishops are] going to think that, of course they're going to think they're best. But for someone who is not Catholic, or for someone who is perhaps progressively Catholic, I think it's frustrating, it's hurtful. I think it really misses the heart and soul of Jesus. The focus on doctrine and dogma. I'm not saying it's unimportant, it's good to know what you believe. But damn. It's meant to be lived out, and this document just feels bloodless. It feels like there's no heart to it. And that is death, and that is detrimental, that's a turn off. It's uninspiring. Why would I want to be part of that? 
James's love of Jesus as a person shines through in this quote, and he has trouble reconciling this love, and his desire to evangelize and live out the Gospel through his love, with the Framework's mandate to catechize, which results in approaching the teaching of theology as a debate. Emma shared a similar perspective; when the Framework first came out, Emma felt more beholden to teach its contents, and found that students felt "defeated" by having to memorize so much material:

They felt defeated. They kind of felt that their journey was not being recognized through the Framework. They may not know the vocabulary, but they know the experience. And the journey to find the sacred can be really hard work. So I just remember them hating those tests. And they weren't valuable in terms of the grades, but for a whole semester of discussion, journey, questing, all those things, to be reduced to one test was defeating.

Emma discovered that not only was catechetical memorization existentially meaningless and irrelevant for her students, but it actively fostered their dislike of theology because it failed to meet their journeys and needs, and/or sustain their beliefs.

Existential Meaning and Relevance. Theme 2, which I generated in response to the first research question, is existential meaning and relevance: participants believe that theology classes should be existentially meaningful and relevant for teenagers, helping them to engage their lives in various ways. This theme directly connects to CRSP's central tenets of providing existentially meaningful content and sustaining students' religious beliefs. While participants expressed various reasons for their opposing the traditional catechesis as exemplified by the USCCB Framework, they also discussed their reasons for teaching theology, and goals for their students. I created three sub-themes based on these discussions: (2a) translating Catholicism, (2b) well-being and personal spirituality, and (2c) discovering the sacred. 
Figure 13, "Hierarchy Chart of Child Codes within Parent Code 'Purposes of Theology Teaching,"” displays the child codes into which I coded participants' stated purposes of theology (the overarching parent code), which are, in order of numerical quantity: goals for relevance, goals for students with particular beliefs, spiritual goals, and intellectual goals. Codes from this hierarchy contributed to the themes of "existential meaning and relevance," (as well as theme 3, "freedom for exploration and authentic selfexpression" and theme 5, "critical exploration") in particular. There were times when participants mentioned specific goals for students who were not Catholic (such as "understanding Catholicism" or "finding common ground with religion"), or who were nominally but not practicing Catholic (such as helping them to see that theology is relevant), and so on. Regarding the three other categories, participants discussed overarching goals, unrelated to students' particular belief systems (participants generally do not differentiate learning for students of particular beliefs, but provide freedom for students to engage from whatever beliefs they hold, which I think is an educational act of emancipating students for authentic self-expression). While some intellectual and spiritual goals are of course relevant to the experiential learning of students, participants responded to direct questions about teaching theology in a manner that was relevant and meaningful for students, and it was from these responses that I coded "Goals for Relevance.” The hierarchy chart (Figure 14) depicting references within this family of codes demonstrates that participants strive to make theology existentially meaningful in a variety of ways, and also aim to stimulate students' intellects and spiritualities through 
the subject, all the while remaining attentive to, and sustaining of, the variety of religious or non-religious beliefs that students hold.

\section{Figure 13}

Hierarchy Chart of Child Codes within Parent Code "Purpose of Theology Teaching"

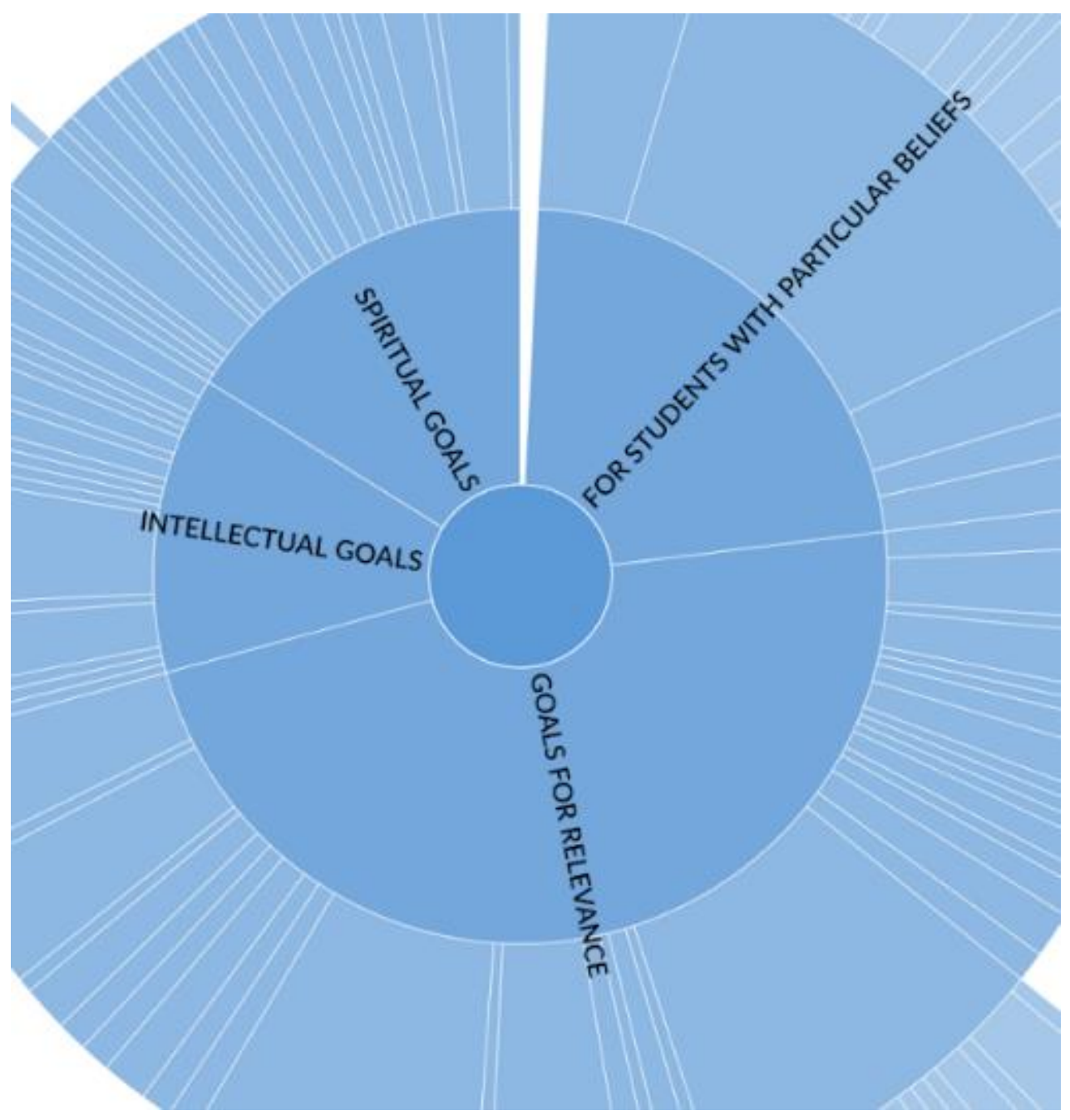

Figure 14 breaks down participants' goals for relevance (a child code of "purposes of theology"), which primarily include means of emancipating students from unhealthy influences from society and culture, or issues surrounding mental health, goals for helping students to build healthy relationships with people in their lives, various 
psychological benefits, and tools for developing virtues or skills that could be used in students' lives. These codes, and their corresponding preponderance of references, contributed most significantly to my generating theme 2 , "existential meaning and relevance," and theme 5, "critical exploration," and certainly relate to CRSP's central tenets of existentially meaningful content and religiously sustaining instruction. As the hierarchy demonstrates, participants had many different goals for teaching theology such that it is relevant to the lives of (or existentially meaningful for) students. Participants stated many different goals for relevance, some of which were more numerically prevalent than others, and statements pertaining to these goals were present across all the interviews. Thus, this particular hierarchy chart was especially significant for understanding the plethora of ways in which teachers approach theology as a subject that is deeply relevant for students.

\section{Figure 14}

Hierarchy Chart of Child Codes "Goals for Relevance" within "Purpose of Theology" Codes

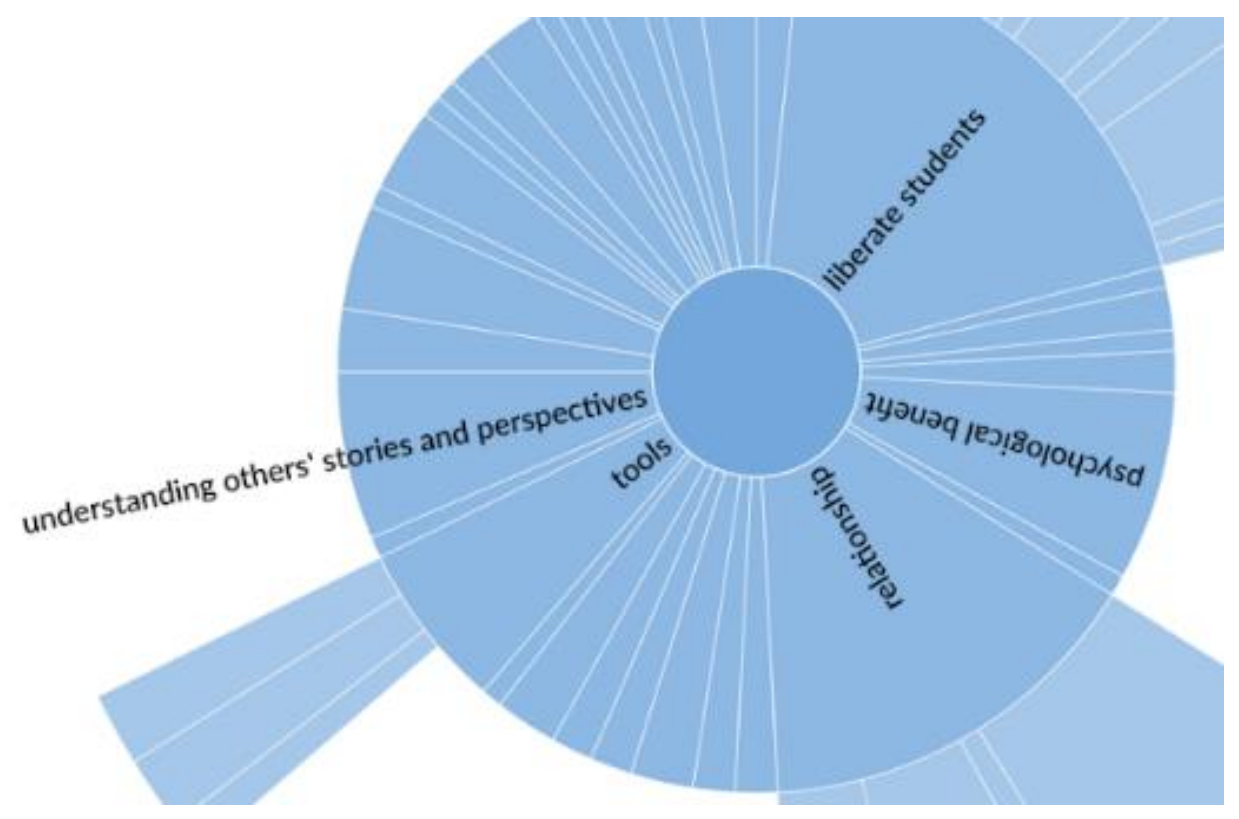


Perhaps the most revealing aspect of Figure 15, which shows the results of the query pertaining to participants' goals for the purposes of theology, are the red columns, which quantify their mentioning of goals for relevance. I found it important to visualize the number of times that participants spoke of these various purposes of theology, as doing so gave me insight into why participants spoke of their goals as they did. Francis most frequently spoke to teaching theology in a way that is existentially meaningful for students, largely because he expressed great interest in the emancipating psychological and mental health benefits of theology and spiritual practices. Father Paul, perhaps because he is most interested in intellectual pursuit of theological "ideas," discussed goals for relevance least frequently.

\section{Figure 15}

Bar Graph Depicting Matrix Coding Query of Participants' Purposes of Theology

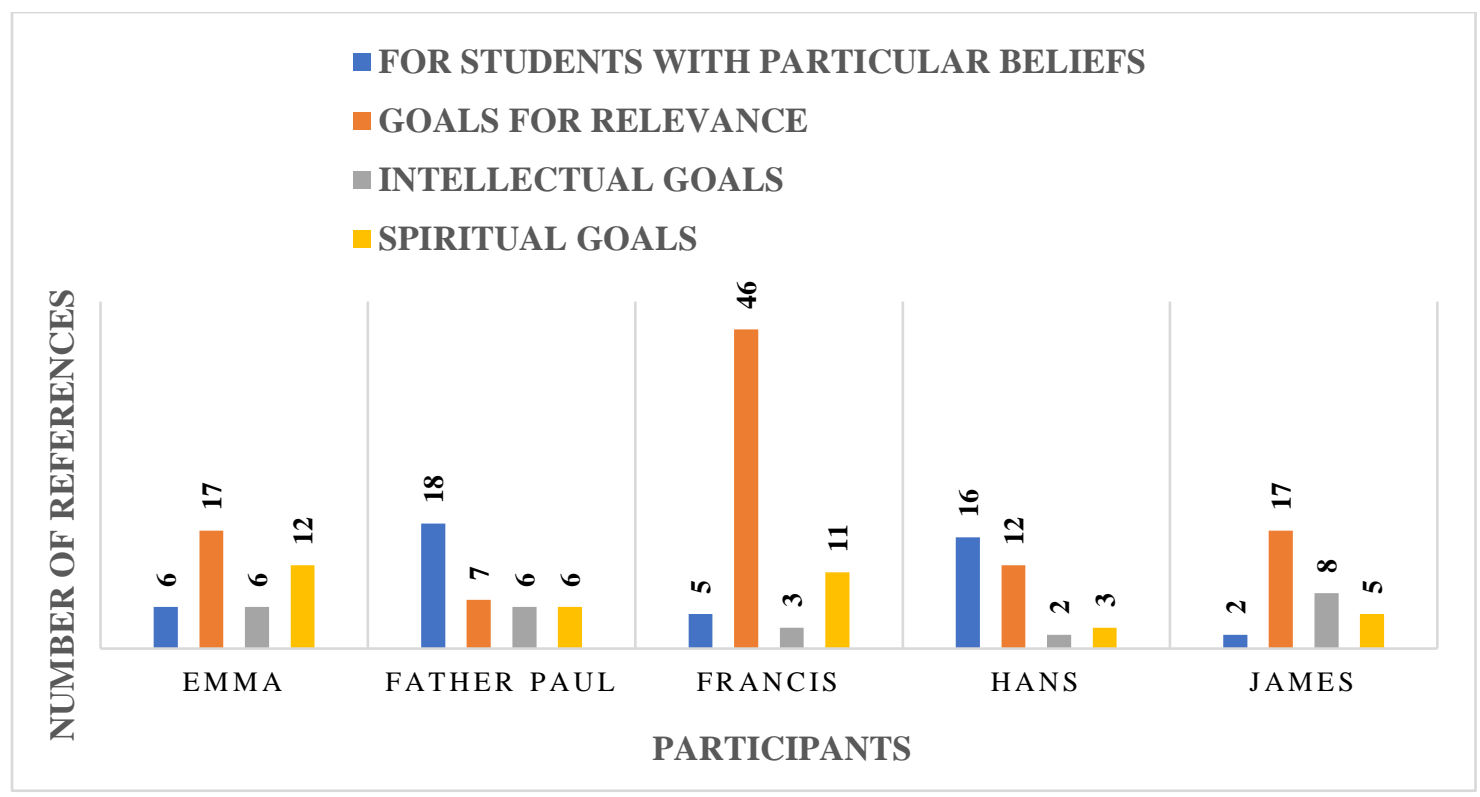

Participants addressed theme 2 of "existential meaning and relevance" differently, largely due to their own interests, influences, and backgrounds. Emma's academic 
training in history, coupled with her experience of teaching in a school comprised of over $90 \%$ students of Color, leads her to explore theology through the lens of history, story, and narrative: "I'm trying to find stories in the Catholic experience where the kids can resonate into the struggle of people of color within the church." She wants students to be able to connect their own experiences with the experiences of others, and so Emma approaches theology as a means of helping students to see their lives reflected in the lives of others, such that it is existentially meaningful. Francis spoke about how his interest in psychology has grown over the years, especially as he sought therapy to heal from strained relationships with his parents. In turn, Francis maintains a keen interest in the toxic influences of culture on students' mental health, and views theology as a means of liberating students from those pressures:

What I see in the classroom is, students benefit from a deeper....they're tired of the shallowness of the culture, they're tired of the shallowness of the church, they're tired of the doctrine of the church. They benefit from something that's real and meaningful and deep and profound enough to last longer than an opinion, or a theory.

With his more orthodox approach, Father Paul wants students to use Catholic theological concepts as a way to consider their own worldviews, perspectives, and experiences. As he said, Father Paul hopes to help students "with whatever faith they do have." Hans, who also desires to teach Catholicism authentically, is heavily oriented toward providing students with tools that they can meaningfully apply in any number of ways to their existences, aiming to help students apply theology to difficulties, challenges, and questions that arise within their lived experiences. For example, in his class on Morality and Catholic Social Teaching, Hans does not merely teach students about different 
virtues by means of direct instruction, he invites students to actively practice virtues so that "hopefully after you leave, and that by having these practices as you're working toward excellence, that this could serve you in...wherever you go"; Hans and his wife, who is a digital artist, have spent dozens of hours devising engaging infographics about virtues and how they are practiced. In his Vocations class, Hans's students do projects that are highly pragmatic; he designed a unit on money for example, wherein students learn how to budget for the real world and become responsible stewards of their resources.

Translating Catholicism. Participants intentionally try to "translate" Catholic theology (sub-theme 2a), in order to make theology class meaningfully relevant for students; they do so by universalizing essential theological concepts, and showing students how these concepts can be used by anyone, regardless of their religious beliefs. As I discuss in theme 6, "instructional delivery," participants often replace explicit Catholic terms with language that students can more easily understand or connect with; while this is an example of translating Catholicism, it is more directly a pedagogical strategy. Of all the participants, Francis was most interested in this notion of translating Catholicism, and used the language of "translation" regularly in our interviews:

And if I can't translate it into their world, and I expect them to believe because I said so, I'm asking them to be unfaithful. I'm also not trusting the believableness of what I'm saying, if I can't translate it. It must not be real if I can't make it realized in their real world. You don't, theoretically, love people, it has to be realized in actual life. 
In this statement, Francis touched on the tension between translating theology for students, as opposed to simply telling them what to believe (through catechesis, for example). Francis translates theology in every class he teaches:

So different classes, I might use different examples based on their lives. So the key strategy is to get to know the world that your students are living in. Get out of the ivory tower and don't make them try to understand some philosophical thing, go into their world, as messy as it is, like Jesus did. Go right to their world and explain this in their terms. And that's the hard part. It's not my agenda. Can I translate this into your world? Which is what Jesus did, I think he was brilliant at that.

Because Francis primarily teaches World Religions, rather than courses that involve more content directly drawing from Catholic theology, he speaks of translating theology as a general approach (and one that models Jesus, who often spoke in metaphors and analogies grounded in the context of his audience), rather than translating Catholic concepts for students. James also primarily teaches World Religions, and I think that these course assignments influence their position as outliers.

Regarding translating Catholic theology in particular, Emma, Hans, James, and Father Paul all spoke to similar practices. When teaching a course on the Catholic Sacraments, Emma helps students explore the universal themes that underlie the Catholic Sacraments:

With the Sacraments, they are not memorizing the ritual. I'm trying to get to the heart of it, so we talk about forgiveness, but none of them would walk into a confessional and be able to do all the steps. And I'm okay with that. So I don't think I...so the classes I teach, I don't think I would match a very strict interpretation of the rituals of certain things. But I feel very confident that I go for the central themes, the universal themes, and how the church does this is in a really good way. 
Believing herself responsible for teaching Catholic theology, Emma universalizes the Sacrament of Reconciliation, so that all students are able to understand and reflect on the importance of forgiveness in their relationships, even though they might not know how to confess their sins to a Catholic priest in formal ritual. Emma does see the need to use Catholic theology as a starting point for her classes, “but if I don't make the Sacraments of Vocation accessible to them, then what do the words really mean?" ${ }^{\prime 3}$ Father Paul, in remaining close to teaching the content of the Framework, also seeks to help students make sense of Catholic theology, by relating potentially abstract theology to their own beliefs and experiences: "So I'm always confident that [...] I can find a way for people who are not Catholic, or not Christian, to understand, and at least have some respect for, this very Catholic idea, because it relates to something that most human beings would also say makes sense." In teaching about the Paschal Mystery (the torture, crucifixion, and resurrection of Jesus), Father Paul invites his sophomores to undertake some philosophical reflection on suffering that is existentially meaningful, and consider how their own sufferings can be transformed, or how they experience resurrection. Chuckling, Father Paul remarked that discussing suffering for sophomores is particularly ageappropriate. James takes a similar approach to Emma and Father Paul, and stated that when he teaches specifically Catholic theology,

what I start with is looking for the fundamental principles, what is....say, in the Eucharist or the Sacrament of Reconciliation, what is common to humanity?

\footnotetext{
${ }^{13}$ While teaching the Sacraments often involves a broader discussion of "sacramentals" (such as objects, rituals, and relationships that make God's presence known in the world), there are seven Sacraments in Catholicism, divided between three categories: the Sacraments of Initiation (Baptism, Eucharist, and Confirmation); the Sacraments of Healing (Reconciliation and Anointing of the Sick); and Sacraments of Vocation (Matrimony and Holy Orders, where a man is ordained to be a deacon, priest, or bishop). These "big 'S" Sacraments are theologically understood to be distinct markers in the life of a Catholic, where God's presence and activity are uniquely manifest.
} 
Whether you're religious or nonreligious? And that's what I look for and encourage the kids to talk about. I do encourage them to talk about their different perspectives too. If they're non-Catholic, you know, is there something you can bring from your own experience, your own traditions?

Thus, James not only provides religiously sustaining instruction by emphasizing how students can bring their own experience and religious tradition into dialogue with the essential themes that underlie particularly Catholic concepts, he wants them to be able to identify commonalities across worldviews, traditions, experiences, and perspectives.

Personal Well-Being and Spirituality. Participants strive to make theology class a resource that promotes students' well-being (sub-theme $2 b$ ), with regard to their spiritualities and psychological and emotional health, thereby approaching theology as an academic subject that can emancipate students. While there is certainly crossover between this sub-theme and the next one (discovering the sacred), participants saw the deepening and growth of students' spiritualities as an expression of personal well-being, and so I separated the two sub-themes from one another.

Emma, Francis, and James discussed the ways in which students are suffering from oppressive forces: Emma focused on systematic injustice and racism, Francis spoke about the toxic influences of popular culture and social media (such as shallowness, isolation, loneliness), and James brought up mental health. Participants focus on the psychological and emotional health of students, and how spiritual concepts (that are not just from the Catholic tradition) can liberate students in the process of learning theology. It became clear, over the course of my interviews, that these participants approach theology as unique among school disciplines in its ability to help students find healing and emancipation. In teaching World Religions, James strives to lay out a "banquet table" 
of spiritual practices and insights from religious traditions that students can pick and choose from as they develop their own belief systems and spiritual worldviews. He does so because

I have no interest in the question of how many of our kids are going to stay Catholic. How many of these kids are going to convert to Catholicism? I don't care. I want them to be authentic. I want them to be in relationship with love, with Spirit, with this mystery that many people call "God." Let them experience that. The experience before information. Before the kind of knowledge that you can express on a test. I don't give a shit about that. The reality is, and I said it again to the students today, "You are going to remember maybe three or four things...if you're like me, and I'm a geek about this stuff...you're going to remember three or four things from your high school religious experience. That's it. That's the truth." For a lot of these kids. It's the truth for me at least, and I've been a theologian since I was 16. A lot of us are not going to remember this stuff. But we're going to remember what it was like to meet the Spirit in a hallway, or on a beach, or on a retreat. Or in a teacher who gave a shit. That's what I care about.

Ultimately, James maintains a constant awareness that students will not remember content so much as they will be influenced by the emancipatory feelings and relationships that arise from their experiences, both within the classroom and outside of it.

Likewise, Francis is heavily dialed into the psychological dimensions and benefits of spirituality and religious practice, in large part due to his own benefiting from therapy and Eastern religious practices such as mindfulness and meditation. In his own words, "So for me, the goal is not whether you should believe it or not, or to tell you what to believe, but does it work?" Francis wants his students to think about theology, and apply spiritual or religious practices, because he believes that such applications are emancipating antidotes to the shallowness, isolation, anxiety, and loneliness that so many teenagers suffer. Francis also encourages students to reflect on and discuss their emotional states of being: 
How do you feel when you're angry and resentful? How do you feel when you forgive? And so we add the emotional dimension to it. And that's actually a big breakthrough for some of the kids. Because everyone can understand that. Even the kids that are atheist or not religious go, "Yeah, that makes sense."

Moreover, Francis views this psychological and emotional learning to be distinct from, and even oppositional to catechetical learning, precisely because students do not possess awareness or experience of the transcendent. In his words, "you don't want a glorified CCD [Confraternity of Christian Doctrine, a standard program of catechesis used by parishes] teacher doing the kind of deeper work that we need to do here" because students who lack a "profound understanding of religion, they just all leave the church when they go to college. And not that I'm a recruiter for the church, but I want them to have a meaningful spiritual life. That's really important." Francis avoided couching the development of personal spirituality in terms of religious belief, because he is of the opinion that spirituality can be detrimentally trivialized by doctrinal belief; this semantic distinction does not make what Francis does any less existentially meaningful, sustaining, or emancipatory. Father Paul, in a similar vein, wants students to "fall in love with God," and recognizes that "I'm also there to help them as an opportunity for them to grow in the faith that they do have. Live the faith that they do have." And so, even though Father Paul bases his teaching on the Framework, in alignment with the rest of his department, he hopes that non-Catholic students use the content of Catholic theology as a dialogue partner of sorts, in the process of developing their own faith life.

Discovering the Sacred. Participants strive to help students discover the sacred (sub-theme 2c) outside of the boundaries of that which explicitly belongs to organized religious tradition, and do so in three areas: in a student's own life, in other religious 
traditions, and in the world. First, regarding students discovering the sacred in their own lives and lived experiences, Emma said that the Catholic Sacraments are

so church-y, should I say, so very Catholic. So I start the unit with their spiritual gifts. I want them to see: if they can see the sacred in themselves, they can recognize it in others and in other traditions. So that's why I start with the spiritual gifts that they have. I turn to the rituals that they have. So it starts with the human experience to search for sacred, is how I start it, and then I go into the Catholic experience, go into the Sacraments.

Francis and James, who also teach World Religions, home in on students being able to recognize the sacred in other religious traditions, especially non-Western ones, such as Buddhism and Hinduism. This involves not only learning about these religions, but perhaps even learning how to practice some of their rituals, methods of prayer, and art.

Francis wants students to see the ways in which all religious traditions approach the same transcendent dimension of reality and human existence. Just as Emma helps students to recognize their own sacredness before they can explore sacredness in other religions, James hopes

that they'll be curious about what it means to be a human being... really what it means to be human being in relationship to each other, and in relationship to the earth, and relationship to our own self, and in relationship to spirit as they understand it, this spirit, this God, whatever it is that is bigger than ourselves and that we are part of.

Finally, Emma and Francis emphasized teaching students to discover the sacred in the world around them. Emma does so through inviting students to reflect on sacred objects that students find meaning in, even something so seemingly quotidian as a teddy bear that possesses special significance. During the COVID pandemic, at students' request, Emma used video clips from nature to silently contemplate at the start of class. Similarly, Francis uses secular music as a medium through which students reflect upon 
their lives, and discover the sacred in that which is ostensibly not religious, "because we gotta find things in their culture" given that "Christian music is too happy, too fake, and it's like, you can't connect to it."

Freedom for Authentic Self-Expression and Exploration. The third and final theme that I created in response to the first research question is "Freedom for Authentic Self-Expression and Exploration," as participants give students freedom to express themselves honestly and authentically, and to explore theology as they desire and need. On the whole, participants do not assume anything about students' religious beliefs or experiences, and are very aware of the religious diversity of their students. Two subthemes belong to this Theme 3: (3a) exploration of content, and (3b) assessments.

Exploration of Content. Participants give students the freedom to explore theology as they desire. James likened his World Religious course to laying out "a banquet table" where he is "not going to try to convince them to change their particular point of view," and

there's gonna be all sorts of stuff on that banquet table, and you get to choose what you're going to take and what you're going to leave behind. And if you take something you don't like, then leave it behind. If you find something that really works for you, that it resonates for you, or that it's practical, it's useful...say mindfulness, meditation, or mindful eating, great, take it.

At the start of the World Religions course, James asks students to generate ten "life questions," which will drive their engagement with the class. As students move through their study of different religious traditions, they research and reflect on how each tradition responds to these questions. Thus, James foregrounds students' engagement of content through their existential interests. Emma constantly offers students the "freedom 
to make [theology] their own," because she understands that teaching theology is "not just about me," or imparting her Catholic beliefs.

In our focus group, participants spoke about the freedom they give to students in prayer. Hans intentionally offers students minimal direction when he offers time and space for prayer, because "I find often when there's a lot of direction, then I'm focused on following directions rather than praying." Emma, Father Paul, and James all spoke about inviting students to pray in whatever ways feel most comfortable to them. In James's words,

If you can't say [a particular phrase] with a clear heart, if that's not true for you, then I invite you not to say it. Remember that we are in a Catholic house, though. And this is the way that this Catholic community prays, and so out of respect for the house in which we are meeting, stay present. Stay present. You can pray in your way, or you can just be silent, but I invite you to not say, 'Amen,' something that doesn't feel authentic to you.

In a similar vein, Emma asks students to offer what they are grateful for, so as to avoid "locking them into any particular tradition." Father Paul wants to "present prayers as Catholics believe," while at the same time "allowing the students to pray as they are comfortable." And so, while my participants all incorporate prayer into their teaching, and sometimes model Catholic forms of prayer (such as call and response, or meditation, or examination of conscience), they do not mandate that students pray in a particular manner. While participants give time and space for conversation to flow in directions not dictated by their lesson plans, the primary venue for students to explore theology freely is in their formative assessments.

Assessments. Participants especially give students freedom to explore in formative assessments, with regard to ways in which students can express their learning, 
and how they choose to respond to particular questions and prompts. James, for example, tries "to ask open-ended questions [...] that are not so much right and wrong answers, but I'm looking for how they respond to it." For certain assignments, James invites creative responses, so as to allow students a variety of means of expressing their learning, either through artwork or dance. Hans never assumes a student's religious identity, and strives to make sure that students never have to "pretend to be Catholic" in order to succeed; for example, on an assignment about marriage in the senior Vocations class, Hans asks students to consider their values, and how they might share those values with a partner. The first question on this assignment is "Who is God for you?" but students are able to answer this question, regardless of their religious belief because he offers an alternative option for non-believers. He instructs students with a page of written explanation and the following verbal instruction:

OK, we're going to look at this question. If you are Catholic or Christian, you need to really go in deep into it. You don't get a free pass either. You don't get to just say like, 'Oh, God is father who...next question.' And if you're not Christian, or you don't believe in God, think about ultimate reality... what in experience has meaning? Has purpose? Is true? Is reliable?

This is a wonderful example of Hans giving freedom because he wants to challenge his students and make theology "real." As the interviews progressed, especially with the second interview, which was focused on specific curricular and pedagogical decisions that these teachers make in the service of their non-Catholic students, it became abundantly clear that none of the participants expect students to be Catholic, or to accept Catholic theology as true. This lack of expectation manifested in the select number of assessments that participants shared with me, as well. 


\section{Research Question 2: Curricular and Pedagogical Decisions}

Analysis of the data yielded three themes in response to this research question: (4) relationship building, (5) critical exploration, and (6) instructional delivery. As the participants spoke about their teaching and relationships with students, I came to understand that not only do teachers not view themselves as catechists, but they approach theology primarily as a subject that involves a great degree of trust and safety, given that students share deeply about their beliefs and their lives because theology relies heavily upon critical exploration of self and content. Participants build nurturing and loving relationships through a variety of means, both intentionally and unintentionally; that is, these teachers do specific things in their classrooms to co-create communities of learning. The participants intentionally attempt to create spaces within which students can pursue questioning and dialogue honestly. Teachers also maintain dispositions in their interactions with students that invite relationships. With regard to the theme of critical exploration, participants encourage and ask students to critically examine themselves, their beliefs, theological content, and the world around them, thereby raising their consciences in a Freirean sense of conscientização. Finally, with regard to instructional delivery, these teachers deliver content in such a way that they invite all students, regardless of their religious beliefs, to participate equally.

Relationship-Building. Theme 4 pertains to how participants intentionally foster nurturing and loving relationships with students, which directly relates to the conceptual framework of CRSP. While there is nothing terribly sui generis about how these particular theology teachers go about building relationships, compared to teachers in 
other disciplines, or in schools that are not Catholic, the two sub-themes of (4a) classroom culture and environment and (4b) ways of relating, do take on unique characteristics given the nature of theology class. As will become clear, the various techniques and attitudes shared by these participants do not pertain exclusively to nonCatholic students, and throughout the course of interviews, it struck me that the teachers do not approach non-Catholics and Catholics differently when it comes to building relationships.

Figure 16 shows the frequency with which participants mentioned building relationships with students, which is divided into three border categories. As the graph depicts, classroom community and management and ways of relating to students are at the forefront of how these teachers engage students on communal and personal levels. I asked participants how they built relationships with students, but these concepts emerged from other parts of the interview transcripts as well. Participants focused on the classroom environments they create through management and developing community, and the more informally defined ways that they relate to students, through casual conversations and interactions. 
Figure 16

Bar Graph Depicting Matrix Coding Query of Participants' References to “Building Relationships" Codes

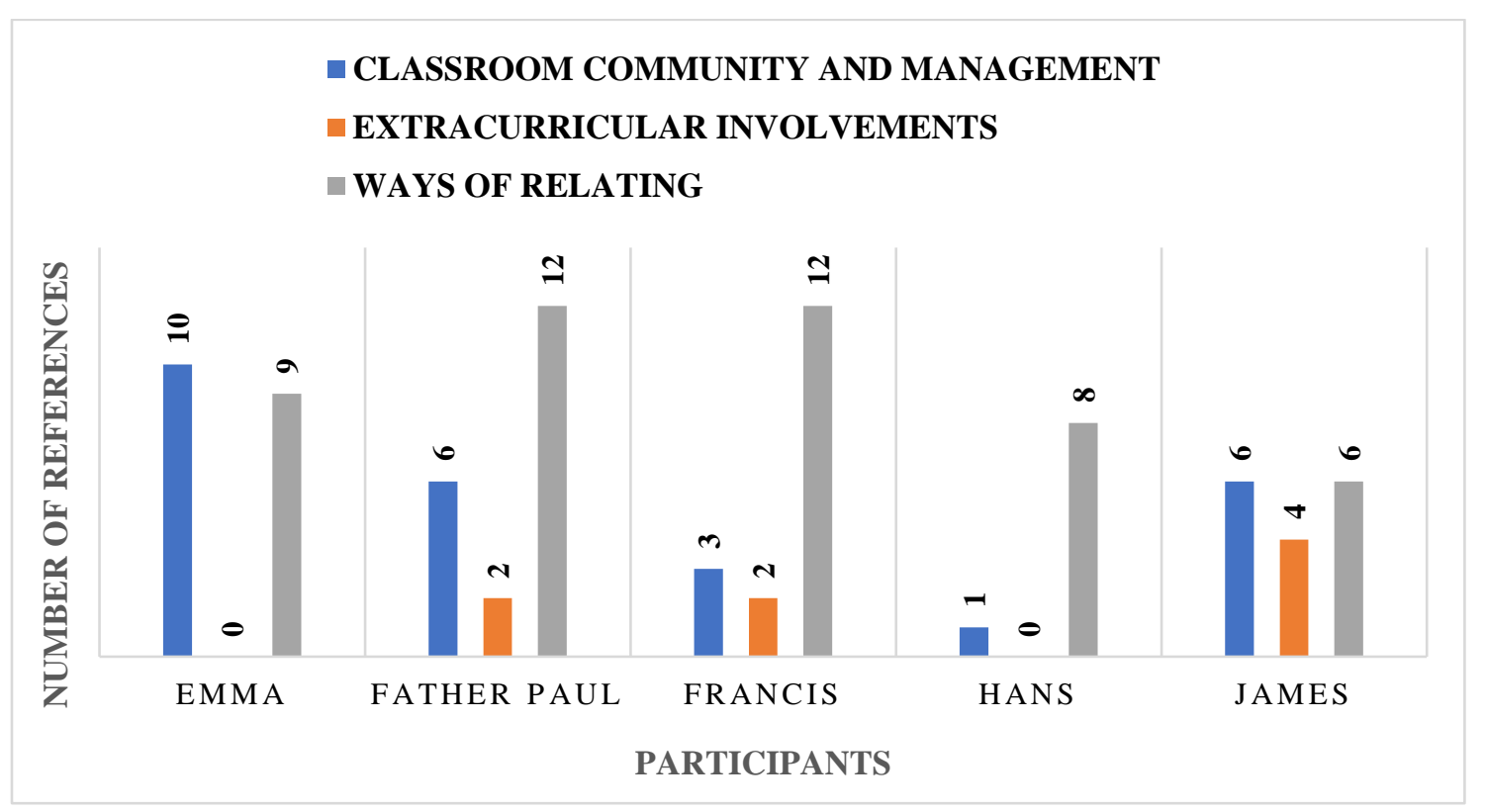

Classroom Culture and Environment. Participants create classroom cultures and environments where all students feel safe and that they have the potential to succeed. This first sub-theme (4a) pertains to how participants create a space wherein learning occurs. While there are elements of traditional classroom management that belong to this sub-theme, there are also elements of the "hidden curriculum" (Giroux \& Penna, 1979) as well. For example, when I interviewed Francis, I noticed that he had pictures hanging behind him, and when I commented on them, he showed me that his entire wall was a giant collage of student pictures, some of whose children he now teaches. James hosts a feast at the end of his World Religions class, inspired by the Potlatch tradition of the Pacific Northwest Coast Indigenous Peoples. Emma discussed the first assignment for her seniors, as she tries to "start a class where it's in relationship." Her entire discussion of creating a safe, welcoming, and inclusive classroom environment is worth citing in full: 
I'm not giving them the rules of the class. We're acknowledging how we need to work together as a community from the first day. So I think that gives a sense of safety and relaxation that goes in it. And then I have them write a reflection the very first day, and then I read those, underlining everything that is significant, so they get used to...I'm really reading their work and processing their work. And then, it's all affirmations on those things. So the first thing they get back for me is...the first day, they get a sense that: "It's safe, I can ask for things, I know how to relate to me as a student, my classmates, and my teacher. My first grade is an A. So it's safe here. In all of this." So I think that's a great way to start that relationship.

And then I try to have a variety of assignments or things to do, where everyone feels safe and successful, so we color or we create something together. And they're always welcome to ask questions, and if they feel intimidated of asking it in the class, they're always welcome to send it in an email, or write it on the bottom of the sheet. I think that creating an atmosphere, a community where they feel safe from the first day, starts to build that. And I try to find examples where, you know, I'll say, "We need to do the churchy stuff, we need to do the official Catholic Church stuff, because that's my job and that's what it is. So how do you see this? Or why do you question why the church does what it does?" So there's always freedom for growth, question, and investigation.

Emma thus strives to affirm students' abilities, welcome their questioning, and give them the understanding that they can succeed in her class, right from the opening days of the school year.

Regarding more traditional classroom management practices, Father Paul noted that over the course of his teaching career, he has intentionally relaxed his approach, and learned how to mediate conflict. If a student breaks a rule, he avoids a punitive approach, and opens conversation to understand why a student broke a rule and what they were thinking, which in turn builds relationship. James also spoke about offering flexibility when "there's a student who's struggling and needs some grace," which he believes goes a long way to building relationship. With similar sentiment, and with a chuckle, Francis claimed that he's "never punished a student in 30 years, and I don't have any rules." On 
the whole, these participants do not treat non-Catholic students and Catholic students differently, but aim to foster inclusive, safe spaces for all.

Ways of Relating. Sub-theme $4 \mathrm{~b}$ pertains to the ways in which participants build rapport with students through casual conversation and interaction that is not related to theology class. Each participant mentioned engaging in casual conversation with students, discussing their personal lives, their interests and hobbies, so on and so forth; such conversations involve self-revelation on the teacher's part, especially with regard to story-telling. James and Father Paul both mentioned avoiding using Catholic or religious jargon in conversations, and Father Paul specifically mentioned his intentional use of colloquialisms he learned from students. Teachers also discussed personality traits that they try to develop: being natural and relaxed, humorous, humble, and friendly. In our final one-on-one interview, James told a moving story that brought him to tears. He recounted how a student came to him when he was early on in his teaching career, and disclosed that she was a victim of sexual abuse. Given his own victimhood, James related to her, sought to help her out, and the student did not accept his intervention gladly. Just recently, she called to tell James that he had saved her life, and he told her that she saved his. This story came up when I asked him how his goals and motivations have changed over the course of his career, and James offered these words after telling this story:

And so I had these goals...I had this goal to just save their lives, to save them from decades of pain, decades of silence and decades of hurt. That was my primary motivation. Even then, I wasn't doing this because I love the Catholic Church, and I wanted to bring kids or keep kids in the church. I wasn't interested in that. I was in love with...love...I was in love with Spirit, call it "God" if you will. I was in love with leading a passionate life, and encouraging other kids to find their own way. And that was my goal. That was another goal of mine. I'm not sure it's all that different today. All these years later. 
Not all relationship building has such dramatic results, but these teachers clearly value and centralize the humanizing potentials of their work.

Participants also brought up their involvement in extracurriculars, even outside of when I asked them about building relationships. This might be because they do not treat such participation as a means to the end of building relationships, but rather as an end in and of itself. From coaching athletic teams (Francis and Hans) to leading retreats (Francis, Father Paul, and James) to attending theater and sporting events (James and Emma) to serving as the football team's chaplain and unofficial waterboy as a way of reflecting Jesus's love (James), teachers are very clearly involved in the culture of a school. Francis discussed how his experience in leading retreats feeds his approach to teaching, where he hears about their struggles and perseverance, and discovers their needs through conversations that do not naturally occur in the context of an ordinary school day:

Because that's their world, they feel like the culture isn't for them. "Do I really matter?" And I think all you have to do is ask them. But ask them deeply. And they kind of want to share. Look at what people are willing to reveal on those junior retreats and stuff. Look what's not that far below the surface of their lives. They are longing to meet that need, to connect on that level, and their phones aren't meeting that need. Nothing is. And so there is a longing for that, that's why religion courses have an opportunity, if we just get off our dogmatic agenda and just start getting into the hearts of the people who we're teaching. And if they believe the teacher cares, it seems to go well.

Thus, involvement in extracurricular activities feeds into Francis's teaching, and his teaching feeds into his desire to be involved with students' lives outside of the classroom. He perceives theology to be a deeply therapeutic class for his students, because they long for meaning-making pursuits. 
Critical Exploration. Participants emphasized the centrality of critical exploration (theme 5) in their classes, in order to include all students, regardless of their religious beliefs. This exploration involves students' critical exploration of themselves (sub-theme 5a) - that is, the various layers of their experiences and lives, including areas outside of religious belief — and critical exploration of content (sub-theme 5b); I view critical exploration as a means of sustaining students' positionalities regarding their beliefs. Such critical exploration is not necessarily part and parcel of a primarily catechetical approach to theological education, given that the memorization of doctrine does not require such a mode of engagement. The "challenges" sections at the end of each of the Framework's sections evidences this, wherein the bishops provide answers that simplistically answer hypothetical questions raised by imaginary students. Francis lamented the difficulty of finding theology teachers who are capable of engaging theology and students in this critically-driven manner:

Now there's also some people who are not comfortable with critical thinking about religion. And sometimes they apply and they want to be a religion teacher. And there's also some that have an agenda. That you just don't want. And so that's the hardest part: getting good teachers, who have a deeper understanding. Because some teachers, they just go: "It's in the textbook, and that's it." And that's hard.

Francis was proud that his department's members often have graduate degrees in theology, and are not the well-intentioned "naive believers" that he avoids hiring. Father Paul, who was the least critical of the Framework, did offer the critique that it "is a little too focused on individual facts, and not giving the freedom enough to inform a Catholic worldview." Thus, even as Father Paul hopes to teach the components of the Framework and stay true to its content, he wants students to 
put these ideas together, and help them to build a theological framework from the Catholic worldview. [...] They don't even necessarily have to agree with it, like we're not trying to evangelize [i.e. proselytize, rather than evangelize in the broader sense], necessarily, directly every student that comes into the school. But at least in their understanding, maybe having an understanding of why Catholics think they way they think.

Thus, in teaching Catholicism through a more traditional or orthodox lens than other participants do, Father Paul wants non-Catholics to develop their beliefs and religious worldviews, placing them in dialogue with Catholic theology. Two primary forms of critical exploration emerged from the data, from which I created sub-themes: (5a) critical exploration of self, and (5b) critical exploration of content.

Of Self. First, participants constantly invite students to critically reflect upon their faiths, beliefs, spiritualities, perspectives, and lived experiences. Each participant spoke to assessments and classroom conversations that prompt such reflection. Given his interest in the psychological benefits of theology and spirituality, Francis, in particular, expressed his desire to address students' preconceptions, misconceptions, and biases. In his words, teachers "need to get underneath what they're saying, and get them to think about... most of them don't think about why they're doing what they're doing. And so we try to get to the underlying assumptions, to go deeper that way." James also stated that he places "a lot of emphasis on personal experience. The encounter, the opportunity for relationship with the divine, however you perceive the divine, or those deeper, bigger things than just myself." Even when studying World Religions, James tends not to discuss the influence of religion on culture and history, but provides students with the opportunity to develop their spiritualities through the process of bricolage, with the aforementioned metaphor of the "banquet table." One example of this is a reflective 
assessment based on the Five Pillars of Islam, wherein James asked students to reflect on the pillars of their own lives (such as "What would you give up from dawn to dusk for 28 days?" and "What prayers or statements [mantras, quotations, etc.] would you find valuable five times daily?" in words or images.

Hans offered me a "Marriage Prep Questionnaire," which he uses in his Vocations class for seniors. Thirty-three questions and eight pages long, this assignment asks students to write about their fundamental beliefs surrounding "God" or "ultimate reality," the "fundamental principles regarding your personal morality," their "expectations and desires" for getting engaged or married, and their thoughts on various dynamics that are present in a marital relationship. In questions where Hans raises Catholic teaching about technology that aids infertility (one of the more controversial areas of Catholic Social Teaching, because it prohibits "artificial" means of conception, such as in vitro fertilization), he asks students to write about their responses to that teaching. This assessment exemplified Hans's desire for students to be able to express themselves authentically throughout their written work, and not feel the need to feign belief for the sake of a higher grade.

Of Content. Participants invite students to critically explore content (sub-theme $5 b)$ that is being taught, and encourage students to openly and honestly discuss that content. Emma is an especially keen example of enacting this sub-theme in her pedagogical practice, given her interest in teaching the honest, hard history of the Catholic Church, "warts and all": "You really have to be authentic about who the Church is, where God is in that, and you don't sugarcoat or overlook things that aren't 
comfortable." In her unit on Native Peoples for her junior Morality course, Emma has students read the USCCB document "Open Wide Our Hearts: The Enduring Call to Love, a Pastoral Against Racism," wherein the bishops wrote about systematic racism in the U.S. In one assignment, she invites students to consider the most important aspects of the bishops' writing on racism, and to offer their critique. Throughout the assignment, Emma encourages students to bring their lived experience of racism into dialogue with this text, and one particular question, "In your opinion, did the Catholic bishops take responsibility for the destructive consequences of evangelization/colonization?" asks students to honestly and thoroughly highlight the bishops' deficiencies and failures in attempting to bring Christianity to Indigenous peoples. In teaching the Hebrew Scriptures, Hans analyzed the Book of Joshua ${ }^{14}$ (wherein the Hebrew armies conquer the land of Canaan after escaping slavery in Egypt) with his students and argued that "it's the most dangerous book in the Bible, and that we need to be careful about how it's used today, because it has, is currently, and will be used to promote violence." Christians have read, and continue to read, the Book of Joshua as condoning the conquering of those who do not follow the biblical God, and thus Hans seeks to raise the critical consciousness of his students in examining Joshua's historical and contemporary applications.

Moreover, Father Paul, Francis, and Hans also brought up the role of struggle, doubt, and opposition to Catholic teaching in theology class. Francis stated that "we encourage" the "challenging questions" that students bring, and that "we encourage

\footnotetext{
${ }^{14}$ Ironically, many biblical scholars believe that the Book of Joshua is largely fictional; archaeological evidence demonstrates that the territory of Canaan, or the "land flowing with milk and honey," was not conquered within a generation, but was rather settled by tribal peoples over the course of hundreds of years.
} 
questioning things, because if you just naively believe something, that's not going to last in the real world." Likewise, Hans intentionally tells students that struggle and doubt are good things, and that faith of any sort in fact requires such dynamics. When I asked Hans how he helps students to explore their beliefs, he discussed this encouraging of struggle and doubt in exploring different "stages of faith," which he believes is a means of showing "that there's a lot of room for exploration, doubt, struggle in a faith journey." Father Paul highlighted providing room for dissent and struggle in our focus group interview:

We want the kids to start exploring, and to feel free to ask those questions, and to challenge the Church's teaching in the classroom. Because we do really want them to be sincere and honest in their inquiry. Until you know: "What's important in life?" So I really think, that's a skill I think I'm always trying to hone, is really trying to help students really honestly grapple with what they honestly are concerned about, when it comes to whatever we're teaching. And to try to get them to...to bring forth that honesty...is, I think, one of the things that should guide our religious education.

At no point in any of the interviews did participants indicate that they prevent such disagreement or questioning, even when students might express hostility toward Catholic teaching. Emma did bring up one example of a student who "seemed" to have "basic hatred and internal turmoil, and all I was asking him to see was from somebody else's perspective. [...] But there was too much going on, and religion became a quick way of separating himself." Emma's response to that particular student was to continue to invite him to expand his perspective, and to learn about other perspectives through conversation and exploration.

Instructional Delivery. The third and final theme (6) that I created in response to the second research question is instructional delivery, which most concretely addresses 
teachers' pedagogical practices and decisions. Participants are intentional in how they go about delivering instruction to their religiously diverse students, and make sure that students do not need to be Catholic in order to succeed. Three sub-themes belong to this overarching category: (6a) centering student voice in assessment and conversation, (6b) responding to student need, and (6c) intentionality in wording.

\section{Centering Student Voice in Conversation and Assessment. Participants}

foreground students' voices in class, do not solely rely upon lecture, and actively invite dialogue and conversation wherein students are able to express themselves authentically and speak from their religious and experiential positionalities. Throughout the interviews, participants infrequently referred to lecturing, and more commonly brought up their stimulating conversation, dialogue, and discussion. When I asked James how he supports students' beliefs, especially if they are not Catholic, he responded:

First and foremost, it's by letting them know from the beginning that this is a place where I hope they'll feel free. What it means to be, as I said earlier, a good human being in relation to all that is. That that's our focus, and my job is to help you to think through your questions, to hear these other concepts. If you're not Catholic, if you're not Christian, you'll at least hear that this is what Christians and Catholics believe, and then tell me how you're responding to that. Tell me what you're thinking about that.

Given that all participants aim to help students develop and understand their own selfawareness, spiritualities, and beliefs, it came as no surprise that teachers do not exclusively rely upon direct instruction of concepts and ideas for this process. Father Paul and James spoke about implementing discussion protocols to generate conversation among students, and James remarked that some of the most interesting conversations in 
class spontaneously result from inviting students to discuss their disagreements and divergent perspectives in these discussion protocols.

Participants' discussion of assessments also highlighted the centering of student voice, given that many assessments prompt self-reflection to various degrees. For example, James's final assessment for his world religions course asked students to create some sort of object (e.g., a piece of artwork, or a choreographed dance) that represented their takeaway from the class, especially as it related to their thinking through their ten "big life questions." Hans gives his senior Vocations class a "Discernment Project," over the course of which they "learn how to practice discernment": students consider "an important personal question to which you don't know the answer right now" and write their way through a number of smaller questions as a means of discerning an answer to the overarching question. Thus, not only does this assignment center student voice in the learning process, but is imminently practical for graduating seniors.

Responding to Student Need. In their praxis, participants solicit student feedback in order to address students' needs and desires for learning, and craft their pedagogy around the self-reported needs of students. On the whole, participants diverge from the content and catechetical methodology of the USCCB Framework as a consequence of responding to students' needs and desires for learning, which I will discuss in my analysis of themes related to the third research question. The five participants respond to students' religious identities and beliefs in addition to students' needs for relevant and practical theological application, and their psychological and emotional states of being. I have already discussed theology's potential relevance and applicability in previous 
themes. In his teaching, Father Paul is cognizant of students' secularism and unfamiliarity with the Bible:

...relevant to our current situation of freshmen, incoming freshmen... which is to say, a lot of freshmen coming into our school these days do not have much knowledge of the Bible. And so, I think before you get into a lot of other thought and doctrine and teaching of Catholicism, there needs to be a foundation of the Bible. So you kind of have to catch freshmen up who are coming in from many from secular schools, or even sometimes when they're coming in from Catholic grade schools, they still don't have, necessarily, a very good foundation of the Bible. Some do, for sure, have a decent background of the Bible. But I find that even for them, it's helpful to get a survey of the Bible itself.

Hans expressed a similar perception, that many students do not possess the "grammar" of Christianity, which makes teaching the doctrine, or the "logic" and "rhetoric" of Catholic theology untenable; in making these distinctions, Hans referred to the Trivium of grammar, logic, and rhetoric, which formed the basis of medieval Europe's Renaissance Humanism, and was used through the twentieth century in many Eurocentric universities. Hans's "general organizing principle" is thinking through his responses to the questions of "what I think students need? Or from teaching this course so many times, or from never teaching this, what is necessary?" And so, in teaching a course on Sacred Scripture, he adds in material on the Book of Joshua, and its application to exploring concepts of "cultural and systemic racism." In so doing, Hans is concretely using theology to respond to increasing awareness of and activism surrounding racial injustice.

Additionally, Hans spoke to changing his approach from the overtly theological and philosophical to the practical over the course of his career, as did Francis. When Francis began teaching out of graduate school, the first year, I just taught straight out of the textbook, I did things like that. I thought a few things were odd. Like, you're worried about transubstantiation and 
they don't know basic Christianity. So that was the first thing I noticed, was that just basic things about Christianity were not there. And then I started asking the class, "Is this worthwhile? Is this meaningful?"

Francis stated that at the end of each semester, he asks students what they found worthwhile, what material they consider to be worth keeping, or throwing out. Consequently, Francis's departmental curricula are "designed on zeroing in on the spiritual needs of students. And that comes in dialogue with students. What are they struggling with?" As department chair, Francis wants all his teachers to focus on the needs of their students; he spoke about meeting with his teachers regularly, getting them to solicit feedback from their students on a semesterly basis, and even conferencing with one new teacher on a daily basis to review his materials.

Intentionality in Wording. Participants are careful with their spoken language and written word, so as to include non-Catholic students. Employing intentionality in wording involves using religiously inclusive language when delivering instruction, asking questions, and interacting with students, and ensuring that all students, regardless of religious identity, are able to complete assessments honestly. Francis, James, and Father Paul spoke about intentionally wording their direct instruction. The former two participants will use words such as "love," "spirit," "energy," and "life" in place of "God," so as to not exclude students with no religious belief. Francis believes that the transcendent, or God, is encountered when students experience energy and invigoration in their lives, and so actively asks students to speak and write about such moments wherein they have felt alive and energized. Although Father Paul did not address replacing Catholic or religious language, he did speak about "qualifying my language" in 
order "to find ideas that are similar, to try to help students who are, you know, not Catholic and Christian." In qualifying his spoken word, Father Paul is especially sensitive to ecumenical (inter-denominational Christian) dialogue (given that he belongs to an ecumenical Christian community) when he addresses students of different Christian denominations.

Participants also spoke to wording their questions on assessments such that students are able to respond honestly and authentically from whatever their positionalities are. Hans addressed this in detail:

I'll never have a question that presupposes any sort of faith. So, if I am wanting them to articulate a Catholic way of thinking, I'll say, "How would Catholics argue this?" or "How would Catholics explain this?" And sometimes what I'm saying is, not the Catholic thing, and so I'll say, "How did Mr. [Hans] explain this?" Every once in a while, I'll ask for what I think, sometimes I'll ask what a Catholic would think, sometimes I'll ask what a Christian would think. Let's all use those things, and whenever I use the word "you," I'm meaning you. I think that's helpful, because I think that a lot of students...I think one of the things that kills the ability to nurture faith, and where there is a variety of faiths, is compulsion, or pretending. And so I try to never have anything that compels faith.

In this excerpt, Hans explained that he differentiates between questions that assess different forms of understanding and learning, from objective understanding of Catholic theological concepts to personal interpretation of material. Because he understands that people do not respond well to coercion, Hans very much avoids any hint of manipulation in his teaching.

Essential Questions. Participants focus their teaching around essential questions that drive student learning. In reviewing the interview data, I coded one hundred questions that participants value as important to their teaching, either broadly or pertaining to more specific material. For example, regarding Francis's overarching goal 
of addressing students' emotional and psychological challenges, he asks his students, 'You know, what's getting in the way? What's stopping you from living the life you're meant to live, and being the person you're meant to be?” James wants to help students explore "what it means to be a human being [...] in relationship to each other, and in relationship to the earth, and relationship to our own self, and in relationship to 'spirit' as they understand it." In her teaching of Morality and Catholic Social Teaching, Emma considers the questions "What is my moral compass?" and "What are my values? How do I live them?" to be of primary importance. In reviewing all of these essential questions, it became clear that they greatly influence the goals of participants, and the pedagogical decisions they made, especially with regard to the ways in which they adhere to and diverge from the USCCB Framework. While I had attempted to categorize these essential questions, doing so proved quite challenging, and I instead opted to double code such questions when they aimed toward existential relevance, religiously sustaining pedagogy, or other pertinent codes.

\section{Research Question 3: Use of the Framework}

The third research question is "How do theology teachers in Pacific Northwest Catholic high schools consciously diverge from/and or adapt the USCCB Framework (if at all) in their service of religiously diverse student populations who represent Catholic, non-Catholic Christian, non-Christian, and non-religious traditions and contexts?" I generated three themes in response to this research question: (7) structural adherence, (8) benefits of the Framework, and (9) divergences. Overall, each participant spoke to the fact that they adhere to the Framework with regard to its overall structure; that is, their 
departments make sure that the courses they offer align with the Framework's scope and sequence, although they might reorder its content. Second, participants spoke to certain benefits that the Framework provides teachers, and these benefits largely pertained to holding theology departments and teachers accountable for teaching the main areas of theology, as expressed in the Framework's general structure. Third, participants spoke to the many ways they diverge from the Framework: they omit content, add content, and choose to emphasize and de-emphasize specific content.

Of the five participants, Father Paul was the only one who expressed general approval of the Framework, and believes that he-along with the rest of his department-follow it closely. Father Paul's disagreements with the Framework did not have to do with content, as he thinks "the ideas are...they're wonderful ideas, insofar as like, students actually understanding those ideas. If they do pick them up, I think they can be very beneficial to the students, just help them have a good Catholic worldview." Unfortunately, I missed the opportunity to probe Father Paul further in order to provide some examples of what he considered to be "wonderful ideas," although he did address the relevance and applicability of suffering and resurrection to the lives of sophomores. This said, Father Paul did express some misgivings about the ordering of the Framework's contents, with regard to it meeting the maturity and needs of students (namely, he is not sure if ecclesiology, the study of what the church is and does, is too abstract for sophomores, and if an entire semester on the Sacraments is beneficial for seniors). The remaining four participants all diverge from the Framework in profound and important ways. 
Regarding participants' use of the USCCB Framework in Figure 17, there are three broad categories: divergences, adherences, and uses for non-Catholic students. While "divergences" is the most populous category, "adherences" is also significantly represented. This said, "adherences" included codes such as "begrudgingly follows" and "checks periodically," which indicated participants' adherence to the Framework in minimal ways, rather than a wholehearted fidelity to conveying doctrine. This hierarchy chart was crucial in my developing the themes of "structural adherence" and "divergences," in response to the third research question. Given that I considered the third research question to be such a focal point of this study, visualizing the ways that participants diverge from or adhere to the Framework was vital to my interpretations. Moreover, because participants diverge from the Framework so much more than they adhere to it (even minimally), this confirmed my suspicions that theology teachers do not really use, and even depart from, the Framework in their teaching. 


\section{Figure 17}

Hierarchy Chart of Child Codes within Parent Code "Use of the Framework"

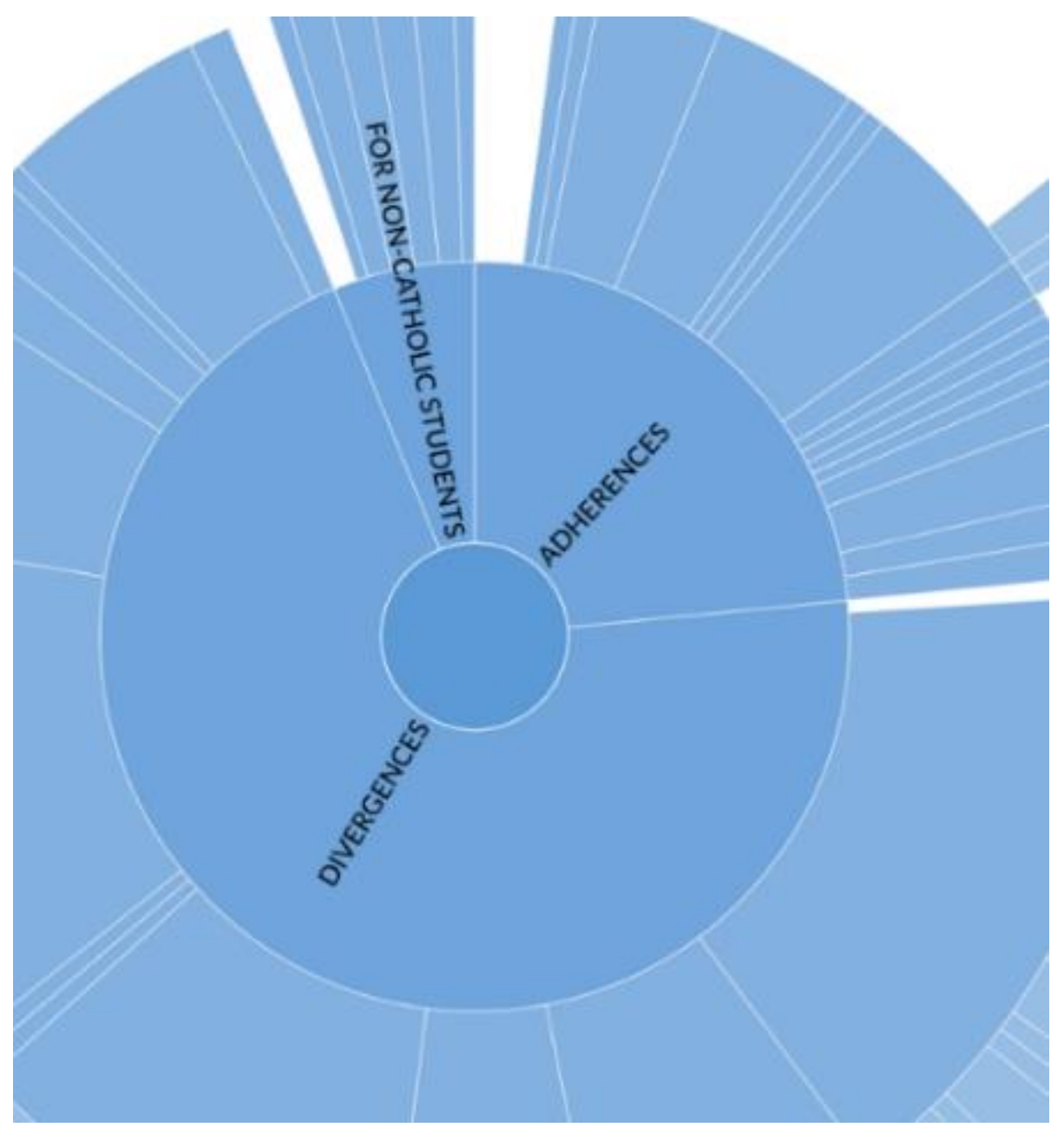

Figure 18 shows how participants adhere to, or diverge from, the USCCB

Framework, or adapt it for teaching non-Catholic students. Because participants tend not to differentiate between their teaching of Catholic and non-Catholic students (and provide options for students to express themselves in assessments, and give freedom in classroom dialogue), their use of the Framework for non-Catholic students is minimally represented in the quantifying of coding references; under this parent code, I created seven child 
codes (e.g. "direct instruction," "process of discovery," "learning Catholic basics," and "questioning") that were more or less equally represented, with only one or two references. In the second interview, wherein I asked participants about their teaching of non-Catholic students, I did not mention their use of the Framework, and so that category of codes has a relatively low count of references. On the whole, participants more frequently diverged from the Framework than adhered to it, although the vast majority of "adherence" codes pertained to participants' relying upon the Framework to base their curricula's structures upon.

Figure 18

Bar Graph Depicting Matrix Coding Query of Participants' References to "Uses of the Framework” Codes

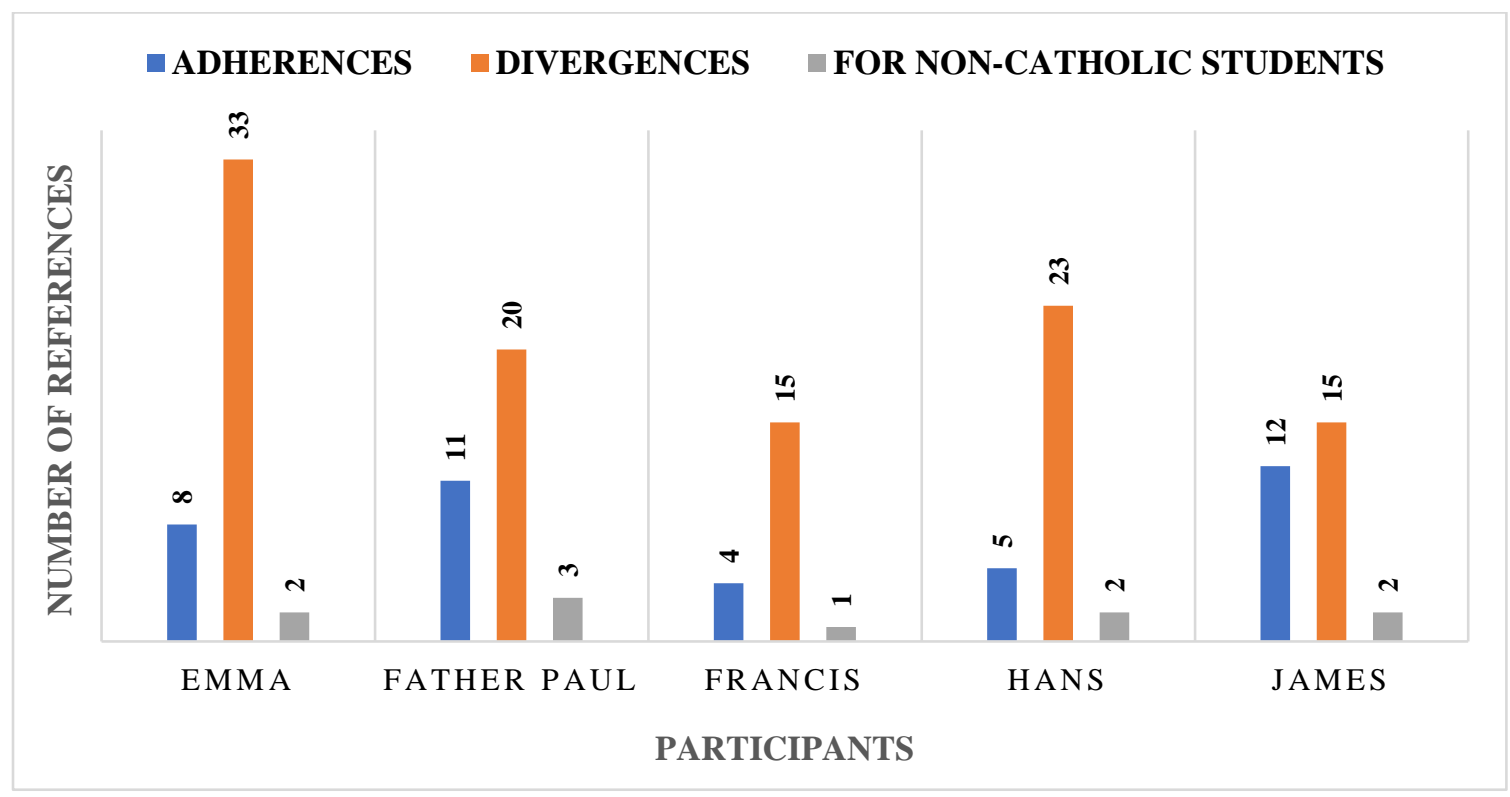

Structural Adherence. Participants generally do not view themselves as strictly adhering to the Framework; rather, they use it as a skeleton for developing their curricular scope and sequences, but do not consult the Framework on a regular, ongoing basis. When the Framework was first introduced, Emma spent many hours with 
departmental documentation in her role as department chair, making sure that her department's courses all reflected the Framework's content, as she needed to submit documentation to the archdiocesan education office. She believes that we taught all the checks and the different numbers that we've done on those, remember? Number nine point point point.... we can do all that, we can match the content. But I feel very confident and comfortable with the way that we've been able to give it a heart.

Emma did remark that she has become less and less emotionally invested in the Framework over the past decade, but that "it doesn't come up in conversations anymore. It's kind of been one of those things you put on the shelf and it collects dust." She even went so far as to say that even at archdiocesan meetings of department chairs, the Framework is not discussed, and so "I wonder how much it really matters anymore." While Emma's departmental documentation makes sure that the Framework's numbered content corresponds to the curricular scope and sequences ("number nine point point point point...”), she approaches this cross-referencing as more of a formality than anything else. Francis echoed a similar sentiment, that the Framework was "a good opportunity in one sense. It had us sit and reflect on, 'What are we teaching? Let's take a look at what we're teaching.' It was a good time to see what we're doing and see if it's working and stuff." On the other hand, Francis stated,

I mean, I take a look at it because I don't want to make waves with the diocese, I don't want to deal with it. But it's not like a guiding principle. It's more just like a 'check the box,' to make sure it's kosher.

In other words, Francis wants to avoid diocesan oversight and not get in trouble due to his department's courses diverging from the Framework. Moreover, Francis offered the primary reason for not consulting the Framework regularly as being that it lacked depth, 
and his department had to go much "deeper" than the doctrinal points offered within its list of content.

Hans also remarked that his department meets every few years to check their courses' scope and sequences against the Framework, and although he participates in such meetings "sincerely," there is "very little accountability" with regard to the administration making sure that theology teachers are teaching the Framework. When I asked Hans about how his courses line up with the Framework's contents, he responded:

I think...I would say, fairly closely, in that it does tend to be the first step. In building any particular course. But I think that as the course takes shape, I wouldn't say that the course looks like, I wouldn't say that my syllabus ends up looking like the Framework. Although it might in the first year that I teach it.

James, who was perhaps the most negative in his critiques of the Framework as missing the "heart and soul" of Jesus, does not pay any attention to the Framework whatsoever:

And to be honest, I haven't spent a lot of time unpacking the Framework. I haven't...I've really kind of given a cursory review of the Framework, trying to see what's in it, what are the big pieces. And so my...just admittedly, I have not gone in depth to have really mastered the Framework. Or to read about the motivation behind it. And I own that, and I don't think that is...I don't see that as a really positive thing. I've been pretty closed-minded about it from the beginning. I'm not proud of that, I'm not ashamed of it. It's not perhaps the best modeling of intellectual integrity.

James's ability to ignore the Framework is due, I believe, to the fact that his school is sponsored by a religious order, as are Emma's, Francis's, and Hans's schools; Father Paul was the only participant who remarked that he does not have such autonomy (nor do I think he would want to ignore the Framework to begin with) given that his school is archdiocesan. On the whole, while the different schools' theology departments use the Framework to provide their curricula with an overall structure, the individual teachers 
(including Father Paul, because he is confident that the curricula he shares with colleagues corresponds closely to the Framework) do not consult the Framework on a regular basis.

Benefits of the Framework. When I asked participants about the benefits of the Framework (theme 8) for students, they offered a variety of valuable perspectives. Truth be told, participants' praise of the Framework, however limited in frequency and scope, was the most surprising finding, and I was ignorant of it before the study began, given my biases against the Framework. This said, these responses are held in tension with the ways in which the teachers diverge from the Framework, and I will discuss these divergences in the next theme.

Hans and Father Paul expressed similar opinions, that the Framework makes sure that all Catholic schools are following a standard curriculum; this is, in Hans's words, "beneficial for students, in that if teachers are following it across the various dioceses, that they could reliably be giving solid Catholic teaching." Hans and Emma also noted that the Framework holds teachers accountable to teach particular content that they might not be otherwise inclined to teach. Emma, in her role as department chair, uses the Framework to hire teachers with particular expertise in certain areas. Emma continued to offer the following perspective, in which she praised the Framework for keeping teachers connected to aspects of Catholic theology they might otherwise avoid:

Each person brings their totality [that is, the totality of their beliefs and positionalities] into [teaching], and with theology, I think there's this kind of this dance, where we're given a huge responsibility with teaching the faith, so that's why you kind of have to have that bishops' Framework to remind us to teach warts and all. I can't just teach what I want to teach, I need to make sure I'm teaching what I need to teach to make sure it's authentically Catholic, as well as 
authentically meaningful with all of that. So I think that's kind of my approach to the Framework. It's a reminder to stay universal in my teaching, connected to that universal church, but my job is to make sure my domestic church, my classroom, has life meaning and direction.

Emma employs the Framework as a reminder to teach the gaps that it ignores, which in her perspective involves the ugly history and atrocities perpetuated by institutional Catholicism. She also finds immense beauty and goodness in Catholicism universally, as it is experienced and lived out in cultures outside of the Eurocentric, and outside of the United States. In our first interview, Emma made known her desire to foster students' awareness of the sacred within themselves and the world around them, and thus tries to cultivate her classroom into a "domestic church," a space wherein students can encounter the sacred. Emma, Hans, and Father Paul all expressed the desire to teach what is authentically Catholic, but for different reasons. Emma uses the Framework as a basis to remain connected to the broader Church, but does not shy away from teaching the injustices that have been perpetrated by Catholic laity and clergy in the name of their religion. Hans sees "continuity within our department, and making sure that we're teaching the Catholic faith as important," and he finds this particularly valuable because he asks himself:

"Is this student receiving a clear and accurate and solid understanding of Catholicism? That they could reasonably take with them? And apply it in other contexts?" So basically, like if they're interested in being Catholic, "Is the Catholicism that I've presented, is that something that they could reasonably decide to join or not?"

Father Paul and Hans both want to convey Catholicism to the best of their ability, to leave open the possibility of a non-Catholic converting to Catholicism. Given that Hans himself is a convert who was on the brink of leaving Catholicism before having his 
passion reignited in college and graduate school, I suspect that he wants to be able to offer students the same opportunity that he had, and the same approach to theology that he found meaningful. Hans also told me that he's recently come to see that students do actually need some philosophy in order to engage theology well; while I cannot be entirely sure what he meant by "philosophy," I sensed Hans's desire to have students engage metaphysical (e.g., what do they believe about the nature of reality?) and epistemological (e.g., how do they know what they know, and trust what they perceive?) concepts.

Although James offered the heaviest critique of the Framework, he did offer a positive evaluation of the Framework, with regard to conveying the actual, stated teachings of the Catholic faith. He does

think that it's valuable to let non-Catholic students know, "This is what is important to the church. This is what the church values, this is what it believes in." I think that's appropriate. And it is reasonable, and fair for the school to ask our department, to ask me as an individual teacher, to make sure that the students are familiar with Catholic teaching. Especially as it...I don't know quite how to say it, according to the Framework, the bishops have clearly stated what they want us to talk about. And I could use it to make sure that the students know about these things. I think that's fair, and that's good.

In this manner, he stated, teaching the Framework can help non-Catholics to legitimately understand what they reject and do not believe in. James has a deep disdain for the institutional Church, given the abuse he suffered at the hands of a religious brother in high school, his witnessing of the myriad ways in which the institution relocated "a known serial pederast" and covered "up his crimes," and how the archdiocesan attorneys treated James during legal proceedings. This said, James conveys Catholic teaching clearly when it is pertinent to do so. He shared in the focus group interview that he will 
reveal to students his own personal beliefs when asked, but only after helping them to think through their own beliefs and come to their own conclusions.

Divergences. Emma, Francis, Hans, and James diverge from the content and catechetical impetus of the Framework. Given that I had a fair sense of the participants' theological and educational beliefs and practices from the first two interviews, the findings that emerged from the third interview, which was focused on their use of the Framework, came as no great surprise. Figure 19 reveals the ways in which participants consciously diverge from implementing the USCCB Framework in their pedagogical praxis, and there are a number of ways in which participants diverge. This figure's hierarchy chart clearly delineates between and depicts the number of references to these various means of divergence from the Framework. Divergences largely center around the ways in which teachers emphasize or de-emphasize content (sub-theme 9c) within the Framework, and in the process of doing so, omit content, or provide additional content and materials. I used this hierarchy chart to analyze and interpret these divergences, which in turn brought me to generate theme 9 of "divergences" in response to the third research question. As the chart demonstrates, there are many child codes for "additions" (which led me to generate sub-theme 9b) and "emphasis on essentials." It became very clear that participants are familiar with the Framework to varying degrees, but primarily use it to provide curricular structure and do not consult it on an ongoing basis. This lack of regular consultation is a form of adherence, but is also a means of diverging from adherence. 


\section{Figure 19}

Hierarchy Chart of Child Codes within "Use of the Framework: Divergences" Codes

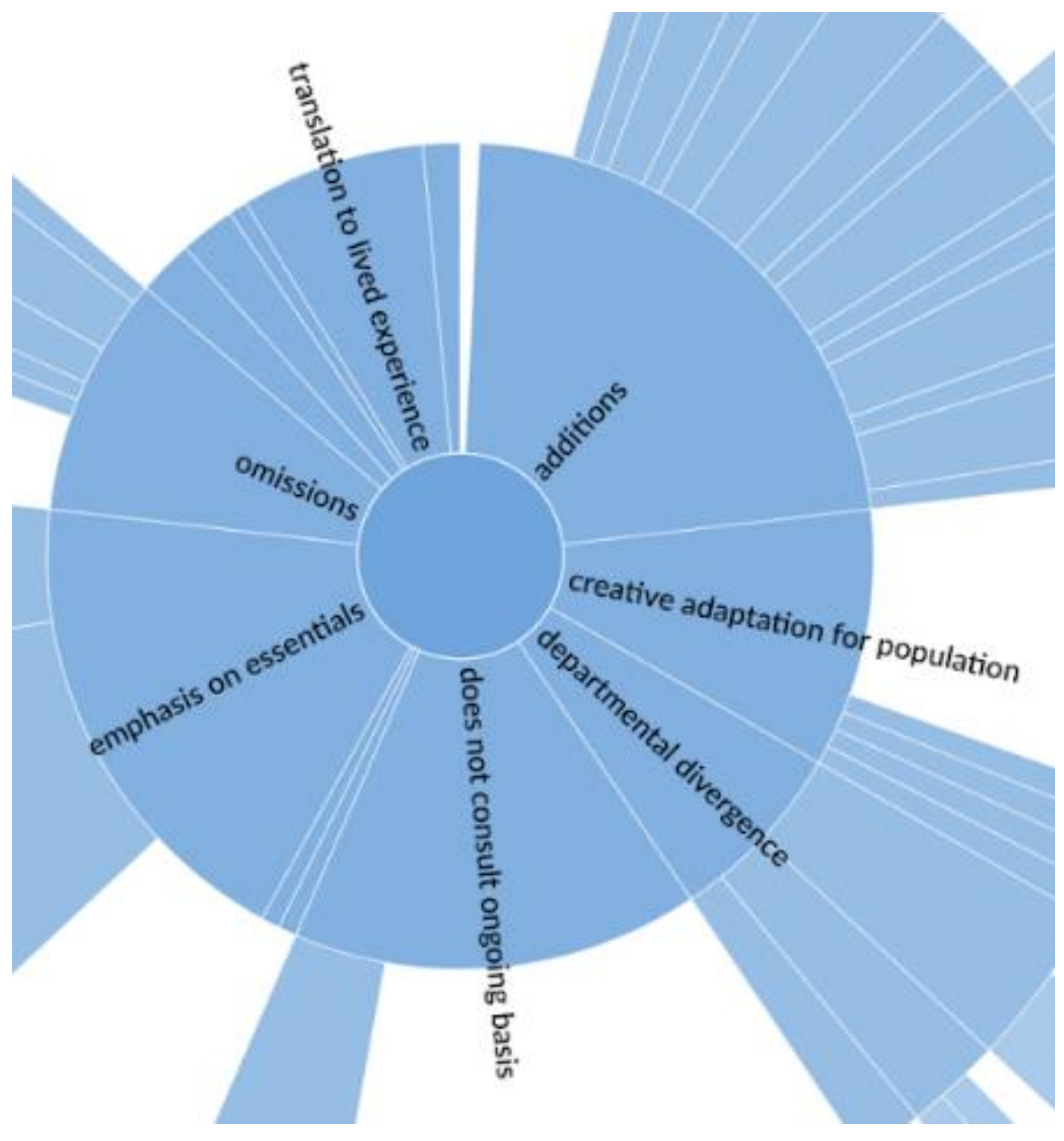

Participants diverge from the Framework in three primary ways, which I coalesced into three sub-themes: (9a) omissions, (9b) additions, and (9c) emphases and de-demphases. However, these divergences are not so much negations of Catholic teaching, as they are means of fostering students' engagement with concepts within the Framework in ways that are relevant, meaningful, and applicable. 
Omissions. Participants omit content from the Framework in their curricula and pedagogy, and they do not emphasize the role of memorization of doctrine. Given the earlier analysis of theme 1 regarding "opposition to catechesis and the Framework," it is not necessary to discuss that form of omission here. Moreover, given departments' adherences to the overall structure of the Framework, teachers do not omit entire courses. This said, participants tend to omit content not due to personal disagreement (although Hans said that of his department, he is the only one to really discuss the priesthood, because other teachers disagree with Church teaching on ordination), but rather due to the amount of information contained within the Framework. Emma's school has an uncommon schedule, and so although "we don't have the scope of everything, but I think we can do pretty well with the basics, and hopefully the meaningful basics that the kids will know from the Hebrew Scripture and Christian Scripture.” Similarly, Father Paul remarked that over time, "I've been less concerned with covering all of the ideas presented in the Framework, you could say." Elaborating on his waning concern, Father Paul stated:

So I give myself a little bit of leeway to perhaps not teach one particular idea, because I don't think I'll be able to do justice to other ideas in the Framework that I think are more essential. So my conscience is clean, or at least I feel like my conscience is free to say, "I just can't cover everything, I'm not going to be able to cover this particular doctrine." [...] But just generally speaking, I feel like you can't cover all the ideas that are presented in the Framework and do justice to all of them in one single year. That's probably the most limiting factor, is time.

Thus, Father Paul's omissions do not result from personal disagreement, but from a choice to cover other content in greater depth, at the cost of omitting others. 
Regarding particular omissions, Emma, Francis, and James do not share with students the claim that the Catholic Church possesses more truth than other traditions, as the bishops expressed in the Framework. Thus, in their teaching of World Religions, these teachers do not convey the notion that Catholicism is more true, or better, than other religious traditions, because they disagree with the bishops. When I asked Hans what content he specifically omits from the Framework, he mentioned the theological distinction between mortal and venial sin, because he finds the Catholic notion of mortal $\sin ^{15}$ being a complete "severing" of the soul from God to be "more like an abusive, codependent relationship," and does not teach this because "I would struggle to own it." I think that Hans is wary of teaching such technical dogma because it potentially posits God as a being of finite or imperfect love, or a deity to be feared. Someone's awareness of their sin is a good thing, but to remain in a stage of guilt is not; action and reconciliation require awareness, otherwise one could not seek forgiveness. Hans believes it to be important in such cases where he personally disagrees or struggles with church teaching, that he tries "not to put myself in the equation" and aims to present all sides of a particular perspective when inviting students into discussion. Hans also mentioned leaving out some teachings on the priesthood and Marian doctrine (such as the Assumption of Mary directly into Heaven when her earthly life came to an end without death, or her perpetual virginity). In retrospect, I realize that most of the participants were

\footnotetext{
${ }^{15}$ In Catholic theology, a mortal sin is distinct from a venial sin; the former is an action that is grave in its action (such as murder) and is committed in full freedom and awareness. A venial sin is less severe, and is not necessarily committed in full freedom and awareness. For example, stealing food from a grocery store to feed one's starving family is a venial sin: not only does stealing food from a wealthy corporation do little harm, but the actor's situation limits their freedom.
} 
unfamiliar with the Framework because they read it so rarely, and wish that I had pushed them to consider this question of omission more concretely; Hans was able to mention specific content that he omits because he went so far as to browse through the document during our conversation, but he was unique in this concurrent reading.

Additions. Participants include content outside of the Framework in their curricula, primarily because they view some Framework content as incomplete. Addition involves including elective courses from the Framework into standard theology coursework. First, the largest overall changes that departments (St. John's, St. Oscar Romero, and All Saints) make to the Framework is requiring certain courses that the bishops listed as electives: Catholic Social Teaching (or Social Justice), the Hebrew Scriptures, and World Religions. Father Paul, for example, remains true to the content of the Framework, but shifts the attention of his freshmen class towards a survey of the Bible. Emma and Francis teach World Religions as a mandatory class for seniors, and James teaches it as an elective for seniors. All of the participants' schools have a required course on Catholic Social Teaching, Morality, or Social Justice.

A second major addition to the Framework comes through using sources other than USCCB-approved textbooks; Father Paul is the only participant who uses USCCBapproved texts, but he finds them sometimes discombobulated and out of order. Emma brings in sources from secular news media, especially for case studies in her Junior morality class, and Francis draws from psychological articles to "go beyond" what the Framework offers. The World Religions teachers emphasized using primary sources from the sacred texts of other religious traditions. Hans uses writings from the pastor of a non- 
denominational church that he attends, and other Protestant sources because they "speak to this cultural moment really well," while "the best Catholic material tends to be good at 'the what,' I mean 'the what' and 'the why,' but tends to really lack on 'the how." Keen on helping students to apply theology, Hans finds Protestant sources useful in their pragmatism, and their ability to help students live out Christian theology. According to Francis, regarding his addition of concepts and texts to supplement the Framework, he believes that he is

not [...] diverging from it, but to fill in what is necessary for this to be actually believable. By the way, an appeal to authority is never an approach. I think an appeal to authority...well, first of all, it's a logical fallacy. But it also doesn't work in the sense that if you're appealing to authority, you're also saying, "I don't have a good reason, so I'm just going to appeal to my authority." So we really try to be persuasive in that sense. So, if it doesn't seem persuasive, not from my standpoint...the kids are telling me, "I ain't buying this." So we add things to make it believable. And it's usually said differently than, "Believe that this comes from God because the apostles told us so." It's usually not that kind of approach. So then, the question is "How do we know this is true?" And so, we have to go deeper.

This statement sums up why participants draw material outside of standard Catholic resources (such as the Catechism of the Catholic Church, which Francis and Father Paul use): they do not view themselves so much as diverging from the content of the Framework, as they do supplementing it to enhance some of the concepts that are there.

Emphasis and De-Emphasis. With the third and final sub-theme 9c, participants will emphasize or de-emphasize content and ideas in the Framework in order to meet the learning needs and desires of students. Although this final sub-theme can be understood as a distinct sub-theme from omissions from and additions to the Framework, it is also a reason why participants will omit or add content. For example, Hans will omit discussion 
of the traditional Catholic distinction between mortal and venial sin, but he will emphasize what makes certain actions excusable or forgivable (based on the writing of C.S. Lewis), because he finds such concepts to be far more relevant to the lived experience of his students. Hans also mentioned "that I do everything or most everything in the Framework, but I do entire units in often one or two classes. Rather than in whole units." For example, he covers an entire unit on the priesthood in one or two class periods, and assesses student understanding through a single multiple-choice question on a test, favoring that students spend their time on larger critical and reflective writing assignments. Thus, while Hans still covers the concept of sin, as posited by the Framework, he does so in a manner that is responsive and relevant. When he teaches about the concepts of sin and reconciliation, James favors a hands-on activity (which he tries to do regularly in his World Religions class): he has students burn pieces of paper upon which they have written down their mistakes, after which students burn these slips and smear their ashes on a windowpane. James explains to students that sin obscures our vision, while the process of reconciliation (akin to cleaning the glass) enables humans to see the world clearly once again. In this activity, James de-emphasizes the technical, doctrinal definitions of sin and reconciliation, and emphasizes the felt, affective, and practical meaning of these concepts instead. In James's own words:

What are the core principles around the Sacrament of Reconciliation? You could spend a lot of time on the details of how it's done, meeting with the priest, blah blah blah, but if we get down to the core principle, everyone needs to be reconciled in some way. That's where we go. 
This statement very much synchronizes with James's overall goals of helping students to live passionately, and to understand what it means to be human in relationship with themselves and with others.

Just as Father Paul omits certain content, he also emphasizes other content once certain things are omitted. When I asked him how his goals and practices had changed over the years, Father Paul commented:

Well, I've been less concerned with covering all of the ideas presented in the Framework, you could say. And more concerned about covering the most important ideas well. I guess it's partly as you teach the course over and over again, you get a better sense of what those are.

Other participants also spoke about teaching concepts and content that they consider to be "essential." Emma, for example, believes that her department teaches "the essentials" in such a way "that it's not watered down, it's not really simplified," which involves "not worrying so much about the vocabulary." And in focusing on the "essential heart" of a concept, or the "meaningful basics," she is "hoping that if we immerse people into the Catholic culture, they pick up some of that vocabulary and kind of the rules and the structure that go with that. Instead of a memorized Baltimore Catechism ${ }^{16}$ approach."

\section{Limitations of the Study}

As a qualitative interview study with a small group of participants, the findings of this study are not generalizable to all theology teachers. One cannot make any conclusions about the experiences, beliefs, or practices of theology teachers in other areas of the country or other schools. This said, I have little doubt that the findings of this study

\footnotetext{
${ }^{16}$ The Baltimore Catechism was the first catechism composed in North America, and Catholic school religion teachers used it from the 1880s into the 1960s.
} 
would resonate with the experiences of many theology teachers; and so, while the findings are not generalizable in a strict sense of proving overall trends for the majority of theology teachers, I do think that those teachers who work with students of diverse religious identities and faith traditions might very well tend to see their work in these findings, or see these findings in their work. Moreover, not all Catholic high schools have as many non-Catholics or non-practicing Catholics as these teachers' schools do, and so the questions I posed in this study would be less relevant to Catholic high schools whose students are overwhelmingly Catholic. I do not question the role of catechesis in helping people convert to Catholicism, or deepen the faith of Catholics, but these findings certainly support my suspicion that catechesis is irrelevant for, and even harms, nonCatholics in Catholic high schools.

Moreover, as a novice qualitative researcher, this was my first time coding this amount of data, consisting of almost three hundred pages of single-spaced transcripts. Although I tried my damnedest not to, I am sure that I missed opportunities for codes here and there, or miscategorized certain codes. I would not be surprised if I overlooked opportunities for deeper analysis, despite my consultation of several texts about qualitative analysis. In retrospect, I wish I had been more forward in asking probing questions, and in asking participants to elaborate on certain questions in subsequent interviews (for example, I would have benefited greatly from knowing what areas of the USCCB Framework participants intentionally omit). Additionally, I think that participants would have been better prepared to answer certain questions about how they 
diverge from or adhere to the Framework if they had read the document in preparation for our interview.

Perhaps the greatest limitation of this study was the fact that all interviews were conducted via Zoom, and that I was unable to visit and observe my participants teaching, given the constraints imposed by the COVID pandemic. Social distancing constraints made it challenging to truly triangulate data; while I had some documentary artifacts to confirm and deepen my understanding of these teachers' praxes, I wish I had the opportunity to observe teachers in action, and take field notes. I would have been able to ask more focused questions based on such observations.

Finally, this study does not incorporate the voices of our students, whose lives and educations we ultimately serve. The participants have very clearly molded their curricula around the needs, desires, and beliefs of their students (often based on direct feedback from students). This said, it is impossible to come to conclusions as to whether these teachers are in fact effective in their teaching, given that the primary judges of whether or not education has been empowering, sustaining, and liberating are the students.

\section{Summary of Results}

In this chapter, I have presented the themes and sub-themes that I developed in response to the three research questions that drove this study. While the five participants teach different courses to different populations of students, and employ different pedagogical styles and strategies in their work, I generated common themes from our interviews. With regard to their beliefs about religious education in Catholic high schools, and the role of catechesis therein, participants share: 
1. strong opposition to catechesis and general opposition to the USCCB Framework within the context of theology classrooms that have religiously diverse students;

2. efforts to make theology existentially meaningful and relevant by (a) translating Catholicism, (b) fostering students' well-beings and spiritualities, and (c) helping students to discover the sacred;

3. and efforts to offer students the freedom for exploration and authentic self expression in (a) exploration of content and (b) assessments.

With regard to their pedagogical decisions in education religiously diverse students in Catholic high schools, participants:

1. seek to nurture and foster loving relationships through their (a) creating classroom environments and culture that are safe, welcoming, and inclusive and (b) ways of relating to students;

2. encourage critical exploration (a) of self and (b) of content;

3. and deliver instruction such that it (a) centers student voice in conversation and assessment, (b) responds to student need, (c) is intentionally worded, and (d) revolves around essential questions.

With regard to their use of the USCCB Framework, participants:

1. adhere to the overall structure of the Framework;

2. identified benefits of the Framework; 
3. and diverge from the Framework in (a) omitting Framework content, (b) adding content not present in the Framework, and (c) emphasize and deemphasize content present in the Framework.

In Chapter 5, I connect these thematic findings and analysis to the literature review, particularly through the lens of the conceptual framework of Critical Religiously Sustaining Pedagogy. I situate these thematic findings within the broader context of scholarship, particularly as it pertains to catechesis in Catholic high schools and the practice of critical pedagogical models, and conclude with suggestions for future research and remarks on the implications of this study. 


\section{Chapter 5: Synthesis and Conclusion}

\section{Introduction}

In this fifth and final chapter, I provide a synthesis of the findings, specifically as they relate to the conceptual framework of Critical Religiously Sustaining Pedagogy. With this synthesis at hand, I proceed to situate this study within the broader context of theological education within Catholic high schools, and critical pedagogical theories. Finally, I suggest implications of this study with an eye toward its central findings and suggestions for future research, before offering some concluding thoughts.

\section{Synthesis of Findings}

As I studied the literature surrounding religious education in international contexts, in the context of U.S. Catholic high school education, and as both contexts relate to critical pedagogies such as CRT, CRP, CSP, and CRE, I generated the conceptual framework of CRSP. Using this conceptual framework, I developed my research questions, methodological approach, and analysis methods to foreground the ways in which theology teachers educate religiously diverse students in emancipating and evangelizing ways. In this synthesis, I provide the central insights that I gleaned from the interviews, and from my analysis of them, in relation to CRSP's overarching goals of evangelization and emancipation, and CRSP's central tenets: fostering nurturing and loving relationships, teaching existentially meaningful content, and providing religiously sustaining instruction. 


\section{Overarching Goals of Evangelization and Emancipation}

The mission to evangelize, to live out the love of Jesus and love of the Gospel, forms the beating heart of Catholic education. Each of my participants spoke to this love, and the ways in which they live out this evangelizing mission in their teaching; Hans was the only teacher who addressed this mission concretely, setting it up as a model of Catholic theological education as being oppositional to catechesis, but each of the other participants clearly remains grounded in their passion for Catholic theology. Emma seeks to accompany her students on their journeys of faith and to teach Catholicism authentically; Father Paul helps students to engage the Catholic theological tradition in the pursuit of beauty, truth, and goodness; Francis helps his students encounter and engage the transcendent, and to understand that faith is a mode of being rather than a systematic means of intellectual assent; Hans hopes to provide a model of Catholicism by the way he lives his life, and in his teaching gives students practical tools to help them understand and implement theology in relevant ways; and James wants his students to encounter the "Spirit" by having them engage a spectrum of religious traditions and practices. Catholic faith is an animating force in these individuals' lives and pedagogies, although none of them seek to convert their students to Catholicism as catechesis would have them do. These teachers do, however, provide students with the freedom to critically engage Catholic theology, leaving open the possibility of conversion if any given student so desires. In sum, I perceive that my participants evangelize by "attraction," as Pope Francis would have it, following the fabled (though likely misattributed) dictum of Saint Francis of Assisi: "Preach the Gospel always. Use words if necessary." While I think that 
CRSP could be applied to religious education outside of Catholic schools, such application would require replacing the overarching goal of evangelization with something else, or eliminating it entirely. Then again, non-Catholic Christian, Jewish, and Muslim schools tend to educate more religiously homogenous student populations; in the same way that a Catholic school serving an entirely Catholic student population does not need to consider religious diversity, neither would their non-Catholic counterparts.

I maintain that each teacher also emancipates their students in their own way, some with greater intentionality than others. Francis and James, in particular, are cognizant of the many ways in which students suffer, and hope that their classes are a means to liberate students from this suffering. Keenly aware of the toxic cultural influences on the teenage psyche that cause profound anxiety, stress, and loneliness, Francis and James work to correct students' misconceptions surrounding their knowledge of and the general practice of religion, and both aim to help students encounter the "transcendent" and the "Spirit" through the process of liberation. Emma helps students to recognize the sacred in themselves, thereby liberating them from poor self-esteem due to a lack of this awareness. Father Paul, with his devotion to the Catholic intellectual tradition, wants students to engage this tradition such that they might develop their beliefs, whatever those might be. Hans, eminently practical in his approach to theology, emancipates students from not knowing how to steward their money, or from unhealthy habits and lack of self-awareness in their relationships. Emancipation moves in two directions: freedom from and freedom toward. Each teacher, in his or her own right, helps to free students from unhealthy practices, ideas, and misconceptions, in order to free them 
toward fullness of life and well-being. I have provided a few examples of how these participants educate for emancipation in both directions. Education as a whole, as Freire expounded, can be oppressing or liberating, and in rejecting the catechetical impulse to convert their students or assume their belonging to the Catholic faith, my participants approach education as a vocation of emancipatory power.

\section{The Tenets of Critical Religiously Sustaining Pedagogy}

In this section, I provide syntheses of the CRSP's three tenets: nurturing and loving relationships, existentially meaningful content, and religiously sustaining instruction. Understanding how teachers engage these tenets was at the heart of many of my interview questions.

Nurturing and Loving Relationships. The first tenet of CRSP, fostering nurturing and loving relationships, is connected to themes 1, 4, 4a, and 4b. Regarding theme 1, my participants oppose catechesis and the Framework because as modes of theological education, they approach non-Catholics through a deficit lens. As CRT, CRP, and CSP explicate, deficit-based education, which is grounded in the pursuit of educating white middle-class children, wreaks havoc on students who are of Color, do not belong to financially privileged classes, or who are multilingual. In a similar vein, because catechesis and the Framework assume that teachers are educating students who are Catholic or desire to become Catholic, they actively harm, invisibilize, and oppress nonCatholic students.

Participants generally do not differentiate between Catholics and non-Catholics when they seek to build relationships with their students; in fact, most teachers prefer not 
to maintain an active awareness of who is Catholic and who is not, although they are certainly aware of the diversity of beliefs that their students possess. Even though teachers might not be directly aware of students' particular religious positionalities at the start of a school year, they naturally gain awareness as the months wear on. It is certainly legitimate to ask whether a theology teacher can sustain a student's beliefs if their beliefs are unknown to the teacher; I think, however, that given the right questions and assignments, offering students the freedom to undertake metacognition and self-reflection is a sustaining practice. Given that none of my participants spoke about building relationships with non-Catholic students differently than they would with their Catholic counterparts, I perceive that building relationships for these teachers has more to do with the creation of a general classroom atmosphere or community (sub-theme 4a), and relating to students (sub-theme $4 \mathrm{~b}$ ) in ways that are conducive to forming relationships, than reaching out to non-Catholic students in a particular way.

Each participant relates to students through maintaining warm and inviting demeanors: they attend and participate in extracurricular activities, thereby becoming part of their schools' culture and community; they practice humor, engage in casual conversations, and use teenage colloquialisms; they offer flexibility and grace with students who are having trouble in class. Interacting with students outside of the strictly academic is part and parcel of how these teachers live out their vocations as educators. Even more specifically, as they manage their classrooms and develop community with their students, participants co-create community agreements, and enact particular practices that make their classrooms spaces where students feel safe to express 
themselves, and feel that they are able to succeed: they avoid punitive discipline, they give feedback that meaningfully affirms students' perspectives and expertise; they have potluck feasts; and they reveal who they are as human beings to their students, thereby inviting students to do the same.

Existentially Meaningful Content. The second tenet of providing existentially meaningful content manifested in a number of ways throughout the interviews and themes (specifically, themes and sub-themes 1, 2, 2a, 2b, 2c, 5a, 6d, 9, 9a, 9b, and 9c). Teachers oppose catechesis and the Framework (theme 1) because catechesis and the Framework posit theological education that is existentially meaningless for many of their students, and irrelevant to their lived experiences and beliefs. In reality, devoutly practicing Catholic students are very much a minority at each of my participants' schools, and so none of them take a catechetical approach to theological education. While my participants certainly teach Catholic theology and doctrine, I perceive that none of them are intent upon having students memorize theology and doctrine, so as to achieve high scores on the ACRE test. None of the participants discussed whether or not their principals or departments use the ACRE test to inform their teaching, which I find unsurprising given the immense autonomy my participants have in deciding what to teach or how to teach. Instead, Emma, Father Paul, Francis, Hans, and James teach Catholic theology and doctrine to provide material with which students can engage and dialogue, and reject or accept.

Regarding theme 2, existential meaning and relevance, and sub-themes $2 \mathrm{a}, 2 \mathrm{~b}$, and 2c (translating Catholicism, personal well-being and spirituality, and discovering the 
sacred, respectively), teachers provide their students with content and exploration that is meaningful and relevant to their lived experience. They do this by way of the three subthemes. First, teachers translate Catholicism, using language and concepts derived from the lived experiences and beliefs of students; by translating the essential themes from a point of Catholic theology into teenagers' lived experience - as between the Sacrament of Reconciliation and the humanizing effects of forgiveness, for example - teachers build bridges between Catholic theological concepts and the lived experiences of students. Teachers' decoding and elucidating otherwise irrelevant theology removes the catechetical impetus on the memorization of doctrine and dogma, given that such a process would be irrelevant to many non-Catholic (and non-practicing Catholic) students' learning. This process of translating theology frequently uses various media such as film, music, and visual art, and connects to theme $2 \mathrm{~b}$, as teachers strive to make theology a liberating discipline, one that helps to foster the well-being of students, and aids in the development of their spiritualities. Most importantly, as these teachers constantly build bridges between theological content and students' lived experiences, they ask students to build and walk across these bridges communally. All of these practices coalesce with, and even exemplify, the central ideas at the heart of CRT.

With regard to the second sub-theme of personal well-being and spirituality, teachers such as Francis and James are keenly aware of the detrimental and isolating effects of culture and technology on students' psyches, and they approach the teaching and learning of theology as a way to combat these oppressive forces. Cast in Freirean terms, theology can be live-affirming and biophilic, starkly contrasted against the 
destructive and necrophilic forces at play in U.S. culture. In gearing theology class toward the development of personal spirituality, teachers encourage students to discover the sacred in their own lives, and in the worlds that surround them. From Emma's focus on students being able to discover and articulate their spiritual gifts to Francis opening students to the possibility of engaging the transcendent in their athletics, coursework, and extracurriculars, teachers work to unveil the presence of God outside of the traditional strictures defined by organized religion. Others, such as Hans and Father Paul, aim to convey Catholic theology so that students can see it as a means of developing a relationship with God. Those who teach world religions for seniors aim to demonstrate the commonalities shared by religious traditions, in order to help their students respect and value perspectives that diverge from, or are opposed to, their own. As discussed in the literature review, those countries in Europe that mandate religious education as a standard subject approach religious education similarly: students learn about religion, rather than experience indoctrination into religion, all for the purposes of forming citizens who can harmoniously coexist in a pluralistic, democratic society. To recall Freire once again, this is an example of reading the word and reading the world, one that teachers orient toward praxis. Teachers' deep interest in providing existentially meaningful instruction of course involves critical exploration of self, as there can be no pursuit of relevancy without leveraging students' funds of knowledge in their engagement with theology class.

Throughout our interviews, my participants provided the questions that drive their teaching (though not in response to any requests from me), which led me to generate sub- 
theme $6 \mathrm{~d}$, essential questions; by and large, these questions centered around teachers' desire to make theology existentially meaningful. My participants are constantly framing their pedagogy around questions that prompt theological explorations and reflections, thereby motivating students to consider the implications of theology for their own lives. In all of this, teachers diverge from the USCCB Framework by omitting meaningless and irrelevant content, adding meaningful and relevant content, and emphasizing and deemphasizing content such that theology is meaningful and relevant.

Religiously Sustaining Instruction. Invoking Paris and Alim's (2017) model of CSP, and understanding religious belief as a central aspect of a students' cultures, I sought to understand how my participants approach students' religious positionalities through an asset-based lens, recognize that beliefs are fluid and dynamic, rather than static, and sustain students' beliefs, regardless of what they are. There are a number of themes and sub-themes that connect to teachers' providing religiously sustaining instruction: (1) opposition to catechesis and the Framework; (2a) translating Catholicism; (2b) personal well-being and spirituality; (3) freedom for exploration and authentic selfexpression; (3b) freedom in assessments; (4a) classroom culture and environment; (6a) centering student voice in conversation and assessment; (6b) responding to student need; (6d) essential questions; (9) divergences from the Framework; (9a) omissions; (9b) additions; and (9c) emphasis and de-emphasis. These themes and sub-themes, when viewed through the lens of CRSP's tenet of religiously sustaining instruction, involve a different dynamic than do the themes related to its partner tenet of existentially 
meaningful content; with this tenet, I sought to explore how teachers sustain the beliefs of students, regardless of what those beliefs are.

All of the participants reject catechesis (theme 1) as a means of theological education within their classrooms, I argue, because catechetical education reifies hegemonic religious discourse. Teachers simply do not expect their students to be Catholic, nor do they attempt to convert their students; this said, Father Paul and Hans both expressed their desire to teach Catholic theology in such a way that leaves students with the opportunity to convert, if they desire. While religious education in certain European countries provides students with teachers who are of their own religious tradition, such a move to employ non-Catholic theology teachers would be impossible in U.S. Catholic high schools. Employing religiously diverse theology teachers could provide religiously sustaining education, but I think an equally (if not potentially more) sustaining possibility is to bring students of diverse religious perspectives in dialogue with one another, and with other religious traditions, so as to oppose religious hegemony. Teaching students about religion(s), after all, does not inherently help them to sustain their own religion(s); as Paris and Alim (2017) articulated, that which is culturally relevant is not necessarily culturally sustaining. In order to sustain students' beliefs, participants must leave behind the desire to proselytize, and teach from the Catholic theological tradition in such a manner that students can refine their own beliefs in dialogue. Not once did a participate indicate conversion as being a central goal, and in fact, all participants actively avoid pursuing this goal. Consequently, placing students' religious (or non-religious) positionalities in conversation with Catholic theology requires 
participants to translate Catholic theology into students' understandings and experiences. This requires, I posit, a nuanced understanding of religious belief on spiritual, sociological, and psychological levels, but does not necessitate that teachers know and understand what each and every student believes; offering students freedom to question, to explore, to dialogue, to think, and to write as students desire is a religiously sustaining pedagogical practice. However, I would add that in order to truly be religiously sustaining, knowing and understanding students' religious positionalities would enable theology teachers to proactively address and leverage students' funds of religious belief. Ultimately, I found that these five teachers invite their students to engage theology as a discipline that is not just about meeting curricular standards, but about refining, defining, and forging their individual spiritualities, if students so choose.

I believe the most powerful themes for understanding how teachers provide religiously sustaining instruction are those pertaining to freedom for exploration and authentic self-expression (theme 3) and the sub-themes of freedom for exploration of content and freedom in assessments (sub-themes $3 \mathrm{a}$ and $3 \mathrm{~b}$, respectively). These themes manifested in the interview and artifact data in a variety of ways. Given that devout Catholics who regularly partake in the institutional practice of their religion are in the minority of their students, my participants recognize that many students might not have any familiarity with religious traditions, practices, sacred texts, or rituals. Consequently, these teachers do not assume the Catholic beliefs of their students, and remain largely (and intentionally) unaware of the religious traditions with which particular students identify. As such, teachers provide students with a range of ways and means for students 
to critically examine their own beliefs and theology as a whole, and to express their identities and beliefs safely and honestly, without fear of being ostracized or penalized. Thus, not only are these teachers enacting religiously relevant pedagogy, but they go beyond relevant pedagogy by inviting students to sustain and develop their beliefs. First, my participants give their students the freedom to explore theology in ways that are helpful or interesting to them. James, for example, teaches World Religions as a means of helping students to participate in the process of bricolage, approaching religious traditions through the lens of their big life questions, so that students can take what they find helpful and discard what they do not. Although other participants did not concretely address bricolage with the same language that James did, I believe that this concept lies at the heart of their various pedagogies: students use what they find helpful or meaningful, and no teacher forces doctrine upon their students. As teachers spoke about their assessments, they spoke about giving students a variety of options to complete assignments, from choices of questions or essay prompts to answer, to choosing different mediums through which they can express their learning. In providing students with remarkable freedom and flexibility, these teachers acknowledge that beliefs are fluid and dynamic.

In the classroom culture and environment that teachers create (sub-theme 6a), teachers intentionally develop learning communities wherein all students feel safe, and feel that they can succeed. Some participants, for example, explicitly tell their students that they have no interest in converting them from the very beginning of the academic year. Emma especially focuses on the area of classroom culture and environment in the 
first few days of class, providing affirming feedback on students' reflective writing; other teachers spoke to eschewing punitive discipline (Francis) in favor of conversational, restorative practices (Father Paul). Fostering safe spaces that are inclusive of diverse beliefs helps students to feel safe in expressing their thoughts, opinions, and beliefs. With regard to disconfirming evidence, Hans remarked several times that devoutly religious students, be they Catholic or Protestant, tend to refrain from vocally expressing their beliefs in class, even to the point of asking Hans to avoid calling on them (perhaps for fear of judgment from their peers). This said, devout students are comfortable expressing their beliefs in the written word, provided that their writing will only be read by the teacher, and Hans was the only participant who mentioned such hesitancy on the part of students. Participants frequently spoke about generating dialogue and conversation between students, through discussion protocols (Father Paul and James), or sharing beliefs, opinions, and experiences with great regularity.

On a related note, teachers center student voice in conversation and assessment (sub-theme 6a), and do not center assessments around objective knowledge of doctrine and dogma. While such objective knowledge is necessary to generate meaningful classroom dialogue (as Emma pointed out, students need to be able to ground their opinions in some sort of objective understanding of concepts and history), by no means did my participants speak to any intent or practice that reflects the catechetical interest in the memorization of doctrine. Moreover, teachers are highly cognizant of responding to student need (sub-theme 6b), and shape their teaching around students' desires: Francis spoke a number of times about soliciting student feedback each semester, and Emma re- 
shapes her curricula year to year, depending on current events (given that her students are mostly of Color, Emma has increasingly brought in anti-racist content into her classes). Hans focuses on making theology eminently practical for his students, because he perceives that they need help knowing how to discern major decisions and how to steward their financial resources, for example.

Initially, I was curious to see how teachers help students to understand the influence of religious beliefs in a religiously pluralistic world. I found that while the teachers who teach World Religions are intent upon helping students to understand the beliefs of those around them, none of my participants spoke about investigating the sociological impact of religious belief on culture and society. Perhaps this was because the regional demographics surrounding these schools do not contain significant representations of large non-Abrahamic, or non-Christian, populations. I honestly expected my participants to address the roles that religious belief plays in politics, government, war, and peace, and although this did arise at a couple of points (such as with Emma's focus on historical narratives, and Hans's exploration of the weaponization of the Book of Joshua), I was somewhat surprised to find that neither Francis nor James delve into political or sociological theology. This said, each and every participant spoke of helping students to understand their beliefs, to articulate them, and to grow or develop them as a student needed. Students have the freedom to express themselves and their beliefs, along with their doubts and questions (even if they run contrary to Catholic theology), without reservation. Given that my participants all leverage students' experiences, and invite their students to think, speak, and write from their positionalities, 
I consider their approach to theological education to be affirming and validating for students, thereby exemplifying some of the central ideas of CSP. I believe that teachers' attempts to provide existentially meaningful content and religiously sustaining instruction influence their use of the USCCB Framework, namely how they diverge from it (theme 9) by omitting content (sub-theme $9 \mathrm{a}$ ), adding content (sub-theme $9 \mathrm{~b}$ ) and emphasizing or de-emphasizing content (sub-theme 9c).

\section{Use of the USCCB Framework}

My participants' efforts to be relevant and responsive to, and sustaining of, students' religious positionalities have led them to implement highly creative (and even unorthodox) pedagogy in their classrooms. Most participants have found that their goals for their classes depart and diverge from the USCCB Framework's goals of forming disciples of Christ by means of catechesis. As a direct consequence, participants rarely consult the Framework, and while they rely upon it to provide structure for their department scope and sequence (theme 7), they ignore the Framework's impetus to have students memorize doctrine and dogma. They omit, add, de-emphasize, and emphasize content within the Framework, such that they are able to translate Catholic theology, meet students' religious (or non-religious, or anti-religious) positionalities, and invite students to engage theology honestly and authentically from those positionalities. This study confirmed all of my suspicions, that teachers are essentially eschewing and ignoring the Framework in their teaching. And while I refrain from generalizing these findings to other contexts and Catholic high schools, I strongly suspect that they are in fact indicative of teachers' beliefs, goals, and practices in other Catholic high schools as 
well, especially for teachers who educate students in schools that are run by religious orders (such as Emma's, Francis's, Hans's, and James's schools) rather than dioceses and archdioceses (as at Father Paul's school).

\section{Situated in the Larger Context of Scholarship}

The landscape of Catholic education has shifted tremendously over the past four decades, as students of many different cultural and religious backgrounds have matriculated into Catholic schools. In the research surrounding pedagogy that is critically relevant, responsive, and sustaining, religion has been overlooked as part and parcel of students' cultures. Over the course of human history, religious traditions have shaped human experience, language, art, history, and culture in untold ways. Indeed, religious beliefs throughout history have determined how human beings live, move, and breathe in this world. My research, I believe, has pushed the boundaries of these critical pedagogical theories and models forward into the realm of religion; although my study focused on teaching within the highly specific niche of theological education within U.S. Catholic high schools, I argue that educators need to maintain an awareness of students' religious beliefs as they seek to be culturally relevant, responsive, and sustaining. Teachers' avoidance of inviting students' religious orientations into the classroom might even be likened to racist colorblindness. We must honor and affirm the religious beliefs of students whose beliefs differ from, or oppose, our own. We must fight the urge to secularize students who are religious, but rather invite their beliefs into the classroom, honoring and affirming their cultural positionalities with regard to religious belief, if we are to humanize education in a truly holistic manner. 
In this section, I situate my study within the context of scholarly literature that I reviewed in the second chapter. While I synthesized my findings in the previous section through the lens of the CRSP conceptual framework, in this section I situate my findings within the extant literature in light of the three research questions. This said, because no studies have been conducted on theology teachers' use of the Framework in service of religiously diverse students, I have left out a potentially expected section on the third research question.

\section{Research Question 1: Beliefs About Theology's Goals and Catechesis}

As I examined the interview data from the first interviews, which were centered around the first research question, "What do Catholic theology teachers in Pacific Northwest Catholic high schools believe about the purposes and goals of religious education for religiously diverse student populations, especially with regard to the role of catechesis therein?", I discovered three primary themes: (1) opposition to catechesis and the Framework, (2) existential meaning and relevance, and (3) freedom for exploration and authentic self-expression. I discovered that participants' educational backgrounds and life experiences very much influence their approach to teaching theology. For example, Emma's education in a secular state school, followed by her coursework with rebellious professors of Church history at a Catholic university, have led to her willingness to not shy away from teaching about the evils within Catholicism's history. James and Francis spoke of clerical abuse and institutional hypocrisy that they experienced or witnessed, and they held the most negative attitudes toward catechesis and the Framework. Father Paul, in contrast, who graduated from a Catholic university and was trained in a 
seminary, takes a much more "orthodox" approach to his teaching. Hans, who endured vapid and uninteresting religious education before exploring theology's relationship to literature and culture in college and graduate school, dives into these same relationships with his students. When considering how a theology teacher goes about their work, understanding their backgrounds and experiences sheds helps one to understand their reasoning and positionality.

Regarding the first theme of opposition to catechesis and the Framework, most of my participants' evaluations of catechesis as a mode of theological education and the USCCB Framework were negative. Their evaluations cohere with numerous scholars' (Groome, 1999; Groome, 2011; Harris \& Moran, 1992; Harris \& Moran, 1998; Moran, 1983; Moran, 1989; Moran, 1997; Moran, 2018; Rossiter, 1982; Rossiter, 2011;

Rummery, 1975; Schipani, 1988; Switzer, 2006; Wright, 2007) questionings and critiques of catechesis as being appropriate for religiously diverse student populations. Just as Emma and James identified the Framework's catechetical impetus as being dehumanizing of and oppressive toward non-Catholic students, studies in international religious education (Aronson, Amatullah, \& Laughter, 2016; Franck, 2015; Hand, 2004; Hill, Harris, \& Martinez-Vasquez, 2009; Wright, 2008) have identified the harms caused by indoctrinatory religious education. Moreover, my participants' perceptions of catechesis's harmful effects on non-Catholics parallel the perceptions of students who deemed their theology classes as irrelevant or having minimal impact on their spiritualities in Aldana's (2015) and Martin's (2016) studies that foregrounded students' voices. None of my participants identified their teaching as catechetical, which 
interestingly contradicts Cook and Hudson's (2003) study, which found that 55\% of U.S. Catholic school religious educators identified as catechists, although it is difficult to hypothesize why this contradiction exists. Perhaps it is due to an older generation of theology teachers being replaced by a younger one that has experienced different modes of theological education apart from catechesis. I find this contradiction especially intriguing given that Cook and Hudson conducted their study before the Framework mandated the use of catechesis in 2008. Hans called into question the appropriateness of the catechetical mode of theological education for religiously diverse students, precisely because they have not experienced foundational faith formation from their homes or parishes, and rather advocates an "evangelical" model, which coheres well with Cardinal Baum's (CCE, 1988) emphasis on “pre-evangelization.” My participants remain very much grounded in their religious beliefs and love for Jesus and Catholicism; these animating sources of faith echo Cho's (2012) and Dallavis's (2014) findings that Catholic school educators are primarily motivated by religious beliefs. And given that my participants certainly aim to communicate Catholic theology authentically, and to translate theological concepts for their students, I would characterize their practice of faith-based religious education as "semi-confessional" (Franken \& Vermeer, 2017) rather than fully confessional, catechetical, or indoctrinatory. In other words, while these teachers remain grounded in the Catholic theological tradition, they avoid proselytization.

Focusing on the Framework itself, my participants shared many of the same dissatisfactions as Schroeder's (2013) participants did, insofar as they felt the Framework was irrelevant for high school students (given that the Framework is dry, confrontational, 
and does not lend itself well to sharing and discussions), although rarely did my participants state that they felt overburdened by its hundreds of doctrinal points (in all likelihood because they do not consult the Framework with any regularity whatsoever). Francis and Emma, who have been teaching for over three decades, both noted the bishops' lack of consultation with teachers and educational experts, thereby iterating Schroeder's (2015) findings about the Framework's development. More pointedly, O'Malley's (2009) and Ostasiewski's (2010) critiques of the Framework soon after its publication very much resonated with my participants' views on the Framework, insofar as the bishops do not understand the reality that teenagers do not possess "faith" and “awareness of the transcendent” (O’Malley, 2009). Father Paul, Francis, and Hans all noted that although they might have significant numbers of students who identify as Catholic, in reality many of them do not partake in catechetical education or active participation in their parishes.

Moreover, my participants described their students as being largely unfamiliar with theology and religious traditions, which certainly coheres with Smith and Denton's (2009) findings about the religious and spiritual lives of teenagers. Participants very rarely discussed instances wherein students voiced active hostility to theology and religion, which also echoed Smith and Denton's discoveries about U.S. teenagers' general "fairly inclusive and pluralistic position" $(2009$, p. 74$)$ regarding claims to religious truth. All of my participants teach in schools with significant populations of non-Catholic students, and in each of these schools, devout, practicing Catholic students are in the minority. Francis and Robbins (2011) found that religious educators in UK 
Catholic and Anglican schools aimed for critical engagement with religion and theology over and above faith formation, whereas my participants direct their efforts toward both goals. I suspect this difference might exist because European religious education tends to be more focused on objective understanding of religion, rather than the faith formation of individual students, although I consider the latter to be an important goal of religiously sustaining instruction. This said, Zilliacus (2013) found that religious educators in Helsinki centralize students expressing their beliefs, views, and experiences (just as my participants do), and so European religious education is far from monolithic.

The findings of my study, I believe, sync (with few exceptions) with the rest of the available literature on teachers' beliefs surrounding the goals of theological education and the role of catechesis in U.S. Catholic high schools.

\section{Research Question 2: Pedagogy for Non-Catholics}

With regard to the second research question, "What particular curricular and pedagogical decisions do Catholic theology teachers in Pacific Northwest Catholic high schools make in order to meet the needs, interests, and positionalities of their nonCatholic students?" my participants spoke about a wide variety of practices that they use to meet the needs of their religiously diverse students. First of all, none of my participants assume that their students are Catholic or desire to become Catholic, and respect their students' religious consciences in so doing, which Donlevy (2007) also found true for his Canadian theology teacher participants. In honoring and respecting their students' freedom of religious conscience, my participants' approaches cohere with the CCE's defense of students' religious consciences (CCE, 1988). When it comes to students 
voicing their disagreement with Catholic theology, I did not find any evidence of teachers preventing students from expressing dissent, although McDonough (2009) found that his Canadian religion teachers expressed experiencing greater tension with doctrinal authority as they tried to implement student-centered pedagogy and incorporate students' voices, which sometimes dissented from official Catholic teaching. Dallavis's (2013) participants stated that because they taught in Catholic schools, they could not teach about topics that are controversial in the realm of Catholic Social Teaching (such as abortion). Father Paul expressed a similar sentiment: he believes that Catholic high school theology teachers are beholden to the institutional church, and therefore have a responsibility to refrain from expressing their dissent on matters of doctrine and dogma. My other participants expressed no such qualms in exploring controversial areas with their students; James is willing to express his own disagreement with Catholicism's official teachings, and while Emma and Hans do not permit their own biases or disagreements with Catholic theology to enter into their teaching, they very willingly foster conversations wherein students can freely express their disagreements. In light of their varied approaches, my participants would fit well into the "dialogical" and "open" models of Catholic schools that Garcia-Huidobro (2017) proposed with regard to how they approach curricula. My participants' conversational and emancipatory approaches to teaching theology oppose the rigid and doctrinaire approach that McDonough (2016) discovered clashed with Canadian students' spiritualities, and that Village and Francis (2016) found resulted in non-Catholic students' lower self-esteems and negative attitudes toward their Catholic schools. 
Regarding their pedagogical decisions as they diverge from or adapt the Framework, my participants discussed how they go about teaching theology so that it is relevant for and applicable to their students' lived experiences. Their concern for relevance and applicability complements McGah's (2013) findings about teachers' selfreported best practices in Washington state's Catholic high schools. In his study of religion classes' impact for alumni from one Catholic high school, Hortsch (2021) discovered that students praised teachers' incorporation of student questions, tailoring instruction to meet their needs, inviting students to see themselves in Christianity, and focusing on experiential learning, all of which are practices that my participants reported. Emma and Francis shift their curricula from year to year, based on student feedback (Francis) and perceptions of current events (Emma); James engages World Religions through creative and artistic projects, and invites students to express their learning through media other than the traditional written essay; and all my participants translate Catholic theology into their students' lived experiences and beliefs. My participants frequently ask students to do reflective writing in their classes, which maintains certain similarities to Camangian's (2010) pedagogical tool of sharing autoethnographic writing and teachers leveraging CSP by asking students to express their funds of knowledge through their writing (Jaffe-Walter \& Lee, 2018). James's goals for his students to develop their spiritualities and sense of the divine through the process of bricolage resonates with the process of religious bricolage as explored by international scholars of religious education (Freathy, Doney, Freathy, Walshe \& Teece, G. 2017), which seems 
attuned to U.S. teenagers' open-minded attitudes as reported by Smith and Denton (2009).

Religious education in international contexts (Everington, ter Avest, Bakker, \& van der Want, 2011; Everington et al, 2016; Franken \& Vermeer, 2017; Mitchell, 2016; Zilliacus, 2013) tends to invite students to learn about religion, rather than from religion, the latter of which is geared toward the development of students' beliefs and spiritualities, for example. I found that my participants strive for the goal of learning about religion, but also go beyond it, moving into the realms of relevant, responsive, and sustaining pedagogies. In so doing, they put into practice some of the CRE's tenets (Easton, Goodman, Wright \& Wright, 2018), specifically epistemic relativity and judgmental rationality, given that their teaching theology involves foregrounding students' active construction of beliefs, perceptions, and judgments. Literature about religious education from other parts of the world did not discuss the centrality of relationships to the educational process, while CRT, CRP, and CSP all foreground the invaluable nature of healthy relationships between students and teachers. When I asked my participants what advice they would give a new teacher working with religiously diverse students in our focus group interview, they all agreed that loving students needs to be a priority. In prior individual interviews, my participants highlighted the importance of building relationships, which bolsters the findings and arguments posited by scholars who have conducted studies of U.S. Catholic schools: Dallavis (2014) found that teachers' religious beliefs drove their engagement with CRP, and Maney, King, and Kiely (2018) found that White teachers in Midwestern Catholic schools were failing 
students of Color because they failed to foster relationships with their students. Donlevy's (2007a) Canadian Catholic high school teacher participants all strive to welcome, appreciate, empathize with, and protect their non-Catholic students, which echoes my participants' attitudes towards fostering religiously inclusive classroom spaces as well.

Educational theorist-practitioners within the realm of CRP, such as LadsonBillings (1995a, 2009), Irvine (2010), and Milner (2010b), have all foregrounded the importance of relationships, communal empowerment, and asset-based approaches to educating students of Color. Emma was the only participant who spoke about educating students of Color who are economically oppressed, and I do not intend to draw too strong a parallel between race and religious identity, which would trivialize the crucial work surrounding antiracist education. I do think, however, that whenever educators are teaching students who do not share their beliefs, perspectives, and experiences, their unconscious biases can of course unjustly impact their students, and so I do perceive some connections between my study's findings and scholarship within CRP: my participants build community through nurturing and loving relationships, ensure that every student (regardless of their religious beliefs) in their classroom can succeed, and reject catechetical models of education that reify Catholic hegemony and brand nonCatholics as less-than or undesirable. Milner (2010a) and Kidwell and Herrera (2019) discussed the importance of learning about students and practicing self-understanding and self-examination, and my participants especially highlighted the latter qualities in our focus group. As for Gay's (2018) model of CRT, I believe that my participants enact a 
number of her central recommendations as well: they honor and respect non-Catholic students' beliefs, they build bridges 'between academic abstractions and lived sociocultural realities," (p. 37) and promote dialogue between students, so as to foster mutual respect for the dignity and humanity of their peers.

Finally, I believe that my participants exemplify the spirit and forcefulness that CSP's scholars (Paris, 2012; Paris \& Alim, 2014; Paris \& Alim, 2017; Paris \& Winn, 2014) pioneered: they reject the religious hegemony that the bishops assumed and/or aimed to promote through their Framework, they leverage students' skills and funds of knowledge by offering students freedom of exploration and self-expression (as Stenberg [2006] and Esteban-Guitart et al. [2019] also recommended), and they recognize the dynamism and unendingly shifting, hybridic nature of religious belief. As Kinloch (2017, p. 29, emphasis in original) stated, "for CSP to be effective, then collaborative, collective, critical, and loving environments must be fostered that support young people's cultural identities," and in order to do so,

we must work to combat and eradicate oppressive, racist educational policies that advantage monoculturalism, that debase the linguistic virtuosities of communities of color, and that recode terms such as relevance and responsiveness to mark tolerance over acceptance, normalization over difference, demonization over humanization, and hate over love.

If we replace "racist" with "hegemonically Catholic," "monoculturalism" with "monoreligiosity," "linguistic virtuosities" with "religious virtuosities," and "communities of color" with "non-Catholic communities," we arrive at a perspective of CSP that foregrounds the role of religion in students' cultures. While religious education remains largely anathema to public education in the U.S. (although certain IB and 
humanities programs involve education about religion in their curricula), students will continue to bring their beliefs into the classroom, unspoken though they may be. If nonCatholic students continue to matriculate into Catholic high schools in increasing numbers, and if Catholic students become less and less invested in their inherited religious tradition, theology teachers would have much to learn from these many strands of critical pedagogy.

\section{Implications}

In this section, I outline several major implications for this research, which I believe prompt important considerations for Catholic secondary education broadly, and stimulate thinking for further research.

\section{Reconsidering the Framework and Catechesis}

If the beliefs and goals of Emma, Father Paul, Francis, Hans, and James are any indication of the beliefs and goals of Catholic high school theology teachers in other areas of the country (especially urban settings, where populations of non-Catholic students attending Catholic schools tend to be higher), I believe that it is time to reconsider whether the USCCB Framework ought to be universally implemented across all U.S. Catholic high schools. As veteran department chairs Emma and Francis indicated, the bishops utterly failed to consider the expertise of educators and relevant practitioners (such as adolescent psychologists) as they drafted the Framework, instead relying upon the Catechism of the Catholic Church and their own experience of catechetical theological education for its content. Many bishops grew up in a generation of priests who began seminary formation as high school students, as young as fourteen 
years old. Others entered the seminary immediately following college, although their families and parishes exposed them to, and immersed them in, catechesis. While high school seminaries are few and far between nowadays, the bishops' document indubitably (in my mind, at least) reflects a mode of theological education that is no longer relevant for many students, who are increasingly secularized and areligious. My participants spoke to their sense that students long for meaning and depth in the lives, precisely because U.S. culture is plagued by technocracy and the commodification of the human person. In light of the desiccation brought on by these dehumanizing and necrophilic forces, perhaps the greatest gift that theological education can offer students is the gift of self-reflection and metacognition, that is, the opportunity to develop and deepen an awareness of the spiritual dimensions of our existences.

My participants want to witness their love of Jesus and Catholic theology for their students, thereby embodying the most transformative of all Gospel values: love that is not conditioned upon socioeconomic status, race, religion, or any of the many positionalities that unnecessarily catalyze hostilities among our citizenry. If students convert to Catholicism as a result of time spent in my participants' theology classes, it will not be by coercive memorization or indoctrination, but rather through the sheer force of gravitational attraction to the sort of life that vibrates with joy and beauty and goodness. Francis's words have stuck in my mind ever since he spoke them: salvation is not information, and nobody ever changed religions because they lost an argument. If the bishops believe they will shore up their authority in the wake of scandal and abuse through the Framework, I believe they are mistaken. If the bishops believe they will 
retain Catholics through the catechizing of unwilling teenagers, I believe they are mistaken. Teachers' implementation of the Framework will not aid U.S. bishops in their attempts to keep Catholics in the pews.

\section{Considering a Different Scope and Sequence}

In our focus group interview, I asked my participants to collaborate on a Google Document, where they mapped out suggestions for an ideal four-year scope and sequence that would serve religiously diverse student populations well. For first-year high school theology classes, my participants largely agreed that some sort of introduction is necessary; they suggested introducing students to models of spirituality (including mysticism and non-Christian traditions), religious ideas and themes and language, Catholicism, and so on. In this first year, students would develop the requisite concepts and language to engage theology fruitfully throughout their remaining three years, using their own lived experiences to do so. In the second year, my participants suggested surveys of Scripture and Catholic theology; based on my own experience of teaching the Bible, I believe that Christian theology's most central concepts can be explored through biblical studies, rendering independent courses on Christology or Ecclesiology unnecessary. For the third year, participants agreed that teaching morality and Catholic Social Teachings are suitable for juniors. Finally, they suggested that seniors take courses in World Religions, Vocation, and Social Justice, with the possibility of electives (such as a Service Seminar, Faith in the Arts, Faith and Philosophy, or a more intensive seminar on Trinitarian theology or Ecclesiology). 
In sum, I think that participants largely agreed that because the solid majority of their students are not terribly versed in Catholic theology, they want to make sure that students are conversant with spirituality and religion on a broad level, and all that they entail. Such a foundation, they believe, is necessary before more detailed explorations of sacred texts, rituals, and moral teachings can be pursued.

\section{Leaning into Critical Theories of Pedagogy}

A final implication, I believe, is that theology teachers would greatly benefit from leaning into, and learning from, critical pedagogies such as Culturally Relevant Teaching, Culturally Responsive Pedagogy, and Culturally Sustaining Pedagogy. Broader educational scholarship tends to ignore religious beliefs as a central dimension of human culture, focusing on spoken and written language and collaborative learning styles. Teachers in many schools go through professional development that exposes them to means of creating more inclusive and welcoming classrooms that strive to guarantee the success of all students. Students of many different religious backgrounds (or none whatsoever) are now taking theology classes in Catholic high schools, and our student populations will continue to diversify with regard to their religious affiliations. If we can collectively transition the paradigm of culturally relevant, responsive, and sustaining pedagogy towards religiously relevant, responsive, and sustaining pedagogy, I believe that such an effort would benefit theology teachers immensely. Emma, Father Paul, Francis, Hans, and James enact the central tenets of these models in their own teaching, and my findings outlined many of their self-reported practices. These participants are a panel of exemplars, with many years of experience teaching religiously diverse student 
populations; they intuitively practice CRSP, and new theology teachers or theology teachers unfamiliar with teaching religiously diverse student populations would benefit from learning from their goals, attitudes, and practices. My sample is a small one, but I believe it to be a valuable one, and I hope that whoever comes across this research will learn from their brilliance and insights.

\section{Future Considerations and Recommendations for Research}

Having spent over three years reading many hundreds of pages of scholarship, and analyzing many hours of interviews, I have arrived at some recommendations for future research. First, I think the USCCB (or other scholars, given the general lack of transparency in the U.S. bishops' ways of proceeding) would do well to conduct a nationwide survey of theology teachers in Catholic high schools, in order to investigate their thoughts on the role of catechesis and their use of the Framework. I have little doubt that the findings of such a survey would bear out my findings on a much larger scale. Second, there is much room for qualitative and quantitative studies on the practices of theology teachers who serve religiously diverse student populations. The profound lack of studies in this realm is not surprising (perhaps because of the dearth of teachers who have the time and energy to conduct such research, or the dearth of scholars who maintain interest in such a niche area), and much work can be done. Finally, it would do us well to turn to the voices of students. Martin (2016) and Hortsch (2021) have done studies that foreground student experience, but to focus specifically on the experiences of non-Catholic students would prove, I think, tremendously enlightening. Where have students felt oppressed? Liberated? Failed? Successful? These are the questions I try to 
respond to in my own practice, and hearing from their students would benefit those interested in Catholic secondary education.

\section{Concluding Remarks}

About a decade ago, I purchased two posters of paintings by Peter Paul Rubens of Saint Ignatius of Loyola and Saint Francis Xavier for my classroom. These two Jesuits are heroes of mine, and in these paintings, Ignatius is exorcising folks who are demonically possessed, while Xavier is raising people from the dead. While these events probably never happened, and rather belong to the sphere of pious though fictitious hagiography, these images symbolize with a ferocious intensity how I approach teaching theology: it is an act of humanizing love that combats evil, both within the human heart and in broader systems, and brings people into new life.

I began this dissertation journey with a few main goals in mind. As a theology teacher, I had almost a decade of teaching experience, but no formal training in education, and I figured it was time to learn some educational theory. Second, I had spent my relatively short career inventing and refining curricula for religiously diverse students, and I wanted to understand how other teachers like me undertook their work. At the forefront of my mind was the question of how I could become a better teacher, and I somewhat selfishly wanted to learn from my fellow educators. Suffice it to say, I learned far more than I had bargained for, and wrote far more than I expected to. Many pages of notes and drafts will remain forgotten in the electronic landfill of Google Drive. None of this, I am happy to say, was useless. I discovered Freire, whose thoughts on education reinforced my thoughts on theological education, as represented by the aforementioned 
depictions of Ignatius and Xavier, to consist of liberating the oppressed (both my students and myself) from death-dealing forces. In turn, I discovered that all of critical education is more or less a series of footnotes to Freire.

In the words of one of my all-time favorite professors, the late Father James Schall, S.J., the most important thing a classroom does is connect minds: the microcosmic community of a group of students and their teacher is one of few spaces remaining in our technocratic, individualistic, and capitalistic world where human hearts and minds (whether alive or dead) can meet one another, without interference. Father Schall's words echoed in my skull as I pondered how to approach my research questions, and I opted for what I considered to be the most humanizing means possible: in-depth interviews, so that I could learn from human beings, and understand what makes them tick. My conversations with Emma, Father Paul, Francis, Hans, and James filled me with wonder. This experience of wonder, I think, was the reason I became a teacher to begin with: teachers have been moving my heart and mind and soul for as long as I can remember. I am grateful for all the learning I've done over the past few years, which has not only enlightened my mind to the many injustices that plague all sorts of educational systems and lives, but has served to improve my own practice. If my students are the only ones to benefit from my learning, then this project will have been time used well. I hope, however, that others will learn from the thoughts and practices within these pages. 


\section{References}

Aldana, U.S. (2014). Moving beyond the college-preparatory high school model to a college-going culture in urban Catholic high schools. Journal of Catholic Education, 17(2), 131-153. https://doi.org/10.15365/joce.1702092014

Aldana, U. S. (2015). “Does Jesus want us to be poor?”: Student perspectives of the religious program at a Cristo Rey Network school. Journal of Catholic Education, 19(1), 201-222. https://doi.org/10.15365/joce.1901102015

Ango, S. (2018). Educating for justice and righteousness in Nigerian society: Applying Freire's pedagogy of the oppressed. International Journal of Christianity \& Education, 22(2), 99-111. https://doi.org/10.1177/2056997118755410

Aronson, B., Amatullah, T., \& Laughter, J. (2016). Culturally relevant education: Extending the conversation to religious diversity. Multicultural Perspectives, 18(3), 140-149. https://doi.org/10.1080/15210960.2016.1185609

Aşlamac1, I. \& Kaymakcan, R. (2017). A model for Islamic education from Turkey: The Imam-Hatip schools. British Journal of Religious Education, 39(3), 279-292. https://doi.org/10.1080/01416200.2015.1128390

Augustine of Hippo. (1998). The confessions (M. Boulding, Trans.). Vintage Books. (Original work published ca. 397-400 C.E.)

Barnes, M. (2012). Interreligious learning: Dialogue, spirituality, and the Christian imagination. Cambridge University Press. 
Barnes, L. P., \& Wright, A. (2006). Romanticism, representations of religion and critical religious education. British Journal of Religious Education, 28(1), 65-77. https://doi.org/10.1080/01416200500273695

Beaudoin, T. M. (2001). Teaching the 'subject' of theology: The theologian as postmodern educator, with continual reference to Michel Foucault (Publication No. 3021567) [Doctoral dissertation, Boston College]. ProQuest Dissertations \& Theses Global.

Bennhold, K. (2008, September 29). French Muslims find haven in Catholic schools. The New York Times. https://www.nytimes.com/2008/09/30/world/europe/30schools.html

Borrero, N., \& Sanchez, G. (2017). Enacting culturally relevant pedagogy: Asset mapping in urban classrooms. Teaching Education, 28(3), 279-295. https://doi.org/10.1080/10476210.2017.1296827

Boschki, R. (2015). Catholic religious education in German schools: An ecumenical and interreligious perspective. In M.T. Buchanan and A. Gellel (Eds.), Global Perspectives on Catholic Religious Education in Schools (pp. 195-206). Springer International Publishing.

Bradley-Levine, J., \& Carr, K. A. (2015). Critical theory and Catholic social teaching: A research framework for Catholic schools. Journal of Catholic Education, 18(2), 27-43. https://doi.org/10.15365/joce.1802032015

Breen, D. (2009). Religious diversity, inter-ethnic relations and the Catholic school: Introducing the responsive approach to single faith schooling. British Journal of 
Religious Education, 31(2), 103-115.

https://doi.org/10.1080/01416200802661076

Brinig, M., \& Garnett, N.S. (2014). Lost classroom, lost community: Catholic schools' importance in urban America. The University of Chicago Press.

Bryk, A.S., Lee, V.E., \& Holland, P.B. (1993). Catholic schools and the common good. Harvard University Press.

Buchanan, M.T. (2005). Pedagogical drift: The evolution of new approaches and paradigms in religious education. Religious Education, 100(1), 20-

37. https://doi.org/10.1080/00344080590904662

Buchanan, M. T. (2006). Factors that impede curriculum change: A preliminary report. British Journal of Religious Education, 28(1), 51-63.

https://doi.org/10.1080/01416200500273646

Buck, B. (2016). Culturally responsive peace education: A case study at one urban Latino K-8 Catholic school. Journal of Catholic Education, 20(1), 32-55. https://doi.org/10.15365/joce.2001022016

Burke, K. (2015). Curricular documents and the positioning of teachers and students in Catholic schools: The cult of personality. Religion \& Education, 42(3), 321-338. https://doi.org/10.1080/15507394.2015.1034605

Burke, K., \& Gilbert, B. (2016). Racing tradition: Catholic schooling and the maintenance of boundaries. Race Ethnicity and Education, 19(3), 524-545. https://doi.org/10.1080/13613324.2015.1013461 
Byrne, C. (2012). 'Jeesis is alive! He is the King of Australia': Segregated religious instruction, child identity and exclusion. British Journal of Religious Education, 34(3), 317-331. https://doi.org/10.1080/01416200.2011.649343

Camangian, P. (2010). Starting with self: Teaching autoethnography to foster critically caring literacies. Research in the Teaching of English, 45(2), 179-204. www.jstor.org/stable/40997089

Camangian, P. (2013). Seeing through lies: Teaching ideological literacy as a corrective lens. Equity \& Excellence in Education, 46(1), 119-134. https://doi.org/10.1080/10665684.2013.750185

Caraballo, L., \& Soleimany, S. (2019). In the name of (pedagogical) love: A conceptual framework for transformative teaching grounded in critical youth research. The Urban Review, 5l(1), 81-100. https://doi.org/10.1007/s11256-018-0486-5

Carey, P., \& Muller, E.C. (Eds.). (1997). Theological education in the Catholic tradition: Contemporary challenges. Crossroad Publishing.

Carmody, B. P. (2017). The Catholic school: Non-confessional? International Studies in Catholic Education, 9(2), 162-175. https://doi.org/:10.1080/19422539.2017.1360608

Cattaro, G., \& Russo, C. J. (2015). Gravissimum educationis: Golden opportunities in American Catholic education 50 years after Vatican II. Rowman \& Littlefield. Catholic Church. (1992/1997). Catechism of the Catholic Church: Revised in accordance with the official Latin text promulgated by Pope John Paul II (2nd ed.). United States Catholic Conference. 
Chambers, M. (2012). Students who are not Catholics in Catholic schools: Lessons from the Second Vatican Council about the Catholicity of schools. International Studies in Catholic Education, 4(2), 186-199. https://doi.org/10.1080/19422539.2012.708174

Chazan, B. (2005). Toward a critical study of Jewish education. Journal of Jewish Education, 71(1), 95-105. https://doi.org/10.1080/00216240590924051

Chidester, D. (2003). Religion education in South Africa: Teaching and learning about religion, religions, and religious diversity. British Journal of Religious Education, 25(4), 261-278. https://doi.org/10.1080/0141620030250402

Cho, R. Y. (2012). The relationship between the Catholic teacher's faith and commitment in the Catholic high school. Journal of Catholic Education, 15(2), 117-139. https://doi.org/10.15365/joce.1502022013

Christiani, T. K. (2005). Blessed are the peacemakers: Christian religious education for peacebuilding in the pluralistic Indonesian context (Publication No. 3176658) [Doctoral dissertation, Boston College]. ProQuest Dissertations \& Theses Global.

Clandinin, D.J. \& Connelly, F. M. (2000). Narrative inquiry: Experience and story in qualitative research (1st ed., Jossey-Bass education series). Jossey-Bass.

Cohen, A.B. (2011). Religion and culture. Online Readings in Psychology and Culture, 4(4), 2-13. https://doi.org/10.9707/2307-0919.1108

Colbert, P. J. (2010). Developing a culturally responsive classroom collaborative of faculty, students, and institution. Contemporary Issues in Education Research, 3(9), 17-26. https://doi.org/10.19030/cier.v3i9.231 
Cone, J. (2010). A Black theology of liberation (40th anniversary ed.). Orbis Books.

Cone, J. (2013). The cross and the lynching tree. Orbis Books.

Congregation for Catholic Education \& Garrone, G.M. (Ed.). (1977, March 19). The Catholic school.

http://www.vatican.va/roman_curia/congregations/ccatheduc/documents/rc_con_c catheduc_doc_19770319_catholic-school_en.html

Congregation for Catholic Education \& Baum, W. (Ed.). (1988, April 7). The religious dimension of education in a Catholic school. http://www.vatican.va/roman_curia/congregations/ccatheduc/documents/rc_con_c catheduc_doc_19880407_catholic-school_en.html

Congregation for Catholic Education \& Laghi, P. (Ed.). (1997, December 28). The Catholic school on the threshold of the third millennium. http://www.vatican.va/roman_curia/congregations/ccatheduc/documents/rc_con_c catheduc_doc_27041998_school2000_en.html

Congregation for Catholic Education \& Grocholewski, Z. (Ed.). (2013, October 2013). Educating to intercultural dialogue in Catholic schools: Living in harmony for a civilization of love. http://www.vatican.va/roman_curia/congregations/ccatheduc/documents/rc_con_c catheduc_doc_20131028_dialogo-interculturale_en.html

Congregation for Catholic Education. (2014). Educating today and tomorrow: A renewing passion [Instrumentum laboris from plenary assembly of the CCE]. 
http://www.vatican.va/roman_curia/congregations/ccatheduc/documents/rc_con_c catheduc_doc_20140407_educare-oggi-e-domani_en.html

Cook, T.J., \& Hudson, W.J. (2003, April 21-25). Professionalization of Catholic high school religion teachers [Paper presentation]. American Educational Research Association Annual Meeting, Chicago, IL, United States.

Cook, T. J., \& Hudson, W.J. (2006). Toward the professionalization of Catholic high school religion teachers: An assessment of religion teaching as a profession. Journal of Catholic Education, 9(4), 399-424. http://dx.doi.org/10.15365/joce.0904022013

Crawford, M. \& Rossiter, G. (2006). Reasons for living: Education and young people's search for meaning, identity and spirituality. Acer Press.

Creswell, J. \& Creswell, J.D. (2018). Research design: Qualitative, quantitative, and mixed methods approaches (Fifth ed.). SAGE Publications.

Cruz, F. M. (2001). Religious education for participatory action (Publication No. 3008902) [Doctoral dissertation, Boston College]. ProQuest Dissertations \& Theses Global.

Cruz, L. M., \& Petersen, S. C. (2011). Teaching diverse students: How to avoid marginalizing difference. Journal of Physical Education, Recreation \& Dance, 82(6), 21-24. https://doi.org/10.1080/07303084.2011.10598640

Daily, E.M. (2015). Core outcomes for Catholic religious education. Religious Education, 110(1), 10-15. https://doi.org/10.1080/00344087.2015.989091 
Dallavis, C. (2011). "Because that's who I am": Extending theories of culturally responsive pedagogy to consider religious identity, belief, and practice. Multicultural Perspectives, 13(3), 138-144. https://doi.org/10.1080/15210960.2011.594375

Dallavis, C. (2013). Qualifying sociopolitical consciousness: Complicating culturally responsive pedagogy for faith-based schools. Education and Urban Society, 45(2), 266-284. https://doi.org/10.1177/0013124511408597

Dallavis, C. (2014). Culturally responsive caring and expectations for academic achievement in a Catholic school. Journal of Catholic Education, 17(2), 154-171. https://doi.org/10.15365/joce.1702082014

Darder, A. (2015). Freire and education. Routledge.

Darder, A. (2016). Latinos, education, and the Church: Toward a culturally democratic future. Journal of Catholic Education, 19(2), 18-53. https://doi.org/10.15365/joce.1902032016

Darder, A. (2017). Reinventing Paulo Freire: A pedagogy of love. Routledge.

Davis, R.A., \& Franchi, L. (2013). A Catholic curriculum for the twenty-first century? International Studies in Catholic Education, 5(1), 36-52, https://doi.org/0.1080/19422539.2012.754587

De Silva, R., Gleditsch, R., Job, C., Jesme, S., Urness, B., \& Hunter, C. (2018). Gloria Ladson-Billings: Igniting student learning through teacher engagement in "culturally relevant pedagogy". Multicultural Education, 25(3-4), 23-29. https://link-gale- 
com.proxy.lib.pdx.edu/apps/doc/A564127229/AONE?u=s1185784\&sid=AONE\& $\underline{\mathrm{xid}=\mathrm{ecb} 52708}$

Dillen, A. (2015). Aren't they too young? The challenge of hermeneutical and interreligious learning in Catholic religious education: A Flemish perspective. In M.T. Buchanan and A. Gellel (Eds.), Global Perspectives on Catholic Religious Education in Schools (pp. 155-166). Springer International Publishing.

Dilworth, M.A. (1996). A good education and fear of God. In J.J. Irvine \& M. Foster (Eds.), Growing up African American in Catholic schools (pp. 106-115). Teachers College Press.

Donlevy, J.K. (2003). Catholic separate schools and the inclusion of non-Catholic students: Qualitative findings and implications (Publication No. 305233976) [Doctoral dissertation, The University of Saskatchewan]. ProQuest Dissertations \& Theses Global.

Donlevy, J.K. (2007a). Non-Catholic students impact on Catholic teachers in four Catholic high schools. Religious Education, 102(1), 4-24. https://doi.org/10.1080/00344080601117663

Donlevy, J.K. (2007b). Ten dimensions of inclusion: Non-Catholic students in Catholic schools. Journal of Catholic Education, 10(3), 293-320. https://doi.org/10.15365/joce.1003042013

Donlevy, J.K. (2009a). The ten dimensions of inclusion: Non-Catholic students in Catholic schools. Sense Publishers. 
Donlevy, J.K. (2009b). Catholic school administrators and the inclusion of non-Catholic students. Journal of Educational Administration, 47(5), 586-608. https://doi.org/10.1108/09578230910981071

D’Souza, M.O. (2015). The progression of religious education since the Second Vatican Council as seen through some church documents. In M.T. Buchanan and A. Gellel (Eds.), Global perspectives on Catholic religious education in schools (pp. 9-22). Springer International Publishing.

Duncan-Andrade, J.M.R. and Morrell, E. (2008). The art of critical pedagogy: Possibilities for moving from theory to practice in urban schools. Peter Lang.

Easton, C., Goodman, A., Wright, A., \& Wright A. (2019). Critical religious education in practice: A teacher's guide for the secondary classroom. Routledge.

Eisner, E. (2000). The enlightened eye: Qualitative inquiry and the enhancement of educational practice. Prentice-Hall.

Elias, J. L. (2003). Reflections on the vocation of a religious educator. Religious Education, 98(3), 297-310. https://doi.org/10.1080/00344080390217504

Ellis, K.C., (1996). Topsy goes to Catholic school: Lessons in academic excellence, refinement, and religion. In J.J. Irvine \& M. Foster (Eds.), Growing up African American in Catholic schools (pp. 153-169). Teachers College Press.

Esteban-Guitart, M., Lalueza, J.L., Zhang-Yu, C., \& Llopart, M. Sustaining students' cultures and identities: A qualitative study based on the funds of knowledge and identity approaches. Sustainability, 11(12), 1-12.

https://doi.org/10.3390/su11123400 
Evangelinou-Yiannakis, A. (2016). Challenges faced by a faith-based school in a rural, predominantly secular setting: Implications. Issues in Educational Research, 26(4), 561-575. http://www.iier.org.au/iier26/evangelinou-yiannakis.pdf

Everington, J., ter Avest, I., Bakker, C., \& van der Want, A. (2011). European religious education teachers' perceptions of and responses to classroom diversity and their relationship to personal and professional biographies. British Journal of Religious Education, 33(2), 241-256. https://doi.org/10.1080/01416200.2011.546669

Feeney, S., Freeman, N. K., \& Muller, M. (2012). Differing faiths in a faith-based program. Young Children, 67(3), 70-71. https://www.jstor.org/stable/42731178

Finefter-Rosenbluh, I., \& Perry-Hazan, L. (2018). Teacher diversity and the right to adaptable education in the religiously oriented school: What can we learn from students' perceptions? Youth \& Society, 50(5), 615-635. https://doi.org/10.1177/0044118X15621224

Foucault, M. (1995). Discipline \& punish: The birth of the prison. (A. Sheridan, Trans.; 2nd ed.). Vintage Books. (Original work published 1975)

Fowler, J. (1981). Stages of faith: The psychology of human development and the quest for meaning. Harper \& Row.

Frabutt, J.M., Holter, A.C., \& Nuzzi, R.J. (2013). What are they saying about Catholic schools? Discourse on PK-12 Catholic education, 2005 to 2010. Journal of Research on Christian Education, 22(1), 75-96.

https://doi.org/10.1080/10656219.2013.768125 
Franchi, L.J. (2011). Healing the wounds: St. Augustine, catechesis, and religious education today. Religious Education, 106(3), 299-311. https://doi.org/10.1080/00344087.2011.569656

Francis, L. J. (1986). Roman Catholic secondary schools: Falling rolls and pupil attitudes. Educational Studies, 12(2), 119-127. https://doi.org/10.1080/0305569860120201

Francis, L.J., \& Robbins, M. (2011). Teaching secondary RE at faith schools in England and Wales: listening to the teachers. Journal of Beliefs \& Values, 32(2), 219-233. https://doi.org/10.1080/13617672.2011.600820

Franck, O. (2015). Critical religious education: Highlighting religious truth-claims in non-confessional educational contexts. British Journal of Religious Education, 37(3), 225-239. https://doi.org/10.1080/01416200.2014.940845

Franken, L., \& Vermeer, P. (2019). Deconfessionalising RE in pillarised education systems: A case study of Belgium and the Netherlands. British Journal of Religious Education, 41(3), 272-285.

https://doi.org/0.1080/01416200.2017.1405792

Frankl, V. (2006). Man's search for meaning (Mini book ed.). Beacon Press. (Original work published 1946)

Freathy, R., Doney, J., Freathy, G., Walshe, K., \& Teece, G. (2017). Pedagogical bricoleurs and bricolage researchers: The case of religious education. British Journal of Educational Studies, 65(4), 425-443.

https://doi.org/10.1080/00071005.2017.1343454 
Freire, P. (2018). Pedagogy of the oppressed: 50th anniversary edition (M.B. Ramos, Trans.; 4th ed.). Bloomsbury. (Original work published 1970)

Freire, P. (1984). Education, liberation and the church. Religious Education, 79(4), 524545. https://doi.org/10.1080/0034408400790405

Freire, P. (1985). The politics of education: Culture, power, and liberation (D. Macedo, Trans.). Bergin \& Garvey Publishers, Inc.

Freire, P. (1998). Pedagogy of freedom: Ethics, democracy, and civic courage (P. Clarke, Trans.). Rowman \& Littlefield.

Freire, P. \& Araújo Freire, A.M. (2014). Pedagogy of hope: Reliving pedagogy of the oppressed (R. Barr, Trans.). Bloomsbury. (Original work published 1992)

Gambrell, J. A. (2017). Is culturally responsive pedagogy enough? Toward culturally "real"-evant curriculum: A response to "Democratic foundations for spiritually responsive pedagogy". Democracy \& Education, 25(1), 1-7. https://democracyeducationjournal.org/home/vol25/iss1/12

Garcia-Huidobro, J. (2017). What are Catholic schools teaching to make a difference? A literature review of curriculum studies in Catholic schools in the U.S. and the U.K. since 1993. Journal of Catholic Education, 20(2), 64-97. https://doi.org/10.15365/joce.2002032017

Gay, G. (1988). Designing relevant curricula for diverse learners. Education and Urban Society, 20(4), 327-340. https://doi.org/10.1177/0013124588020004003

Gay, G. (2002). Preparing for culturally responsive teaching. Journal Of Teacher Education, 53(2), 106-116. https://doi.org/10.1177/0022487102053002003 
Gay, G. (2018). Culturally responsive teaching: Theory, research, and practice (3rd ed.). Teachers College Press. (Original work published 2000)

Gilmour, P. (2015). Educating the educators: A fifty-year retrospective of religious education in the Catholic context. Religious Education, 110(5), 555-568. https://doi.org/10.1080/00344087.2015.1089727

Giroux, H., \& Penna, A. (1979). Social education in the classroom: The dynamics of the hidden curriculum. Theory \& Research in Social Education, 7(1), 21-42. https://doi.org/10.1080/00933104.1979.10506048

Gleeson, J., O'Gorman, J., Goldburg, P., \& O'Neill, M. (2018). The characteristics of Catholic schools: Comparative perspectives from the USA and Queensland, Australia. Journal of Catholic Education, 21(2), 76-106. https://doi.org/10.15365/joce.2102042018

Glesne, Q. (2016). Becoming qualitative researchers: An introduction (5th ed.). Pearson. Grajczonek, J. (2015). "To thine own self be true": Respecting both religious diversity and religious integrity in contemporary Australian early childhood religious education. In M.T. Buchanan and A. Gellel (Eds.), Global perspectives on Catholic religious education in schools (pp. 103-114). Springer International Publishing.

Grant, C. A., \& Zwier, E. (2011). Intersectionality and student outcomes: Sharpening the struggle against racism, sexism, classism, ableism, heterosexism, nationalism, and linguistic, religious, and geographical discrimination in teaching and learning. 
Multicultural Perspectives, 13(4), 181-188.

https://doi.org/10.1080/15210960.2011.616813

Greeley, A. (2002). Catholic high schools and minority students (2nd ed.). Transaction Publishers. (Original work published 1982)

Griner, A., \& Stewart, M. (2013). Addressing the achievement gap and disproportionality through the use of culturally responsive teaching practices. Urban Education, 48(4), 585-621. https://doi.org/10.1177/0042085912456847

Grocholewski, C. (2015). The Congregation for Catholic Education: How it works to support the educational mission of universities and schools internationally. International Studies in Catholic Education, 7(2), 134-144. https://doi.org/10.1080/19422539.2015.1072954

Groome, T. H. (1999). Christian religious education: Sharing our story and vision. Jossey-Bass.

Groome, T. H. (2011). Will there be faith?: A new vision for educating and growing disciples (1st ed.). HarperOne.

Guba, E. G. \& Lincoln, Y. A. (2005). Paradigmatic controversies, contradictions, and emerging confluences. In N. K. Denzin \& Y. S. Lincoln (Eds.), The Sage handbook of qualitative research (3rd ed., pp. 191-215). Sage Publications. Gutiérrez, G. (1973). A theology of liberation: History, politics, and salvation. Orbis Books. 
Gutiérrez, K. D., \& Rogoff, B. (2003). Cultural ways of learning: Individual traits or repertoires of practice. Educational Researcher, 32(5), 19-25. https://doi.org/10.3102/0013189X032005019

Hall, D., Sultmann, W., \& Townend, G. (2019). Constants in context: An exploration of conciliar and post-conciliar documents on the Catholic school. Journal of Religious Education, 67(1), 17-39. https://doi.org/10.1007/s40839-019-00074-6

Hallinan, M., \& Kubitschek, W. (2010). School sector, school poverty, and the Catholic school advantage. Catholic Education: A Journal of Inquiry and Practice, 14(2), 143-172. https://doi.org/10.15365/joce.1402022013

Hand, M. (2004). The problem with faith schools: A reply to my critics. Theory and Research in Education, 2(3), 343-353. https://doi.org/10.1177/1477878504046529

Hansen-Thomas, H., \& Chennapragada, S. (2018). Culture clash in the multicultural classroom: A case study from a newcomer school. English Language Teaching, 11(4), 82-90. http://doi.org/10.5539/elt.v11n4p82

Harris, M. (1987). Teaching and religious imagination (1st ed.). Harper \& Row.

Harris, M., \& Moran, G. (1992). Catechetical language and religious education. Theology Today, 49(1), 21-30. https://doi.org/10.1177/004057369204900103

Harris, M., \& Moran, G. (1998). Reshaping religious education: Conversations on contemporary practice (1st ed.). Westminster John Knox Press. 
Heft, J., Groome, T., Taymans, M., Lund, L. (1997). Patterns and possibilities: Exploring religious education in the Catholic secondary school (M.F. Taymans, Ed.). National Catholic Educational Association.

Hill, B. (1999). Can religious education be theologically neutral? International Journal of Christianity \& Education, 42(1), 9-24. https://doi.org/10.1177/002196579904200104

Hill, J., Harris, M., \& Martínez-Vázquez, H.A. (2009). Fighting the elephant in the room: Ethical reflections on White privilege and other systems of advantage in the teaching of religion. Teaching Theology \& Religion, 12(1), 3-23. https://doi.org/10.1111/j.1467-9647.2008.00471.x

Hortsch, Gary L. (2021). Listening to graduates: An evaluation of a U.S. Catholic high school religious education program. (Publication No. 28496253) [Doctoral dissertation, University of Portland]. ProQuest Dissertations and Theses Global.

Howard, T. C. (2003). Culturally relevant pedagogy: ingredients for critical teacher reflection. Theory into Practice, 42(3), 195-202. https://doi.org/10.1207/s15430421tip4203_5

Irizarry, J. (2007). A bilingual aesthetic for religious education. Religious Education, 102(2), 124-127. https://doi.org/10.1080/00344080701285337

Irvine, J.J. (1996). Lessons learned: Implications for the education of African Americans in public schools. In J.J. Irvine \& M. Foster (Eds.), Growing up African American in Catholic schools (pp. 170-176). Teachers College Press.

Irvine, J.J. (2010). Culturally relevant pedagogy. Education Digest, 75(8), 57-61. 
Jackson, K., \& Bazeley, P. (2019). Qualitative Data Analysis with NVivo (3 ${ }^{\text {rd }}$ ed.). SAGE Publications Ltd.

Jackson, R. (2004). Rethinking religious education and plurality. RoutledgeFarmer.

Jaffe-Walter, R., \& Lee, S. (2018). Engaging the transnational lives of immigrant youth in public schooling: Toward a culturally sustaining pedagogy for newcomer immigrant youth. American Journal of Education, 124(3), 257-283. https://doi.org/10.1086/697070

Jeynes, W. H.(1999). The effects of religious commitment on the academic achievement of Black and Hispanic children. Urban Education, 34(4), 458-479. https://doi.org/10.1177/0042085999344003

Jeynes, W.H. (2002a). A meta-analysis of the effects of attending religious schools and religiosity on Black and Hispanic academic achievement. Education and Urban Society, 35(1), 27-49. https://doi.org.10.1177/001312402237213

Jeynes, W.H. (2002b). Why religious schools positively impact the academic achievement of children. International Journal of Education and Religion, 3(1), 16-32. https://doi.org/10.1163/157006202760182418

Jeynes, W.H. (2003a). Religion, education, and academic success (Research in religion and education). Information Age Publishers.

Jeynes, W.H. (2003b). The effects of Black And Hispanic 12th graders living in intact families and being religious on their academic achievement. Urban Education, 38(1), 35-57. https://doi.org/10.1177/0042085902238685 
Jeynes, W.H. (2003c). The effects of religious commitment on the academic achievement of urban and other children. Education and Urban Society, 36(1), 44-62. https://doi.org/10.1177/0013124503257206

Jeynes, W. H. (2004). Comparing the influence of religion on education in the United States and overseas: A meta-analysis. Religion \& Education, 31(2), 83-97. https://doi.org/10.1080/15507394.2004.10012342

Jeynes, W.H. (2005). The impact of religious schools on the academic achievement of low-SES students. Journal of Empirical Theology, 18(1), 22-40. https://doi.org/10.1163/1570925054048965

Jeynes, W.H. (2009). The relationship between biblical literacy, academic achievement, and school behavior among Christian- and public-school students. Journal of Research on Christian Education, 18(1), 36-55. https://doi.org/10.1080/10656210902751826

Jeynes, W.H. (2010a). Religiosity, religious schools, and their relationship with the achievement gap: A research synthesis and meta-analysis. The Journal of Negro Education, 79(3), 263-279. https://www.jstor.org/stable/20798348

Jeynes, W.H. (2010b). The relationship between Bible literacy and behavioral and academic outcomes in urban areas: A meta-analysis. Education and Urban Society, 42(5), 522-544. https://doi.org/10.1177/0013124510366648

Kazanjian, C.J. (2019). Culturally responsive secondary education: Exploring cultural differences through existential pedagogy. Multicultural Education Review, 11(1), 20-36. https://doi.org/10.1080/2005615X.2019.1567094 
Kidwell, T., \& Pentón Herrera, L.J. (2019). Culturally sustaining pedagogy in action: Views from Indonesia and the United States. Kappa Delta Pi Record, 55(2), 6065. https://doi.org/10.1080/00228958.2019.1580982

Kinloch, V. (2017). "You ain’t making me write": Culturally sustaining pedagogies and Black youths’ performances of resistance. In D. Paris \& H.S. Alim (Eds.), Culturally sustaining pedagogies: Teaching and learning for justice in a changing world (pp. 25-41). Teachers College Press.

Kimanen, A. (2019). Truth claims, commitment and openness in Finnish Islamic and Lutheran religious education classrooms. Issues in Educational Research, 29(1), 141-157. https://http://www.iier.org.au/iier29/kimanen.pdf

Kirylo, J. D., \& Boyd, D. (2017). Paulo Freire: His faith, spirituality, and theology. Sense Publishers.

Kremer, M. E. (1998). The role of liberation theology in four Catholic high school religion classrooms (Publication No. 9903464) [Doctoral dissertation, The University of Illinois at Chicago]. ProQuest Dissertations \& Theses Global.

Kremer, M. (2003, April 21-25). Religious education for the disenfranchised: Fusing multicultural strategies into Catholic high school religion classes [Paper presentation]. American Educational Research Association 84th Annual Meeting, Chicago, IL, United States.

Ladson-Billings, G. (1995a). But that's just good teaching! The case for culturally relevant pedagogy. Theory Into Practice, 34(3), 159-165. https://doi.org/10.1080/00405849509543675 
Ladson-Billings, G. (1995b). Toward a theory of culturally relevant pedagogy. American Educational Research Journal, 32(3), 465-491. https://doi.org/10.3102/00028312032003465

Ladson-Billings, G. (2009). The dreamkeepers: Successful teachers of African American children (2nd ed.). Jossey-Bass.

Ladson-Billings, G. (2014). Culturally relevant pedagogy 2.0: A.k.a. the remix. Harvard Educational Review, 84(1), 74-84.

https://doi.org/10.17763/haer.84.1.p2rj131485484751

Leavey, M.C. (1990). About deschooling Christianity. In L. Francis \& A. Thatcher (Eds.), Christian perspectives for education: A reader in the theology of education (pp. 142-154). Fowler Wright Books.

Lee, J. (1971). The shape of religious instruction: A social-science approach. Pflaum. Lewthwaite, B. E., Osborne, B., Lloyd, N., Boon, H., Llewellyn, L., Webber, T., Laffin, G., Harrison, M., Day, C., Kemp, C., \& Wills, J. (2015). Seeking a pedagogy of difference: What Aboriginal students and their parents in North Queensland say about teaching and their learning. Australian Journal of Teacher Education, 40(5), 132-159. http://ro.ecu.edu.au/ajte/vol40/iss5/8

LoFaro, K.P. (2019). Cooperating teachers' perceived preparedness to support science teacher candidates for culturally sustaining science teaching (Publication No. 22622837) [Doctoral dissertation, Portland State University]. ProQuest Dissertations \& Theses Global. 
Louie, V., \& Holdaway, J. (2009). Catholic schools and immigrant students: A new generation. Teachers College Record, 111(3), 783-816. https://www.tcrecord.org/content.asp?contentid=15344

Maasum, T., Maarof, N., \& Ali, M. (2014). Addressing student diversity via culturally responsive pedagogy. Procedia - Social and Behavioral Sciences, 134(C), 101108. https://doi.org/10.1016/j.sbspro.2014.04.227

Machado, E., Vaughan, A., Coppola, R., \& Woodard, R. (2017). "Lived life through a colored lens": Culturally sustaining poetry in an urban literacy classroom. Language Arts, 94(6), 367-381.

https://www.ncte.org/library/NCTEFiles/Resources/Journals/LA/0946july2017/LA0946Lived.pdf

Maney, J., King, C., \& Kiely, T. (2017). Who do you say you are: Relationships and faith in Catholic schools. Journal of Catholic Education, 21(1), 36-61. https://doi.org/10.15365/joce.2101032017

Manning, P. (2018). Disintegrating worldviews and the future of Catholic education: Addressing the deep roots of Catholic disaffiliation. Journal of Catholic Education, 21(2), 26-52. https://doi.org/10.15365/joce.2102022018

Marks, M. J., Binkley, R., \& Daly, J. K. (2014). Preservice teachers and religion: Serious gaps in religious knowledge and the first amendment. Social Studies, 105(5), 245256. https://doi.org/10.1080/00377996.2014.927344

Martin, R. L. (2016). Catholic secondary school students' religious profiles and perceptions of religious influence: A case study (Publication No. 10127979) 
[Doctoral dissertation, The University of San Francisco]. ProQuest Dissertations \& Theses Global.

Martin, S. (1996). Cultural diversity in Catholic schools: Challenges and opportunities for Catholic educators. National Catholic Education Association. https://eric.ed.gov/?id=ED409157

Martínez-Ariño, J., \& Teinturier, S. (2019). Faith-based schools in contexts of religious diversity: An introduction. Religion \& Education, 46(2), 147-158. https://doi.org/10.1080/15507394.2019.1590941

Maxwell, J.A. (2013). Qualitative research design: An interactive approach (3rd ed.). Sage Publications, Inc.

McBride, A. (2009, September 28). A study framework: A defense of the bishops' new high school catechesis. American Magazine. https://www.americamagazine.org/issue/708/article/sturdy-framework

McDonald, D., \& Schultz, M. M. (2021). United States Catholic elementary and secondary schools 2020-2021: The annual statistical report on schools, enrollment and staffing. National Catholic Educational Association.

McDonough, G.P. (2009). Can there be 'faithful dissent' within Catholic religious education in schools? International Studies in Catholic Education, 1(2), 187-199. https://doi.org/10.1080/19422530903138150

McDonough, G. P. (2016). Bearers of diverse ecclesiologies: Imagining Catholic school students as informing a broader articulation of Catholic school aims. Journal of Catholic Education, 19(3). https://doi.org/10.15365/joce.190052016 
McGah, M. H. (2013). Instructional practices of high school religion teachers in Washington state (Publication No. 3572568) [Doctoral dissertation, Seattle University]. ProQuest Dissertations \& Theses Global.

Merriam, S.B., \& Tisdell, E.J. (2016). Qualitative research: A guide to design and implementation (4th ed.). Jossey-Bass.

Merry, M. S. (2018). Indoctrination, Islamic schools, and the broader scope of harm. Theory and Research in Education, 16(2), 162-178. https://doi.org/10.1177/1477878518779668

Milner, H.R. (2010a). Culturally relevant pedagogy in a diverse urban classroom. Urban Review, 43(1), 66-89. https://doi.org/10.1007/s11256-009-0143-0

Milner, H. (2010b). Start where you are, but don't stay there: Understanding diversity, opportunity gaps, and teaching in today's classrooms. Harvard Education Press.

Mitchell, D. (2016). Diversities in education: Effective ways to reach all learners. Taylor and Francis.

Moran, G. (1983). Religious education development: Images for the future. Winston Press.

Moran, G. (1989). Religious education as a second language. Religious Education Press. Moran, G. (1997). Showing how: The act of teaching. Trinity Press International. Moran, G. (2018). Missed opportunities: Rethinking Catholic tradition. Book Whip. Morris, A. (1998). By their fruits you will know them: Distinctive features of Catholic education. Research Papers in Education, 13(1), 87-112. https://doi.org/10.1080/0267152980130106 
National Catholic Education Association. (n.d.) ACRE (Assessment of Child/Youth Religious Education). National Catholic Education Association. Retrieved August 3, 2021, from https://www.nceaifg.com/

Natsis, E. (2016). A new discourse on spirituality in public education: Confronting the challenges in a post-secular society. International Journal of Children's Spirituality, 21(1), 66-77. https://doi.org/10.1080/1364436X.2016.1154818

New Revised Standard Version Bible. (2010). The new Oxford annotated Bible: New Revised Standard Version: With the Apocrypha: An ecumenical study Bible (Fourth ed.). Oxford University Press.

Niemi, K. (2018). Drawing a line between the religious and the secular: The cases of religious education in Sweden and India. Journal of Beliefs \& Values, 39(2), 182194. https://doi.org/10.1080/13617672.2018.1450806

Niyozov, S. \& Pluim, G. (2009). Teachers' perspectives on the education of Muslim students: A missing voice in Muslim education research. Curriculum Inquiry, 39(5), 637-677. https://doi.org/10.1111/j.1467-873X.2009.00463.X

Norman, J. (2018, April 6). The religious regions of the U.S. https://news.gallup.com/poll/232223/religious-regions.aspx

O'Connell, D. (2008). Educating religiously toward a public spirituality (Publication No. 3318131) [Doctoral dissertation, Boston College]. ProQuest Dissertations \& Theses Global. 
O’Malley, W. (2009, September 14). Faulty guidance: A new framework for high school catechesis fails to persuade. America Magazine. https://www.americamagazine.org/issue/707/article/faulty-guidance

Ospino, H. (2007). Teaching theology in culturally diverse contexts: Foundations for an intercultural model of theological education (Publication No. 3256238) [Doctoral dissertation, Boston College]. ProQuest Dissertations \& Theses Global.

Ostasiewski, D. M. (2010). Looking for love: A critique of "Doctrinal Elements of a Curriculum Framework for the Development of Catechetical Materials for Young People of High School Age" published by the U.S. Conference of Catholic Bishops (USCCB), November 2007 (Publication No. 3403701) [Doctoral dissertation, The University of North Carolina at Greensboro]. ProQuest Dissertations \& Theses Global.

Paletta, A., \& Fiorin, I. (2016). The challenges of Catholic education: Evidence from the responses to the Instrumentum Laboris 'Educating today and tomorrow'. International Studies in Catholic Education, 8(2), 136-154. https://doi.org/10.1080/19422539.2016.1206397

Paris, D. (2012). Culturally sustaining pedagogy: A needed change in stance, terminology, and practice. Educational Researcher, 41(3), 93-97. https://doi.org/10.3102/0013189X12441244

Paris, D., \& Alim, H. S. (2014). What are we seeking to sustain through culturally sustaining pedagogy? A loving critique forward. Harvard Educational Review, 84(1), 85-100. 
http://search.proquest.com.proxy.lib.pdx.edu/docview/1651857175?accountid=13 $\underline{265}$

Paris, D., \& Alim, H. (2017). Culturally sustaining pedagogies: Teaching and learning for justice in a changing world. Teachers College Press.

Paris, D., \& Winn, M.T. (2014). Humanizing research: Decolonizing qualitative inquiry with youth and communities. SAGE.

Parker, L. (2014). Religious education for peaceful coexistence in Indonesia? South East Asia Research, 22(4), 487-504. https://www.jstor.org/stable/43818549

Patton, M. Q. (2015). Qualitative research \& evaluation methods (4th ed.). Sage Publications, Inc.

Pieris, A. (1988). An Asian theology of liberation. T \& T Clark.

Pope Francis. (24 November, 2013). Evangelii gaudium: Apostolic exhortation to the bishops, clergy, consecrated persons, and the lay faithful on the proclamation of the Gospel in today's world. http://www.vatican.va/content/francesco/en/apost_exhortations/documents/papafrancesco_esortazione-ap_20131124_evangeliigaudium.html\#III.\%E2\%80\%82The new_evangelization_for_the transmission_o f the faith

Pope John Paul II. (October 16, 1979). Catechesi tradendae: Apostolic exhortation on evangelization in our time. http://www.vatican.va/content/john-paulii/en/apost_exhortations/documents/hf_jp-ii_exh_16101979_catechesitradendae.html 
Pope John Paul II. (December 7, 1990). Redemptoris missio: On the permanent validity of the Church's missionary mandate. http://www.vatican.va/content/john-paulii/en/encyclicals/documents/hf_jp-ii_enc_07121990_redemptoris-missio.html

Pope Paul VI. (1965, October 28). Gravissimum educationis: Declaration on Christian education.

http://www.vatican.va/archive/hist_councils/ii_vatican_council/documents/vatii_decl_19651028_gravissimum-educationis_en.html

Pope Paul VI. (1965a, October 28). Nostra aetate: Declaration on the relation of the Church to non-Christian religions. http://www.vatican.va/archive/hist_councils/ii_vatican_council/documents/vatii_decl_19651028_nostra-aetate_en.html

Pope Paul VI. (1965b, December 7). Dignitatis humanae: Declaration on religious freedom on the right of the person and of communities to social and civil freedom in matters religious. http://www.vatican.va/archive/hist_councils/ii_vatican_council/documents/vatii_decl_19651207_dignitatis-humanae_en.html

Pope Paul VI. (1975c, December 8). Evangelii nuntiandi: Apostolic exhortation on evangelization in the modern world. http://www.vatican.va/content/paulvi/en/apost_exhortations/documents/hf_p-vi_exh_19751208_evangelii$\underline{\text { nuntiandi.html }}$

Puzio, K., Newcomer, S., Pratt, K., McNeely, K., Jacobs, M., \& Hooker, S. (2017). Creative failures in culturally sustaining pedagogy. Language Arts, 94(4), 223- 
233.

http://search.proquest.com.proxy.lib.pdx.edu/docview/1871423679?accountid=13 $\underline{265}$

Rackley, E. (2016). Religious youths' motivations for reading complex, religious texts. Teachers College Record, 118(11), 1-50. https://www.tcrecord.org/content.asp?contentid=21603

Radice, L. M. (2016). A multiple case study investigation into the instructional methodologies utilized by Catholic school religion teachers to implement the Doctrinal Elements of Curriculum Framework for the Development of Catechetical Materials for Young People of High School Age (Publication No. 10117633) [Doctoral dissertation, The Catholic University of America]. ProQuest Dissertations \& Theses Global.

Reddie, A. (2003). Developing a Black Christian education of liberation for the British context. Religious Education, 98(2), 221-238. https://doi.org/10.1080/00344080308288

Richards, H. V., Brown, A. E., \& Forde, T. B. (2007). Addressing diversity in schools: Culturally responsive pedagogy. Teaching Exceptional Children, 39(3), 64-68. https://doi.org/10.1177/004005990703900310

Roebben, B. (2015). How much and which theology in religious education? On the intimate place of theology in the public space of the school. In M.T. Buchanan and A. Gellel (Eds.), Global perspectives on Catholic religious education in schools (pp. 35-46). Springer International Publishing. 
Rossiter, G. M. (1982). The need for a "creative divorce" between catechesis and religious education in Catholic schools. Religious Education, 77(1), 21-40. https://doi.org/10.1080/0034408820770103

Rossiter, G. (2011). Reorienting the religion curriculum in Catholic schools to address the needs of contemporary youth spirituality. International Studies in Catholic Education, 3(1), 57-72. https://doi.org/10.1080/19422539.2011.540140

Rothrock, B. (2014). Authenticity, meaning, and the quest for God: Philosophical theology for Catholic religious and theological education today (Publication No. 3669039) [Doctoral dissertation, Boston College]. ProQuest Dissertations \& Theses Global.

Rummery, R. M. (1975). Catechesis and religious education in a pluralist society. Our Sunday Visitor.

Rymarz, R. (2011). Catechesis and religious education in Canadian Catholic schools. Religious Education, 106(5), 537-549. https://doi.org/10.1080/00344087.2011.613355

Rymarz, R. (2012). The new evangelisation: Issues and challenges for Catholic schools. Connor Court Publishing.

Rymarz, R. (2013). Comparing religious education in Canadian and Australian Catholic high schools: Identifying some key structural issues. British Journal of Religious Education, 35(2), 175-187. https://doi.org/10.1080/01416200.2011.628203

Rymarz, R., \& Cleary, A. (2018). Examining some aspects of the worldview of students in Australian Catholic schools: Some implications for religious education. British 
Journal of Religious Education, 40(3), 327-336.

https://doi.org/10.1080/01416200.2017.1352486

Saldaña, J. (2016). The coding manual for qualitative researchers (3rd ed.). Sage Publications, Inc.

Samuel, N. G. (2013). Story-making: A narrative pedagogy for transformative Christian faith (Publication No. 3607675) [Doctoral dissertation, Boston College]. ProQuest Dissertations \& Theses Global.

Scanlan, M., Kim, M., Burns, M. B., \& Vuilleumier, C. (2016). Poco a poco: Leadership practices supporting productive communities of practice in schools serving the new mainstream. Educational Administration Quarterly, 52(1), 3-44. https://doi.org/10.1177/0013161X15615390

Schein, E., \& Schein, P. (2017). Organizational culture and leadership (5th ed.). Hoboken, NJ: John Wiley \& Sons.

Schipani, D. (1988). Religious education encounters liberation theology. Religious Education Press.

Schroeder, C. J. (2013). The U.S. Conference of Catholic Bishops' "Doctrinal Elements of a Curriculum Framework for the Development of Catechetical Materials for Young People of High School Age": Pedagogical and theological perspectives of religious studies teachers in U.S. Catholic secondary schools (Publication No. 3563435) [Doctoral dissertation, The University of San Francisco]. ProQuest Dissertations \& Theses Global. 
Schroeder, C.J. (2015). The USCCB Curriculum Framework: Origins, questions, and a call for research. Journal of Catholic Education, 19(1), 5-26. https://doi.org/10.15365/joce.1901022015

Scott, J., \& Armstrong, A. (2014). Through a Freirean lens: Professional learning, faithbased schooling and liberatory education. Professional Development in Education, 40(4), 610-626. https://doi.org/10.1080/19415257.2013.830273

Scott, K. (2015). Problem or paradox: Teaching the Catholic religion in Catholic schools. In M.T. Buchanan and A. Gellel (Eds.), Global Perspectives on Catholic Religious Education in Schools (pp. 47-60). Switzerland: Springer International Publishing.

Seidman, I. (2019). Interviewing for qualitative research: A guide for researchers in education and the social sciences (5th ed.). Teachers College Press.

Shahjahan, R.A. (2005). Spirituality in the academy: Reclaiming from the margins and evoking a transformative way of knowing the world. International Journal of Qualitative Studies in Education, 18(6), 685-711. https://doi.org/10.1080/09518390500298188

Shahjahan, R. A., Wagner, A., \& Wane, N. N. (2009). Rekindling the sacred: Toward a decolonizing pedagogy in higher education. Journal of Thought, 44(1), 59-75. https://doi.org/10.2307/jthought.44.1-2.59

Short, G. (2003). Faith schools and indoctrination: A response to Michael Hand. Theory and Research in Education, 1(3), 331-341. https://doi.org/10.1177/1477878503001003005 
Seligman, A.B. (Ed.). (2014). Religious education and the challenge of pluralism. Oxford University Press.

Simon, R. (2015). Gramsci's political thought: An introduction. (3rd ed.). Lawrence \& Wishart. https://muse.jhu.edu/book/40155

Small, J. L. (2015). From religion to praxis: Incorporating personal understandings of religion, spirituality, and faith into teaching. Journal of College and Character, 16(1), 44-49. https://doi.org/10.1080/2194587X.2014.992909

Smith, C. and Denton, M.L. (2009). Soul searching: The religious and spiritual lives of American teenagers. Oxford University Press.

Sobrino, J. (1988). Spirituality of liberation: Toward political holiness. Orbis Books.

Sobrino, J. (1993). Jesus the liberator: A historical-theological reading of Jesus of Nazareth. Orbis Books.

Sparks, W. (1994). Culturally responsive pedagogy: A framework for addressing multicultural issues. Journal of Physical Education, Recreation \& Dance, 65(9), 33-61. https://doi.org/10.1080/07303084.1994.10606999

Stenberg, S. (2006). Liberation theology and liberatory pedagogies: Renewing the dialogue. College English, 68(3), 271-290. https://doi.org/10.2307/25472152

Stockdale, B. J. (2019). Catholic identity of students of Jesuit high schools (Publication No. 13806999) [Doctoral dissertation, The Catholic University of America]. ProQuest Dissertations \& Theses Global. 
Svensson, J. (2010). Divisions, diversity and educational directives: IRE teachers' didactic choices in Kisumu, Kenya. British Journal of Religious Education, 32(3), 245-258. https://doi.org/10.1080/01416200.2010.498610

Switzer, J. B. (2006). Strangers no more: The pedagogy of interreligious hospitality (Publication No. 3207009) [Doctoral dissertation, Boston College]. ProQuest Dissertations \& Theses Global.

Talley-Matthews, S., \& Wiggan, G. (2018). Culturally sustaining pedagogy: How teachers can teach the new majority in public schools. Black History Bulletin, 81(2), 24-27. https://www.jstor.org/stable/10.5323/blachistbull.81.2.0024

Teece, G. (2005). Traversing the gap: Andrew Wright, John Hick and critical religious education. British Journal of Religious Education, 27(1), 29-40. https://doi.org/10.1080/0141620052000276500

Teece, G. (2010). Is it learning about and from religions, religion or religious education? And is it any wonder some teachers don't get it? British Journal of Religious Education, 32(2), 93-103. https://doi.org/10.1080/01416200903537399

Thurman, H. (1996). Jesus and the disinherited. Beacon Press. (Original work published in 1949)

United States Conference of Catholic Bishops. (1997). Renewing the vision: A framework for Catholic youth ministry. http://www.usccb.org/about/laitymarriage-family-life-and-youth/young-adults/renewing-the-vision.cfm United States Conference of Catholic Bishops. (1998). Sharing Catholic Social Teaching: Challenges and directions. http://www.usccb.org/beliefs-and-teachings/what-we- 
believe/catholic-social-teaching/sharing-catholic-social-teaching-challenges-anddirections.cfm

United States Conference of Catholic Bishops. (2005). National directory for catechesis. United States Conference of Catholic Bishops.

United States Conference of Catholic Bishops. (2005). Renewing our commitment to Catholic elementary and secondary schools in the third millennium. http://www.usccb.org/beliefs-and-teachings/how-we-teach/catholiceducation/upload/renewing-our-commitment-2005.pdf

United States Conference of Catholic Bishops. (2008). Doctrinal elements of a curriculum framework for the development of catechetical materials for young people of high school age. http://www.usccb.org/beliefs-and-teachings/how-weteach/catechesis/upload/high-school-curriculum-framework.pdf

Ucan, A.D., \& Wright, A. (2019). Improving the pedagogy of Islamic religious education through an application of critical religious education, variation theory and the learning study model. British Journal of Religious Education, 41(2), 202-217. https://doi.org/10.1080/01416200.2018.1484695

Vagle, M. (2018). Crafting Phenomenological Research. (2nd ed.). Taylor and Francis.

Valenzuela, A. (1999). Subtractive schooling: U. S.-Mexican youth and the politics of caring. State University of New York Press.

Van Manen, M. (2016). Phenomenology of practice: Meaning-giving methods in phenomenological research and writing. Routledge. 
Van Manen, M. (2016). Researching lived experience: Human science for an action sensitive pedagogy (2nd ed.). Routledge.

Vilà Baños, R., Freixa Niella, M., Sánchez-Martí, A., \& Rubio Hurtado, M.R. (2019). Head teachers' attitudes towards religious diversity and interreligious dialogue and their implications for secondary schools in Catalonia. British Journal of Religious Education, 41(2), 1-13. https://doi.org/10.1080/01416200.2019.1584742

Village, A., \& Francis, L. (2016). Measuring the contribution of Roman Catholic secondary schools to students' religious, personal and social values. Journal of Catholic Education, 19(3), 66-115. https://doi.org/10.15365/joce.1903062016

Villegas, A., Strom, K., \& Lucas, T. (2012). Closing the racial/ethnic gap between students of color and their teachers: An elusive goal. Equity \& Excellence in Education, 45(2), 283-301. https://doi.org/10.1080/10665684.2012.656541

Wang, C. (2013). Fostering critical religious thinking in multicultural education for teacher education. Journal of Beliefs \& Values, 34(2), 152-164. https://doi.org/10.1080/13617672.2013.802127

Weiss, R. (1994). Learning from strangers: The art and method of qualitative interview studies. The Free Press.

Westerhoff, J. (2012). Will our children have faith? (3rd ed.). Morehouse Publishing. (Original work published in 1976)

Williams, D. (2013/1993). Sisters in the wilderness: The challenge of womanist God-talk. Orbis Books. 
Wilkerson, B. (Ed.). (1997). Multicultural religious education. Religious Education Press.

Wright, A. (2004). The justification of compulsory religious education: A response to Professor White. British Journal of Religious Education, 26(2), 165-174. https://doi.org/10.1080/01416200420042000181938

Wright, A. (2004). Religion, education and post-modernity. Routledge Farmer.

Wright, A. (2007). Critical religious education, multiculturalism and the pursuit of truth. University of Wales Press.

Wright, A. (2008). Critical religious education and the national framework for religious education in England and Wales. Religious Education, 103(5), 517-521. https://doi.org/10.1080/00344080802427184

Young, E. (2010). Challenges to conceptualizing and actualizing culturally relevant pedagogy: How viable is the theory in classroom practice? Journal of Teacher Education, 61(3), 248-260. https://doi.org/10.1177/0022487109359775

Young, K.S., Herring, T.J., \& Morrison, A.D. (2017). Conceptual strategies for culturally sustaining and inclusive education. Kappa Delta Pi Record, 53(4), 174-178. https://doi.org/10.1080/00228958.2017.1369279

Youniss, J., \& Convey, J.J. (2000). Catholic schools at the crossroads: Survival and transformation. Teachers College Press.

Zilliacus, H. (2013). Addressing religious plurality: A teacher perspective on minority religion and secular ethics education. Intercultural Education, 24(6), 507-520. https://doi.org/10.1080/14675986.2013.867761 


\section{Appendix A: Invitation Letter to Principals and Department Chairs}

Dear X,

My name is Dave Gregory, and I am a theology teacher and instructional coach at De La Salle North Catholic High School. I am also working on a doctorate in curriculum and instruction at Portland State University, where I am researching theological education for non-Catholic and religiously diverse student populations in Catholic high schools. More specifically, I am interested in learning about the curricular and pedagogical decisions that theology teachers in Portland-area Catholic high schools make in their education of religiously diverse classrooms.

I am writing because I would like to recruit a member of your theology department to participate in my research. With your approval, I will email another letter to every member of your theology department, inviting their participation in my study. I will conduct a series of three interviews with teacher-participants, and each interview will focus on a different theme, which are as follows: participants' beliefs regarding the purposes and goals of religious education for religiously diverse student populations; participants' experiences and impressions of the USCCB Framework as it relates to the education of religiously diverse student populations; and, in light of the above, the curricular and pedagogical decisions the participants make in their classrooms.

Participation is, of course, entirely voluntary, and I will be safeguarding schools' and participants' identities through the use of pseudonyms in my writing. Confidentiality is of the utmost importance to me. I hope that this research will spark dialogue and conversation within our city's Catholic schools, and perhaps even within educational communities outside of Portland.

All that said, if you are not interested in your faculty's participation, please let me know, and you will receive no further communication from me. If you are interested in having one of your faculty participate, please email me back, and indicate how you would like to proceed. If you have any questions about the research, please do not hesitate to contact either myself or my doctoral advisor, Dot McElhone (dmcelhone@pdx.edu). Many thanks for your consideration of this request, and I look forward to working with you!

In Christ,

Dave Gregory

dgregory@dlsnc.org

917.627.3160 


\section{Appendix B: Invitation Letter to Theology Teachers}

Dear X,

My name is Dave Gregory, and I am a theology teacher and instructional coach at De La Salle North Catholic High School. I am also working on a doctorate in curriculum and instruction at Portland State University, where I am researching theological education for non-Catholic and religiously diverse student populations in Catholic high schools. More specifically, I am interested in learning about the curricular and pedagogical decisions that theology teachers in Portland-area Catholic high schools make in their education of religiously diverse classrooms.

I am writing to invite your participation in my research. Given the focus of this research, I would like to recruit teachers who are actively interested in the theological education of religiously diverse classrooms, and who intentionally craft their pedagogy in the service of non-Catholic students.

If you are interested in participating, we'll hold a series of three 60 to 90 minute interviews spaced about a month apart. Each interview will focus on a different theme, which are as follows: your beliefs regarding the purposes and goals of religious education for religiously diverse student populations; your experiences and impressions of the USCCB Framework as it relates to the education of religiously diverse student populations; and, in light of the above, the curricular and pedagogical decisions you make in your classroom. I am aiming to recruit approximately 6 teachers for this research, and at the end of all the interviews, we'll hold a focus group interview with all interested participants. Moreover, I will invite you to read and provide feedback on my findings, for the purposes of accuracy and integrity.

Participation is, of course, entirely voluntary, and I will be safeguarding both your identity and your school's through the use of pseudonyms in my writing. Confidentiality is of the utmost importance to me. I hope that this research will spark dialogue and conversation within our city's Catholic schools, and perhaps even within educational communities outside of Portland. Beyond this, and more immediately, I hope that we all have something to learn from one another.

All that said, if you are not interested, please let me know, and you will receive no further communication from me. If you are interested in participating, please email me back, and indicate how you would like to proceed. If you have any questions about the research, please do not hesitate to contact either myself or my doctoral advisor, Dot McElhone (dmcelhone@ pdx.edu). Many thanks for your consideration of this request, and I look forward to working with and learning from you!

In Christ, Dave Gregory 
dgregory@dlsnc.org

917.627.3160 


\section{Appendix C: Consent Form for Participants}

\section{Consent to Participate in Research}

Project Title: God-Talk in Catholic High Schools: Theology Teachers Doing

Theological Education for and with Religiously Diverse Student

Populations

Population: $\quad$ Adults, Interviews

Researcher: $\quad$ David M. A. Gregory, College of Education

Portland State University

Researcher Contact: dgreg2@pdx.edu, 917.627.3160

You are being asked to take part in a research study. The box below highlights key information about this research for you to consider when making a decision whether or not to participate. Carefully review the information provided on this form. Please ask questions about any of the information you do not understand before you decide to participate.

\section{Key Information for You to Consider}

Voluntary Consent. You are being asked to volunteer for a research study. It is up to you whether you choose to participate or not. There is no penalty if you choose not to participate or discontinue participation.

Purpose. The purpose of this research is to investigate how theology teachers in Catholic high schools engage theological education for religiously diverse student populations.

Duration. It is expected that your participation will last approximately five to six months, given that interviews will be spread out over the course of this time. Procedures and Activities. You will be asked to participate in a series of three one-on-one interviews, lasting approximately an hour to an hour and a half each; these interviews will be scheduled at mutually convenient times. You will be asked to review the findings of the study, provide feedback, and participate in a final focus group interview with a small group of other participants.

Risks. Some of the foreseeable risks or discomforts of your participation include professional ramifications, although your identity and participation will remain completely anonymous in the study.

Benefits. Some of the benefits that may be expected include collaboration with other Portland-area theology teachers, advancing the knowledge and 
understanding of theological education in Catholic high schools with religiously diverse student populations.

Alternatives. Participation is voluntary and the only alternative is to not participate.

\section{What happens to the information collected?}

Information collected for this research will be analyzed by the researcher as part of a dissertation. While this dissertation will eventually be published and disseminated in online research databases, all identifiable information of participants (and participants' schools) will be kept confidential through the use of pseudonyms.

\section{How will my privacy and data confidentiality be protected?}

I will take measures to protect your privacy including the use of pseudonyms to hide any and all identifiable information. Despite taking steps to protect your privacy, I can never fully guarantee that your privacy will be protected.

To protect the security of all of your personal information, I will maintain records of personal information (such as phone numbers and email addresses) on passwordprotected electronic devices. Despite these precautions, I can never fully guarantee the confidentiality of all study information.

Individuals and organizations that conduct or monitor this research may be permitted access to inspect research records. This may include private information. These individuals and organizations include the Institutional Review Board that reviewed this research and my doctoral advisor, Dot McElhone.

\section{What if I want to stop participating in this research?}

Your participation is voluntary. You do not have to take part in this study, but if you do, you may stop at any time. You have the right to choose not to participate in any study activity or completely withdraw from participation at any point without penalty or loss of benefits to which you are otherwise entitled. Your decision whether or not to participate will not affect your relationship with the researchers or Portland State University.

\section{Will it cost me money to take part in this research?}

There are no costs associated with participation, apart from the cost of transportation should interviews be conducted in-person.

Will I be paid for participating in this research?

You will not receive monetary compensation for participating in this research.

\section{Who can answer my questions about this research?}


If you have questions, concerns, or have experienced a research related injury, contact the research team at:

David Gregory

917.627.3160

dgreg2@pdx.edu

\section{Who can I speak to about my rights as a research participant?}

The Portland State University Institutional Review Board ("IRB") is overseeing this research. The IRB is a group of people who independently review research studies to ensure the rights and welfare of participants are protected. The Office of Research Integrity is the office at Portland State University that supports the IRB. If you have questions about your rights, or wish to speak with someone other than the research team, you may contact:

Office of Research Integrity

PO Box 751

Portland, OR 97207-0751

Phone: (503) 725-5484

Toll Free: 1 (877) 480-4400

Email: psuirb@pdx.edu

\section{Consent Statement}

I have had the opportunity to read and consider the information in this form. I have asked any questions necessary to make a decision about my participation. I understand that I can ask additional questions throughout my participation.

By signing below, I understand that I am volunteering to participate in this research. I understand that I am not waiving any legal rights. I have been provided with a copy of this consent form. I understand that if my ability to consent for myself changes, either I or my legal representative may be asked to provide consent prior to me continuing in the study.

I consent to participate in this study.

Name of Adult Participant

Signature of Adult Participant 


\section{Date}

Researcher Signature (to be completed at time of informed consent)

I have explained the research to the participant and answered all of his/her questions. I believe that he/she understands the information described in this consent form and freely consents to participate.

Name of Research Team Member

\section{Signature of Research Team Member}

\section{Date}




\section{Appendix D: Interview Protocol for First Interview}

1. Tell me about your current role, and how long you've been teaching theology/religion for?

2. Tell me about your educational background.

a. Tell me more about your experience of Catholic school.

b. Tell me more about your preparation in the academic discipline of theology, in terms of your interests and your expertise.

3. What did you most appreciate about, or learn from, your academic preparation?

4. Why did you become a theology teacher?

a. Can you describe any defining experiences that contributed to that desire?

b. (If needed) Were there any particular moments or relationships that contributed to that desire?

5. What do you hope your students learn from their time with you?

a. How are those hopes for what students might learn from you different for Catholic students, as opposed to those for non-Catholic or non-Christian students?

6. All that said, what does the term "catechesis" mean to you?

a. What do you think about the role of catechesis in Catholic high school religious education?

7. (If the teacher does view catechesis favorably) How do you present catechesis to your non-Catholic students? 
a. How do you differentiate between the goals of catechesis for students of different religious or non-religious backgrounds?

8. (If the teacher does not view catechesis favorably) What other forms of religious education do you pursue apart from catechesis, and why do you pursue them? 


\section{Appendix E: Interview Protocol for Second Interview}

1. Based on our last interview, do you have any further thoughts on the goals of theological education, either personally or in Catholic secondary education, more broadly? Is there anything you would care to revisit?

2. Tell me about the students you serve, in terms of their religious beliefs and identities.

a. How do you seek to nurture students' beliefs, regardless of whether or not they are Catholic?

b. How do you support students' beliefs, especially those who are not Catholic?

3. What are some specific strategies or pedagogical approaches in your support of these students?

4. Tell me about the process of building loving relationships and trust with nonCatholic, non-Christian, or non-religious students.

a. Tell me about what you do outside of the classroom in order to foster these relationships.

5. To what degree do you think it is important for students to make sense of and explore their own beliefs in theology class?

a. How do you provide instruction and opportunities for learning that help students to make sense of and explore their own beliefs?

6. To what degree do you think it is important for students to make sense of and explore others' beliefs, and how religious belief shapes society and culture? 
a. How do you provide instruction and opportunities for learning that help students to make sense of and explore others' beliefs, and how religious belief shapes society and culture?

7. How do you invite students to share their beliefs, especially if they are not Catholic, with you and their classmates? In other words, how do you center students' voices in the classroom experience? 


\section{Appendix F: Interview Protocol for Third Interview}

1. Tell me about how and when you were introduced to the USCCB Framework.

2. What did you notice, and what were your first impressions of it?

3. What are your impressions of the Framework these days?

a. How have your impressions shifted over time, if they have?

4. I'm going to ask about your impression of the benefits and detriments of the Framework for students.
a. First, in what ways do you see the Framework as beneficial for students?
b. Which students benefit most?
c. How or why?
d. In what ways do you see the Framework as detrimental to students?
e. Which students are most negatively affected?
f. How or why?

5. Tell me about your department's use of the USCCB Framework.
a. In what ways does your department align its curricula with Framework standards and expectations?

6. In what ways does your department diverge from the USCCB Framework?

7. What are your feelings about implementing the Framework for non-Catholic students?

8. Do you pay attention to the Framework when crafting your curriculum and assignments? 
a. Walk me through your process of planning a lesson or a unit when considering non-Catholic students.

b. What resources do you refer to decide what to teach, and how to teach it?

9. In what ways do you change or adapt the Framework in your curriculum design and teaching?

10. In what ways do you eschew or ignore the Framework in your curriculum and teaching?

11. If you do adapt or diverge from the Framework, can you tell me about why you make the choices you make with regards to your adapting the Framework, either in whole or in part?

12. What have you noticed about how your goals and methods have changed over the course of your career? 


\section{Appendix G: Interview Protocol for Focus Group Interview}

Thank you all so much for coming today, I so appreciate the time you've given me thus far. I've got 257 pages of transcripts from all of our interviews, and I've begun analyzing data, and bringing out key themes from our conversations. Today's interview is about trying to bring out consensus and disagreement amongst you folks with regard to your thoughts on the education of non-Catholic students in our classrooms, and thinking about the overarching goals for what we hope for these students. My hope is to begin sharing this research more broadly, and centering your voices is such an important aspect of the research. I hope that all of this will generate fruitful dialogue for theology teachers, and more efficacious pedagogy for our students.

I know that up until this point, I have been unable to share my own thoughts, positionality, and research with you, even though a few of you have asked; this was very intentional, so as to avoid biasing your responses to my questions. Moving forward, I am happy to share anything and everything. Over the course of this summer, I hope to complete a solid draft of the full dissertation (of which I have 3 chapters completed, and would be happy to share upon request) and defend the completed work in the fall. When I have a completed draft, I will share my analysis and findings with you, so that you can correct any misrepresentations, misunderstandings, or misinterpretations on my part. In qualitative research like this, this process called "member checking" is a vital step, as it ensures the integrity of my interpretations, and makes sure that I haven't misconstrued or falsely depicted your own statements and opinions. 
In a sense, you are a rather self-selected group; two high schools in the [Pacific Northwest] area (XXXXX and XXXXX) opted to not participate in this, but with the approval of your principals and department chairs, you expressed interest in this topic. My intent in recruiting folks was to find a so-called "panel of experts," and you all have blown me away so far. I've learned so much already, and I'm excited to facilitate some conversation and dialogue between everyone here. I expect that we'll take about 90 minutes today, but who knows?

I'd like to present some of the key themes that have arisen throughout our conversations, based on my time with the transcripts so far. Keep in mind that these are preliminary musings, and are not complete. [present Slide deck with these points]

1. None of the participants are intent on converting students, or imposing Catholicism upon them. Everyone wants to respect students' religious consciences.

2. Participants' educational backgrounds and experiences (both of Catholic culture, and Catholic education) heavily influence how they approach their teaching and engage students. Most participants spoke about wounds they suffered at the hands of Church leadership, or witnessing evils and hypocrisies within the institution; consequently, most participants remain wary of episcopal authority.

3. Participants generally feel responsible for conveying Catholicism authentically; even when a participant might disagree with Church teaching, they want to present it fully and honestly. 
4. There is a desire amongst all participants to help make theology applicable and relevant, but this looks different for different teachers: from focus on theory, to spiritual practices, to critical examination of history and religion, each participant in some way tries to help students see that theology can be practical and existentially meaningful.

5. Participants seek to "translate" Catholicism and its theological tradition for students who are un-churched, non-religious, or nominally Catholic to understand.

6. People use the USCCB Framework to various degrees: one department follows it pretty strictly, others use it as a general guiding principle for teachers to understand what they need to be teaching on a broader and looser level. The most important ways that people diverge from the Framework tend to be with regard to omission and emphasis: teachers will omit Framework content they view as unnecessary or irrelevant for their students, while others will emphasize Framework content they view as important for students to engage. A couple of participants believe that the Framework has failed to address certain key elements, and incorporate these elements into their curricula. Some participants bemoaned the fact that the bishops failed to consult teachers and educational experts as they wrote it.

All of this said, as I move through these questions for today's conversation, it's good to keep in mind some basic ground rules. I'm not worried about these, but it's 
helpful to go over them. First, as always, please know that this is confidential. I know that some opinions shared throughout our conversations might not always be favorably looked upon by some potential readers, and so I am taking every precaution to safeguard your identities in my writing. I ask that you not disclose one another's identities to people outside of this circle. While I expect and welcome disagreement, please listen to and respond to one another respectfully. After all, there are no wrong answers here, but there might be differing points of view. Given that I will be transcribing this, please speak one at a time, and be loud and clear. Any questions? Let's get going!

Could you introduce yourself to the group? Tell everyone your name, where you teach, what you teach, and how long you've been teaching for. Take a couple minutes to jot down a couple of thoughts on this second question, which I will copy and paste into the chat:

1. What advice would you give someone who's starting as a theology teacher at a school with lots of non-Catholic students? [pause for a few minutes]

As you respond to this question out loud, I would like to avoid a "going around the circle" sort of situation, because a conversation will yield more interesting responses. So, if you hear something that resonates with you, please feel free to respond. Alternatively, if you disagree, please speak up. I might jump in with probing questions to generate more nuance and depth, because I want to get at the assumptions and goals that are sometimes embedded in one's thinking, yet remain unspoken. 
2. What do you think a non-Catholic student should know, understand, have practiced, or have learned at the end of their four years of taking theology classes?

3. I'm going to give you some time to write down some thoughts on the following question. If you were to create a scope and sequence of a four year theology curriculum that would serve practicing and non-practicing Catholic students, and non-Catholic students, what would it look like? [give some time] Now, we're going to use this Google Doc, where I'd like you all to type in your responses, which we'll use as the basis for discussion.

4. Did you consciously make any inclusions or omissions that depart from the current USCCB Framework? Why did you make these decisions?

5. What were you assuming about students' understandings of religion and/or theology as you were writing?

6. Based on all of our conversations up until this point, do you have any final thoughts you'd care to share with the group about theological education of non-Catholic students?

You all have shared some documents with me, namely specific examples of assignments. It would be really helpful to see some theology department philosophies, and scope and sequences, or course descriptions. This would help to give me a broader sense of what your individual schools do. Please feel free to email me in the coming days with materials you're willing to share. 
I also got the idea a few weeks back to create a website. Apart from textbooks, teachers don't have shared resources. If you're willing to contribute, I'd like to start collecting materials from whomever would be willing to share. I would remove any names or identifying marks from materials, and post them on the website. As I start to take this research around to conferences, which is my hope over the next few years, I'd like to be able to provide people who ask with resources that they can consult. Anything from lesson plans to syllabi to assignments to whatever you use that you think others might find helpful, I would love to see. This will be a project of mine over the next year or so, to put this together. 